Francis Massashi Kakuda

\title{
ESTUDO DE ENSAIOS DE ARRANCAMENTO DE GEOGRELHA COM UTILIZAÇÃO DE UM EQUIPAMENTO REDUZIDO
}

Dissertação apresentada à Escola de Engenharia de São Carlos da Universidade de São Paulo, como parte dos requisitos para a obtenção do Título de Mestre em Geotecnia.

ORIENTADOR: Prof. Dr. Benedito de Souza Bueno

São Carlos 
Dedico esta dissertação a Francisco e Tereza, pais que tanto amo e admiro, cuja dedicação e apoio foram essenciais para a conclusão deste trabalho. E à minha amada esposa Eliane, pelo amor e paciência durante toda elaboração. 


\section{AGRADECIMENTOS}

Ao orientador Prof. Benedito de Souza Bueno pela dedicação, paciência, ensinamento e excelente orientação.

A todos os professores, funcionários e alunos do Departamento de Geotecnia da EESC, pela colaboração e amizade, em especial ao Prof. José Eduardo Rodrigues.

Ao Prof. Nélio Gaioto e Sidnei Teixeira pela grande contribuição e sugestões apresentadas no exame de qualificação.

Aos colegas de turma: Adelvan, Angelita, Josiele, Luciene, Vanessa, Thiago, Sergio e ao grande amigo Danilo.

Aos doutorandos Vinicius, Roger e Heraldo pela amizade e auxílio neste trabalho.

Aos técnicos Clever, Silvio, José Luiz, Oscar e Antonio pela ajuda nas etapas preliminares dos ensaios, e à funcionária Maristela pela sua eficiência administrativa.

À Coordenadoria de Aperfeiçoamento de Pessoal de Nível Superior, CAPES pela concessão da bolsa de estudo.

À empresa HUESKER Ltda. pelo fornecimento das geogrelhas utilizadas nos ensaios.

Aos irmãos Marcio e Luciene pela amizade e companheirismo até hoje compartilhados. 
“O êxito não se consegue só com qualidades especiais. É, sobretudo um trabalho de constância, de método e de organização".

(J.P. Sergent) 


\section{SUMÁRIO}

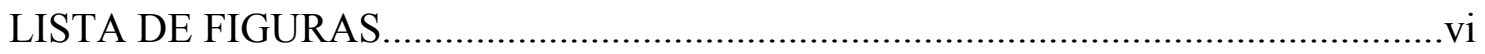

LISTA DE TABELAS......................................................................................

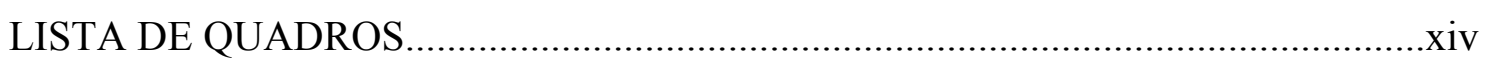

LISTA DE SIGLAS E SIMBOLOS....................................................................

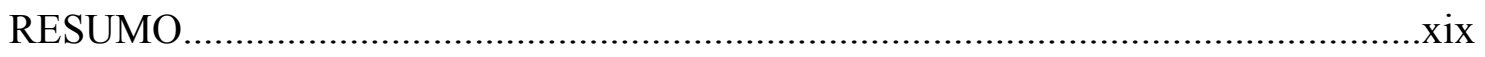

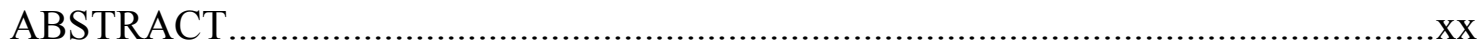

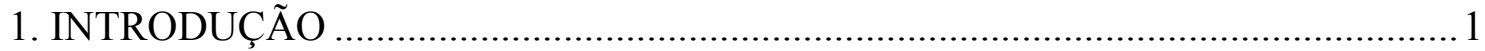

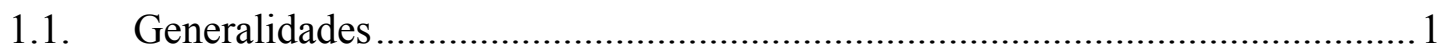

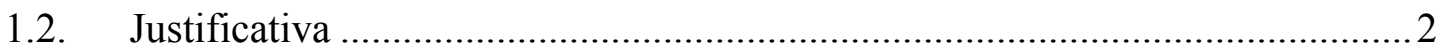

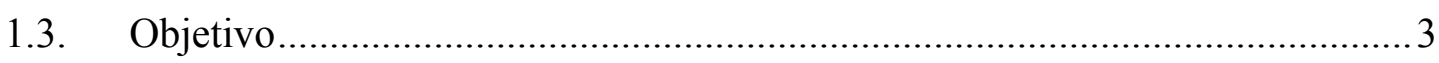

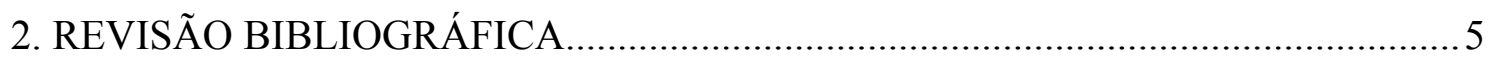

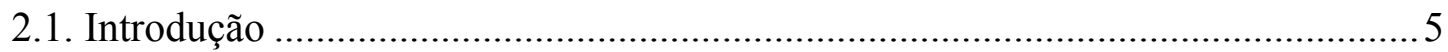

2.2. Características geométricas e de fabricação de geogrelhas.................................... 6

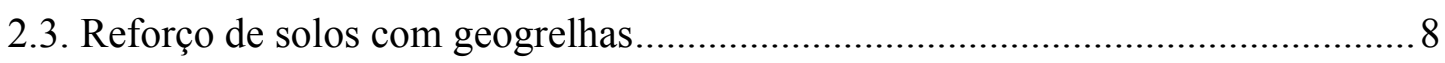

2.3.1. Muros e taludes reforçados em geogrelhas ................................................ 8

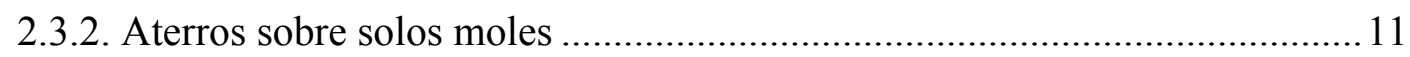

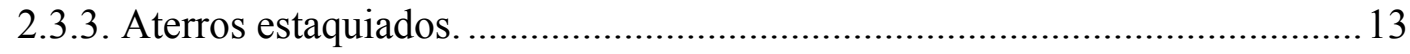

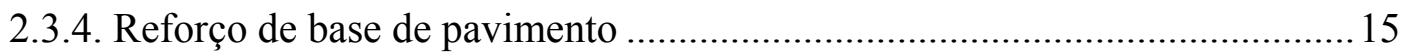

2.4. Ensaios para avaliar a interação solo estrutura ..................................................... 16

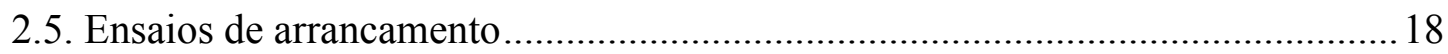

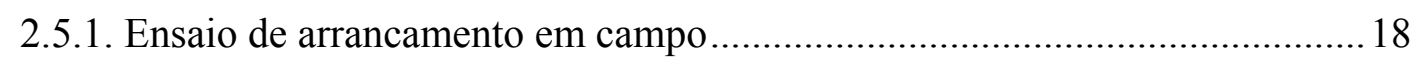

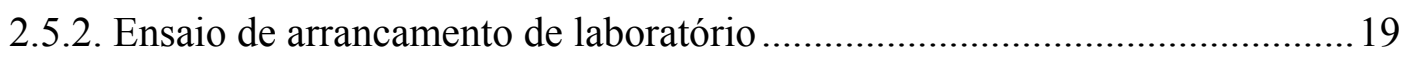

2.6. Mecanismo de interação solo-inclusão no ensaio de arrancamento......................25

2.7. Resistência por atrito e adesão, na área de contato solo-inclusão $\left(P_{f}\right) \ldots \ldots \ldots \ldots \ldots \ldots . . .28$

2.8. Resistência passiva dos elementos transversais.................................................29

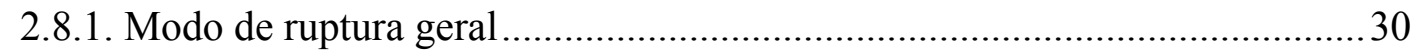

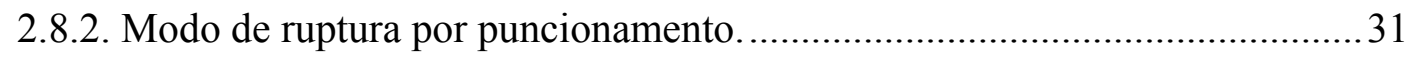

2.9. Mecanismo de transferência de carga solo-geogrelha ........................................ 32

2.10. Efeitos a serem considerados na execução do ensaio de arrancamento...............38 
2.10.1. Efeito da tensão confinante 38

2.10.2. Efeito da dilatância e da compacidade nas areias 40

2.10.3. Efeito do tipo de solo 45

2.10.4. Efeito da rugosidade da parede interna da caixa..... 52

2.10.5. Espessura da camada de solo acima e abaixo da inclusão 55

2.10.6. Influência da velocidade de ensaio $(\mathrm{mm} / \mathrm{min})$ .57

3. MATERIAIS E MÉTODOS. 60

3.1. Equipamentos e instrumentação utilizados. 60

3.2. Os solos utilizados no programa experimental. ...............................................62

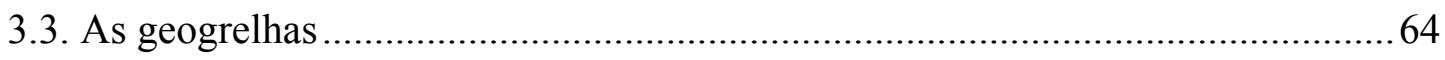

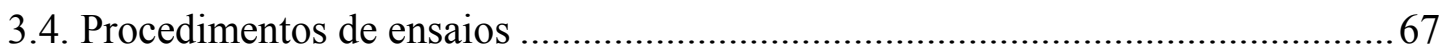

4. ENSAIOS REALIZADOS E ANÁLISES DOS RESULTADOS .............................72

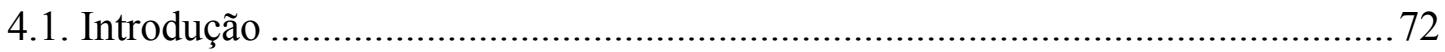

4.2. Viabilização do uso do equipamento de pequeno porte.....................................73

4.2.1. Variabilidade dos resultados de ensaios de arrancamento realizados com

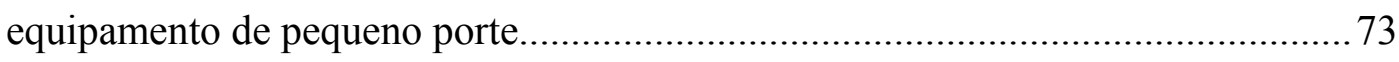

4.3. Efeito da relação entre o tamanho da amostra de geogrelha e a área interna do equipamento.

4.4. Verificação da viabilidade de uso do equipamento de pequeno porte para registro da força de arrancamento de geogrelha.

4.5. Análise paramétrica experimental com uso do equipamento de pequeno porte. .88

4.5.1. Efeito da velocidade de ensaio na resistência ao arrancamento.....................89

4.5.2. Efeito da sobrecarga na resistência ao arrancamento.................................. 92

4.5.3. Efeito do grau de compactação do solo na resistência ao arrancamento .......98

4.5.4. Comparação entre tipos de geogrelha na resistência ao arrancamento ........ 101

4.5.5. Efeito do tipo de solo utilizado na resistência ao arrancamento .................. 105

4.5.6. Valores das tensões normais obtidas através da célula de tensão total........ 108 


\section{LISTA DE FIGURAS}

FIGURA 1- Elementos constituintes das geogrelhas. 7

FIGURA 2 - Esquema sintetizado de uma estrutura reforçada com geogrelha ............... 9

FIGURA 3 - Modos de ruptura de uma estrutura em solo reforçado. 9

FIGURA 4 - Comprimentos das zonas ativas e passivas de um muro reforçado com geossintético em função de sua profundidade.

FIGURA 5 - Mecanismos de estabilidade de reforço de base de aterro sobre solo mole

FIGURA 6 - Determinação geométrica do comprimento mínimo de ancoragem (PALMEIRA, 1992).

FIGURA 7 - Geometria sintetizada de aterro estaqueado e a representação dos principais esforços atuantes (VERTEMATTI, 2004) .....

FIGURA 8 - Detalhe da região de interface geogrelha-base de pavimento.

FIGURA 9- Representação de ensaios de cisalhamento com inclusão no plano de cisalhamento e inclusão inclinada com relação ao plano cisalhante (adaptado de INGOLD, 1983) 16

FIGURA 10 - Representação do ensaio de arrancamento 16

FIGURA 11 - Representação do ensaio de arrancamento (PALMEIRA \& MILLIGAN, 1989).

FIGURA 12 - Equipamento de ensaio de arrancamento de laboratório (adaptado de OCHIAI et al., 1996).

FIGURA 13 - Esquematização do equipamento de pequenas dimensões (NAKAMURA et al. 2003)...... .23

FIGURA 14 - Caixa de testes de pequeno porte (TEIXEIRA, 2003).

FIGURA 15 - Resistências passiva e atritiva na interface solo-grelha (VOOTTIPRUEX et al., 2000).....

FIGURA 16- (a) representação esquemática do desenvolvimento da resistência passiva (JEWELL, 1996); (b) dimensão geométrica da grelha; (c) Correlação teórica entre angulo de atrito e capacidade de carga (JEWELL et al., 1984). 27

FIGURA 17 - Fator de adesão em solos coesivos (TOMLINSON, 1994). 29 
FIGURA 18 - Comparação entre os valores teóricos e experimentais da resistência passiva mobilizada nas barras transversais das grelhas (adaptado de PALMEIRA \& MILLIGAN, 1989).

FIGURA 19 - Mecanismo de modo de ruptura geral (PETERSON e ANDERSON, 1980).

FIGURA 20 - Mecanismo de ruptura por puncionamento (JEWELL et al., 1984) ........32

FIGURA 21 - Curva resistência atritiva $v s$. deslocamento no ensaio de arrancamento 33

FIGURA 22 - Relação entre a força de arrancamento e o deslocamento de várias junções entre elementos transversais e longitudinais ( OCHIAI et al., 1996). 34

FIGURA 23 - Resultados de ensaio de arrancamento de geogrelha com diferentes configurações de elementos longitudinais (ALAGIYAWANNA et al., 2001) ......35

FIGURA 24 - Resultados de ensaio de arrancamento de geogrelha com diferentes configurações de elementos transversais (ALAGIYAWANNA et al., 2001)........36

FIGURA 25 - Caixa de ensaio de arrancamento em elementos transversais. a) seção longitudinal;

FIGURA 26 - Resultados de ensaios de arrancamento para diferentes tensões de confinamento (ALFARO \& BERGADO, 1995)...

FIGURA 27 - Resultados de ensaios de arrancamento para diferentes tensões de confinamento, representado da relação entre taxa de deslocamento e posicionamento dos nós

FIGURA 28 - Relação entre deslocamento e força de arrancamento para diferentes tensões confinantes Ochiai et al. (1996).

FIGURA 29 - Forças atuantes em um ensaio de cisalhamento direto (VILAR, s/d)....41

FIGURA 30 - Modelo de dente de serra (adaptado de BOLTON, 1986).

FIGURA 31- Mecanismo de interação conceitual para elementos da geogrelha; (a) e (c) são tensão cisalhantes e deformações em volta de um elemento de um reforço e distribuição da tensão normal para amostra grande; (c) e (d) para amostra pequena, respectivamente (ALFARO et al., 1995).

FIGURA 32 - Força de arrancamento vs. largura de amostra em diferentes tensão normal

FIGURA 33 - Influencia qualitativa do aumento da dimensão dos grãos do solo em movimento relativo de cisalhamento direto (JEWELL et al., 1984).

FIGURA 34 - Ilustração esquemática da influência da dimensão dos grãos de solo na resistência ao cisalhamento direto (JEWELL et al., 1984). 
FIGURA 35 - Influência da relação (B/D50) na a resistência passiva do reforço

(JEWELL, 1990).

FIGURA 36 - Resultados de ensaios de arrancamento para diferentes abertura entre membros transversais de geogrelhas (PALMEIRA \& MILLIGAN, 1998).

FIGURA 37 - Representações dos tipos de rugosidade na parede frontal do equipamento (PALMEIRA \& MILLIGAN, 1989).

FIGURA 38 - Relação entre tensão cisalhante e normal vs. deslocamento nos ensaios de arrancamento para diferentes rugosidade da parede frontal do equipamento (PALMEIRA \&MILLIGAN, 1989).

FIGURA 39 - Representação do atrito nas paredes interna da caixa de arrancamento. 54

FIGURA 40 - Esquema da colocação da manga no equipamento de ensaio ( FARRAG et al., 1993)

FIGURA 41 - a) efeito do comprimento da manga no ensaio de arrancamento; b) empuxos medidos nas células (FARRAG et al., 1993).....

FIGURA 42 - Resultados de ensaios de arrancamento de geogrelha para diferente espessuras de solo arenoso (FARRAG et al., 1993).

FIGURA 43 - Resultados de ensaio de arrancamento executados com diferentes velocidades de ensaio (LADEIRA \& LOPES, 1996).

FIGURA 44 - Vista superior e frontal da caixa de arrancamento.

FIGURA 45 - Vista da tampa da caixa de arrancamento.

FIGURA 46 - (a) célula de carga da marca Kyowa; (b) compactador pneumático e (c) sapata utilizada na compactação do solo.

FIGURA 47 - Curva granulométrica dos solos utilizados no trabalho. .63

FIGURA 48 - Curva força $v s$. deformação (Fortrac 35/20-20) ......................................65

FIGURA 49 - Curva força $v s$. deformação (Fortrac 55/20-20)..................................... 65

FIGURA 50 - Curva força vs. deformação do modelo Fortrac 110/30-20 (Teixeira, 2003) 66

FIGURA 51 - Revestimento das paredes interna do equipamento. 68

FIGURA 52 - Primeira camada de solo compactado e colocação da célula de carga. ..69

FIGURA 53 - (a) garra de fixação da geogrelha; (b) detalhe da proteção dos elementos de geogrelha com tiras de geotêxteis. 70

FIGURA 54 - Vista geral do equipamento de arrancamento durante a execução do ensaio. .70

FIGURA 55 - Execução do ensaio de arrancamento. 
FIGURA 56 - Curvas de deslocamento vs. força de arrancamento obtidas de ensaios realizados para verificar a variabilidade dos resultados de ensaios.

FIGURA 57 - Média das leituras de tensão normal, registradas pela célula, dos testes 1 a 8 . 75

FIGURA 58 - Repetição do ensaio de arrancamento com a utilização do solo 1 e geogrelha1.

FIGURA 59 - Quantidade de elementos longitudinais vs. tensão máxima de arrancamento. 78

FIGURA 60 - Testes realizados com diferentes comprimento de amostra de geogrelha.

FIGURA 61 - Variação da quantidade de elementos transversais: (a) fixando 8 elementos longitudinais; (b) fixando 12 elementos longitudinais. 81

FIGURA 62 - Envoltórias de interface solo-geogrelha em termos de tensões totais: (a) utilizando equipamento de pequeno porte; (b) utilizando equipamento de grande porte.

FIGURA 63 (a) e (b) - Tensão de arrancamento vs. deslocamento obtido de equipamento de pequeno porte: (a) amostra com 8 elementos e (b) com 12 elementos longitudinais.

FIGURA 64 (a) e (b) - Deslocamento vs leituras da célula de tensão total: (a) resultados dos testes 28, 29 e 30; (b) resultados dos testes 31, 32 e 33. .86

FIGURA 65 - Comparação das tensões de arrancamento obtidas através de equipamento de grande e pequeno porte.

FIGURA 66 - (a) Efeito da velocidade de ensaio na força de arrancamento $(\mathrm{kN} / \mathrm{m})$; (b) Efeito da variação da velocidade de ensaio de arrancamento na força de arrancamento e deslocamento na ruptura.

FIGURA 67 - Resultados de ensaios de arrancamento com velocidades de 1, 2 e $5 \mathrm{~mm} / \mathrm{min}$ com a utilização do solo 2 .

FIGURA 68 - Efeito da sobrecarga na resistência ao arrancamento para o solo 1: (a) curvas deslocamento vs. tensão de arrancamento; (b) envoltória de resistência de interface solo-geogrelha.

FIGURA 69 - Efeito da sobrecarga na resistência ao arrancamento para o solo 2: (a) curvas deslocamento vs. tensão de arrancamento; (b) envoltória de resistência de interface solo-geogrelha. 
FIGURA 70 - Efeito da sobrecarga na resistência ao arrancamento para o solo 3: (a) curvas deslocamento vs. tensão de arrancamento; (b) envoltória de resistência de interface solo-geogrelha.

FIGURA 71 - Efeito da sobrecarga na resistência ao arrancamento para o solo 4: (a) curvas deslocamento vs. tensão de arrancamento; (b) envoltória de resistência de interface solo-geogrelha.

FIGURA 72 - Efeito da sobrecarga na resistência ao arrancamento para o solo 5: (a) curvas deslocamento vs. tensão de arrancamento; (b) envoltória de resistência de interface solo-geogrelha.

FIGURA 73 - Efeito do grau de compactação na tensão de arrancamento.

FIGURA 74 - Efeito do grau de compactação na tensão de arrancamento: (a) 96\% ; (b) $98 \%$ e (c) $100 \%$

FIGURA 75 - Comparação entre resultados obtidos com as geogrelhas Fortrac 35/2020 e 55/30-20 (solo 2): (a) curvas deslocamento vs. tensão de arrancamento; (b) envoltória de resistência de interface.

FIGURA 76 - Comparação das curvas deslocamento vs. tensão de arrancamento obtidas com geogrelhas Fortrac 1 e 2, inserido no solo 3.

FIGURA 77 - Comparação dos resultados obtidos das geogrelhas Fortrac 1 e 2 através das envoltórias de resistência de interface solo-geogrelha. 104

FIGURA 78 - Curvas de deslocamento vs. tensão de arrancamento para os cinco solos analisados com sobrecarga de $40 \mathrm{kPa}$ 106

FIGURA 79 - Efeito do tipo de solo na resistência ao arrancamento representado pela relação entre \% de argila $v s$. tensão de arrancamento.

FIGURA 80 - Diâmetro médio das partículas de solo vs. coeficiente de interação..... 108

FIGURA 81- Leituras de tensão normal obtidas com a utilização da célula (testes referente ao estudo da velocidade de ensaio).

FIGURA 82 - Leituras de tensão normal obtidas com a utilização da célula (testes referente efeito da sobrecarga no ensaio de arrancamento utilizando o solo 1).... 109

FIGURA 83 - Leituras de tensão normal obtidas com a utilização da célula (testes referente efeito da sobrecarga no ensaio de arrancamento utilizando o solo 2).... 110

FIGURA 84 - Leituras de tensão normal obtidas com a utilização da célula (testes referente efeito da sobrecarga no ensaio de arrancamento utilizando o solo 3).... 110

FIGURA 85 -Leituras de tensão normal obtidas com a utilização da célula (testes referente efeito da sobrecarga no ensaio de arrancamento utilizando o solo 4).... 111 
FIGURA 86 - Leituras de tensão normal obtidas com a utilização da célula (testes referente efeito da sobrecarga no ensaio de arrancamento utilizando o solo 5).... 111

FIGURA 87 - Leituras de tensão normal obtidas com a utilização da célula (testes referente efeito do GC no ensaio de arrancamento utilizando o solo 4 com GC $98 \%)$.

FIGURA 88 - Leituras de tensão normal obtidas com a utilização da célula (testes referente efeito do GC no ensaio de arrancamento utilizando o solo 4 com GC $100 \%)$. 


\section{LISTA DE TABELA}

TABELA 1- Características dos principais polímeros utilizados na fabricação de geogrelha

TABELA 2 - Influencia da taxa de deslocamento (Lopes e Ladeira, 1996). 58

TABELA 3 - Propriedades dos solos utilizados nos ensaios de arrancamento. 63

TABELA 4 - Propriedades da geogrelha utilizadas. 64

TABELA 5 - Ensaios para verificar a repetição dos resultados de ensaio de arrancamento.

TABELA 6 - Valor de força de arrancamento e deslocamento no ponto de pico de carregamento.

TABELA 7 - Serie complementar de ensaios de arrancamento para averiguar a variabilidade dos resultados de força de arrancamento e deslocamento no ponto de pico. .75

TABELA 8 - Valor de força de arrancamento e deslocamento no ponto de pico de carregamento. .76

TABELA 9 - Série de ensaios para avaliar a largura ideal dos corpos-de-prova. .77

TABELA 10 - Série de ensaios para avaliação do comprimento ideal dos corpos-deprova

TABELA 11 - Força e tensão de arrancamento para amostra com variação no comprimento da amostra ( $\mathrm{n}^{\mathrm{o}}$ de elementos transversais).

TABELA 12 - Características gerais do ensaios de arrancamento executados para comparar os equipamentos de grande e pequena dimensão, utilizando a geogrelha $110 / 30-20$. 82

TABELA 13 - Valores obtidos das envoltórias de resistência de interface. 84

TABELA 14 - Resumos dos resultados obtidos dos ensaios de pequeno e grande porte e algumas comparações em termo de porcentagem.

TABELA 15 - Série de ensaios para analisar o efeito da velocidade de ensaio na resistência ao arrancamento.

TABELA 16 - Série de ensaios para analisar o efeito da sobrecarga na resistência ao arrancamento.

TABELA 17 - Ensaios realizados para estudo do efeito da compactação do solo nos parâmetros de arrancamento. 
TABELA 18 - Série de ensaios para analisar o efeito da geometria da geogrelha na resistência ao arrancamento.

TABELA 19 - Parâmetros de resistência de interface solo-geogrelha e de resistência ao

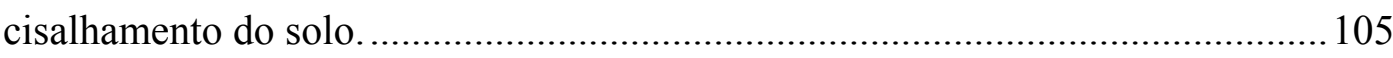

TABELA 20 - Valores máximos de tensão de arrancamento e deslocamento. .............106 


\section{LISTA DE QUADRO}

QUADRO 1- Características de equipamentos de ensaio de arrancamento projetados por alguns autores, ao longo do tempo, ampliado Teixeira (2003).......................20 


\section{LISTA DE ABREVIATURAS, SIGLAS E SÍMBOLOS}

$a_{b}=$ fração unitária do elemento transversal da geogrelha onde é possível desenvolvera a resistência passiva.

$a_{s}=$ fração unitária de área cheia do geossintético

$A=$ área plana de geogrelha em contato com o solo

$B=$ espessura do elemento transversal

$c=$ coesão do solo obtido de ensaio de cisalhamento

$c^{\prime}=$ coesão do solo efetiva

$c_{a}=$ adesão de interface

$C_{u}=$ resistência não drenada do solo

$D_{50}=$ diâmetro médio das partículas de solo

$D_{r}=$ densidade relativa da areia

$f=$ relação entre $\operatorname{tg}(\delta)$ e $\operatorname{tg}(\phi)$

$f^{*}=$ coeficiente de interação entre solo e geogrelha

$f_{a}=$ coeficiente de aderência

$f_{b}=$ fração do elemento transversal no qual a resistência passiva é totalmente

desenvolvida

$F^{*}=$ fator de resistência ao arrancamento

$F_{a n c}=$ fator de segurança contra a ruptura por deficiência de ancorragem

$\mathrm{FF}=$ face frontal do equipamento flexível

$F_{q}=$ fator de capacidade de carga para considerar o embutimento

$F_{p}=$ fator de segurança associado à resistência de arrancamento

$F_{m s}=$ fator de segurança parcial a ser aplicado no ângulo de atrito efetivo do material do aterro a grandes deformações

$\mathrm{FS}=$ fator de segurança

$\mathrm{GC}=$ grau de compactação em relação a Energia de Proctor Normal

$H=$ altura média de aterro sobre o comprimento do reforço

$L=$ comprimento de ancoragem do reforço

$l_{\text {anc }}=$ comprimento mínimo de ancoragem

$L_{b}=$ distancia mínima além da linha mais externa de capitéis 
$L e=$ comprimento do reforço na zona resistente além da superfície potencial de ruptura; comprimento mínimo do reforço para que não ocorra o deslizamento do aterro sobre a inclusão

$L L=$ limite de liquidez

$l_{o}=$ comprimento inicial da geogrelha no ensaio de tração nos elementos longitudinais $\Delta l=$ variação do comprimento de geogrelha no ensaio de tração nos elementos longitudinais

$L P=$ limite de plasticidade

$L_{r}=$ comprimento do reforço no ensaio de arrancamento

LVDTs $=$ Linear Variable Differencial transformer

$N_{c}, N_{c l}=$ fatores de capacidade de resistência passiva (idênticos aos fatores de capacidade de carga)

$N_{q}, N_{q 1}=$ fatores de capacidade de resistência passiva (idênticos aos fatores de capacidade de carga)

$P_{b}=$ resistência passiva gerada pelos elementos transversais quando são solicitados contra o solo na frente de avanço da geogrelha

PEAD $=$ Polietileno de alta densidade

$\mathrm{PET}=$ Poliéster

$P_{f}=$ resistência de interface entre a área exposta de membros longitudinais e transversais e o solo

PP $=$ Polipropileno

$\operatorname{Pr}=$ resistência ao arrancamento por unidade de largura

$P_{T E}=$ máxima resistência efetiva ao arrancamento

$P_{2-D}=$ força de arrancamento para interação bidimensional

$P_{3-D}=$ força de arrancamento para interação tridimensional

$\mathrm{PVC}=$ policloreto de vinila

$\mathrm{RF}=$ face frontal do equipamento rigido

$S=$ espaçamento entre elementos transversais consecutivos

$S_{x}=$ espaçamento longitudinal entre os elementos transversais

$t=$ espessura do elemento transversal de geogrelha

$T=$ força resistente ao esforço de tração no reforço; espessura do solo

$T_{a}=$ força de arrancamento obtido do ensaio

$\mathrm{UV}=$ Ultra violetas 
$W_{r}=$ largura do reforço

$W_{o t}=$ umidade ótima de compactação na energia de Proctor Normal

$\alpha=$ fator de correção do efeito escala; adesão

$\alpha^{\prime}=$ coeficiente de interação relacionando o ângulo de atrito do solo com a resistência de interface solo-reforço

$\alpha 1^{\prime}=$ coeficiente de interação relacionando o ângulo de atrito do solo com a resistência de interface solo-reforço em um dos lado do reforço

$\alpha_{d s}=$ coeficiente de deslizamento

$\alpha_{a d}=$ coeficiente de aderência

$\alpha_{s}=$ fração da superfície sólida de geogrelha

$\delta_{t}=$ deslocamento total obtido registrado pelo equipamento.

$\delta=$ ângulo de atrito de interface slo-geogrelha

$\varepsilon_{v}=$ deformação volumétrica

$\varepsilon_{l}=$ deformação principal maior

$\gamma=$ peso específico do solo

$\lambda=$ relação entre adesão e coesão do solo

$\phi=$ ângulo de atrito interno do solo

$\phi_{c v}{ }^{\prime}=$ ângulo de atrito obtido de ensaio de cisalhamento a volume constante

$\psi=\operatorname{arctg} \mathrm{dx} / \mathrm{dy}$

$\mu=$ coeficiente de atrito

$\rho=$ ângulo de atrito de interface solo-geogrelha

$\rho_{S}=$ massa específica dos soloidos

$\rho_{\text {dmax }}=$ massa específica especifica seca máxima obtida do ensaios de Proctor Normal

$\sigma_{v}{ }^{\prime}=$ tensão efetiva na interface solo-reforço

$\sigma=$ tensão normal no plano do reforço

$\sigma_{n}{ }^{\prime}=$ tensão normal atuante na interface solo-geogrelha

$\sigma_{p}{ }^{\prime}=$ resistência passiva

$\sigma_{l}{ }^{\prime}=$ tensão principal maior no plano de deformação

$\sigma_{3}{ }^{\prime}=$ tensão principal menor no plano de deformação

$\sigma_{l c v}{ }^{\prime}=$ tensão principal maior no plano de deformação na condição de estado crítico $\sigma_{3 c v}{ }^{\prime}=$ tensão principal menor no plano de deformação na condição de estado crítico $\tau-=$ tensão tangencial na interface solo-geogrelha 
$\tau_{a s}=$ tensão de aderência na face superior $\tau_{a i}=$ tensão de aderência na face inferior $\tau_{\text {arrmax }}=$ tensão de arrancamento de pico 


\section{RESUMO}

KAKUDA, F. M. (2005). Estudo de ensaios de arrancamento de geogrelha com utilização de um equipamento reduzido. Dissertação (Mestrado) - Escola de Engenharia de São Carlos, Universidade de São Paulo, São Carlos, 2005.

Este trabalho apresenta resultados de ensaios de arrancamento de geogrelha, obtidos com a utilização de equipamento de dimensões reduzidas. A força de arrancamento foi aplicada por uma máquina universal com capacidade máxima de $30 \mathrm{kN}$, dotada de instrumentação que permitiu registrar a força de arrancamento e o deslocamento da geogrelha em relação ao solo envolvente. Além disto, o ensaio foi instrumentado com uma célula de tensão total instalada no nível da inclusão. A grande vantagem deste equipamento é o pequeno volume de solo utilizado, resultando em um ensaio mais rápido e econômico, proporcionando um controle maior do teor de umidade e do grau de compactação do solo. Considerando que uma grande parte do estado de São Paulo é coberto por solos de granulometria fina, esse equipamento passa a ser uma excelente alternativa para obtenção dos parâmetros de ensaios de arrancamento necessários ao desenvolvimento de projetos em solo reforçado. Para averiguar a possibilidade de uso do ensaio de pequeno porte, nestas condições, para substituir uso das caixas de grandes dimensões foram inicialmente realizadas comparações, através do coeficiente de interação, entre os resultados obtidos através desses dois tipos de ensaios. Os resultados obtidos mostraram que, para as condições de ensaio empregadas utilizando solos com $100 \%$ passando na peneira de abertura $2 \mathrm{~mm}$ e geogrelhas de abertura de malha aproximadamente de $20 \mathrm{~mm}$, a resposta do equipamento, se comparada à de ensaios de grandes dimensões, foi excelente. Isto permitiu que se procedesse a uma ampla análise paramétrica, de cunho experimental, em que se variou a velocidade de ensaio, a tensão confinante, as dimensões das amostras de geogrelha, o tipo de solo e a geogrelha, com o intuído de cobrir diferentes situações possíveis de se encontrar nos projetos de engenharia. $\mathrm{O}$ trabalho apresenta os principais resultados desta análise.

Palavra chave: geogrelha, arrancamento, pequeno porte, geossintético e solo reforçado. 


\title{
ABSTRACT
}

KAKUDA, F. M. (2005). Study of geogrid pull-out tests using a small scale equipment. M.Sc. Dissertation - Escola de Engenharia de São Carlos, Universidade de São Paulo, São Carlos, 2005.

\begin{abstract}
This work presents results of geogrid pullout tests conducted using small scale equipment. The pullout load was applied using a universal load frame, with a maximum capacity of $30 \mathrm{kN}$, capable of recording the pullout load and front displacement. In addition, the test was instrumented with an earth pressure cell installed at the level of the geogrid inclusion. The primary advantage of this equipment is the small volume of soil used in test preparation, resulting in reduced testing time, greater control of the water content and degree of compaction, and significant reduction in overall testing costs. Furthermore, a significant area of the state of Sao Paulo in Brazil is covered by fine grained soils which could be tested according to its pullout behavior using the proposed equipment. To investigate the feasibility of the small scale test facility, comparisons were made between the coefficient of interaction obtained from tests of small and large dimensions. The results show that for the tested materials there were no differences between pull out parameters from both equipment. Additionally it was investigated the effects of testing speed, confining pressure, sample dimensions, and soil and geogrid materials. Results of these tests are presented and discussed.
\end{abstract}

Key words: geogrid, pullout test, small scale, geosynthetics and reinforces soil. 


\section{Capítulo 1}

\section{INTRODUÇÃO}

\subsection{Generalidades}

Os geossintéticos são empregados em obras geotécnicas na substituição ou no aprimoramento de técnicas convencionais de engenharia. Associados ou combinados com solos, os geossintéticos permitem a elaboração de projetos criativos, de alta durabilidade e de baixo custo de execução.

Em grande parte, a crescente utilização de geossintéticos na engenharia civil está relacionada à expansão dos centros urbanos, à execução de vias de acesso e de instalações industriais, que obrigam a ocupação de regiões cujas características topográficas e geológicas não favorecem construções de obras de engenharia. Nestas situações adversas, muitas vezes, as soluções convencionais de engenharia indicam a necessidade de tratamentos dos solos de apoio ou de reforços de aterros e de taludes compactados íngremes, etc. Em tais casos, a técnica de reforço de solo, com a utilização de geossintéticos, apresenta excepcionais vantagens em relação às demais, pois oferece, dentre outras vantagens, o fato de serem pouco exigentes quanto às condições de apoio, podem gerar considerável redução de volume de solo dos aterros, além de garantir resistência e durabilidade. As estruturas em solos reforçados com geossintéticos são constituídas com camadas horizontais de solos compactados intercalados por camadas de geossintéticos, como as geogrelhas e geotêxteis. Das interações que se desenvolvem 
entre as inclusões e o solo é que se garante a condição de estabilidade ao sistema reforçado.

No projeto de sistema reforçado deve-se verificar as condições de ruptura quanto às estabilidades externa e interna. Um dos parâmetros fundamentais nos cálculos decorrentes é a resistência ao arrancamento.

Os parâmetros de resistência ao arrancamento são obtidos através de ensaios de arrancamento e de cisalhamento de interface. No caso das geogrelhas, por apresentarem uma estrutura vazada em forma de grelha e por serem extensíveis, o ensaio de arrancamento é o que melhor simula as condições de solicitações geradas pelo mecanismo de ruptura (RAJU et al., 1998).

Os ensaios de arrancamento convencionais são executados em caixas de grandes dimensões, onde tipicamente se utiliza cerca de $0,5 \mathrm{~m}^{3}$ de solo compactado. A realização destes ensaios é onerosa e demorada, pois requer grande quantidade de solo a ser manipulado.

Para superar estes inconvenientes, em situações particulares em que os solos de reaterro são constituídos de materiais com diâmetros inferiores a $2 \mathrm{~mm}$ pode ser conveniente utilizar um instrumento com menores dimensões para reduzir o tempo de execução dos ensaios e conseqüentemente os custos.

Este texto aborda a conveniência de se utilizar este tipo de equipamento de pequenas dimensões para efetuar ensaios de arrancamento de geogrelhas implantados em solos cujas partículas possuem diâmetros inferiores a $2 \mathrm{~mm}$.

\subsection{Justificativa}

As estruturas de contenção em solo reforçado são hoje de uso freqüente para substituir sistemas de contenção convencionais, pois apresentam quase sempre bons desempenhos e custos reduzidos. Estas estruturas são usadas em aterros de estradas, regularizações de margens de rios, além de obras para gerar desníveis para a construção de edifícios, instalações industriais, trevos, encontros de viadutos e outros benefícios à comunidade.

No projeto de estruturas reforçadas, no geral, se empregam métodos de equilíbrio limite. Neles se admitem um mecanismo cinematicamente admissível e se faz o equilíbrio de esforços considerando que a resistência do solo e da interface solo- 
inclusão seja mobilizada em certo nível de conveniência. Esta análise, denominada verificação de estabilidade interna requer a quantificação de força de arrancamento, cujo parâmetro de maior relevância é a resistência de interface.

Dentre os ensaios utilizados para a obtenção da resistência de interface, o de arrancamento de grandes dimensões, cujas vantagens são fidedignidade, reprodução da estrutura física do maciço reforçado e capacidade de gerar níveis de tensão e deformação próximos dos valores de campo, é aquele que oferece as maiores possibilidades de quantificação adequada dos parâmetros de interface. A partir destes parâmetros pode-se efetuar estudos paramétricos de fatores que afetam o comportamento do sistema solo-inclusão, além de permitir o estudo do aperfeiçoamento dos produtos utilizados como reforço.

Em que pese todas essas qualidades e vantagens, estes ensaios têm como inconveniência os elevados custos, o longo tempo de execução, a complexidade de montagem e a menor possibilidade de repetição das condições de ensaio, quando comparados a ensaios de pequeno porte.

Neste contexto, a opção pela utilização de equipamentos de pequeno porte busca obter vantagens com qualidade satisfatória, de forma a viabilizar a utilização de parâmetros de ensaio em projetos de solo reforçado.

Em vista destes aspectos, o presente trabalho avalia a possibilidade de uso de ensaios de dimensões reduzidas, uma vez que a grande quantidade de dados pode proporcionar melhores análises qualitativas e quantitativas sobre o comportamento da interação solo-estrutura de reforço. Além disso, a utilização de equipamento de pequeno porte é justificada pelo fato de extensas áreas do Estado de São Paulo serem cobertas por solos de granulometria fina, minimizando efeitos de contorno.

\subsection{Objetivo}

O principal objetivo deste trabalho é avaliar a possibilidade de se medir parâmetros de resistência ao arrancamento de geogrelhas implantadas em solos de granulometria fina (diâmetros inferiores a $2 \mathrm{~mm}$ ) em equipamentos de pequeno porte.

Nesse contexto, pretende-se:

- Averiguar a repetitividade dos resultados dos ensaios com a utilização deste equipamento; 
- Comparar os resultados obtidos neste trabalho com resultados obtidos da literatura com utilização de equipamento de grandes dimensões;

- Definir qual a relação entre o tamanho mínimo da amostra de geogrelha a ser utilizada e a área interna do equipamento a partir do qual o ensaio não é mais afetado pelas dimensões do corpo de prova e;

- Fazer uma ampla análise paramétrica, de cunho experimental, utilizando o equipamento de pequeno porte que permite que se varie a velocidade de arrancamento, a tensão confinante, o tamanho da amostra e o tipo de solo e geogrelha. 


\section{CAPÍTULO 2}

\section{REVISÃO BIBLIOGRÁFICA}

\subsection{Introdução}

O desempenho de estruturas em solos reforçados depende fundamentalmente da interação solo-inclusão. Os materiais constituintes destas estruturas apresentam comportamentos mecânicos distintos, mas complementares. O solo, no geral, apresenta resistências à compressão e ao cisalhamento relativamente elevadas, porém pequena resistência à tração, enquanto os geossintéticos possuem elevada resistência à tração.

A transferência de tensões que ocorre entre o solo e o reforço envolve dois mecanismos principais, o atrito e a adesão de interface, e a resistência passiva do solo que se desenvolve à frente dos elementos transversais. A quantificação da resistência de interface solo-geossintético é feita experimentalmente com o uso de ensaios de laboratórios e de campo. Por razões de custo e de melhor controle das condições de contorno, os ensaios de arrancamento de laboratório tornaram os mais utilizados para determinação da resistência de interface (OCHIAI et al., 1996; TEIXEIRA, 2003; SUGIMOTO, 2003; e outros). No entanto, muitos projetistas preferem os ensaios de arrancamento de campo por reproduzirem mais fielmente as reais condições da obra, inclusive os aspectos construtivos que nem sempre podem ser reproduzidos no laboratório.

Para que os resultados obtidos nos ensaios de laboratório sejam representativos das condições de campo, é fundamental que as variáveis como a forma, energia e os parâmetros de compactação e o nível de confinamento de campo, além das condições de contorno e a velocidade do ensaio sejam corretamente reproduzidos no laboratório. 
A decisão entre que tipo de ensaio de arrancamento utilizar (de campo ou de laboratório) depende fundamentalmente do custo envolvido e do tempo e do instrumental disponíveis para a execução dos serviços. Ensaios de campo proporcionam maior representatividade dos estados de tensões e das características dos materiais, mas podem ser mais caros e mais demorados do que os ensaios de laboratório. Além disto, as condições de contorno, e o controle de qualidade da instalação são relativamente mais complexos do que nas montagens de laboratório.

Em vista disto, os ensaios de laboratório de grande porte tem sido executados com muita freqüência. Entretanto, por requerer o manuseio de cerca de um metro cúbico de solo muitas vezes é preterido em relação aos ensaios de campo ou mesmo às correlações empíricas sob alegação de alto custo e de elevado tempo de execução.

Esses fatores não devem constituir em justificativas aceitáveis para se elaborar projetos sem o respaldo de parâmetros de projeto obtidos de ensaios de arrancamento de grandes dimensões. É preciso ter em mente que os parâmetros de projeto devem ter sempre o respaldo em ensaios representativos das condições de campo, independente de qualquer obstáculo que possa surgir durante a fase de projeto.

Em vista disto, em situações particulares em que os solos de reaterro são constituídos de materiais com partículas com diâmetros inferiores a $2 \mathrm{~mm}$ e as geogrelhas possuem malhas densas (espaçamento entre membros da ordem de $25 \mathrm{~mm}$ ) pode ser conveniente utilizar um instrumento de pequeno porte que, a partir de um volume muito menor de solo empregado na sua execução, possa fornecer parâmetros de boa qualidade. Isto pode permitir a redução de tempo de execução dos ensaios e conseqüentemente de custos, além de estimular sempre o emprego em projetos de resultados de ensaios.

\subsection{Características geométricas e de fabricação de geogrelhas}

As geogrelhas são geossintéticos desenvolvidos para aplicação em reforço de solo. A geometria deste geossintético constitui-se de elementos longitudinais e transversais à direção de fabricação conforme mostra a Figura 1. A geometria plana e vazada possibilita uma excelente interação com o solo circundante.

As geogrelhas podem ser fabricadas através da perfuração de mantas poliméricas que são posteriormente tracionadas (em uma ou em duas direções), ou a partir de 
cordões de multifilamentos trançadas em duas direções, urdume (direção longitudinal) e trama (transversal à direção de fabricação). A união dos membros é feita por extrusão, colagem ou entrelaçamento.

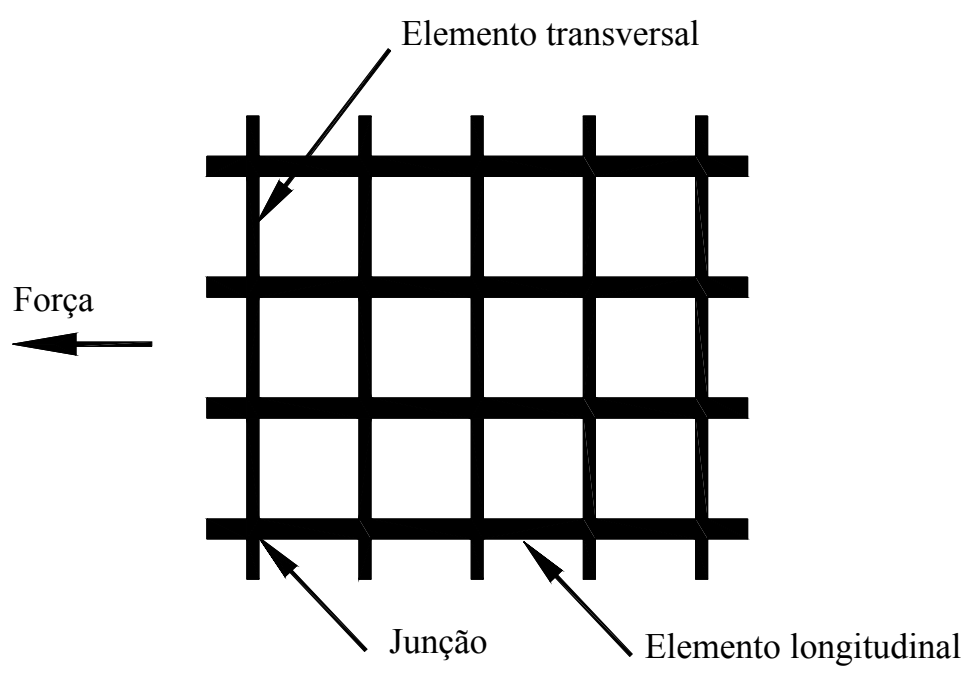

Figura 1- Elementos constituintes das geogrelhas.

Os principais polímeros utilizados na fabricação das geogrelhas estão relacionados na Tabela 1 .

Tabela 1- Características dos principais polímeros utilizados na fabricação de geogrelha (BUENO, 2004).

\begin{tabular}{|c|c|c|}
\hline Polímero & Sigla & Características \\
\hline $\begin{array}{l}\text { Polietileno de } \\
\text { alta densidade }\end{array}$ & PEAD & $\begin{array}{l}\text { È um termoplástico bastante cristalino, resultante da } \\
\text { polimerização de monômeros de etileno. Apresenta alta } \\
\text { resistência química e densidade entre } 0,941 \text { a } 0,959 \mathrm{~g} / \mathrm{cm}^{3} \text {. } \\
\text { Para aumentar sua longevidade quando exposto ao sol } \\
\text { incorpora o aditivo de negro-de-fumo. }\end{array}$ \\
\hline Polipropileno & PP & $\begin{array}{l}\text { Polímero termoplástico semicristalino, os principais } \\
\text { aditivos são estabilizantes térmicos, negro-de-fumo } \\
\text { (proteção aos raios UV), plastificantes e antioxidante. }\end{array}$ \\
\hline Poliéster & PET & $\begin{array}{l}\text { Poliéster é o resultante da polimerização de etilonoglicol e } \\
\text { dimetiltereftalato ou ácido tereftálico. Apresenta alta } \\
\text { resistência à tração e aditivos para combater degradação } \\
\text { térmica e UV. }\end{array}$ \\
\hline
\end{tabular}


As geogrelhas são constituídas essencialmente por polímeros sintéticos, derivados de petróleo. Além das resinas básicas, os polímeros são constituídos por aditivos em menores quantidades, como plastificantes, antioxidantes, estabilizantes antiUV como o negro-de-fumo, etc. Estes aditivos permitem a melhora das propriedades mecânicas, como a flexibilidade, e inibem os efeitos oxidantes e deletérios causados pela radiação ultravioleta.

Como na maioria das obras geotécnicas, os geossintéticos encontram-se protegidos dos efeitos dos raios ultravioletas, aumentando a longevidade do produto.

\subsection{Reforço de solos com geogrelhas}

As geogrelhas são utilizadas em reforço de solos, destacando-se as aplicações em estruturas de contenção (face segmentada ou solo envelopado), taludes compactados íngremes, reforço de base de aterro sobre solo mole, reforço de base de pavimentos rodoviário, ferroviário e aeroportuário, dentre outros.

\subsubsection{Muros e taludes reforçados em geogrelhas}

As estruturas em solos reforçados com geogrelhas são constituídas de camadas horizontais de solo compactado intercalada por inclusões de geogrelhas. Através da interação entre as inclusões e o solo, o sistema ganha uma condição de estabilidade.

A Figura 2 apresenta esquematicamente uma estrutura reforçada com geogrelha com face de blocos pré-moldados (muro de face segmentada). Nela observam-se drenos horizontais na camada inferior do aterro, constituído de brita e um de tubo perfurado colocado na parte interna do pé da face do talude. A colocação de drenos tem a finalidade de minimizar as pressões neutras no interior do maciço reforçado.

A verificação da estabilidade dos projetos de maciço reforçados com geogrelhas é feita segundo duas condições, as estabilidades externa e interna. $\mathrm{Na}$ verificação da estabilidade externa deve-se admitir que o maciço de solo reforçado atua como um corpo rígido, ou seja, a zona reforçada funcione como uma estrutura de gravidade. A partir desse pressuposto, verifica-se a segurança do maciço segundo três mecanismos clássicos de ruptura de estruturas de contenções: a) deslizamento ao longo da base; 
b) ruptura do solo de fundação e c) ruptura global, ou seja, ruptura por uma superfície envolvendo todo o maciço reforçado.
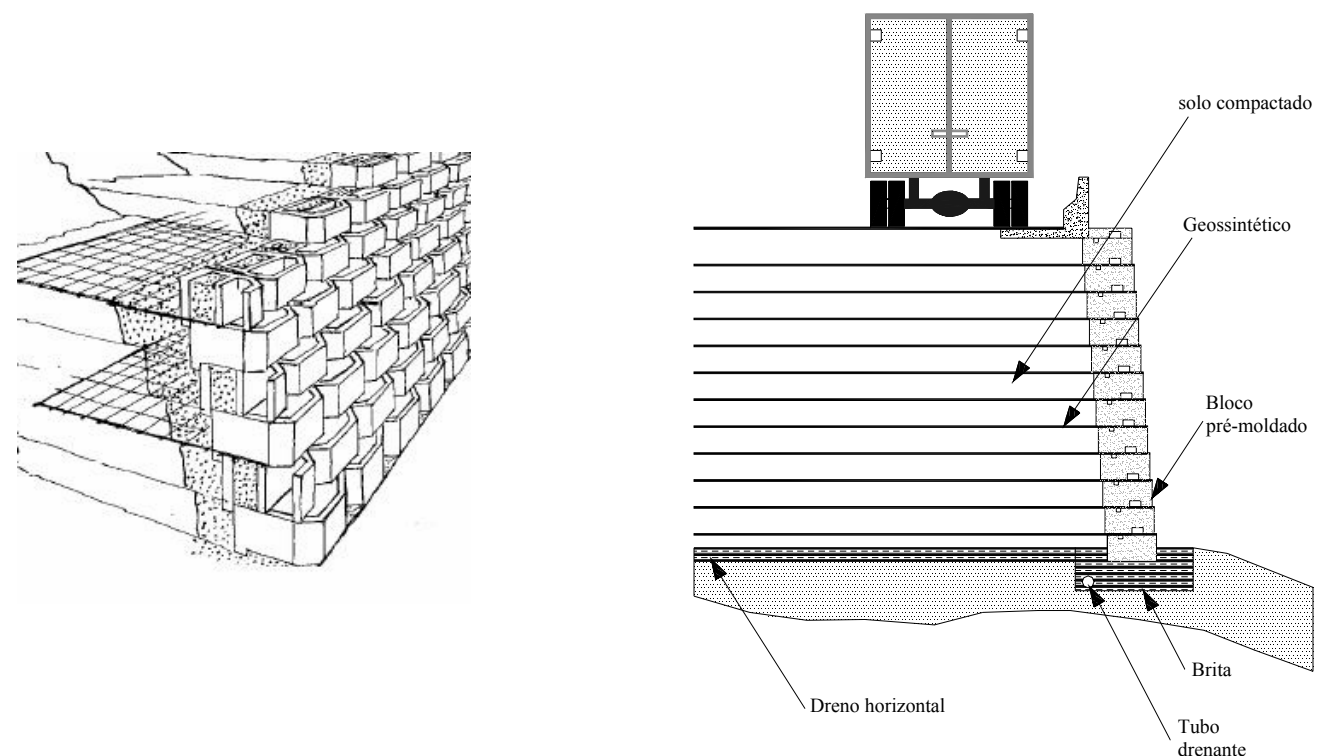

Figura 2 - Esquema sintetizado de uma estrutura reforçada com geogrelha

Já na verificação da estabilidade interna, cada inclusão é analisada separadamente. A verificação baseia-se na análise por equilíbrio limite, separando o maciço em duas regiões denominadas de zonas ativa e resistiva, revelando duas condições: a) arrancamento do reforço e b) ruptura do reforço.

Os modos de rupturas de estruturas em solo reforçado são apresentados de forma esquemática na Figura 3.

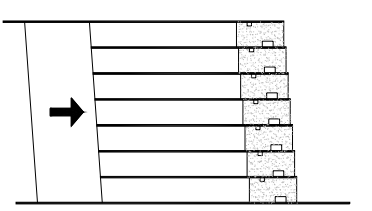

a) deslizamento da base

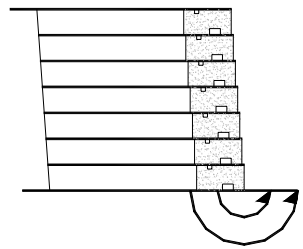

b) ruptura da fundação

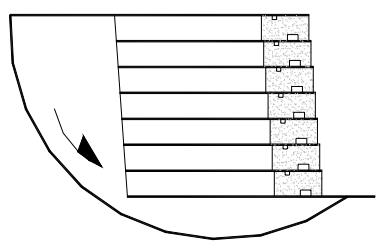

c) ruptura global

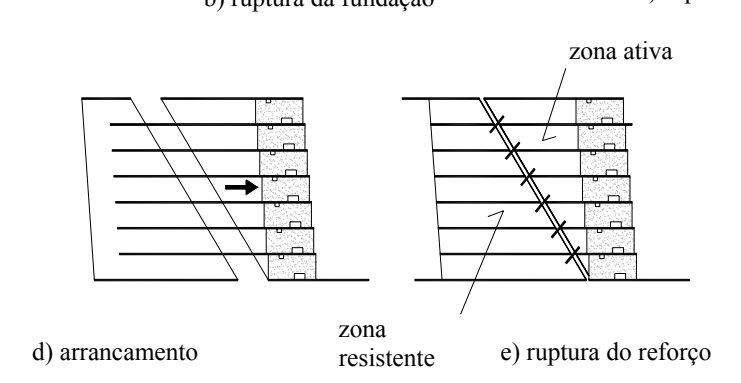

Figura 3 - Modos de ruptura de uma estrutura em solo reforçado 
Nos projetos de estruturas de contenção em solo reforçado, determina-se inicialmente o comprimento da inclusão necessário para garantir a estabilidade do sistema, de forma que atenda os três mecanismos clássicos de ruptura apresentados na Figura 3. Assim, determinado o comprimento da inclusão, efetua-se a verificação quanto ao arrancamento e a quebra do reforço. Para efetuar essa análise, deve-se determinar o comprimento de ancoragem na zona resistente do maciço.

O mecanismo de ruptura usualmente empregado consiste em assumir a condição de ruptura ativa sugerida por Rankine, em que o plano de ruptura forma um ângulo de $45+\phi / 2$ com o plano horizontal, saindo do pé do talude. Na Figura 4, apresenta a superfície potencial de ruptura prevista por Rankine que, pelas hipóteses usuais, coincide com a posição de máxima resistência ao arrancamento utilizados para reforços mais deformáveis, caso dos geotêxteis e das geogrelhas.

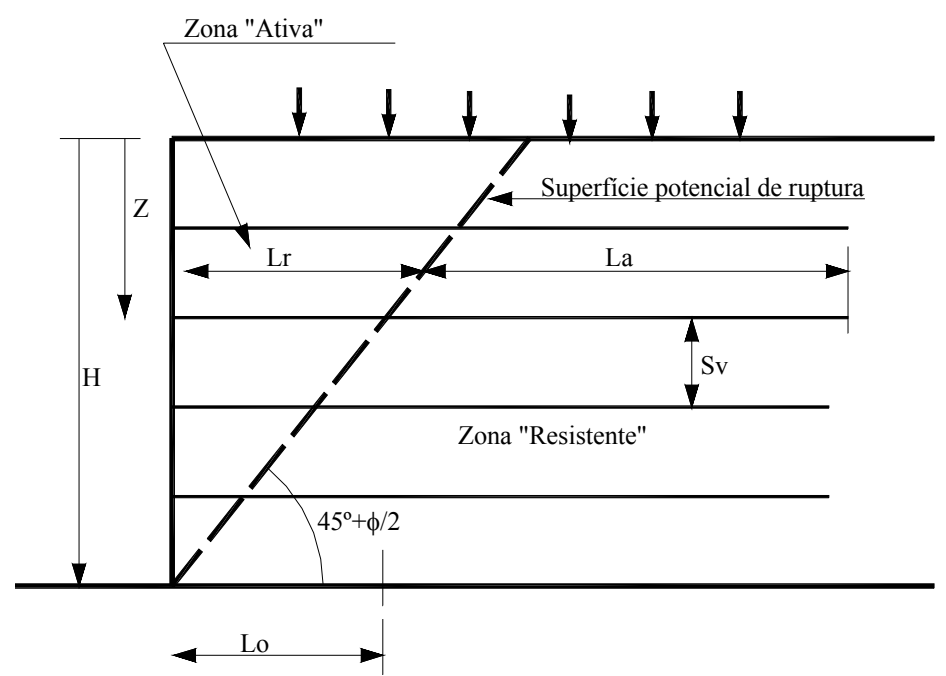

Figura 4 - Comprimentos das zonas ativas e passivas de um muro reforçado com geossintético em função de sua profundidade.

$\mathrm{Na}$ análise da resistência ao arrancamento por unidade de largura do reforço $\left(P_{r}\right)$ proposta por Christopher et al. (1990) segue a expressão (1).

$$
P_{r}=2 \cdot L_{e} \cdot \alpha \cdot \sigma_{v}^{\prime} \cdot F^{*} \geq F S \cdot T_{\max }
$$

Nesta expressão $L_{e}$ é o comprimento de reforço na zona resistente além da superfície potencial de ruptura; $\alpha$ é o fator de correção do efeito escala; $\sigma_{v}^{\prime}$ é a tensão 
efetiva vertical na interface solo-reforço e $F^{*}$ é o fator de resistência ao arrancamento, que é determinado com maior precisão através de ensaios de arrancamento.

Alternativamente, pode-se utilizar a expressão (2), considerando que o fator $F^{*}$ é uma combinação de resistência passiva e a mobilizada pelo atrito entre a geogrelha e solo (JEWELL, 1996).

$$
F^{*}=F_{q} \cdot\left(\frac{a_{b} \cdot B}{2 \cdot S}\right)+\operatorname{tg} \delta \cdot a_{s}
$$

Nesta expressão, os parâmetros utilizados para análise do arrancamento são: $F_{q}$ é o fator de capacidade de carga para considerar o embutimento; $a_{b}$ representa a fração unitária do elemento transversal da geogrelha onde é possível desenvolver a resistência passiva; $B$ é a espessura do elemento transversal; $S$ é o espaçamento entre os elementos transversais; $\delta$ é o angulo de atrito de interface solo-geogrelha; e $a_{s}$ é a fração da superfície sólida de geogrelha.

\subsubsection{Aterros sobre solos moles}

Dentre as soluções convencionais utilizadas para a estabilização de aterros sobre solos moles destaca-se a remoção e substituição do solo mole por material compactado, as bermas de equilíbrio, o aterro estaqueado, o uso de material leve, e o reforço basal, i.e., a colocação de reforço na base do aterro.

A aplicação de geossintéticos como elemento principal de reforço de base de aterro sobre solo mole apresenta algumas vantagens como a rapidez do processo construtivo e a possibilidade de construção de talude mais íngreme. Os geotêxteis e as geogrelhas são os materiais comumente utilizados para esta aplicação.

No dimensionamento do reforço, analisa-se a estabilidade da obra considerando como hipótese inicial, que a superfície de deslizamento seja circular, e emprega-se o método de equilíbrio limite. Basicamente, os mecanismos de estabilidade a serem verificados são a ruptura do corpo do aterro ao longo do contato com o geossintético (a), a ruptura do solo de fundação (b) e a ruptura generalizada (c), sendo estes mecanismos sintetizados na Figura 5. 


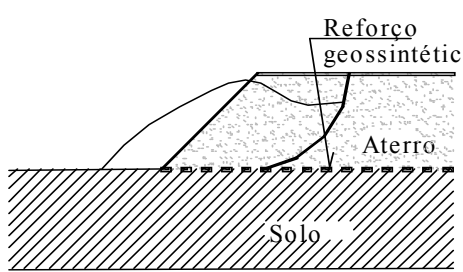

(a)

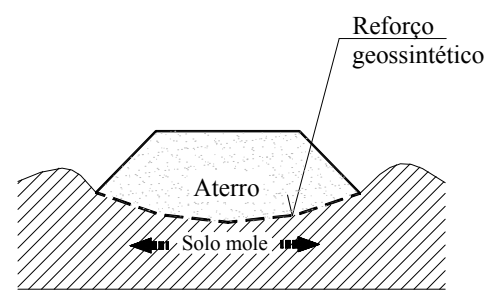

(b)

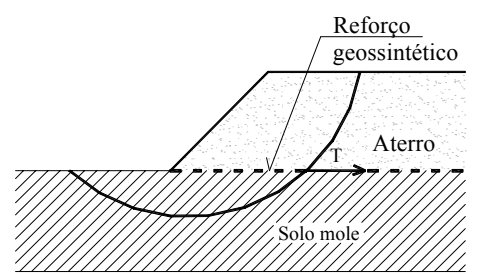

(c)

Figura 5 - Mecanismos de estabilidade de reforço de base de aterro sobre solo mole (adaptado de PALMEIRA, 2002)

Verificado os três mecanismos de instabilidades apresentados na Figura 5, obtém-se o comprimento mínimo de ancoragem do reforço, apropriado para garantir a estabilidade.

A Figura 6 ilustra as forças atuantes no reforço e os comprimentos de ancoragem a serem verificados quanto ao arrancamento. No caso do reforço ser um geotêxtil, as forças resistentes ao esforço de tração no reforço $(T)$ serão dadas pela soma das tensões de aderências nas faces superior e inferior do geotêxtil $\left(\tau_{a s}, \tau_{a i}\right)$ multiplicadas pelo comprimento mínimo de ancoragem $\left(l_{\text {anc }}\right)$. Deve-se considerar um fator de segurança contra a ruptura por deficiência de ancoragem $\left(F_{\text {anc }}\right)$.

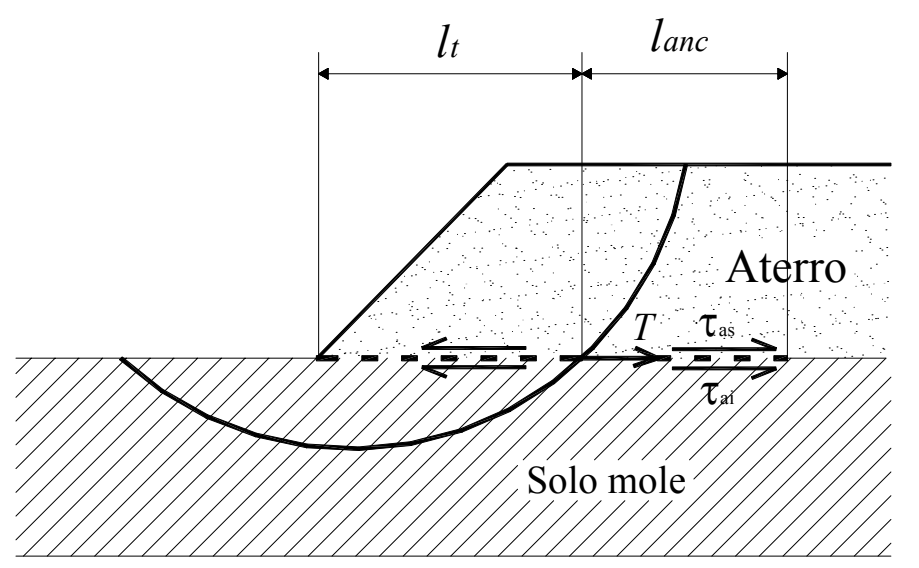

Figura 6 - Determinação geométrica do comprimento mínimo de ancoragem (PALMEIRA, 1992).

A expressão (3), apresentada por Palmeira (1992) fornece o comprimento de ancoragem para materiais contínuos.

$$
l_{a n c}=\frac{F_{a n c} \cdot T}{\left(\tau_{a s}+\tau_{a i}\right)}
$$


Quando o elemento de reforço é uma geogrelha, por se tratar de um elemento descontinuo, o calculo do comprimento mínimo de ancoragem deve-se levar em consideração o coeficiente de interação $(f)$. Em geral, este parâmetro pode ser obtido através de ensaio de arrancamento.

O comprimento de ancoragem $\left(l_{t}\right)$ à esquerda da interseção do reforço com a superfície hipotética circular de ruptura deve atender as mesmas condições de ancoragem, obedecendo a critérios semelhantes ao apresentado pela expressão (3).

\subsubsection{Aterros estaquiados.}

Convencionalmente, a solução utilizada em regiões de solo mole de pequena espessura é a remoção do solo mole e conseqüente reaterro com solo compactado. Em condições mais gerais utilizam-se bermas de equilíbrio. Nas condições em que áreas de empréstimos estão a grandes distancias, o espaço é limitado para a utilização de bermas, o cronograma exige a utilização imediata do aterro ou quando a espessura do solo mole é tal que inviabilize a sua remoção, uma solução alternativa é a utilização de geossintéticos como reforço da base de aterros estaqueados.

O conceito básico do funcionamento de um aterro estaqueado está relacionado ao fenômeno de arqueamento do solo permitindo a utilização de elementos discretos constituídos de estacas e capitéis. Esse fenômeno possibilita a transferência de todas as cargas oriundas do aterro para as cabeças das estacas sem que haja a necessidade de uma laje continua para uni-las.

A utilização de geossintético sobre as estacas introduz esforços adicionais à estrutura, uma vez que apresentam uma considerável resistência à tração e rigidez. Esses esforços, geralmente sub-horizontais, proporcionam algumas vantagens como: aumento do espaçamento entre estacas e eliminação da necessidade de estacas inclinadas nas bordas do aterro para equilibrar os esforços horizontais.

No dimensionamento destas estruturas, em geral, deve-se verificar os estados limites últimos quanto à capacidade de carga do grupo de estacas, extensão lateral do trecho estaqueado, arqueamento da carga vertical, escorregamento lateral e estabilidade global. Além da verificação da adesão entre o reforço e o solo adjacente para cada um dos estados limites. Outros parâmetros geométricos a serem verificados são o comprimento mínimo do reforço $\left(L_{e}\right)$ para que não ocorra o deslizamento do aterro 
sobre a inclusão e a distância mínima $\left(L_{b}\right)$ além da linha mais externa de capitéis. A Figura 7 apresenta os principais esforços atuantes em um modelo hipotético de aterro sobre estacas com utilização de geossintético como elemento de reforço.

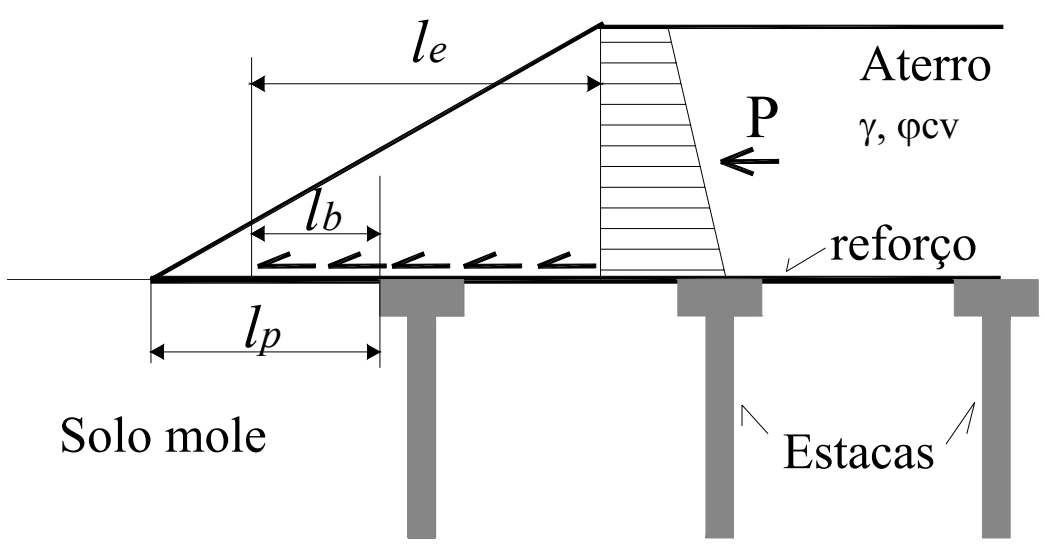

Figura 7 - Geometria sintetizada de aterro estaqueado e a representação dos principais esforços atuantes (VERTEMATTI, 2004)

As expressões (4) e (5) segue a metodologia de dimensionamento proposta pela norma inglesa BS 8006 para os cálculos dos comprimentos $\left(L_{e}\right)$ e $\left(L_{b}\right)$.

$$
\begin{gathered}
L_{e} \geq \frac{\left\lfloor 0,5 \cdot K_{a} \cdot H\left(f_{f s} \cdot \gamma \cdot H+2 \cdot f_{q} \cdot w_{s}\right) \cdot f_{s} \cdot f_{n}\right\rfloor}{\left[\frac{\gamma \cdot h \cdot\left(\alpha^{\prime} \cdot \operatorname{tg} \varphi_{c v}^{\prime}\right)}{f_{m s}}\right]} \\
L_{b} \geq \frac{f_{m s} \cdot f_{n} \cdot f_{p} \cdot\left(T_{r p}-T_{d s}\right)}{\gamma \cdot h \cdot\left[\frac{\alpha_{1}^{\prime} \cdot \operatorname{tg} \varphi_{c v 1}^{\prime}}{f_{m s}}+\alpha_{2}^{\prime} \cdot \operatorname{tg} \varphi_{c v 2}^{\prime}\right]}
\end{gathered}
$$

Nestas expressões, $F S$ é o fator de segurança parcial para a resistência ao escorregamento sobre o reforço; $F p$ é o fator de segurança associado à resistência de arrancamento; Fms é o fator de segurança parcial a ser aplicado no ângulo de atrito efetivo do material do aterro a grandes deformações; $H$ é a altura média de aterro sobre o comprimento Le do reforço; $\alpha$ ' é o coeficiente de interação relacionando o ângulo de atrito do solo com a resistência de interface solo-reforço; $\alpha 1$ ' é o coeficiente de interação relacionado o ângulo de atritos do solo com a resistência de interface soloreforço em um dos lado do reforço; e $\alpha 2$ ' é referente ao lado oposto do reforço. 


\subsubsection{Reforço de base de pavimento}

Outra utilização de geossintético, em especial de geogrelhas, é o reforço de base de pavimentos. A inserção de geossintético em pavimentos proporciona algumas melhorias em seu desempenho como redução das espessuras das camadas granulares e aumento de vida útil de projeto, sendo estas melhorias observadas em resultados de experimentos de laboratório e de campo (KLEIN et al., 2003; MIURA,1990).

Resultados de pesquisas conduzidas por vários autores chegaram a valores de vida útil de projetos três vezes superiores se comparada com projetos sem utilização de reforço de base e, em termos de espessuras levaram à reduções de $20 \mathrm{a} 50 \%$, devido ao uso do geossintético. O emprego de geogrelha, como elemento de reforço em base de pavimento, gera um aumento na capacidade estrutural da camada granular, sendo que esse aumento, em grande parte, associa-se à quatro mecanismos de comportamento distintos: intertravamento, inibição dos movimentos laterais, confinamento e separação.

A Figura 8 mostra os mecanismos envolventes na região de interface soloagregado

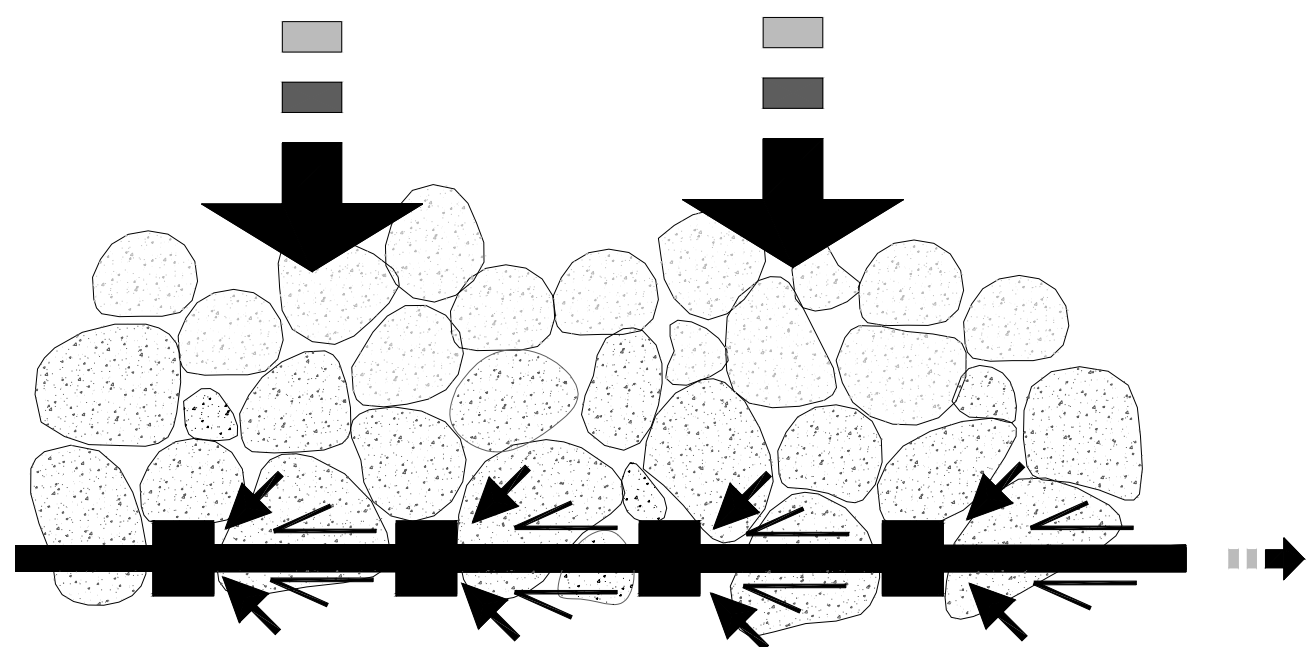

Figura 8 - Detalhe da região de interface geogrelha-base de pavimento. 


\subsection{Ensaios para avaliar a interação solo estrutura}

A resistência de interface solo-inclusão é determinada em ensaios de laboratório: de arrancamento e de cisalhamento direto. As Figuras 9 e 10 representam esquemas destes ensaios. Variações geométricas desses ensaios são encontradas na literatura, como, por exemplo, a que impõe uma inclinação à inclusão (JEWELL, 1980).
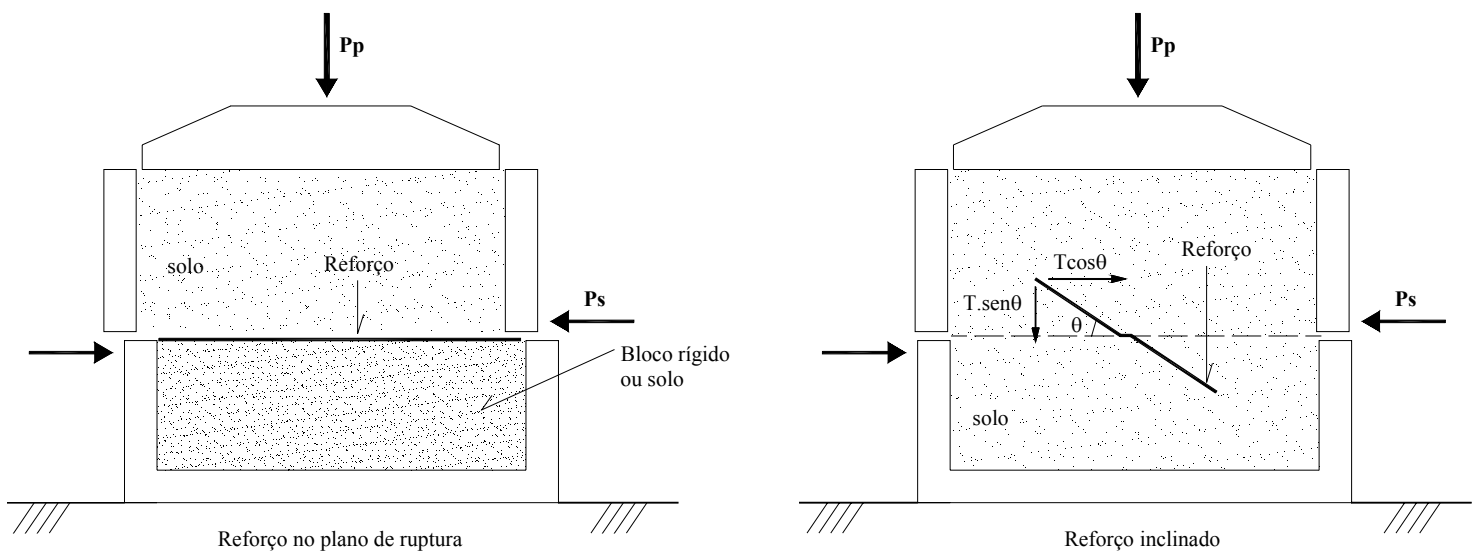

Figura 9- Representação de ensaios de cisalhamento com inclusão no plano de cisalhamento e inclusão inclinada com relação ao plano cisalhante (adaptado de INGOLD, 1983)

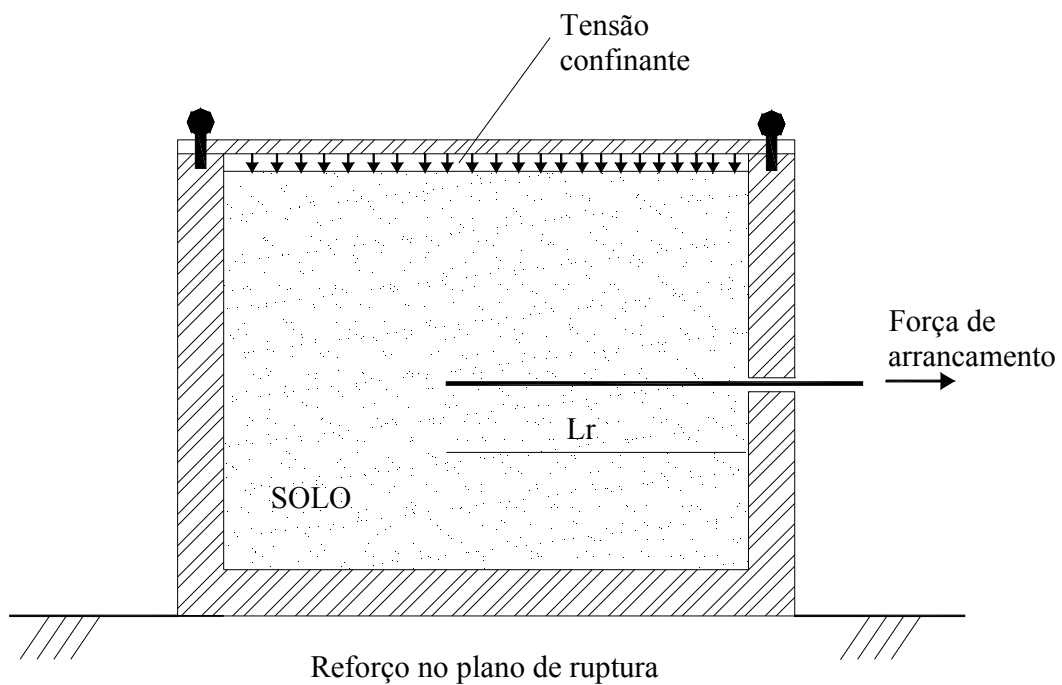

Figura 10 - Representação do ensaio de arrancamento

Os ensaios de cisalhamento direto e de arrancamento diferem-se entre si pelos mecanismos de ruptura impostos ao corpo de prova, pelas condições de contorno e pela forma com que os esforços são aplicados aos geossintéticos. A Figura 11 mostra uma estrutura típica de solo reforçado com geossintético, em que o mecanismo observado na 
região A pode ser representado pelo ensaio de cisalhamento direto. Por sua vez, o mecanismo de ruptura que ocorre na região B pode ser representado por ensaio de arrancamento, em que a inclusão é disposta horizontalmente. Na região $\mathrm{C}$, o mecanismo de ruptura pode ser o de cisalhamento direto com a inclusão disposta inclinada relativa ao plano de ruptura.

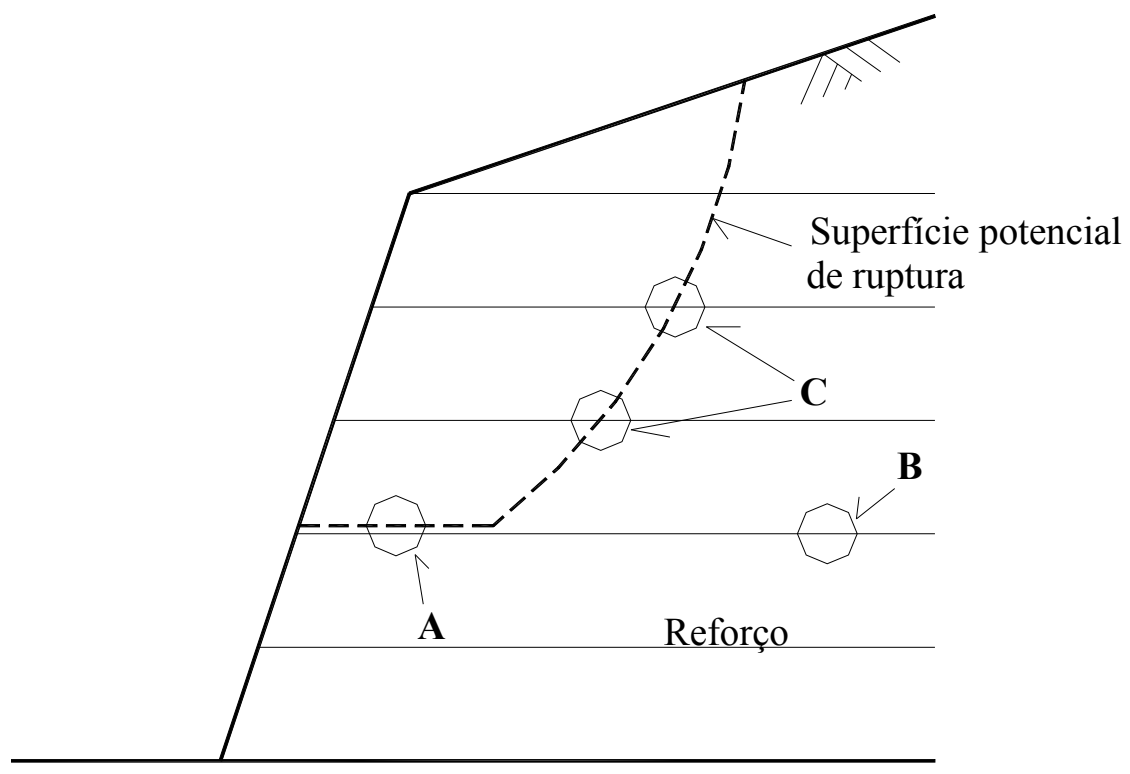

Figura 11 - Representação do ensaio de arrancamento (PALMEIRA \& MILLIGAN, 1989).

Uma das razões que justifica as possíveis diferenças nos resultados obtidos entre os ensaios de cisalhamento direto e arrancamento é o fato da mobilização da deformação cisalhante ser teoricamente uniformemente distribuída ao longo da interface solo-inclusão, enquanto no ensaio de arrancamento, a mobilização da deformação é a combinação da deformação de interface solo-inclusão e o alongamento do geossintético (PALMEIRA, 1989).

Nos casos em que se utiliza a geogrelha como reforço, o ensaio de arrancamento é o que melhor simula os mecanismos de interação solo-inclusão, uma vez que a geometria de grelha e a baixa rigidez à flexão dos membros transversais fazem com que os resultados obtidos nos ensaios de cisalhamento direto não simulem as condições que estão sujeitas as geogrelhas no maciço reforçado. 


\subsection{Ensaios de arrancamento}

Resultados de ensaios de arrancamento têm sido utilizados, não somente para o esclarecimento do mecanismo de interação entre solo-inclusão, mas também para projetos e análises do comportamento de estrutura de solo reforçado. Assim, as condições em que são realizados estes ensaios tornam-se de grande importância para a determinação destes parâmetros. Duas linhas de pesquisa têm sido desenvolvidas com o intuito de obtenção destes parâmetros: ensaios de arrancamento em campo e ensaio de arrancamento em laboratório.

\subsubsection{Ensaio de arrancamento em campo}

Os ensaios de arrancamento em campo geralmente são realizados em aterro, necessitando de grande quantidade de solo, equipamentos pesados para locomoção e compactação do solo, um anteparo resistente para servir de reação ao equipamento de aplicação da força. O controle da compactação, da umidade, da instalação dos instrumentos de medidas, dos deslocamentos da face e dos recalques diferenciais da base do aterro são alguns fatores complicadores desse tipo de ensaio.

Ochiai et al. (1996) realizaram alguns ensaios de arrancamento de campo. O experimento foi conduzido em um aterro construído com camadas de areia reforçada com geogrelhas uniaxial e biaxial, com larguras de $0,5 \mathrm{~m}$ e $1,0 \mathrm{~m}$ e comprimento variando entre 2 a $4 \mathrm{~m}$. Com os resultados dos ensaios obtidos em campo, os autores puderam comparar com os resultados obtidos em laboratório, e observaram que a mobilização da resistência ao arrancamento é similar em ambas situações. A partir desta observação, concluíram que os resultados de ensaios de laboratório podem ser utilizados não somente para esclarecer o mecanismo de interação solo-reforço, mas também para ser utilizado como parâmetro para avaliar quantitativamente a resistência ao arrancamento da geogrelha nas análises e projetos de estrutura de solo reforçado.

É certo que os parâmetros de resistência ao arrancamento obtidos através de ensaios de campo representam com maior fidedignidade o comportamento das estruturas de solo reforçado, porém seu elevado custo, grandes dificuldades na montagem do ensaio e o prolongado tempo de execução fazem com que a grande maioria dos pesquisadores opte pela utilização de ensaios de laboratório. 


\subsubsection{Ensaio de arrancamento de laboratório}

Um equipamento de arrancamento típico é constituído de uma caixa metálica rígida com seção transversal retangular. A força de tração no elemento de reforço é aplicada por uma força motriz, que possibilita o controle da velocidade do ensaio. A tensão confinante é aplicada por um colchão inflável na maioria dos modelos propostos na literatura. $\mathrm{O}$ equipamento apresentado na Figura 12 dá uma idéia deste tipo de equipamento.

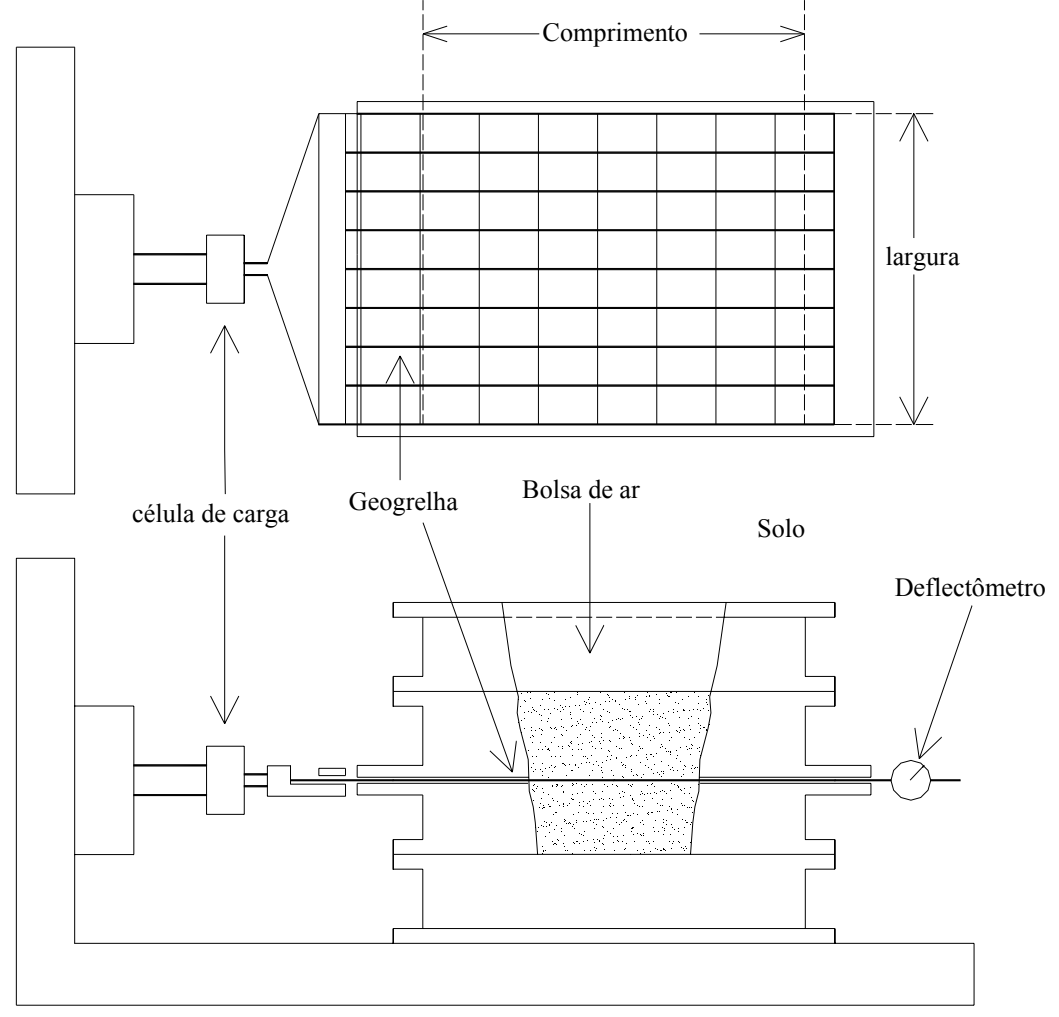

Figura 12 - Equipamento de ensaio de arrancamento de laboratório (adaptado de OCHIAI et al., 1996).

A instrumentação básica do ensaio consiste de células de cargas utilizadas para medir a força de arrancamento; células de tensão total; piezômetros e transdutores de deslocamentos internos.

Vários autores desenvolveram seus próprios equipamentos, acarretando diferentes dimensões e condições de contorno do ensaio. No quadro abaixo, são apresentadas as características dos equipamentos desenvolvidos ao longo do tempo. 
Quadro 1- Características de equipamentos de ensaio de arrancamento projetados por alguns autores, ao longo do tempo, ampliado Teixeira (2003).

\begin{tabular}{|c|c|c|c|c|c|}
\hline Autores & $\begin{array}{l}\text { Altura } \\
(\mathrm{mm})\end{array}$ & $\begin{array}{c}\text { Largura } \\
\text { (mm) }\end{array}$ & $\begin{array}{l}\text { Compri } \\
\text { mento } \\
(\mathrm{mm})\end{array}$ & $\begin{array}{c}\text { Sistema de } \\
\text { aplicação de } \\
\text { sobrecarga }\end{array}$ & Medidas efetuadas \\
\hline $\begin{array}{c}\text { Christopher \& Berg } \\
\text { (1990) }\end{array}$ & 310 & 600 & 1220 & Bolsa de ar & $\begin{array}{l}\text { Deslocamento e força de } \\
\text { arrancamento }\end{array}$ \\
\hline Farrag et al. (1993) & 760 & 900 & 1520 & Bolsa de ar & $\begin{array}{c}\text { Deslocamento, força de } \\
\text { arrancamento e velocidade. }\end{array}$ \\
\hline $\begin{array}{l}\text { Bergado e Chai } \\
\text { (1994) }\end{array}$ & 510 & 750 & 1250 & Bolsa de ar & $\begin{array}{c}\text { Deformação, deslocamento } \\
\text { dilatância e força de } \\
\text { arrancamento. }\end{array}$ \\
\hline Alfaro et al. (1995) & 400 & 600 & 1500 & Bolsa de ar & $\begin{array}{c}\text { Deformação, deslocamento, } \\
\text { dilatância e força de } \\
\text { arrancamento. }\end{array}$ \\
\hline Chang et al. (1995) & 150 & 500 & 400 & Bolsa de ar & $\begin{array}{l}\text { Deslocamento, deformação e } \\
\text { força de arrancamento. }\end{array}$ \\
\hline $\begin{array}{l}\text { Ladeira \& Lopes } \\
\qquad(1995)\end{array}$ & 600 & 1000 & 1530 & $\begin{array}{l}\text { Cilindros } \\
\text { hidráulicos }\end{array}$ & $\begin{array}{l}\text { Deslocamento e força de } \\
\text { arrancamento. }\end{array}$ \\
\hline Miyata (1996) & 220 & 325 & 660 & Bolsa de ar & $\begin{array}{l}\text { Dilatância, deslocamento e } \\
\text { força de arrancamento. }\end{array}$ \\
\hline Ochiai et al. (1996) & 200 & 400 & 600 & Bolsa de ar & $\begin{array}{l}\text { Deslocamento frontal e força } \\
\text { de arrancamento. }\end{array}$ \\
\hline $\begin{array}{c}\text { Bakeer et al., } \\
\text { (1998) }\end{array}$ & 152 & 610 & 610 & $\begin{array}{c}\text { Pistão } \\
\text { pneumático }\end{array}$ & $\begin{array}{c}\text { Deslocamento frontal e força } \\
\text { de arrancamento }\end{array}$ \\
\hline $\begin{array}{l}\text { Teixeira \&Bueno } \\
\text { (1999) }\end{array}$ & 500 & 700 & 1500 & Bolsa de ar & $\begin{array}{l}\text { Força de arrancamento, } \\
\text { tensões no solo e } \\
\text { deslocamentos. }\end{array}$ \\
\hline $\begin{array}{l}\text { Sugimoto et al., } \\
\qquad(2001)\end{array}$ & 625 & 300 & 680 & Bolsa de ar & $\begin{array}{l}\text { Deslocamentos, força de } \\
\text { arrancamento, força na face } \\
\text { frontal, movimento do solo. }\end{array}$ \\
\hline $\begin{array}{l}\text { Teixeira \& Bueno } \\
\qquad(2003)\end{array}$ & 150 & 300 & 250 & Bolsa de ar & $\begin{array}{c}\text { Força de arrancamento, } \\
\text { tensões no solo e } \\
\text { deslocamentos. }\end{array}$ \\
\hline $\begin{array}{l}\text { Nakamura et al., } \\
\qquad(2003)\end{array}$ & 200 & 220 & 500 & Bolsa de ar & $\begin{array}{c}\text { Deslocamento nos nós, força } \\
\text { de arrancamento. }\end{array}$ \\
\hline
\end{tabular}


Os dados, apresentados no Quadro 1, mostram que os equipamentos desenvolvidos apresentam diferentes configurações de dimensão, sendo que o volume médio da caixa de ensaio considerados de grandes dimensões é próximo a $0.5 \mathrm{~m}^{3}$. Notase também, que em função da necessidade de execução do ensaio com menores custos e tempo, alguns autores buscaram desenvolver equipamentos em pequenas dimensões. Quanto à forma de aplicação da tensão confinante, a utilização de bolsa de ar é a mais utilizada nas pesquisas, pois, resultam em distribuições de tensões mais uniformes sobre a camada de solo compactado.

Em função das dimensões internas da caixa de arrancamento, os ensaios realizados em laboratórios podem ser classificados como de grande porte e de pequeno porte.

\subsubsection{Ensaio de grande porte}

Os ensaios de grande porte são ensaios com maior confiabilidade, pois apresentam melhores resultados quanto a fidedignidade, reprodução da estrutura física do maciço reforçado, distribuição das tensões na superfície do reforço e deformações da geogrelha, porém os resultados obtidos acarretam elevado custo e um significativo tempo de execução.

Os equipamentos de grande porte são utilizados na maioria dos ensaios de arrancamento em laboratórios, cujas dimensões de comprimento são superiores a 1,0m e largura de pelo menos 0,5m (RAJU et al., 1998), como verificado no quadro 1. Quanto à altura da caixa de arrancamento, Farrag et al. (1993), através de resultados de ensaios usando diferentes espessuras de solo acima e abaixo da inclusão, sugere que utilize pelo menos $30 \mathrm{~cm}$ de espessura de solo em ambas as posições, porém não deixa claro se mudando as dimensões do equipamento e a granulometria da solo, será mantida a mesma espessura de solo.

Johnston (1985) apud Teixeira (2003) recomenda que a amostra de reforço ensaiada mantenha uma certa distância dos contornos superiores e inferiores para minimizar o efeito de borda.

Teixeira (2003) mencionou que os estudos realizados até o presente momento, não esclareceram a altura mínima da caixa para que não ocorra interferência das condições de contorno. Entretanto, uma espessura mínima que apresenta bons resultados 
em relação às condições de contorno, é obtida adotando a espessura de solo acima e abaixo da inclusão, de pelo menos 50 vezes o $\left(D_{50}\right)$ diâmetro médio das partículas de solo.

O equipamento proposto pela ASTM D6706-01 para realização do ensaio de arrancamento apresenta as dimensões, comprimento mínimo de $610 \mathrm{~mm}$, largura mínima de $460 \mathrm{~mm}$ e profundidade de $305 \mathrm{~mm}$. As dimensões devem ser aumentadas se necessário tal que, a largura mínima seja vinte vezes maior que $D_{85}$ do solo ou seis vezes o tamanho da maior partícula de solo. O comprimento mínimo deve ser maior que cinco vezes a abertura da grelha. A caixa deve ter no mínimo quinze centímetros acima e abaixo da inclusão. A espessura do solo deve ser pelo menos seis vezes maior que $D_{85}$. A aplicação da tensão confinante deve ser feita preferencialmente por bolsa de ar comprimido e na abertura da face frontal deve conter uma luva de transição.

\subsubsection{Ensaio de pequeno porte}

Nos ensaios de arrancamento de pequeno porte tanto o custo quanto o tempo de execução são muito menor, além disso, facilita-se à execução do ensaio, obtendo um melhor controle do teor de umidade e da compactação do solo. Buscando tais vantagens, Teixeira \& Bueno, (1999) e Nakamura et al. (2003) desenvolveram equipamentos em dimensões reduzidas.

Nakamura et al. (2003) utilizaram uma caixa para ensaio de arrancamento com as dimensões de $500 \mathrm{~mm}$ de comprimento, $220 \mathrm{~mm}$ de largura e $200 \mathrm{~mm}$ de profundidade. As paredes internas da caixa foram lubrificadas com graxa e revestidas com membranas de borracha, assim minimizando o efeito de atrito entre o solo e as paredes internas do equipamento. A abertura para aplicação da força de arrancamento foi disposta a meia profundidade e para possibilitar uma mudança da abertura $(t)$, foi acoplado um dispositivo removível conforme apresentado na Figura 13. 


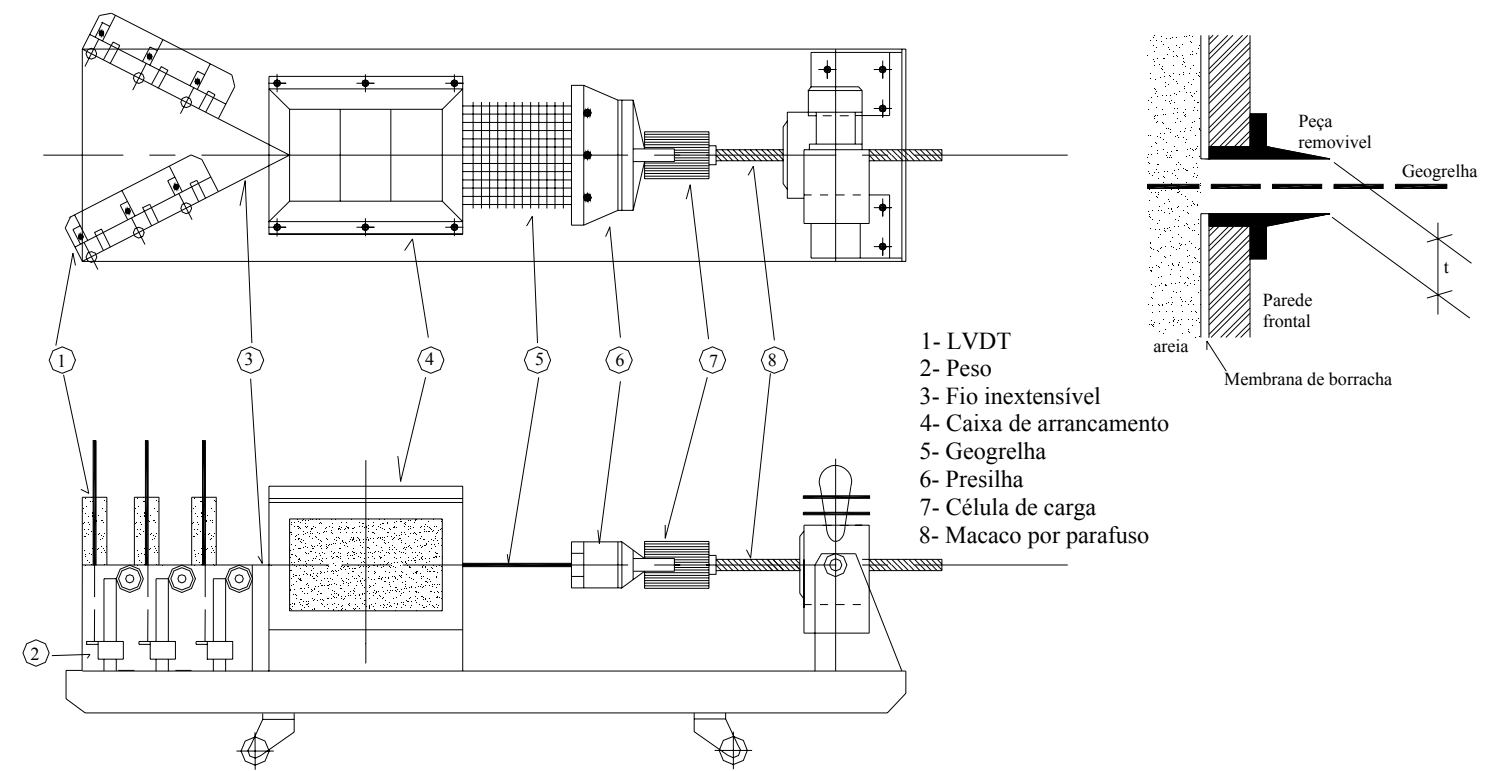

Figura 13 - Esquematização do equipamento de pequenas dimensões (NAKAMURA et al. 2003).

A tensão normal é aplicada no topo da caixa de arrancamento utilizando uma bolsa de borracha com pressão de ar. A velocidade de ensaio utilizada foi de $1 \mathrm{~mm} / \mathrm{min}$, aplicada através de um macaco acionado por parafuso. Para a instrumentação foram utilizadas células de carga e LVDTs, obtendo-se a força de arrancamento e os deslocamentos relativos de pontos da superfície da geogrelha, respectivamente.

Os autores realizaram, nos testes, diferentes configurações de abertura (4, 6 e $8 \mathrm{~mm}$ ), tensões confinantes (de 25, 49 e $74 \mathrm{kPa}$ ), e comprimento da geogrelha. Com base nos resultados dos ensaios puderam concluir que para maiores aberturas $(t)$ da caixa, a força de arrancamento foi menor, sendo adotados para os demais ensaios a abertura de $4 \mathrm{~mm}$ que equivale a duas vezes a espessura da geogrelha.

Teixeira \& Bueno (1999) projetaram um equipamento de pequeno porte, cujas dimensões da caixa de ensaio são de $250 \mathrm{~mm}$ de comprimento por $300 \mathrm{~mm}$ de largura e 150mm de altura, como pode ser observado na Figura 14. 


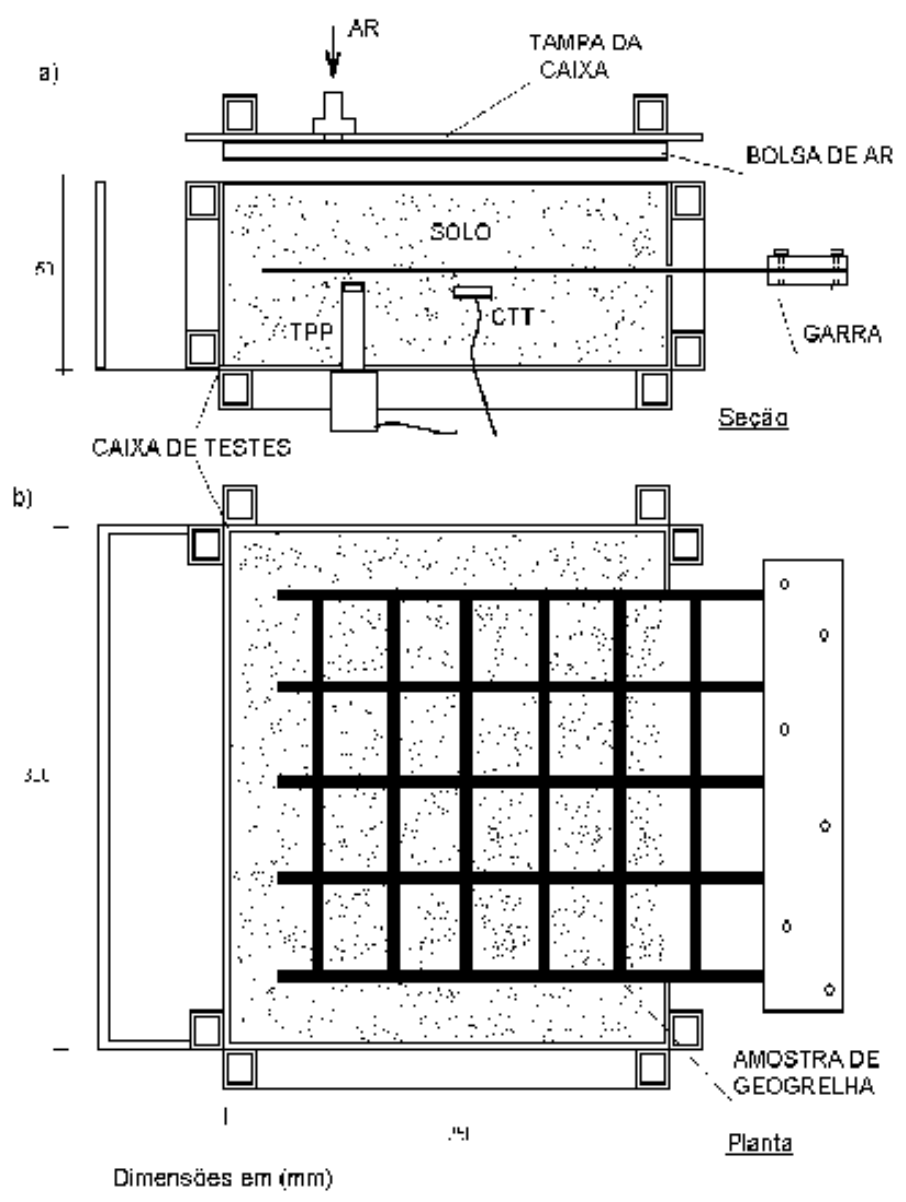

Figura 14 - Caixa de testes de pequeno porte (TEIXEIRA, 2003).

A aplicação da força de arrancamento é feita por uma máquina universal de ensaios. A resistência ao arrancamento e os deslocamentos de pontos da superfície da geogrelha são obtidos através de aquisição automática de dados. Para a aplicação de sobrecarga utilizou-se uma bolsa inflável acoplada à tampa da caixa, sendo que a pressão de confinamento provém do ar comprimido injetado no interior da bolsa. Há ainda células de tensão total e transdutor de poro-pressão instalados próximos da inclusão.

Teixeira (2003) apresentou um modelo numérico que permite utilizar os resultados obtidos no ensaio de pequeno porte para efetuar o estudo do comportamento de inclusões extensíveis de um comprimento qualquer. Comparando este modelo com resultados obtidos em ensaios de grande porte, pode o autor concluir que apesar do ensaio de grande porte apresentar resultados mais precisos, os ensaios de pequeno porte quando utilizados em solos finos apresentaram bons resultados e ainda com a vantagem de serem mais práticos em sua execução. 
Sugimoto et al. (2001) realizaram ensaios de arrancamento com equipamento de dimensão reduzidas com face frontal flexível, para analisar a influencia da rigidez da face no resultado de teste de arrancamento. Algiyawanna, et al. (2001) utilizaram o mesmo equipamento para analisar a influencia dos elementos transversais e longitudinais no comportamento do arrancamento de geogrelha durante a execução do ensaio. $\mathrm{O}$ equipamento apresenta as seguintes dimensões, $0,68 \mathrm{~m}$ de comprimento, $0,3 \mathrm{~m}$ de largura e $0,625 \mathrm{~m}$ de profundidade.

\subsection{Mecanismo de interação solo-inclusão no ensaio de arrancamento}

A resistência ao arrancamento das geogrelhas consiste em duas partes: a primeira é devida à resistência de interface entre a área exposta de membros longitudinais e transversais e o solo, $P_{f}$, e a segunda deve-se à resistência passiva gerada pelos elementos transversais quando são solicitados contra o solo na frente de avanço da geogrelha, $P_{b}$. A resistência ao cisalhamento de interface, por sua vez, pode ser constituída, dependendo do tipo de solo e das condições de drenagem, por uma parcela atritiva e outra adesiva. A Figura 15 ilustra o mecanismo de interação solo - geogrelha, de forma simplificada.
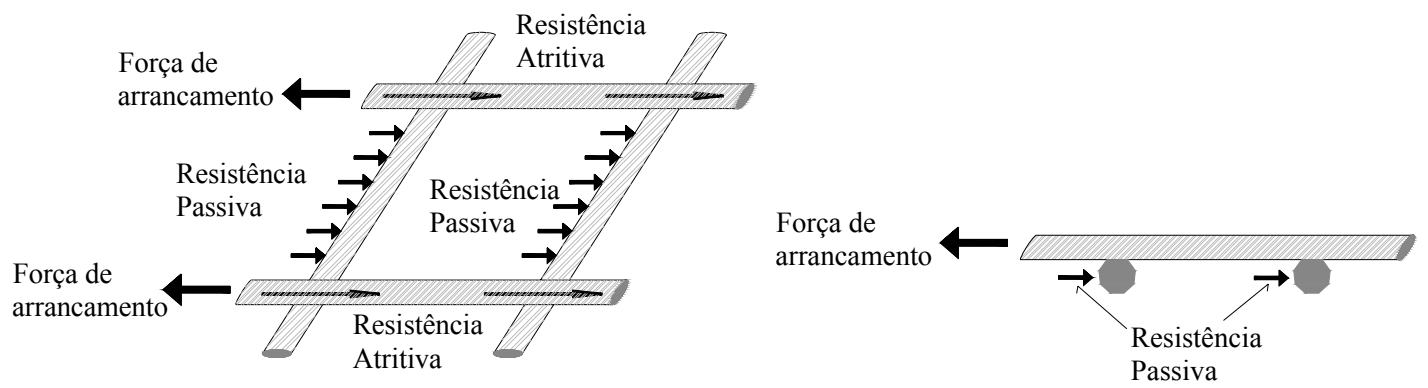

Figura 15 - Resistências passiva e atritiva na interface solo-grelha (VOOTTIPRUEX et al., 2000)

Portanto, a resistência total ao arrancamento, $P_{t}$, é dada pela expressão (6).

$$
P_{t}=P_{f}+P_{b}
$$

Dois coeficientes podem ser definidos para representar isoladamente os efeitos de deslizamento e de aderência entre solo e geossintético (JEWELL, 1996). O coeficiente de deslizamento $\alpha_{d s}$ pode ser obtido da expressão (7). 


$$
\alpha_{d s} \operatorname{tg} \phi^{\prime}=a_{s}\left(c_{\alpha}+\operatorname{tg} \delta\right)+\left(1-a_{s}\right) \operatorname{tg} \phi^{\prime}
$$

Nesta expressão $a_{s}$ representa a fração unitária de área cheia do geossintético, $c_{\alpha}$ a adesão de interface e $\phi$ e $\delta$ são o ângulo de atrito interno do solo e o ângulo de atrito de interface solo-geossintético, respectivamente. No caso de mantas $a_{s}=1 \mathrm{e}$, portanto, em solos granulares:

$$
\alpha_{d s}=\frac{\operatorname{tg} \delta}{\operatorname{tg} \phi^{\prime}}
$$

O coeficiente de aderência, $a_{a d}$, por sua vez, leva em conta não apenas a resistência de interface como também a resistência passiva. Este coeficiente é expresso como:

$$
\alpha_{a d} \operatorname{tg} \phi^{\prime}=a_{s}\left(c_{\alpha}+\operatorname{tg} \delta\right)+\left(\frac{\sigma_{b}^{\prime}}{\sigma_{v}^{\prime}}\right) \frac{a_{b} B}{2 S}
$$

Nesta expressão, $a_{b}$ representa a fração unitária do elemento transversal da geogrelha onde é possível desenvolver a resistência passiva. Os demais termos estão explicitados na Figura 16. 

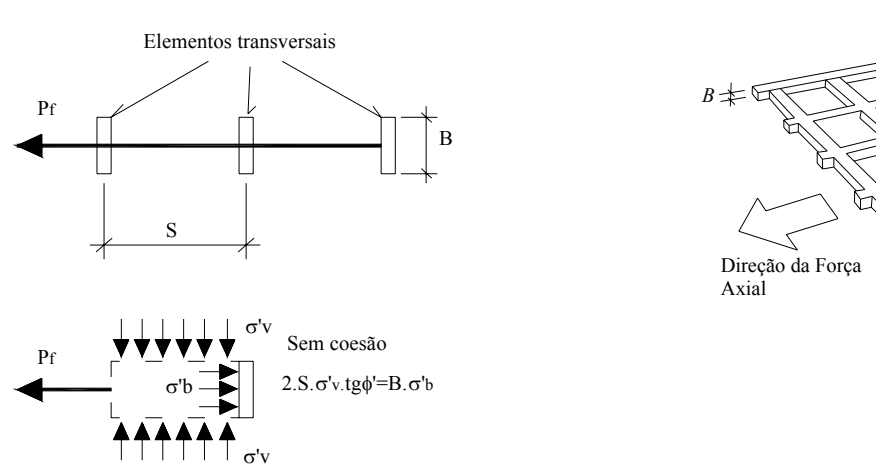

(a)

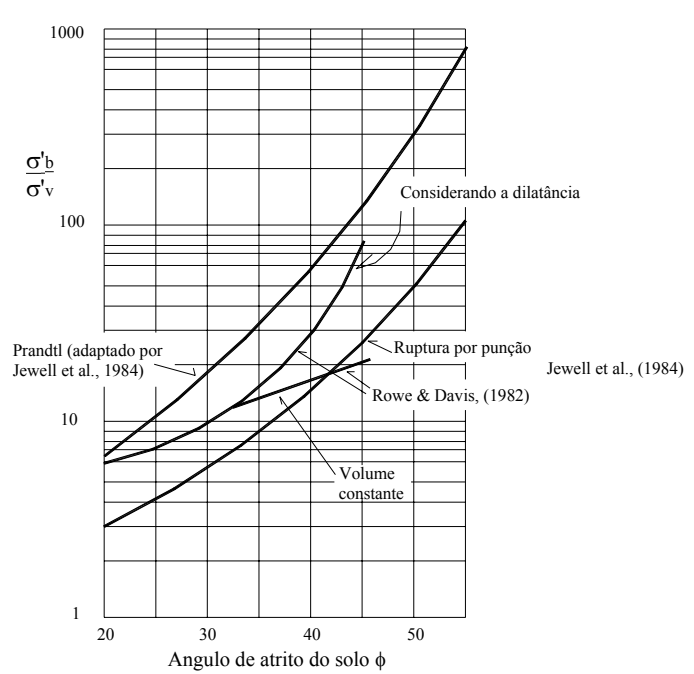

(b)

(c)

Figura 16- (a) representação esquemática do desenvolvimento da resistência passiva (JEWELL, 1996); (b) dimensão geométrica da grelha; (c) Correlação teórica entre angulo de atrito e capacidade de carga (JEWELL et al., 1984).

Devido ao grande número de parâmetros que interferem na capacidade da geogrelha em resistir aos esforços de arrancamento, como se pode depreender das expressões (7) e (9), a expressão (10), utilizada com certa freqüência na prática de projetos de engenharia, não discrimina as parcelas resistência de interface e passiva, mas considera que a resistência ao arrancamento, T, seja apenas função da área, de um coeficiente de interação, $f$, entre o solo e a geogrelha e dos parâmetros de resistência do solo (TEIXEIRA, 2003).

$$
T=2 \cdot A \cdot f \cdot \sigma_{v}^{\prime} \cdot \operatorname{tg} \phi
$$

Nesta expressão, $A$ é a área plana de geogrelha em contato com o solo; $f$ é o coeficiente de interação entre solo e geogrelha, que contempla as ações de resistências 
de interface e passiva; $\sigma_{v}$ ' é a tensão normal efetiva atuante no nível da geogrelha e $\phi$ é o ângulo de atrito efetivo do solo.

O coeficiente de interação $(f)$ pode ser calculado através de resultados de ensaios de arrancamento utilizando-se da expressão (11).

$$
f=\frac{T_{a}}{2 \cdot L \cdot \sigma \cdot \operatorname{tg} \phi}
$$

Nesta expressão, $T a$ é a força de arrancamento obtido do ensaio; $L$ é o comprimento de ancoragem; $\sigma$ é a tensão normal no plano do reforço e $\phi$ é o ângulo de atrito do solo.

As parcelas de resistência por atrito e adesão apresentadas nas equações a seguir foram desenvolvidas para inclusões inextensíveis, como se eles atuassem independentemente. No caso de inclusões extensíveis, exemplo da geogrelha, a determinação destas parcelas separadamente é de difícil obtenção, uma vez que a distribuição da força passiva ao longo dos elementos transversais da geogrelha é não linear e dependem da combinação de outros fatores com a geometria da grelha, a rigidez a tração, o nível de tensão e outros (PALMEIRA, 2004).

\subsection{Resistência por atrito e adesão, na área de contato solo-inclusão $\left(P_{f}\right)$}

A parcela de resistência ao arrancamento de interface que se desenvolve entre a área exposta dos membros longitudinais e transversais e o solo $\left(P_{f}\right)$ dependem das parcelas de atrito e de adesão. A parcela atritiva depende do ângulo de atrito de interface solo-inclusão, da área de atrito e da tensão normal efetiva entre o solo e o reforço. Já a parcela adesiva depende da área de contato entre solo-geogrelha, do fator de adesão superficial e da coesão não drenada do solo, conforme a expressão (12).

$$
P_{f}=2 \cdot L_{r} \cdot W_{r} \cdot \sigma \cdot \alpha_{s} \cdot \operatorname{tg} \delta+\alpha \cdot C_{u} \cdot A_{s}
$$

Nesta expressão, $L_{r}$ é o comprimento do reforço; $W_{r}$ é a largura do reforço; $\sigma$ é a tensão normal ao nível do reforço; $\alpha_{s}$ é a relação entre área cheia e a área total do reforço; $\delta$ é o ângulo de atrito de interface solo-reforço. 
O valor do fator de adesão $(\alpha)$, foi estimado por Tomlinson (1994) através da resistência não drenada do solo $(\mathrm{Cu})$ para diferentes tipos de estacas em solos coesivos, conforme Figura 17.

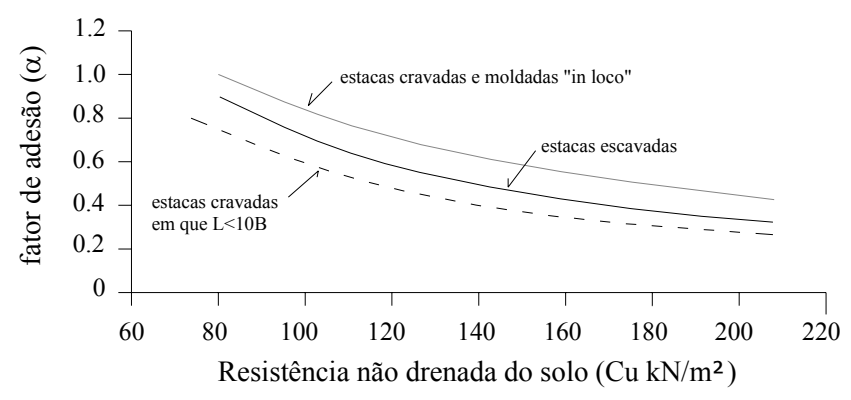

Figura 17 - Fator de adesão em solos coesivos (TOMLINSON, 1994).

\subsection{Resistência passiva dos elementos transversais.}

Para o entendimento do mecanismo de resistência passiva dos elementos transversais das grelhas, Jewell et al. (1984) e Jewell (1990) consideraram existir uma analogia dos comportamentos nos processo de mobilização de capacidade resistente nas barras transversais das grelhas e nas ancoragens de placas profundas em solos granulares. Deste modo, propõem que a aferição dos valores calculados da resistência passiva mobilizada nas barras transversais das grelhas seja feita a partir de resultados experimentais e numéricos publicados. Os mesmos referem se ainda que a resistência passiva mobilizada nas barras transversais das grelhas deve estar compreendida entre os dois valores teóricos indicados na Figura 18.

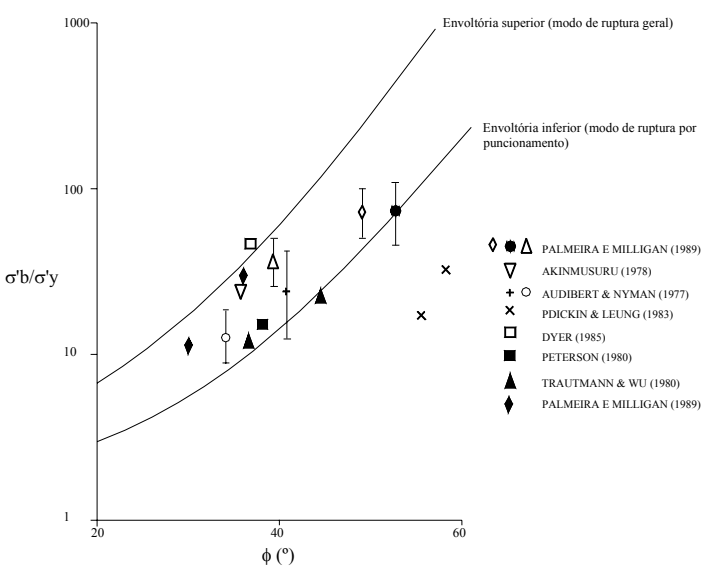

Figura 18 - Comparação entre os valores teóricos e experimentais da resistência passiva mobilizada nas barras transversais das grelhas (adaptado de PALMEIRA \& MILLIGAN, 1989). 
Os valores teóricos de resistências passiva nos elementos transversais da grelha são definidos recorrendo se à teoria geral da capacidade de carga. Então, considera se que as barras transversais das grelhas funcionem, análogas fisicamente, a um conjunto de sucessivas sapatas alongadas, formando um ângulo de $90^{\circ}$ com a direção da aplicação da força de arrancamento (BERGADO et al., 1994). A resistência passiva mobilizada nos elementos transversais da grelha pode ser calculada pela expressão (13).

$$
\sigma_{p}^{\prime}=c^{\prime} \cdot N_{c}+\sigma_{n}^{\prime} \cdot N_{q}
$$

Nesta expressão, $\sigma_{p}^{\prime}$ é a resistência passiva; $\sigma_{n}^{\prime}$ é a tensão normal atuante na interface solo-grelha; c' é a coesão do solo e $N_{q}$ e $N_{c}$ são fatores de capacidade de resistência passiva (idênticos aos fatores de capacidade de carga).

Feita essa analogia, se estabelece dois modos de ruptura associados ao mecanismo de resistência passiva, quais sejam a ruptura geral e por puncionamento, que fornecem, respectivamente, de acordo com Jewell (1984), os limites superior e inferior, para a força de arrancamento (Figura 18).

\subsubsection{Modo de ruptura geral}

O mecanismo de ruptura em frente das barras transversais das grelhas é semelhante, de acordo com Peterson e Anderson (1980), ao mecanismo de ruptura por falta de capacidade de carga em sapatas. A Figura 19 apresenta o mecanismo considerado para ruptura geral e os fatores de capacidade de carga são dados pelas expressões (14) e (15).

$$
\begin{gathered}
N_{q}=e^{\pi \cdot \operatorname{tg} \phi} \cdot \operatorname{tg}^{2}\left(45^{\circ}+\phi / 2\right) \\
N_{c}=\left(N_{q}-1\right) \cdot \cot g \phi
\end{gathered}
$$

No caso de solos arenosos a resistência passiva nas barras transversais das grelhas é dada pela expressão (16). 


$$
\frac{\sigma_{p}^{\prime}}{\sigma_{n}^{\prime}}=e^{\pi t g \phi} \cdot \operatorname{tg}^{2}\left(\frac{\pi}{4}+\frac{\phi^{\prime}}{2}\right)
$$

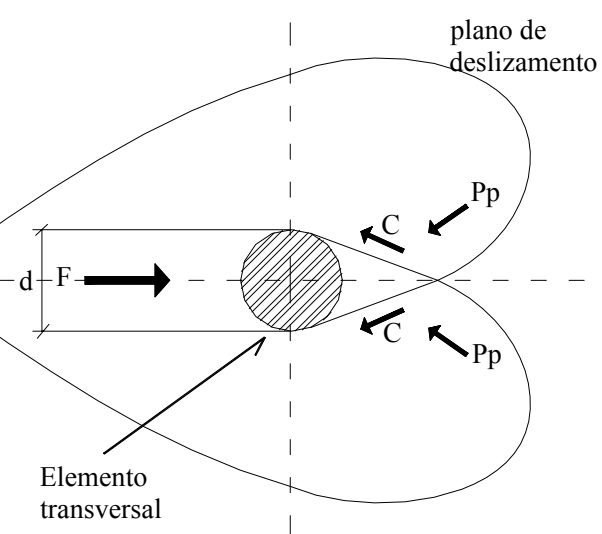

Figura 19 - Mecanismo de modo de ruptura geral (PETERSON e ANDERSON, 1980).

\subsubsection{Modo de ruptura por puncionamento.}

Para o cálculo da resistência passiva, segundo este modo, Jewell et al. (1984) propõem um mecanismo de ruptura em torno das barras transversais das grelhas baseado no mecanismo de ruptura por puncionamento de fundações profundas. Nesse segundo modo de ruptura os fatores de capacidade da carga modificam-se para expressar o efeito de um mecanismo de ruptura mais localizado. Na Figura 20, representa o mecanismo considerado para o modo de ruptura por puncionamento e os fatores $N_{q 1}$ e $N_{c l}$ são expressos pelas expressões (17) e (18), sendo que a única diferença é que no lugar de $\pi$ da expressão (14) é usado $\pi / 2+\phi$, resultando na expressão (17).

$$
\begin{gathered}
N_{q 1}=e^{(\pi / 2+\phi) \cdot \operatorname{tg} \phi} \cdot \operatorname{tg} \cdot\left(45^{\circ}+\phi / 2\right) \\
N_{c 1}=\left(N_{q 1}-1\right) \cdot \cot g \phi
\end{gathered}
$$

De forma análoga ao modo de ruptura geral, se o solo não possuir coesão à resistência passiva nas barras transversais das grelhas é dada pela expressão (19).

$$
\frac{\sigma_{p}^{\prime}}{\sigma_{n}^{\prime}}=e^{(\pi / 2) \operatorname{tg} \phi} \cdot \operatorname{tg}^{2}\left(\frac{\pi}{4}+\frac{\phi^{\prime}}{2}\right)
$$




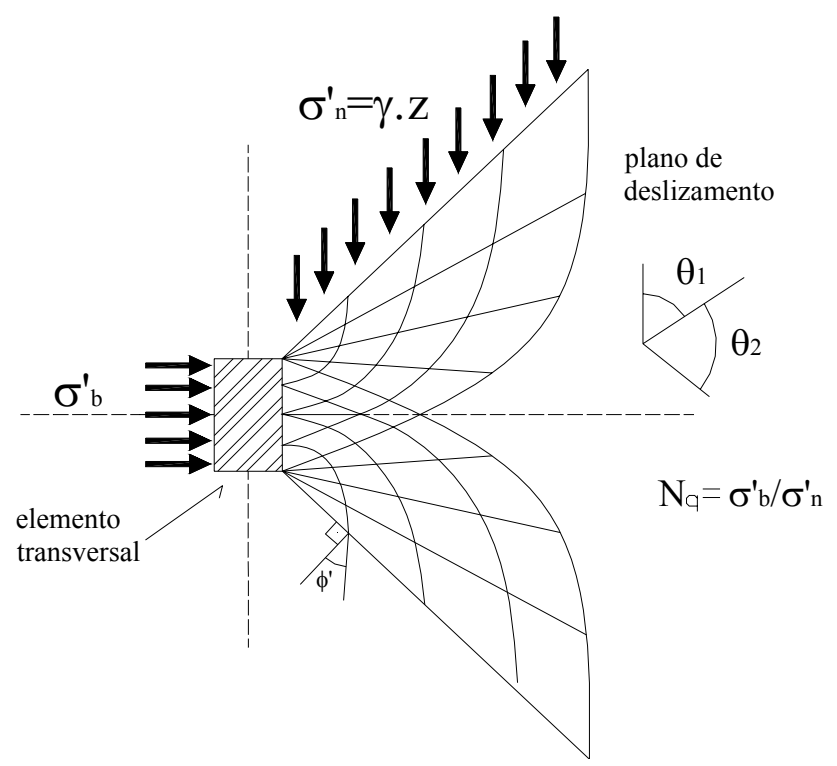

Figura 20 - Mecanismo de ruptura por puncionamento (JEWELL et al., 1984)

Os resultados obtidos através das expressões (16) e (19) estabelecem as envoltórias, superior e inferior para a resistência passiva mobilizada nos elementos transversais das grelhas (PALMEIRA \& MILLIGAN, 1989), apresentado na Figura 18.

\subsection{Mecanismo de transferência de carga solo-geogrelha}

Os primeiros estudos elaborados para o entendimento do mecanismo de transferência de carga solo-reforço foram realizados com a utilização de inclusões inextensíveis (aço).

Durante a execução do ensaio de arrancamento com grelhas de aço, as cargas impostas ao reforço são, primeiramente, transferidas aos elementos longitudinais, que podem ser mobilizados com pequenos deslocamentos (cerca de 2mm). Após a mobilização da parcela atritiva (desenvolvida nos elementos longitudinais), os membros transversais passam a ser solicitados. Ensaios realizados mostraram que cerca de 10\% da resistência total ao arrancamento é provida da parcela atritiva e o restante é resistido pela parcela passiva (JEWELL et al., 1985; BERGADO et al., 1996).

Bergado et al. (1996) realizaram ensaios de arrancamento utilizando grelhas de aço de 6,1 $\mathrm{mm}$ de diâmetro em um solo argiloso (com 82,9\% de finos), sendo utilizados apenas os membros longitudinais com variação da tensão confinante. A Figura 21 
ilustra os resultados obtidos pelos autores, em que se observa picos de resistência ao arrancamento com deslocamentos entre 2 e $3 \mathrm{~mm}$.

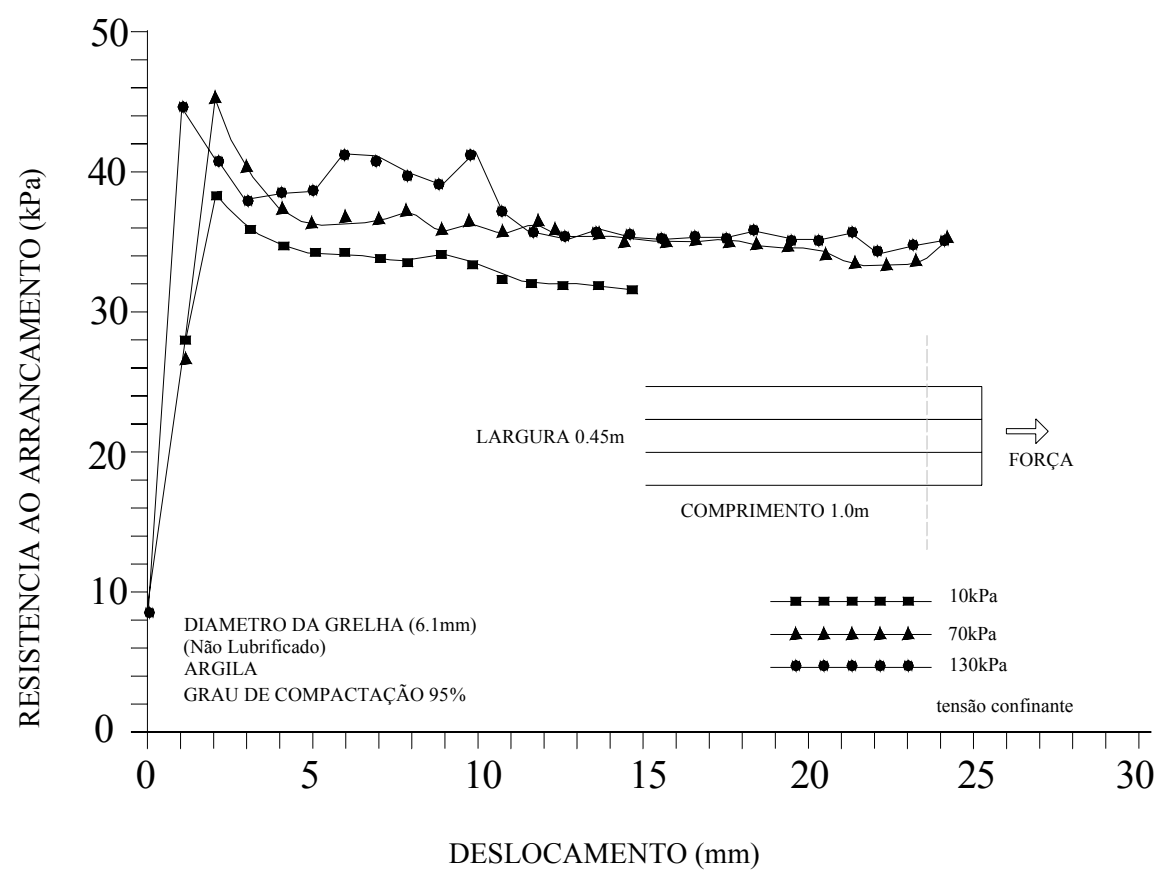

Figura 21 - Curva resistência atritiva vs. deslocamento no ensaio de arrancamento (BERGADO et al., 1996)

$\mathrm{O}$ espaçamento entre os membros transversais condiciona diferentes distribuições de esforços entre os elementos. Quando os elementos estão afastados entre si, o esforço de arrancamento fica distribuído igualmente entre eles. Por outro lado, quando os elementos transversais estão a pequenas distâncias, os elementos mais próximos do ponto de aplicação da força de arrancamento serão os mais solicitados.

No caso da utilização de geogrelha como elemento de reforço, observa-se que, por se tratar de um material polimérico, a sua deformação é maior que a do aço. A estimativa da resistência ao arrancamento torna-se pouco precisa, já que a deformação ao longo do comprimento varia significativamente ao final do carregamento.

Os elementos transversais das geogrelhas apresentam uma baixa rigidez à flexão e os deslocamentos relativos entre sucessivos elementos decrescem à medida que se distanciam do ponto de aplicação da força (OCHAI et al., 1996; SUGIMOTO et al., 2001).

Comparando inclusões inextensíveis com extensíveis, algumas diferenças no comportamento durante o arrancamento podem ser observadas: 
- Inclusões inextensíveis deslocam-se como corpo rígido, em relação ao solo envolvente durante o arrancamento, mobilizando a resistência ao longo do reforço simultaneamente em todas as suas barras transversais;

- Inclusões extensíveis devido à deformabilidade de seus elementos, durante a aplicação da força de arrancamento ficam sujeitas a deslocamentos decrescentes ao longo do comprimento. Com deformações variáveis, tem-se uma mobilização desigual das tensões tangenciais na interface e, portanto, mobilização desigual da resistência ao arrancamento ao longo da geogrelha.

Autores como Ochiai et al. (1996); Lopez e Ladeira (1996 e 1999); Alfaro et al. (1995) e Teixeira (2003) descrevem o mecanismo de interação solo-reforço por meio do coeficiente de interação e de aderência. Todavia, como a força resistente ao arrancamento de geogrelha é um resultado dos efeitos da resistência passiva e atritiva e dependem de fatores como o tipo de solo, a densidade, a geometria e as propriedades mecânicas da grelha, rugosidade da superfície, nível de tensão, velocidade de carregamento e outros. Em especial, quando se utiliza uma geogrelha extensível como elemento de reforço, essas equações anteriormente citadas, devem ser utilizadas, mas com certa precaução.

Na Figura 22 apresenta-se um gráfico de força de arrancamento em função dos deslocamentos referentes a cada junção de uma geogrelha. Observa-se que quando ocorreu a força máxima de arrancamento, as junções mais próximas do ponto de aplicação da força, sofreram maiores deslocamentos.

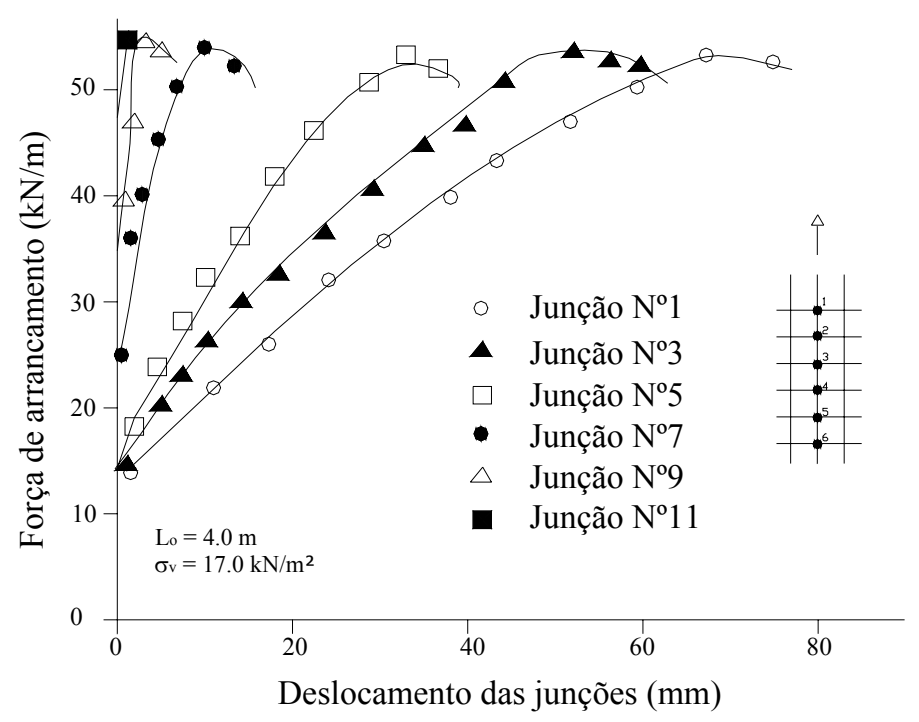

Figura 22 - Relação entre a força de arrancamento e o deslocamento de várias junções entre elementos transversais e longitudinais ( OCHIAI et al., 1996). 
O mecanismo de mobilização dos membros longitudinais e transversais, durante a realização de ensaios, segue uma seqüência, em que, primeiramente, a resistência ao arrancamento é mobilizada pelo atrito e adesão superficial, necessitando de pequenos deslocamentos relativos para serem totalmente mobilizados. Posteriormente, é mobilizada a resistência passiva, necessitando estes de maiores deslocamentos (FARRAG et al., 1993).

Alguns ensaios de arrancamento executados por Alagiyawanna et al. (2001) e Teixeira (2003), com geogrelhas extensivas, foram elaborados com diferentes configurações, variando-se o número de membros longitudinais e transversais para análise das contribuições de ambos os membros na resistência ao arrancamento durante o processo de deformação. Os resultados dos ensaios mostraram que a resistência ao arrancamento obtida quando se ensaia uma geogrelha, variando a porcentagem de elementos transversais, não é tão discrepante quando comparada com ensaios em que se variou a porcentagem de elementos longitudinais.

Nas Figuras 23 e 24 são mostrados resultados de ensaios de arrancamento com variação das porcentagens de membros longitudinais e de membros transversais, respectivamente (ALAGIYAWANNA et al., 2001). O solo estudado foi uma areia com $D_{50}=0,35 \mathrm{~mm}, \phi$ de $29,9^{\circ}$ e $\mathrm{Dr}=70 \%$ e a face frontal do equipamento de arrancamento possuía duas configurações de rigidez: (1) RF - face rígida e (2) FF - face flexível, onde instalava-se bolsas inflável na face frontal de forma que permitisse deslocamentos frontais.

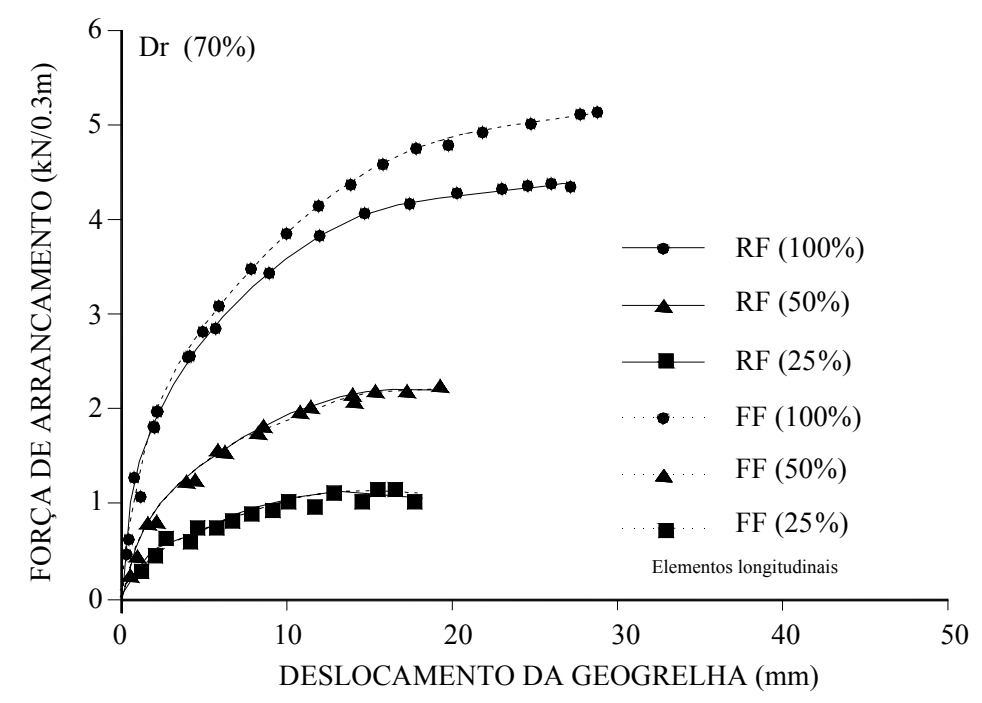

Figura 23 - Resultados de ensaio de arrancamento de geogrelha com diferentes configurações de elementos longitudinais (ALAGIYAWANNA et al., 2001) 


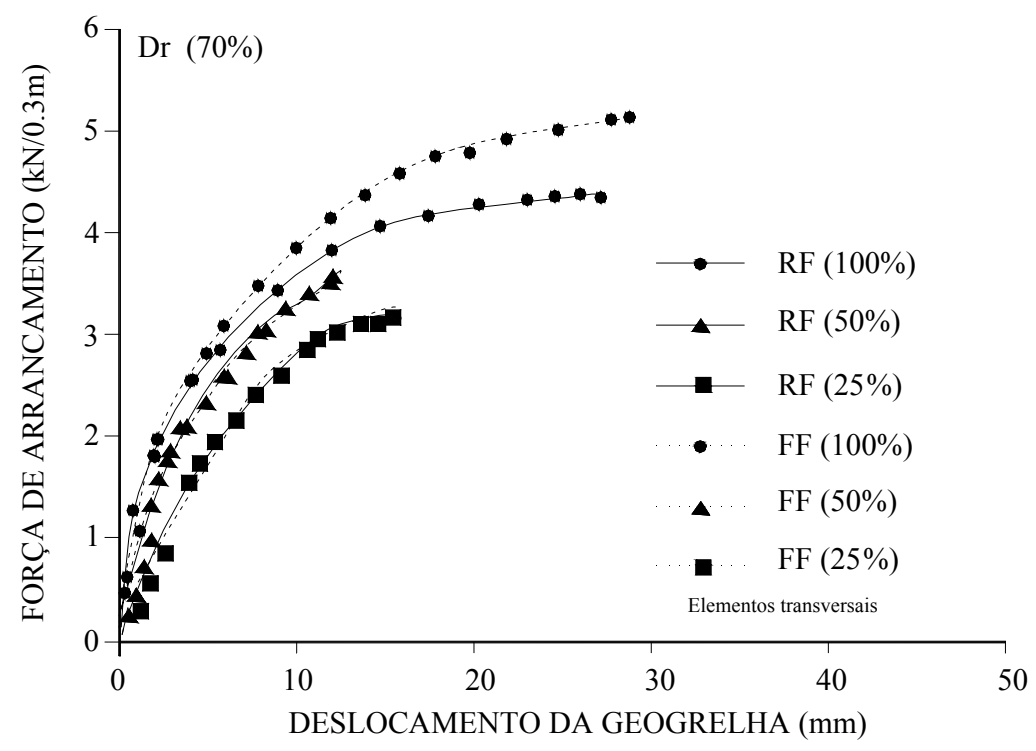

Figura 24 - Resultados de ensaio de arrancamento de geogrelha com diferentes configurações de elementos transversais (ALAGIYAWANNA et al., 2001).

Comparando-se as Figuras 23 e 24, constata-se que a diminuição do nível de resistência mobilizada, quando a porcentagem dos membros longitudinais passou de 100 para $25 \%$, foi maior que as observadas na Figura 24, com a redução da porcentagem de elementos transversais. O pico de resistência ao arrancamento com $100 \%$ dos elementos transversais ocorre em níveis de deslocamentos maiores do que para geogrelhas com menores porcentagens de elementos transversais.

Teixeira (1999) apresentou informações qualitativas e quantitativas sobre as duas principais parcelas de contribuição para a resistência ao arrancamento (resistências atritiva e passiva). No trabalho utilizou um equipamento de ensaio de arrancamento de grandes dimensões, e duas caixas para testes em elementos isolados de geogrelha. Os ensaios realizados em equipamento de grandes dimensões foram utilizados amostras com e sem seus elementos transversais. Os testes em elementos isolados consistiam na imposição de deslocamentos em amostras de elementos longitudinais e transversais de geogrelha e na medição de resistência ao arrancamento oferecida individualmente por eles.

O ensaio de arrancamento em elementos longitudinais foi executado em uma caixa de teste com dimensões internas de $140 \mathrm{~mm}$ de comprimento, $28 \mathrm{~mm}$ de largura e $60 \mathrm{~mm}$ de altura, usando uma amostra de elemento longitudinal de geogrelha com 100 mm de comprimento enterrado. 
No teste de arrancamento em elementos transversais usou-se de duas amostras destes elementos, possuindo as mesmas dimensões e espaçamento tais como aqueles existentes na geogrelha de onde foram extraídas. Neste teste, o deslocamento, é imposto na extremidade de ambas amostras, conforme mostrado na Figura 25. Entretanto, somente a força de arrancamento aplicada no elemento 2 é medida.

a)

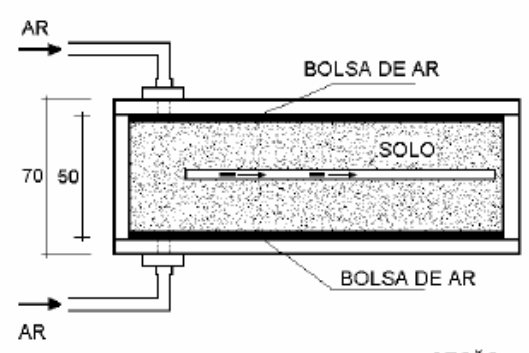

b)

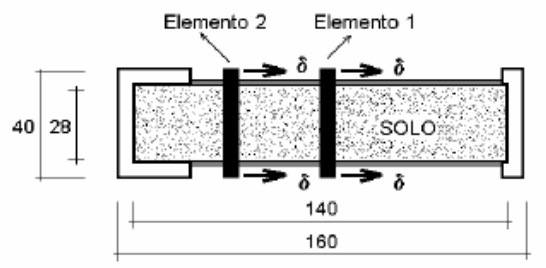

DIMENSŐES EM (mm)

PLANTA

Figura 25 - Caixa de ensaio de arrancamento em elementos transversais. a) seção longitudinal; b) corte em planta (TEIXEIRA, 2003).

Dos resultados de ensaios obtidos do estudo Teixeira (2003) obteve as seguintes conclusões:

- A resistência de interface é completamente mobilizada para pequenos valores de deslocamento, cerca de $3 \mathrm{~mm}$;

- Mecanismo de resistência passiva requer deslocamentos aproximadamente quatro vezes maiores do que os deslocamentos que mobilizam o atrito e a adesão de interface;

- A avaliação das resistências passivas e de interface não pode ser feita isoladamente, e o efeito do alívio de tensões que o mecanismo de resistência passiva exerce sobre o atrito ao longo dos elementos longitudinais deve ser considerado.

- Os mecanismos de resistência passiva do solo, considerando a ruptura geral e por puncionamento, fornecem limites superior e inferior, respectivamente, para a resistência ao arrancamento de elementos transversais de geogrelhas. 
- A resistência ao arrancamento apresentou uma perda quando as junções das geogrelhas não suportaram a carga absorvida pelos elementos transversais, isso se pode constatar nos ensaios com maiores tensões confinantes.

\subsection{Efeitos a serem considerados na execução do ensaio de arrancamento}

\subsubsection{Efeito da tensão confinante}

A tensão confinante pode afetar tanto a resistência ao arrancamento quanto os deslocamentos relativos entre nós sucessivos. Alfaro et al. (1995) ensaiaram geogrelhas Tensar SR80 inclusas num cascalho bem graduado $\left(D_{50}=4,74 \mathrm{~mm}\right)$, com variação da tensão de confinamento. Os resultados deste estudo estão apresentados nas Figuras 26 e 27. Verifica-se que um aumento da tensão confinante provoca um aumento do ponto de ruptura de arrancamento e diminui o deslocamento relativo entre os nós e a parede frontal.

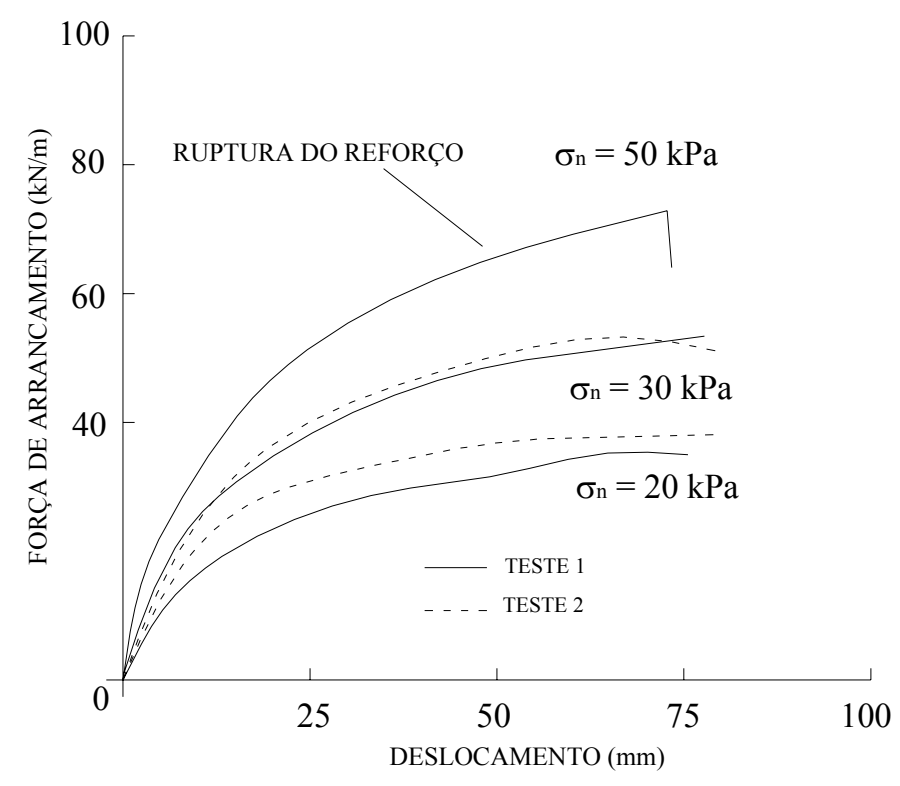

Figura 26 - Resultados de ensaios de arrancamento para diferentes tensões de confinamento (ALFARO \& BERGADO, 1995). 


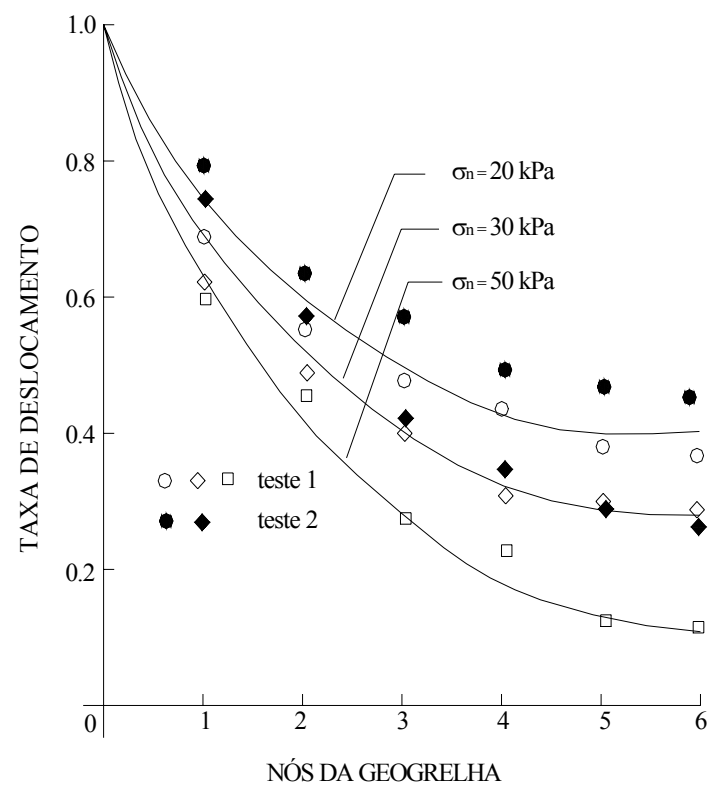

Figura 27 - Resultados de ensaios de arrancamento para diferentes tensões de confinamento, representado da relação entre taxa de deslocamento e posicionamento dos nós

(ALFARO \& BERGADO, 1995).

Resultados similares foram obtidos por Ochiai et al. (1996) que ensaiaram geogrelhas enterradas em areia $\left(\rho_{s}=2,64 \mathrm{~g} / \mathrm{cm}^{3} ; \mathrm{Dr}=80 \%\right)$. Os autores verificaram que o aumento da tensão confinante provoca um deslocamento para a esquerda da curva da força máxima de arrancamento vs. deslocamento, ou seja, o aumento da força de arrancamento deve-se ao aumento da rigidez do sistema, Figura 28. Quando a inclinação das curvas aumenta, o material de reforço sofre menores deslocamentos para atingir a resistência de pico ao arrancamento.

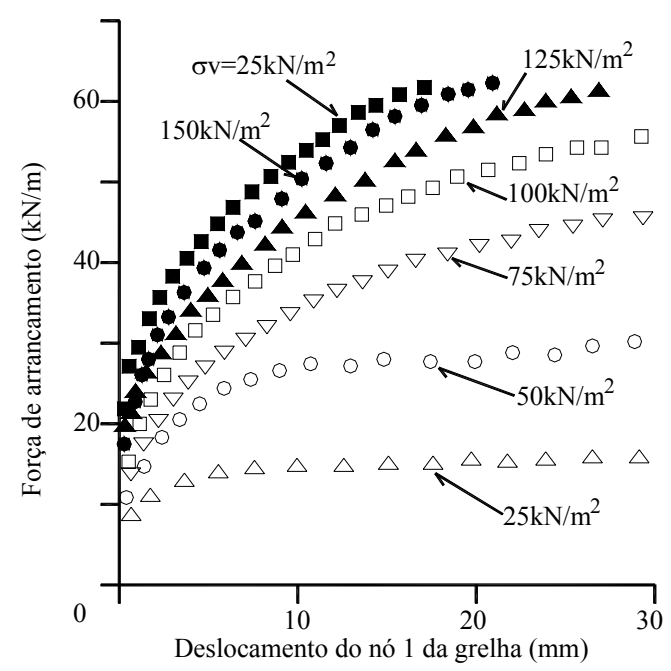

Figura 28 - Relação entre deslocamento e força de arrancamento para diferentes tensões confinantes Ochiai et al. (1996). 
E esse efeito, no comportamento de maciços reforçados com geogrelhas implica em deslocamentos diferenciais em cada nível de reforço, uma vez que as camadas superiores por estarem sob menores tensões confinantes, sofrerão maiores deformações que as inclusões em camadas mais profundas.

Teixeira, 2003 através de séries de ensaios de arrancamento de geogrelha com utilização de equipamento de grande porte constatou que existe uma relação aproximadamente linear entre o confinamento do solo e a resistência ao arrancamento, o que não ocorre, entretanto com o deslocamento frontal no instante próximo da ruptura. Nos ensaios realizados com equipamento de pequeno porte, esse efeito foi novamente constatado.

\subsubsection{Efeito da dilatância e da compacidade nas areias}

A resistência ao cisalhamento das areias deve-se a duas parcelas, a primeira é devida ao atrito propriamente dito, que por sua vez se compõe de duas parcelas: uma relativa ao deslizamento mineral-mineral e a outra, ao rolamento das partículas, umas sobre as outras. A segunda fonte de contribuição refere-se à parcela de resistência estrutural representada pelo trabalho de dilatância.

Uma das primeiras aproximações para explicar a relação entre ângulo de atrito interno do solo e ângulo de dilatação foi feita por Taylor (1948), que sugeriu uma “correção de energia" para considerar o efeito da dilatância. A quantificação do efeito da dilatância, segundo Taylor, pode ser obtida através do trabalho exercido pelas forças presente durante o cisalhamento do solo. A partir desse pressuposto, pode-se propor um equacionamento para avaliar o efeito da dilatância utilizando se de parâmetros obtidos de ensaio de cisalhamento direto. A esquematização do ensaio está apresentada na Figura 29. 

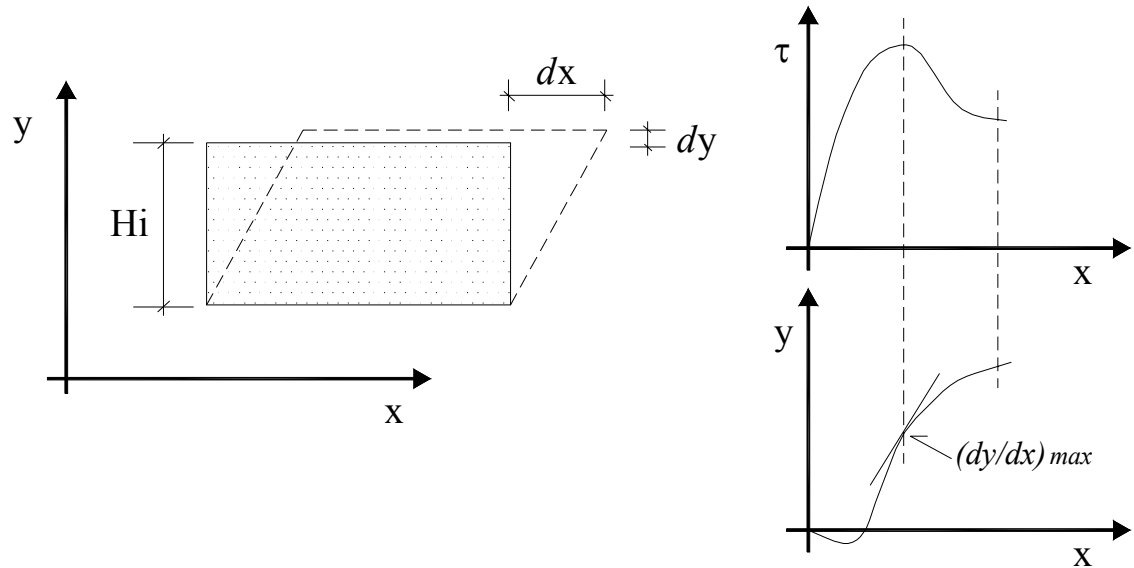

Figura 29 - Forças atuantes em um ensaio de cisalhamento direto (VILAR, s/d).

Igualando o trabalho fornecido à amostra ao trabalho interno por atrito obtém-se a expressão (20).

$$
\tau \cdot d x-\sigma_{n}^{\prime} \cdot d y=\mu \cdot \sigma_{n}^{\prime} \cdot d x
$$

Nesta expressão, $\mu$ é o coeficiente de atrito; $\tau$ e $\sigma_{n}^{\prime}$ são tensões cisalhante e confinante, respectivamente; $d x$ e $d y$ são medidas de deslocamento.

A expressão (20) pode ser apresenta por meio da expressão (21).

$$
\frac{\tau}{\sigma_{n}^{\prime}}=\mu+\frac{d x}{d y}
$$

Nesta expressão, $d x / d y$ representa o efeito da dilatância.

No caso de não ocorrer dilatância durante o ensaio $(d y=0)$, a expressão $(21)$ simplifica para $\tau / \sigma_{n}^{\prime}=\mu=\operatorname{tg} \phi^{\prime}{ }_{c v}$, em que, $\phi_{c v}{ }_{c v}$ é o ângulo de atrito obtido de ensaio de cisalhamento a volume constante (estado crítico das areis). Na Figura 30, observa-se que ocorrendo a dilatância do solo durante o ensaio de cisalhamento direto, $d x / d y=\operatorname{tg} \psi$, assim a expressão (22) pode ser apresentada em termos de ângulos de atrito e dilatância.

$$
\frac{\tau}{\sigma_{n}^{\prime}}=\operatorname{tg} \phi^{\prime}=\operatorname{tg}\left(\phi_{c \nu}^{\prime}+\psi\right) \Leftrightarrow \phi^{\prime}=\phi_{c \nu}^{\prime}+\psi
$$




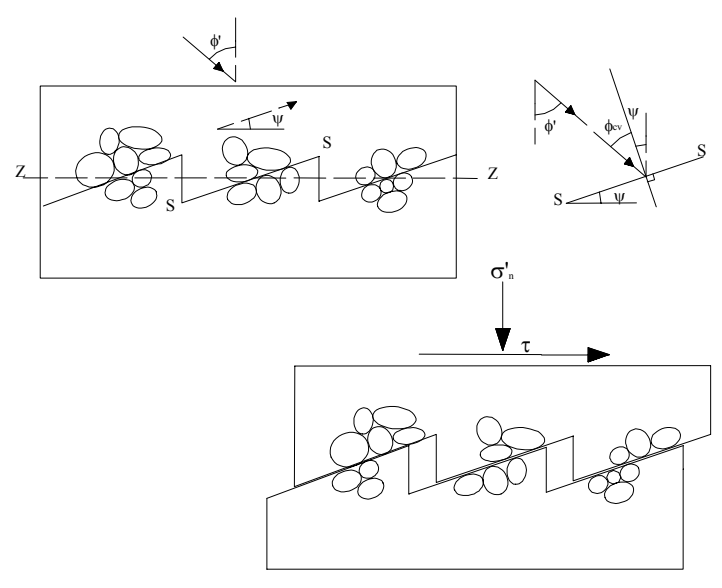

Figura 30 - Modelo de dente de serra (adaptado de BOLTON, 1986).

Um trabalho mais elaborado sobre o tema, utilizando o ensaio triaxial deve-se a Rowe (1962) que propôs uma formulação que incorporava a relação das tensões principais, arranjo das partículas e variações das deformações volumétricas $\left(\varepsilon_{v}\right)$ e da deformação principal maior $\left(\varepsilon_{l}\right)$. A relação entre tensões-dilatância para o plano de deformação é dada como:

$$
\frac{\sigma_{1}^{\prime}}{\sigma_{3}^{\prime}}=\left(\frac{\sigma_{1}^{\prime}}{\sigma_{3}^{\prime}}\right)_{c v}\left(1-\frac{d \varepsilon_{v}}{d \varepsilon_{1}}\right)
$$

Nesta expressão, $\left(\sigma^{\prime}{ }_{l} / \sigma^{\prime} 3\right)_{c v}$ é a razão entre as tensões principais na condição de estado crítico ou de cisalhamento a volume constante.

Bolton (1986) através de dados experimentais de ângulos de atrito e de dilatação obtidos da literatura, propôs um ajuste empírico para a expressão (22), pois observou que os valores de $\phi^{\prime}$ e $\phi_{c v}^{\prime}$ estavam superestimados, então:

$$
\phi^{\prime}=\phi_{c \nu}^{\prime}+0.8 \cdot \psi
$$

A compacidade relativa, a forma e rugosidade dos grãos e a distribuição granulométrica são características das areias que também interferem na resistência ao cisalhamento.

Solos arenosos podem sofrer variações de volume tanto de compressão como de dilatação dependendo da condição de compacidade relativa que se encontram. Nos casos de solos arenosos compactos, os grãos de solo encontram-se entrosados. Com o início das deformações cisalhantes os grãos deslizarão uns sobre os outros de forma a 
atingir uma condição de menor compacidade, ocorrendo um aumento de volume. Nos solos arenosos fofos, as tensões cisalhantes permitem maiores entrosamentos dos grãos, com conseqüente redução de volume.

Diferente do que ocorre nos ensaios de resistência ao cisalhamento, o fenômeno da dilatância é impedida nos ensaios de arrancamento. $\mathrm{O}$ efeito da dilatância impedida provoca um aumento da tensão normal no nível da interface solo-geogrelha, o que provoca um aumento da resistência ao arrancamento (HAYASHI et al., 1999).

Alfaro et al. (1995), realizaram uma série de ensaios de arrancamento utilizando uma geogrelha da marca Tensar SR80 inserida em uma areia pedregulhosa bem graduada, com $D_{50} 4,74 \mathrm{~mm}$. Com base nos resultados de teste mostraram o efeito da dilatância impedida na força de arrancamento para diferentes larguras de amostra de geogrelha. A concepção do mecanismo de interação para amostra de geogrelha está apresentada na Figura 31, que ilustra a distribuição da tensão normal nas proximidades dos elementos de geogrelha. $\mathrm{Na}$ área da borda entre a zona dilatante e não dilatante é que ocorre o aumento da tensão normal, proporcionando um mecanismo tridimensional, e a medida que aumenta-se a largura da amostra, o mecanismo bidimensional passa a prevalecer sobre o tridimensional.

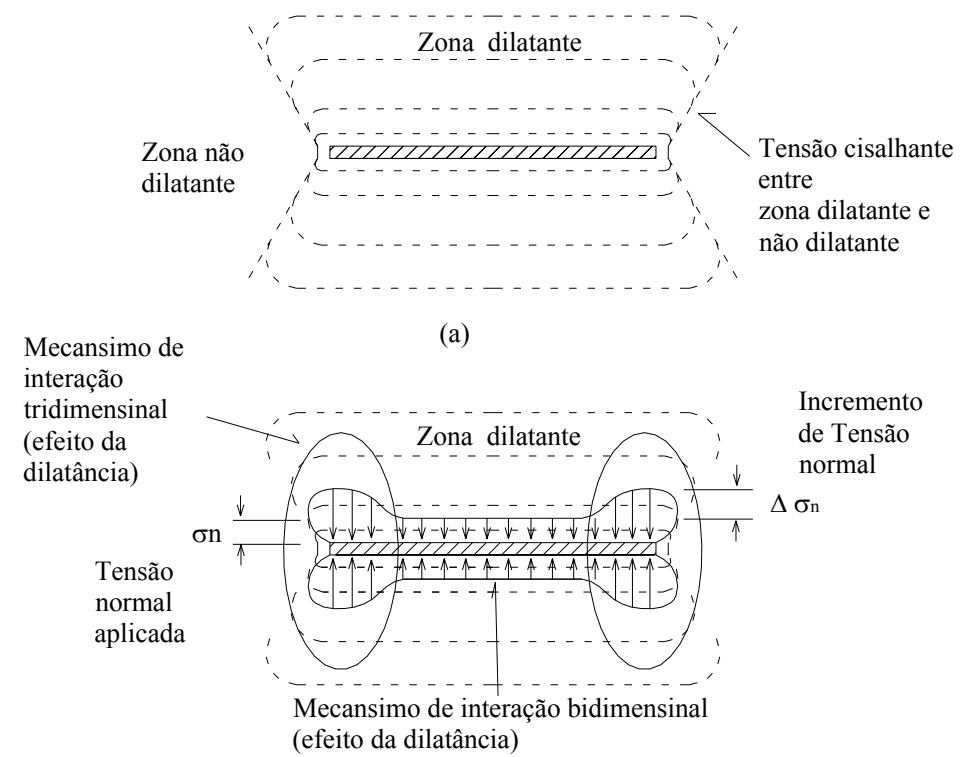

(c)

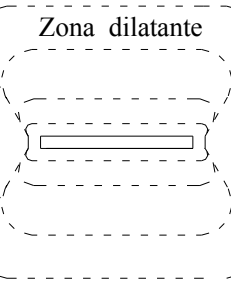

(b)

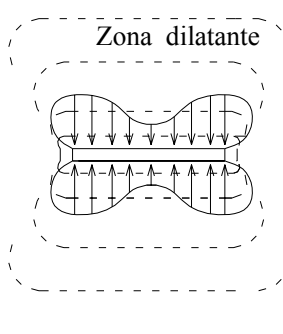

(d)

Figura 31- Mecanismo de interação conceitual para elementos da geogrelha; (a) e (c) são tensão cisalhantes e deformações em volta de um elemento de um reforço e distribuição da tensão normal para amostra grande; (c) e (d) para amostra pequena, respectivamente (ALFARO et al., 1995). 
Para o mecanismo de interação apresentado na Figura 31, a expressão (25) é proposta para determinar a máxima resistência efetiva ao arrancamento.

$$
P_{T E}=P_{2-D}+P_{3-D}
$$

Nesta expressão, $P_{2-D}$ é a força de arrancamento para interação bidimensional e $P_{3-D}$ é para interação tridimensional. A expressão (26) pode ser expressa como:

$$
P_{T E}=2 \cdot B \cdot L_{e} \cdot \sigma_{n} \cdot \tan \delta_{P}+4 \cdot B_{e} \cdot L_{e} \cdot \Delta \sigma_{n} \cdot \tan \delta_{P}
$$

Nesta expressão, $B$ é a largura do reforço, $L_{e}$ é o comprimento efetivo mobilizado do reforço, $\sigma_{n}$ é a tensão normal aplicada, $B_{e}$ é a largura do reforço influenciada pelo efeito da dilatância, $\Delta \sigma_{n}$ é o acréscimo de tensão normal na interface solo-geogrelha devido a restrição da dilatância e $\delta_{p}$ é o angulo de atrito de interface solo-geogrelha.

Os resultados dos testes, em que se variou a largura da geogrelha estão apresentados na Figura 32 que relaciona a largura da amostra com a força de arrancamento para quatro tensões normais. Para cada tensão normal aplicada são apresentadas $P_{T E}$ e $P_{2-D}$.
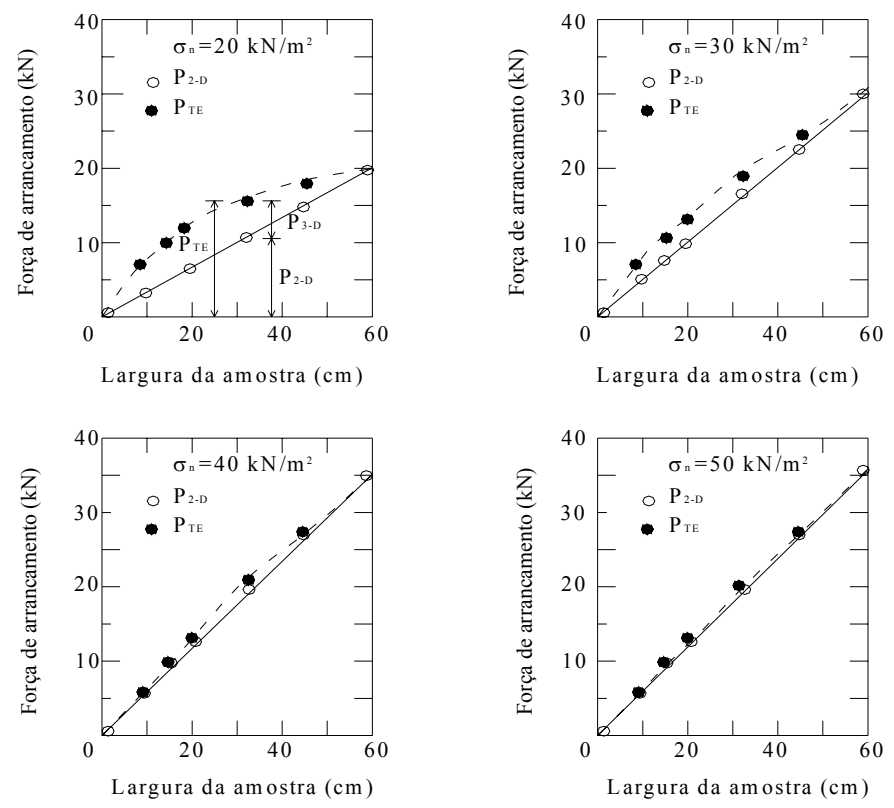

Figura 32 - Força de arrancamento vs. largura de amostra em diferentes tensão normal (ALFARO et al., 1995) 
Os autores concluem que a contribuição de mecanismo de interação tridimensional diminui com o aumento da tensão normal aplicada. E para largura próxima a dimensão interna da caixa de arrancamento o mecanismo que prevalece é o bidimensional.

\subsubsection{Efeito do tipo de solo}

As geogrelhas, quando submetidas ao ensaio de arrancamento, podem sofrer uma variação de comportamento mecânico dependendo do tipo de solo utilizado no ensaio.

Normalmente, os solos arenosos apresentam maiores resistências ao arrancamento se comparados com os solos finos. Os fatores relacionados a esse aumento são o ângulo de atrito de interface solo-geogrelha e o ângulo de atrito interno do solo (CHANG et al., 1995).

Uma verificação do efeito do tipo de solo foi elaborada por Bauer \& Chang (1993) que realizaram ensaios utilizando quatro tipos de solos (solos arenosos, argilosos, areias argilosas e agregados). Com base nos resultados obtidos, os autores constataram que quanto maior o diâmetro das partículas, maior a resistência ao arrancamento. Tal fato foi atribuído parte ao bom entrosamento entre a abertura da grelha e as partículas do solo.

A relação entre o diâmetro médio das partículas de solo $\left(D_{50}\right)$ e a resistência de interface solo-grelhas foi mostrado por Jewell et al. (1984) que estudaram a influência da relação entre as dimensões da abertura do reforço e dos grãos do solo através de ensaios de cisalhamento direto em que utilizaram uma geogrelha da marca Tensar e solos com diferentes granulometrias. Baseados nos resultados dos ensaios, os autores puderam chegar as seguintes conclusões sobre a resistência de interface para diferentes configurações:

a) Nos solos finos com dimensão de silte ou areia fina, a zona de plastificação pode ser ondulada, adaptando-se aos elementos longitudinais e transversais da grelha, observa-se na Figura 33a. 
b) À medida que a dimensão da areia aumenta, a menor resistência na interface resultante da adaptação da superfície de plastificação aos elementos constituintes do reforço, poderá não compensar o aumento de resistência necessário à ondulação de superfície; nestas condições, a superfície de plastificação torna-se plana, apenas tangente aos elementos transversais da grelha, Figura 33b.

c) Quando o solo contém partículas de dimensões idênticas às das aberturas da grelha, algumas dessas partículas instalam-se no vazio e se prendem contra as barras transversais do reforço, sobressaindo de ambos os lados deste; a existência de um número suficiente de partículas nestas condições inibe o deslizamento do solo ao longo das barras transversais, ocorrendo a zona de plastificação no interior da massa do solo, Figura 33c.

d) Finalmente, a situação mais desfavorável surge quando as dimensões dos grãos do solo são tão elevadas que não é possível a sua penetração nas aberturas das grelhas; nesta situação, a resistência na interface pode ser muito baixa, apenas resultante do contato das partículas de solo com o reforço, Figura 33d.

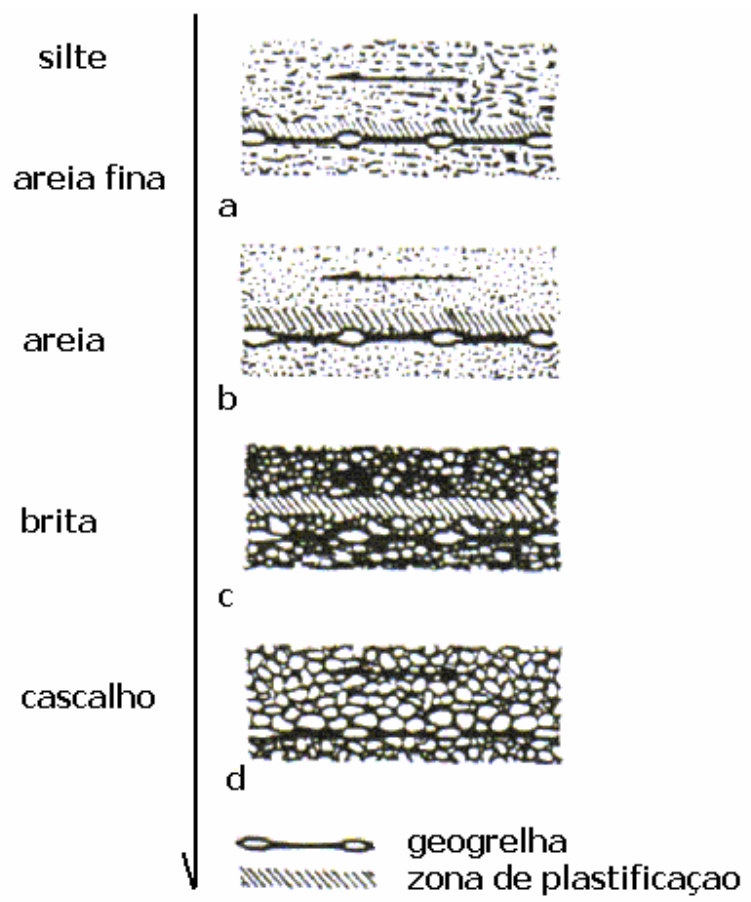


A expressão (27) apresenta o coeficiente de resistência que é obtido através de resultados de ensaios de cisalhamento direto, parâmetros da grelha e dimensão do grão de solo (JEWELL, 1984).

$$
f=1-\alpha_{c}\left(1-\frac{\operatorname{tg} \delta}{\operatorname{tg} \phi^{\prime}}\right)
$$

A Figura 34 apresenta os resultados de $f$ para diferentes granulometria e identificando os trechos configurados na Figura 33.

Nesta expressão, $\delta$ é o ângulo de atrito entre solo e os elementos sólidos da grelha, $\phi$ ' é o angulo de atrito interno do solo, determinado com base em resultados de cisalhamento direto e $\alpha_{c}$ é a fração da área superficial da grelha que resiste ao cisalhamento direto com o solo.

Plotando $(f)$ coeficiente de resistência de interface em função da relação da dimensão da abertura da grelha e da dimensão dos grãos de solo, apresentado na Figura 34, verifica-se que a resistência na interface solo-reforço aumenta com a redução do parâmetro $\alpha_{c}$, e no caso em que a superfície de ruptura se desenvolva afastada do reforço, $\alpha_{c}$, é nulo e a resistência é máxima $(f=1)$. No caso extremo de solos com partículas de grandes dimensões a resistência é mínima, uma vez que, $\alpha_{c}=1$ e $f$ reduz-se a $\operatorname{tg} \delta / \operatorname{tg} \phi$.

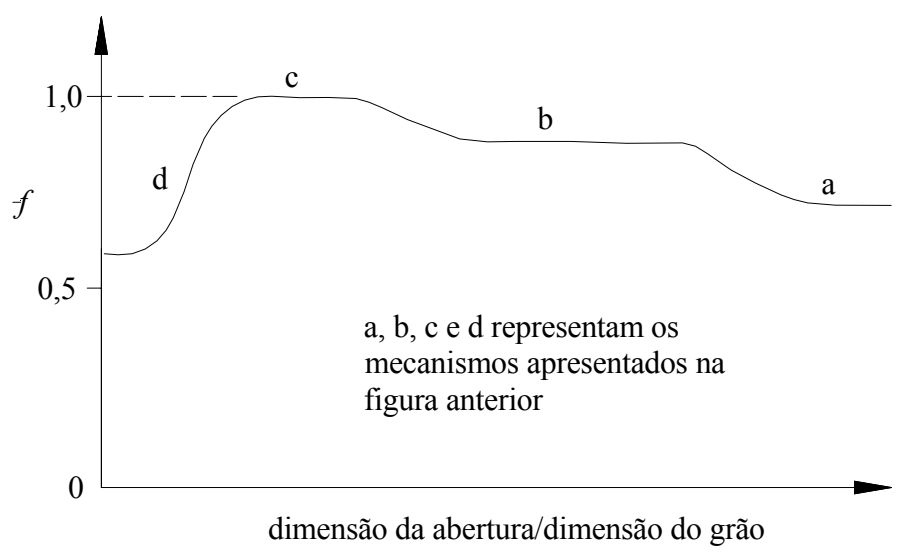

Figura 34 - Ilustração esquemática da influência da dimensão dos grãos de solo na resistência ao cisalhamento direto (JEWELL et al., 1984). 
Baseados em resultados de ensaios de cisalhamento direto realizado com dois tipos de geogrelhas e sete tipos de solos com dimensões de grãos variando entre o silte e a brita, Jewell et al. (1984) recomendaram que a dimensão média dos grãos do material de aterro a aplicar em uma obra reforçada com geogrelhas deve obedecer a expressão (28).

$$
\frac{B}{D_{50}} \geq 3
$$

Nesta expressão, $B$ é a espessura dos membros transversais; e $D_{50}$ é o diâmetro médio das partículas de solo.

Palmeira \& Milligan (1989), através de resultados de ensaios de arrancamento realizados com três tipos de areia e grelhas metálicas (de aço temperado e galvanizado), observaram que o papel da dimensão dos grãos na resistência passiva é determinante para relação entre a espessura da barra transversal e a dimensão média dos grãos $\left(B / D_{50}\right)$, menores que 12 , conforme Figura 35. Assim, só através da escolha adequada do solo é possível aumentar a resistência mobilizada nas barras transversais do reforço. Note-se, ainda que os resultados apresentados na mesma figura não são gerais, pois a resistência passiva depende de outros fatores, tais como a forma das partículas que constituem o solo, as suas características superficiais, as características da superfície dos elementos transversais e outros.

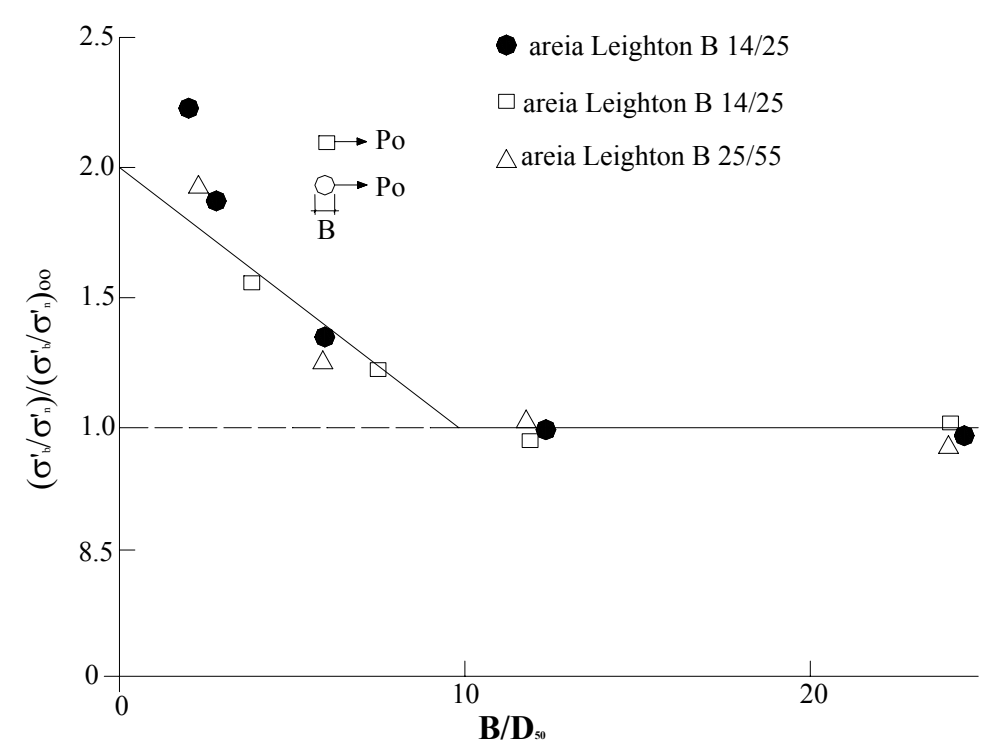

Figura 35 - Influência da relação (B/D50) na a resistência passiva do reforço (JEWELL, 1990). 
Considerando a influência da dimensão dos grãos, em termos da relação $\left(B / D_{50}\right)$ e baseando-se nos resultados de Palmeira e Milligan (1989), Jewell (1990) propôs que esta fosse expressa segunda a expressão (29).

$$
\frac{\sigma_{p}^{\prime}}{\sigma_{n}^{\prime}}=\left(\frac{\sigma_{p}^{\prime}}{\sigma_{n}^{\prime}}\right)_{\infty} \times\left\{\begin{array}{l}
2-\frac{B}{10 \cdot D_{50}} \ldots \ldots \frac{B}{D_{50}}<10 \\
1 \ldots \ldots \ldots \ldots \ldots \cdot \frac{B}{D_{50}}>10
\end{array}\right.
$$

Nesta expressão, $\left(\sigma_{p}^{\prime} / \sigma_{n}^{\prime}\right)_{\infty}$ é a resistência mobilizada nas condições em que a influência da dimensão dos grãos do solo é desprezível. Em situações em que o meio é contínuo esta resistência pode ser definida através do modo de ruptura por puncionamento.

Teixeira (2003) mostra que para cada par solo-geogrelha há um espaçamento ótimo entre os membros transversais que maximiza a força de arrancamento.

\subsubsection{1. solos arenosos}

Nos solos arenosos, por causa da elevada permeabilidade, prevalecem as condições drenadas no ensaio de arrancamento, sendo que, na maioria dos casos, as pressões neutras são desprezadas.

A relação entre o diâmetro das partículas dos solos arenosos $\left(D_{50}\right)$ e a abertura da grelha $(S)$ afetam os resultados do ensaio de arrancamento. A Figura 36 apresenta resultados de ensaios realizados por Palmeira (1989), em que foram utilizadas grelhas com diferentes aberturas $(S)$. Observa-se nos gráficos que o aumento da resistência ao arrancamento é crescente com o aumento do espaçamento $(S)$. 


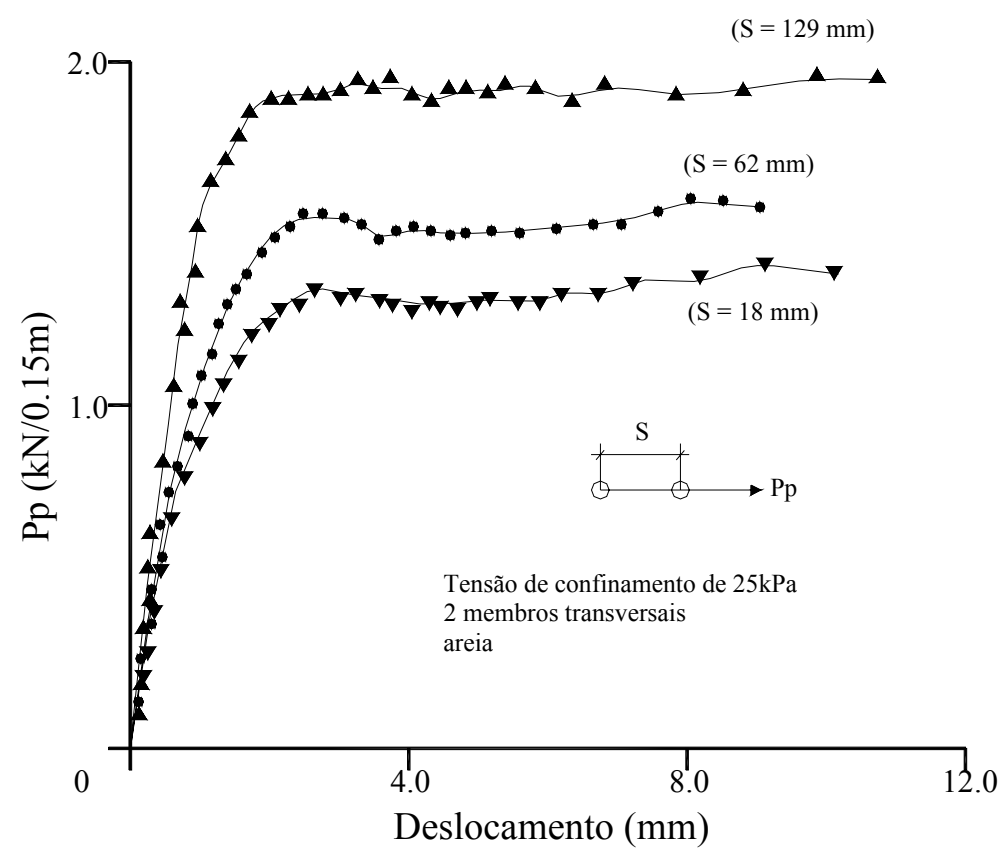

Figura 36 - Resultados de ensaios de arrancamento para diferentes abertura entre membros transversais de geogrelhas (PALMEIRA \& MILLIGAN, 1998).

Lopes \& Lopes (1999), utilizando geogrelha de polietileno de alta densidade e dois solos granulares com $D_{50}$ de 0,43 e $1,3 \mathrm{~mm}$, realizaram ensaios de arrancamento, que para o tipo de reforço utilizado, acreditam ser o mais adequado para analisar o mecanismo de interface solo-geogrelha. Com base nos resultados obtidos puderam concluir que a dimensão das partículas de solo e a dimensão das aberturas e da espessura das barras transversais de geogrelha são condicionantes para a capacidade de mobilização da resistência passiva, sendo, em geral, os solos com uma percentagem significativa de dimensões de grãos ligeiramente superiores às das espessuras das barras transversais e inferiores às das aberturas da geogrelha os que permitem uma maior mobilização desta parcela da resistência;

Teixeira (2003) mostra através de ensaios em que, retirou-se elementos transversais da amostra sistematicamente de forma que os espaçamentos entre eles fossem iguais a 46 e $69 \mathrm{~mm}$. A partir dos resultados sugere a existencia de um espaçamento ótimo entre elementos transversais (S) que maximiza a resistência ao arrancamento das geogrelhas. $\mathrm{O}$ autor concluiu que, quando o valor de $\mathrm{S}$ é menor que um valor ótimo, o bulbo de tensões gerado pela movimentação de um elemento transversal influencia negativamente no mecanismo de interação do elemento subsequente, fazendo com que a contribuição individual de cada um seja pequena. E quando o valor é maior que o ótimo, a contribuição individual de cada elemento é 
melhorada, visto que a interferência entre elementos transversais é menor, porém o somatório das contribuições é prejudicado pelo menor número de elementos transversais, portanto, o espaçamento ótimo é aquele que maximiza o somatório das contribuições individuais de cada elemento.

\subsubsection{Solos coesivos}

Nos ensaios de arrancamento de geogrelhas em solos coesivos, as pressões neutras passam a ter forte influência na resistência ao arrancamento. As condições que ocorrem no campo devem ser avaliadas corretamente e controladas nos ensaios de laboratório, dentre elas: situação em curto prazo sem drenagem e em longo prazo drenados.

Christopher \& Berg (1990) verificaram a partir de testes de arrancamento de geogrelhas em solos coesivos em condições drenada e não drenada, que a variação do teor de umidade resulta em variações da resistência ao arrancamento.

Tan et al. (2001) utilizaram geogrelha de polietileno de alta densidade e geotextil de polipropileno inseridas em solos residuais de origem granítica de Singapura, sendo considerado um solo de má drenagem. A partir de teste para verificar o comportamento de drenagem e dissipação da pressão neutra no nível da inclusão, concluíram que o geotêxtil foi efetivo para a dissipação da pressão neutra na interface solo-inclusão. Por outro lado, a geogrelha não apresentou as mesmas capacidades de drenagem interna e rapidez na dissipação da pressão neutra na interface solo-geotextil. O uso de um adequado geossintético como reforço em estrutura reforçada com a utilização de um solo de baixa capacidade de drenagem pode exercer duas funções a de reforço e de drenagem sub horizontais, desta forma não comprometendo a estabilidade da obra.

Teixeira (2003) realizou ensaios de arrancamento de geogrelhas em solos coesivos em equipamento de grande porte sob diferentes condições de saturação e sobrecarga. Os resultados dos ensaios levaram as seguintes conclusões:

- Existe uma relação linear entre a resistência ao arrancamento e a tensão vertical efetiva média atuante no solo próximo à interface com a geogrelha, independente do grau de saturação; 
- Quando o solo está sob uma condição de alta umidade, a aplicação de uma sobrecarga pode gerar pressões neutras que diminuem a resistência ao arrancamento de geogrelha;

- A utilização de elementos de drenagem aderidos aos elementos longitudinais de geogrelhas promove a dissipação de sobre-pressões;

- Os deslocamentos necessários para mobilizar a resistência ao arrancamento de geogrelhas inseridas em solos previamente sujeitos à inundação são bem superiores à aqueles quando o solo está na umidade de compactação.

- Os elementos de drenagem aderidos à face da geogrelha influenciam apenas levemente o seu comportamento quando o solo é compactado e está na umidade ótima de compactação durante a aplicação do esforço de arrancamento.

\subsubsection{Efeito da rugosidade da parede interna da caixa}

O grau de rugosidade da parte interna da parede frontal da caixa de arrancamento pode resultar em valores sobreestimados da relação $\tau / \sigma_{y}$. O aumento da rugosidade da parede frontal provoca um acréscimo no ângulo de atrito de interface entre solo-parede frontal da caixa, trazendo por conseqüência o aumento da resistência ao arrancamento da inclusão (PALMEIRA, 1989).

Este autor realizou ensaios de arrancamento com variação da rugosidade da parede frontal, utilizando grelhas de aço $(12,5 \times 12,5 \mathrm{~mm})$ em uma areia densa $\left(D_{50}\right.$ $0,8 \mathrm{~mm} ; \gamma=16,98 \mathrm{kN} / \mathrm{m}^{3}$ ). As Figuras 37 e 38 (PALMEIRA \& MILLIGAN, 1989) ilustram, respectivamente, as disposições que resultaram em diferentes rugosidades da parede frontal e a relação entre $\tau / \sigma_{y}$ e o deslocamento. 


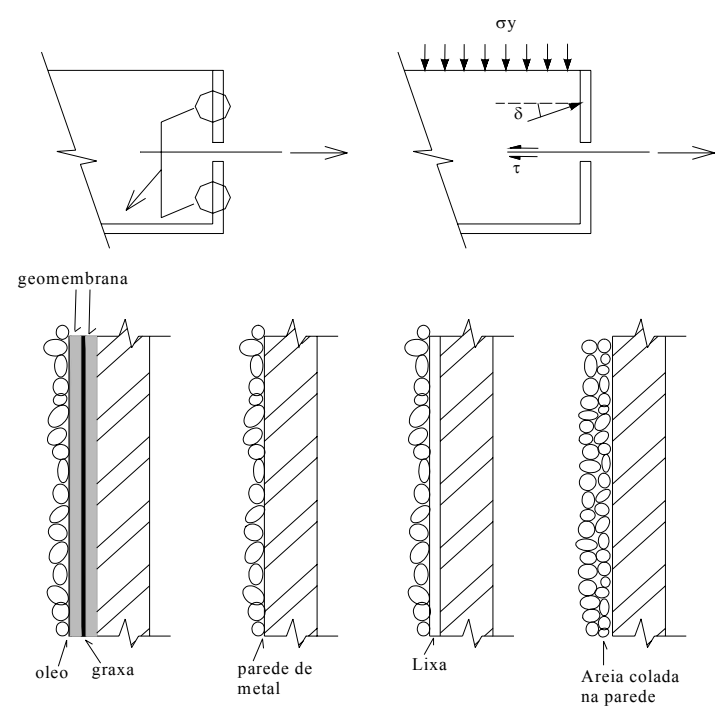

Figura 37 - Representações dos tipos de rugosidade na parede frontal do equipamento (PALMEIRA \& MILLIGAN, 1989).

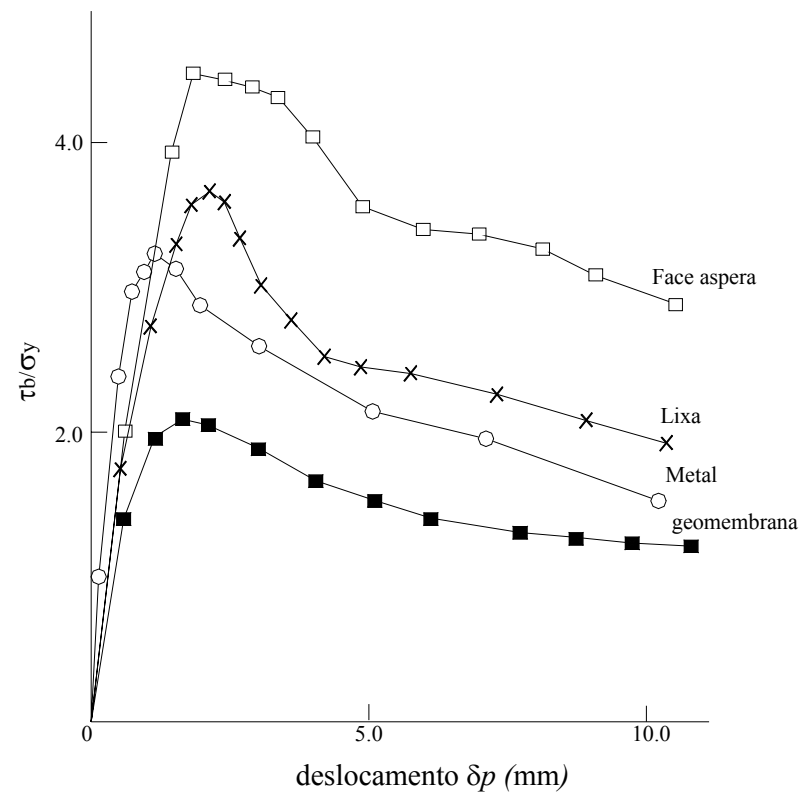

Figura 38 - Relação entre tensão cisalhante e normal vs. deslocamento nos ensaios de arrancamento para diferentes rugosidade da parede frontal do equipamento (PALMEIRA \&MILLIGAN, 1989).

A rugosidade das paredes internas da caixa de arrancamento pode afetar os resultados dos testes, uma vez que o atrito entre solo-parede pode fazer com que a tensão confinante se propague de forma não homogênea. Para minimizar os efeitos de atrito na interface solo-face interna, Palmeira \& Milligan (1989) recomendam que sejam colocadas duas geomembranas intercaladas com um material lubrificante em todas as paredes internas da caixa conforme Figura 39. 


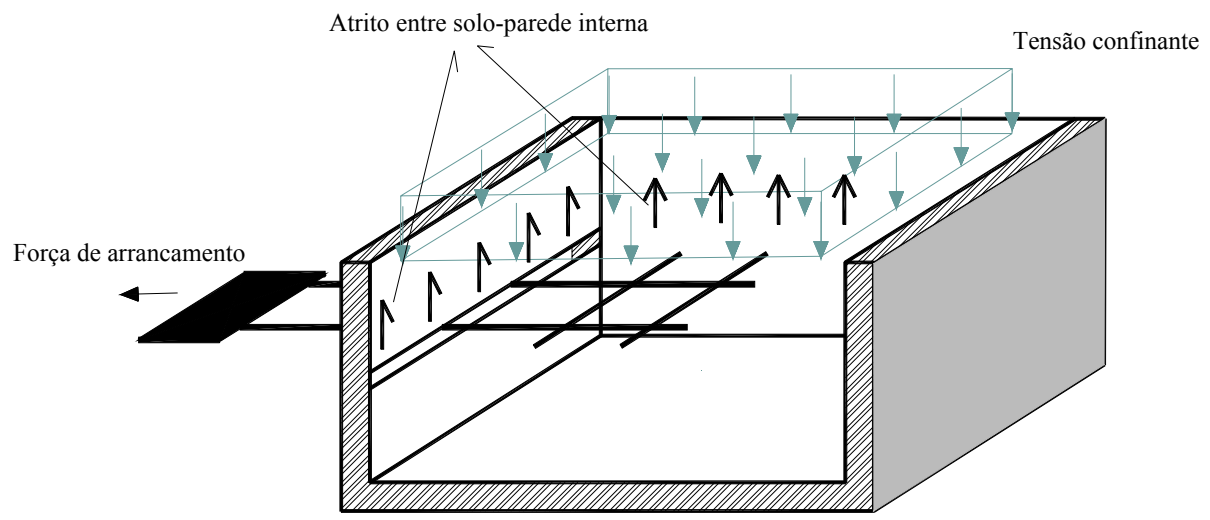

Figura 39 - Representação do atrito nas paredes interna da caixa de arrancamento.

Outra maneira de minimizar a influência da rugosidade da parede frontal do equipamento é a utilização de manga no interior da caixa ao nível do reforço. A utilização da manga permite transferir o ponto de aplicação da força de arrancamento para o interior da massa de solo afastando-o assim da parede frontal.

No intuito de analisar a influência nos resultados do ensaio de arrancamento da existência ou não de uma manga fixada no interior da caixa adjacente à parede frontal, Farrag et al. (1993) realizaram ensaios de arrancamento sem e com utilização de manga de $20 \mathrm{~cm}$ e $30.5 \mathrm{~cm}$ de comprimento. Instalaram-se duas células para medir o empuxo de terra na parede frontal do equipamento de ensaio, conforme Figura 40. Os resultados dos ensaios são verificados pela Figura 41a e 41b, mostrando o efeito do comprimento da manga na resistência ao arrancamento e a relação entre o comprimento da manga e a pressão lateral desenvolvida na face frontal do equipamento, respectivamente.

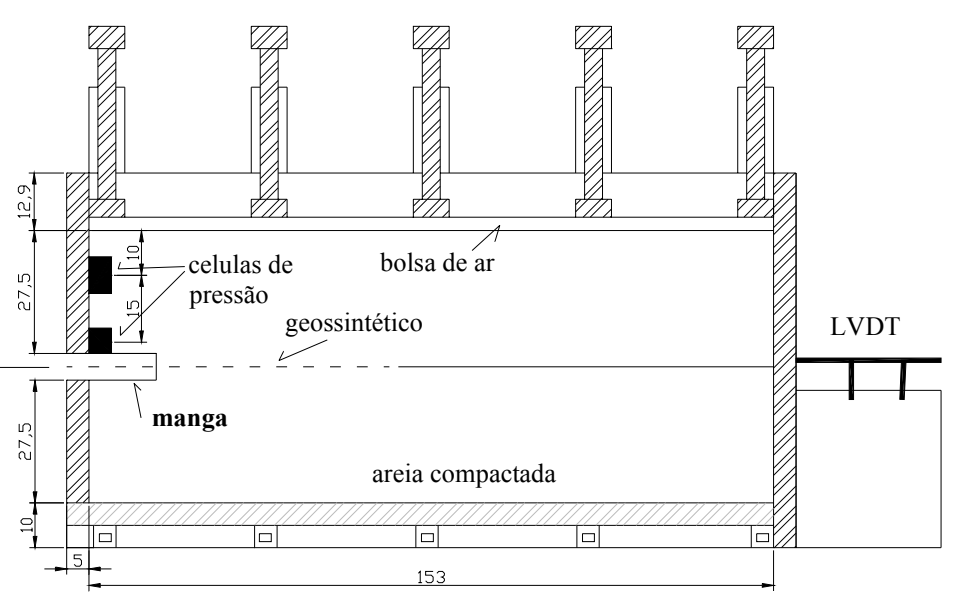

Figura 40 - Esquema da colocação da manga no equipamento de ensaio ( FARRAG et al., 1993). 


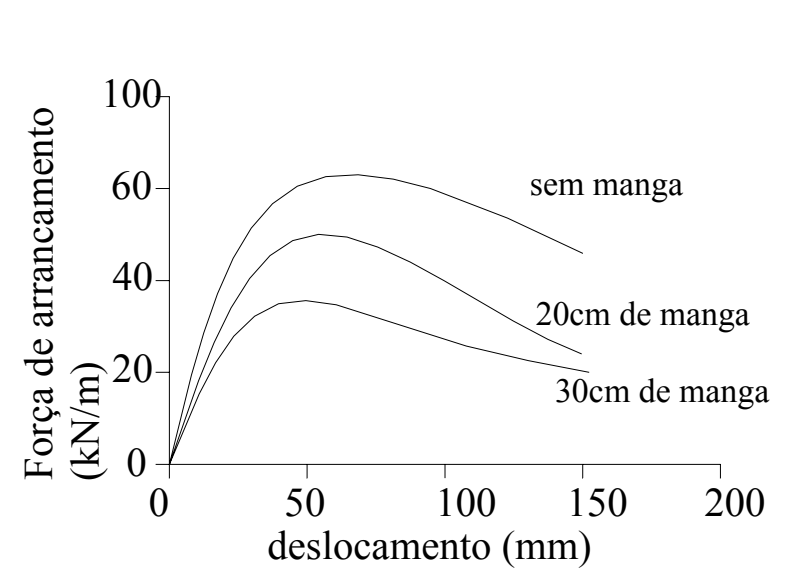

(a)

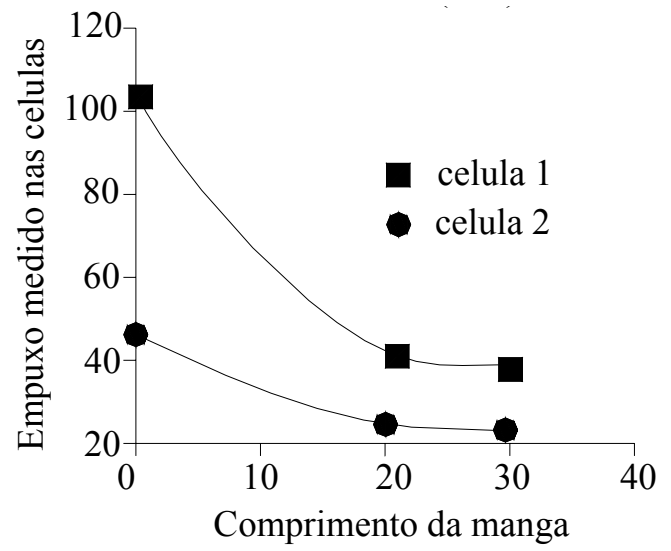

(b)

Figura 41 - a) efeito do comprimento da manga no ensaio de arrancamento; b) empuxos medidos nas células (FARRAG et al., 1993).

Dos resultados obtidos dos ensaios, os autores puderam concluir que o aumento do comprimento da manga conduziu para uma redução do empuxo desenvolvido na parede frontal do equipamento, e conseqüentemente, a redução da resistência ao arrancamento. A Figura 41b mostra que quando o comprimento da manga passou de $20 \mathrm{~cm}$ para $30.5 \mathrm{~cm}$, os valores de empuxo apresentaram pequena variação, assim, os autores recomendam a utilização de manga com comprimento de $30 \mathrm{~cm}$ para minimizarem os efeitos de contorno.

\subsubsection{Espessura da camada de solo acima e abaixo da inclusão}

A espessura da camada de solo acima e abaixo do reforço pode afetar o mecanismo de interação solo-geogrelha. Tal fato pode levar a um acréscimo da tensão confinante próximo a superfície do reforço, especialmente quando a espessura da camada não é suficiente para impedir a dilatância do solo.

Farrag et al. (1993) variaram a espessura da camada de areia acima e abaixo da inclusão no ensaio de arrancamento em um equipamento de grande porte. $\mathrm{O}$ diâmetro médio da areia foi igual a $0,3 \mathrm{~mm}$ e a geogrelha utilizada foi a Tensar SR2. As espessuras totais (duas camadas de solo, uma acima e outra abaixo da inclusão) utilizadas nos ensaios foram de 20,40, 60 e $70 \mathrm{~cm}$. Os resultados obtidos sugerem que espessuras $(T)$ de $60 \mathrm{~cm}$ são suficientes para eliminar os efeito de contorno, ou seja, $30 \mathrm{~cm}$ de espessura de solo acima e abaixo da inclusão, Figura 42. 


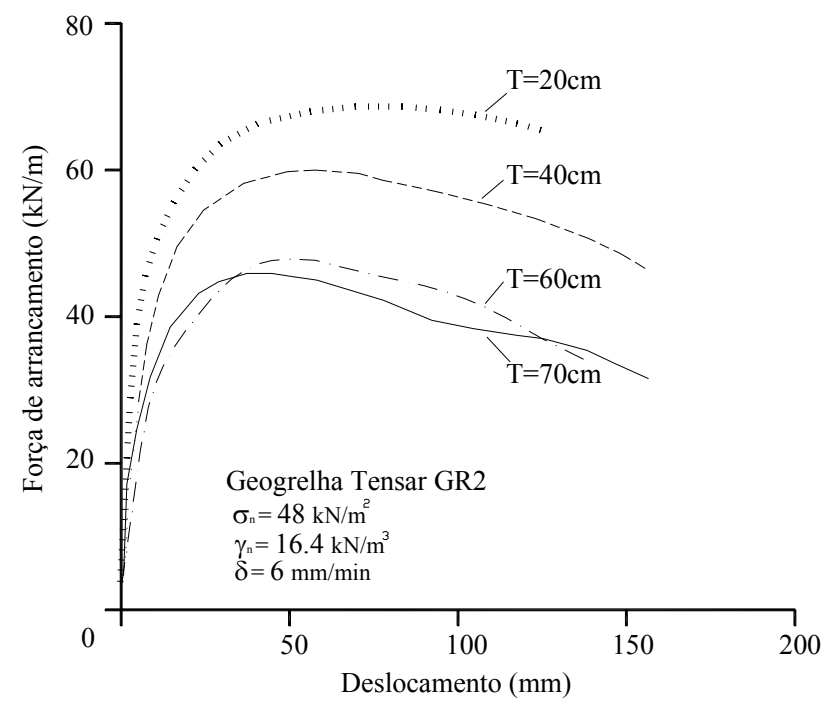

Figura 42 - Resultados de ensaios de arrancamento de geogrelha para diferente espessuras de solo arenoso (FARRAG et al., 1993).

Com o mesmo objetivo, Lopes \& Ladeira (1998) estudaram a influência da altura de solo colocada acima e abaixo do reforço na resposta ao arrancamento através de resultados de dois ensaios. No primeiro ensaio de arrancamento o reforço foi colocado em meio a $0,40 \mathrm{~m}$ de solo e no segundo o mesmo foi colocado em meio a 0,60m do mesmo solo. Os materiais utilizados foram um equipamento de ensaio de grandes dimensões, uma areia com $D_{10}$ de $0,35 \mathrm{~mm}, D_{50}$ de $1,20 \mathrm{~mm}, \gamma$ de $17,5 \mathrm{kN} / \mathrm{m}^{3}$, densidade relativa de $54 \%$, pressão de confinamento de $46,7 \mathrm{kPa}$ e velocidade de ensaio de $5,4 \mathrm{~mm} / \mathrm{min}$.

O ensaio realizado com $0,60 \mathrm{~m}$ de altura total de solo, a força de arrancamento máxima registrada foi de $32,2 \mathrm{kN} / \mathrm{m}$, ocorrendo a um deslocamento frontal de $92,7 \mathrm{~mm}$. Para um valor deste deslocamento de $200 \mathrm{~mm}$ a força de arrancamento diminuiu cerca de $43 \%$. No ensaio realizado com $0,40 \mathrm{~m}$ de altura de solo a força de arrancamento máximo foi de $33,9 \mathrm{kN} / \mathrm{m}$ para um deslocamento frontal de $119 \mathrm{~mm}$. Quando este deslocamento passou para $200 \mathrm{~mm}$ o decréscimo observado na força de arrancamento foi de $25 \%$.

Com base nos resultados obtidos, Lopes \& Ladeira (1998) puderam concluir que apesar da diferença entre os valores da força de arrancamento máxima ser relativamente pequena, constatou-se uma redução da resistência na interface solo-reforço para deslocamentos frontais maiores, sendo que essa diminuição foi mais pronunciada no ensaio com menor espessura de solo. Este comportamento foi devido, não só, às forças atritivas desenvolvidas entre o solo e a fronteiras rígidas horizontais, principalmente a 
fronteira inferior, mas também, à restrição da dilatância do solo que tende a ocorrer neste tipo de ensaio. Como os valores da força máxima de arrancamento e do coeficiente de resistência diferiram apenas de 5\% e $8 \%$, respectivamente, nas duas situações testadas, os autores puderam afirmar que a influência da altura de solo envolvendo a amostra é insignificante na resposta ao arrancamento do reforço ensaiado. Entretanto, consideram que outras alturas de solo devem ser ensaiadas com vista à confirmação dos presentes resultados.

Brand \& Duffy (1987) estudaram o efeito da espessura de solo na resistência ao arrancamento da geogrelha em argila e concluíram que aumentando a espessura da camada de solo, a resistência ao arrancamento decresce até uma resistência mínima, passando a ser constante.

Conforme mencionado anteriormente, os efeitos de contorno no ensaio de arrancamento devido a espessura de solo compactado acima e abaixo da inclusão dependem de outros fatores, dentre eles o diâmetro, a forma e a rugosidade dos grãos de solo. Para evitar-se a influência da altura do solo compactado na resistência ao arrancamento no ensaio em laboratório, vem-se adotando uma espessura superior a cinqüenta vezes o diâmetro médio das partículas de solo.

\subsubsection{Influência da velocidade de ensaio $(\mathrm{mm} / \mathrm{min})$}

$\mathrm{Na}$ execução do ensaio de arrancamento, a mudança da velocidade de ensaio ( $\mathrm{mm} / \mathrm{min})$ leva a uma variação na força máxima de arrancamento. Lopes \& Ladeira (1996) realizaram alguns ensaios de arrancamento mudando se as taxas de deslocamento. O diâmetro médio da areia utilizada foi de $1,2 \mathrm{~mm}$ e a geogrelha testada foi de polietileno de alta densidade. Os resultados mostram que a mudança da taxa de deslocamento de $1,8 \mathrm{~mm} / \mathrm{min}$ para $22 \mathrm{~mm} / \mathrm{min}$ aumenta a resistência ao arrancamento em cerca de 30\%, conforme Figura 43.

O fator de aderência $(f)$ apresentada na Tabela 2 pode ser calculado segundo a expressão (30).

$$
f=\frac{\tau}{\sigma_{n} \operatorname{tg} \phi}
$$


Nesta expressão, $\tau$ e $\sigma_{n}$ são as tensões tangencial e normal na interface; $\phi$ é o ângulo de atrito interno do solo.

Tabela 2 - Influencia da taxa de deslocamento (LOPES \& LADEIRA, 1996).

\begin{tabular}{ccc}
\hline $\begin{array}{c}\text { Taxa de deslocamento } \\
(\mathrm{mm} / \mathrm{min})\end{array}$ & $\begin{array}{c}\text { Máx. força de arrancamento } \\
(\mathrm{KN} / \mathrm{m})\end{array}$ & $\begin{array}{c}\text { Fator de aderência } \\
(f)\end{array}$ \\
\hline 1,8 & 28,9 & 0,506 \\
5,4 & 32,2 & 0,564 \\
11,8 & 34,6 & 0,616 \\
22,0 & 38,0 & 0,677
\end{tabular}

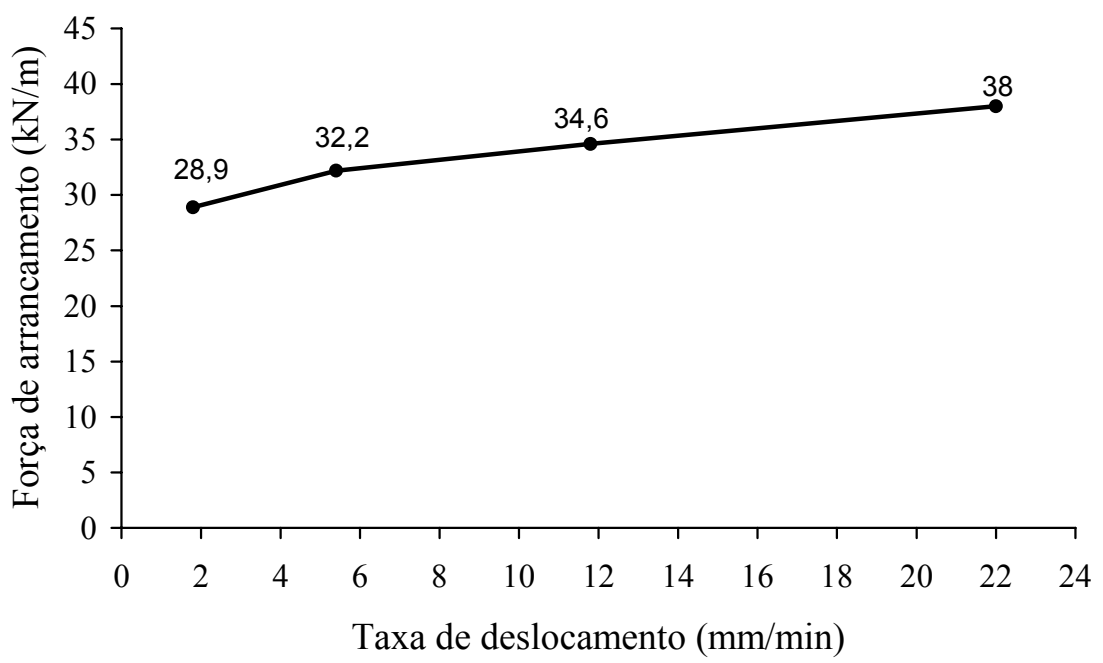

Figura 43 - Resultados de ensaio de arrancamento executados com diferentes velocidades de ensaio (LADEIRA \& LOPES, 1996).

Com base nos resultados obtidos dos ensaios, os autores puderam concluir que:

- Aumento na velocidade de ensaio leva a um aumento da resistência ao arrancamento e do fator de aderência, embora o deslocamento por extensão da geogrelha mostra uma tendência a reduzir;

- O aumento da resistência ao arrancamento e do fator de aderência é resultado do aumento da rigidez do sistema solo-reforço e da dedução da capacidade de rearranjo dos grãos de solo com o aumento da velocidade de ensaio.

Lopes \& Ladeira (1998) realizaram ensaios de arrancamento com velocidade de ensaio de $5.4 \mathrm{~mm} / \mathrm{min}$. Nos ensaios utilizaram geogrelhas em meio a uma camada de areia $\left(D_{50}=1.2 \mathrm{~mm}\right)$. 
De tudo que foi exposto pode-se verificar que o mecanismo de interação soloinclusão nos testes de arrancamento é complexo e depende vários fatores relacionados a geometria e característica do reforço, o tipo de solo utilizado e alguns parâmetros de ensaio, dentre outros não mencionados. Em virtude desta complexidade, os itens a seguir buscaram obter informações qualitativa e quantitativa a respeito do mecanismo de interação solo-geogrelha através da utilização de um equipamento de tamanho reduzido que proporciona uma maior quantidade de ensaio. 


\section{Capitulo 3}

\section{MATERIAIS E MÉTODOS.}

Este capítulo descreve as principais características do equipamento desenvolvido para executar ensaio de arrancamento de dimensões reduzidas. São descritos também as características dos materiais ensaiados, e os procedimentos de preparação da amostra e de execução do ensaio.

\subsection{Equipamentos e instrumentação utilizados.}

O equipamento utilizado para a execução de ensaios de arrancamento de pequeno porte foi projetado e desenvolvido por Teixeira (2003). A caixa de ensaio tem dimensões internas de $250 \mathrm{~mm}$ de comprimento, 300mm de largura e $150 \mathrm{~mm}$ de altura, resultando num volume $0,01125 \mathrm{~m}^{3}$. A aplicação da força de arrancamento é feita através de uma máquina universal da marca Emic, modelo DL 3000, com capacidade máxima de $30 \mathrm{kN}$. A instrumentação interna do sistema fornece a força resistente ao arrancamento e o respectivo deslocamento axial da geogrelha. Estes dados são armazenados em um microcomputador, possibilitando o tratamento e a elaboração de gráficos de deslocamento em função da força resistente ao arrancamento.

Para a fixação da caixa de teste à maquina universal, foi soldado um acoplamento na sua parede traseira. Na parede frontal, foi feita uma abertura de $10 \mathrm{~mm}$ em toda a sua extensão para a colocação da geogrelha, conforme mostra a Figura 44. 

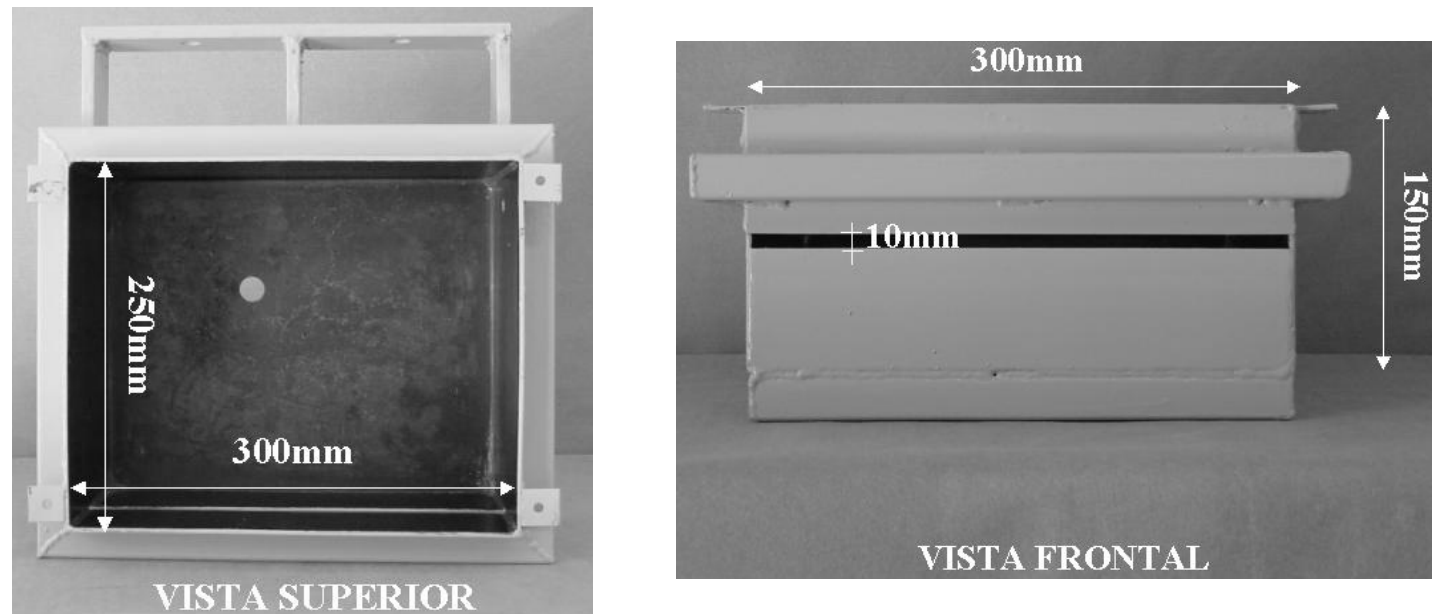

Figura 44 - Vista superior e frontal da caixa de arrancamento.

Na tampa da caixa é fixada uma bolsa inflável de PVC que permite a aplicação de sobrecarga através da injeção de ar comprimido. A pressão de ar é controlada por um manômetro e uma válvula reguladora. Garante-se assim que a sobrecarga seja aplicada de forma homogênea e constante sobre toda a superfície de solo compactado no interior da caixa. Os detalhes da tampa do equipamento podem ser observados na Figura 45.

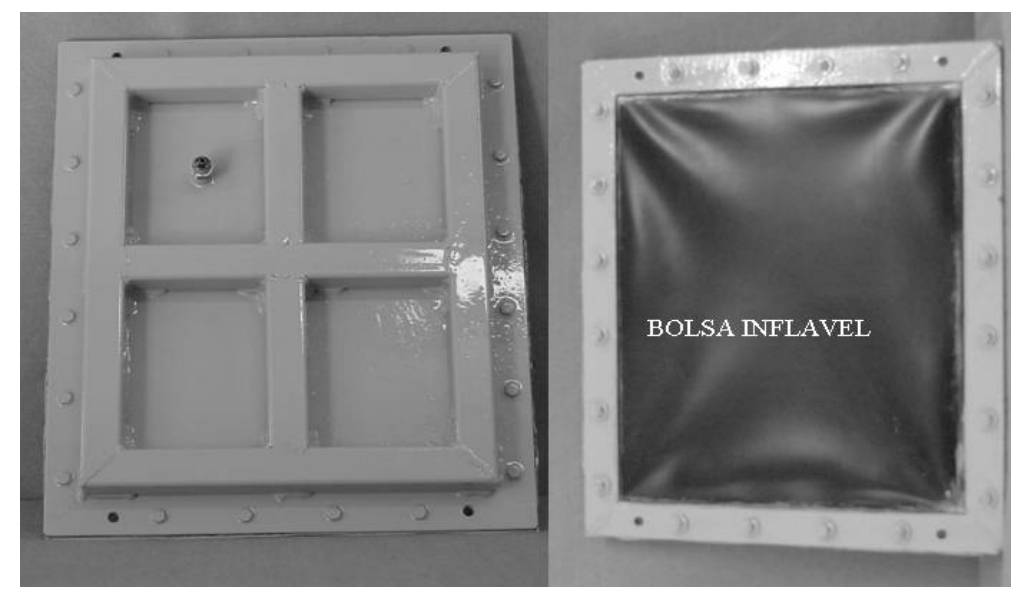

Figura 45 - Vista da tampa da caixa de arrancamento.

A instrumentação interna, apresentado na Figura 46(a), compõe-se de uma célula de carga, da marca Kyowa, para leitura de tensão total no nível imediatamente abaixo da inclusão.

Para a compactação do solo utilizou-se um compactador pneumático da marca Bosch, modelo GSH 11E, em cuja haste se dispôs uma sapata quadrada de $0,15 \mathrm{~m}$ de largura, Figura 46 (b) e (c). Este equipamento pesa 101 N, tem freqüência de 900 a 1890 
impactos por minuto, apresenta uma potencia de 1500 watts e aplica solo uma energia de 6 a 25 Joules por golpe.

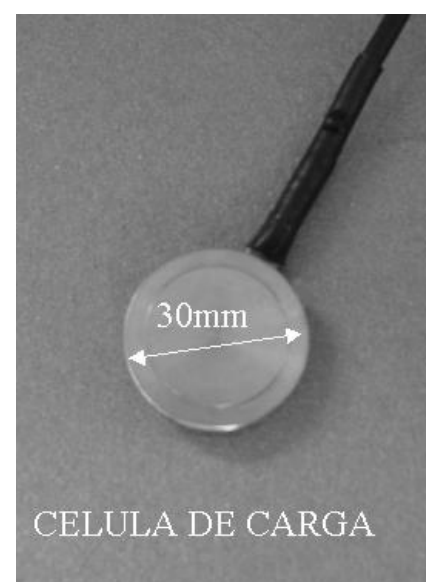

(a)

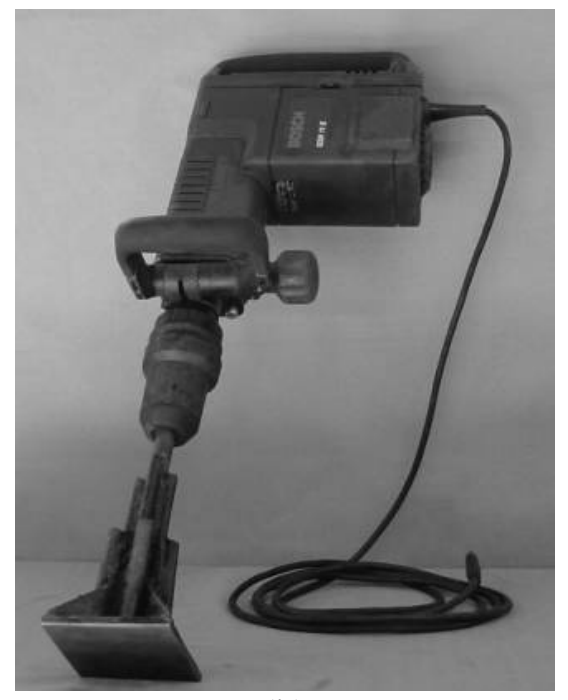

(b)

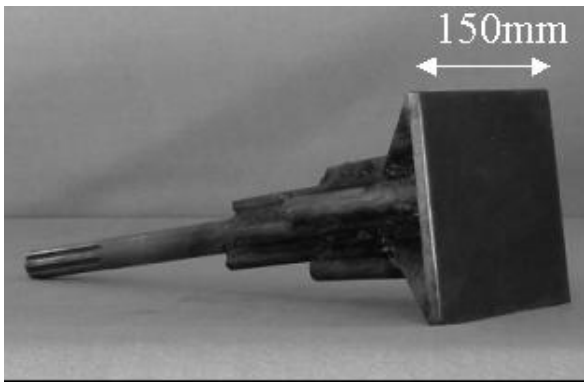

(c)

Figura 46 - (a) célula de carga da marca Kyowa; (b) compactador pneumático e (c) sapata utilizada na compactação do solo.

\subsection{Os solos utilizados no programa experimental.}

Foram utilizados seis solos de características geométricas distintas, cujo critério de escolha principal pautou-se nas informações das curvas granulométricas. Os solos foram coletados em taludes expostos às margens de rodovias de acesso ao município de São Carlos-SP, que não apresentassem visualmente impurezas, tais como raízes e outros materiais estranhos.

Para a facilidade de identificação dos ensaios realizados neste trabalho, as amostras foram classificadas como Solos 1, 2, 3, 4, 5, e B, cujas curvas de distribuição granulométrica estão mostradas na Figura 47. 


\section{PENEIRAS ABNT ( NBR 5734/80 )}

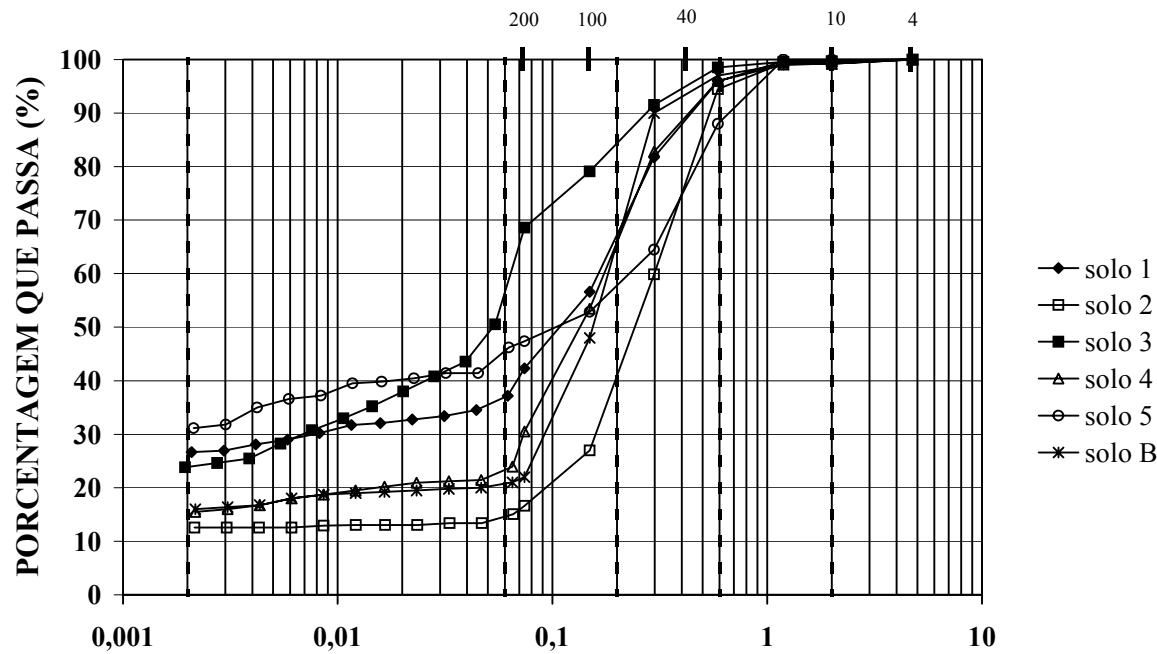

DIÂMETRO DOS GRÃOS (mm)

\begin{tabular}{|l|l|l|c|c|c|}
\hline \multirow{2}{*}{ Argila } & \multirow{2}{*}{ Silte } & \multicolumn{3}{|c|}{ Areia } & \multirow{2}{*}{ Pedregulho } \\
\cline { 3 - 4 } & & Fina & Média & Grossa & \multirow{2}{*}{. } \\
& &
\end{tabular}

Figura 47 - Curva granulométrica dos solos utilizados no trabalho.

Os resultados dos ensaios de caracterização dos solos (massa específica dos sólidos, limite de liquidez, limite de plasticidade, parâmetros de compactação na energia do Proctor Normal, $\rho_{d m a ́ x}$ e $w_{o t}$ ) e os parâmetros de resistência ao cisalhamento (coesão e ângulo de atrito interno), obtidos de ensaios de cisalhamento direto com os corpos de provas moldados nas mesmas condições dos ensaios de arrancamento realizados neste trabalho, estão mostrados na Tabela 3. A classificação dos solos utilizados nos ensaios seguiu ao Sistema Unificado (S.U.C.S. - Casagrande).

Tabela 3 - Propriedades dos solos utilizados nos ensaios de arrancamento.

\begin{tabular}{ccccccc}
\hline Propriedades & $\mathbf{5}$ & $\mathbf{2}$ & $\mathbf{3}$ & $\mathbf{4}$ & $\mathbf{5}$ & $\mathbf{B}$ \\
\hline$\rho_{\boldsymbol{s}}\left(\mathbf{g} / \mathbf{c m}^{\mathbf{3}}\right)$ & 2,71 & 2,66 & 2,98 & 2,67 & 2,64 & 2,67 \\
$\mathbf{L L}(\mathbf{\%})$ & 33 & 17 & 46 & 21 & 50 & 18 \\
$\mathbf{L P}(\mathbf{\%})$ & 22 & 13 & 28 & 17 & 36 & 14 \\
$\rho_{\text {dmáx }}\left(\mathbf{g} / \mathbf{c m}^{\mathbf{3}}\right)$ & 1,78 & 1,97 & 1,65 & 1,97 & 1,68 & 1,95 \\
$\boldsymbol{W}_{\boldsymbol{o t}}(\mathbf{\%})$ & 15,9 & 10,1 & 23,5 & 12,2 & 19,0 & 10,7 \\
$\boldsymbol{\phi}(\mathbf{\%})$ & 34,6 & 33,3 & 34,8 & 33,7 & 29 & 33,5 \\
$\boldsymbol{c}(\mathbf{k P a})$ & 30,0 & 9,8 & 27,5 & 21,0 & 32,6 & 23,8 \\
$\mathbf{G C}(\mathbf{\%})$ & 96 & 96 & 96 & $96,98 \mathrm{e} 100$ & 96 & 93 \\
$\mathbf{C l a s s i f i c a c ̧ a ̃ o}$ & $\mathrm{SC}$ & $\mathrm{SM}-\mathrm{SC}$ & $\mathrm{CL}$ & $\mathrm{SM}$ & $\mathrm{SC}-\mathrm{MH}$ & $\mathrm{SM}$ \\
\hline
\end{tabular}




\subsection{As geogrelhas}

As geogrelhas poliméricas utilizadas neste trabalho são produzidos pela empresa alemã Huesker Synthetic GmbH. Foram selecionados os modelos Fortrac 55/30-20, Fortrac 35/20-20 e Fortrac 110/30-20, sendo que o modelo Fortrac110/30-20 foi a mesma amostra utilizada por Teixeira (2003) em seus ensaios de arrancamento com utilização de equipamento de grandes dimensões. Cabe-se ressaltar que esta ultima não se encontra atualmente disponível no mercado com as mesmas características geométricas.

Estas geogrelhas são flexíveis e constituídas de fios de poliéster de alta tenacidade revestidos com PVC. A Tabela 4 apresenta as propriedades e características de cada modelo de geogrelha empregado.

Tabela 4 - Propriedades da geogrelha utilizadas.

\begin{tabular}{lcccc}
\hline \multicolumn{1}{c}{ Propriedades } & & geogrelhas & \\
& & (1) Fortrac & (2) Fortrac & Fortrac \\
& & $\mathbf{3 5 / 2 0 - 2 0}$ & $\mathbf{5 5 / 3 0 - 2 0}$ & $\mathbf{1 1 0 / 3 0 - 2 0}$ \\
\hline Resistência à tração (kN/m) & Longitudinal & 35 & 55 & 110 \\
Deformação na ruptura (\%) & Transversal & 20 & 30 & 30 \\
Abertura da malha (mm) & & 12 & 12 & 12 \\
Largura do elemento (mm) & Longitudinal & 2,5 & 20 & 18 \\
Espaçamento entre elementos & Transversal & 6 & 6 & 7,0 \\
(mm) & Longitudinal & 23 & 23 & 3 \\
Espessura do elemento (mm) & Transversal & 24,6 & 23,3 & 23 \\
\hline & Transversal & 1,0 & 1,0 & 1,5 \\
\hline
\end{tabular}

As Figura 48 e 49 apresentam as curvas forças $(\mathrm{kN} / \mathrm{m}) v s$ deformações (\%) de ensaios de tração realizados com as geogrelhas do modelo Fortrac35/20-20 e Fortrac55/30-20, respectivamente. Para obtenção das leituras de deformações foram utilizados dois LVDT posicionados de forma que os dois pontos de fixação fossem abaixo de elementos transversais, mantendo-se uma distancia de dois elementos consecutivos. A velocidade de execução do ensaio e o comprimento da amostra foram adotados os mesmos utilizados nos ensaios de arrancamento. 


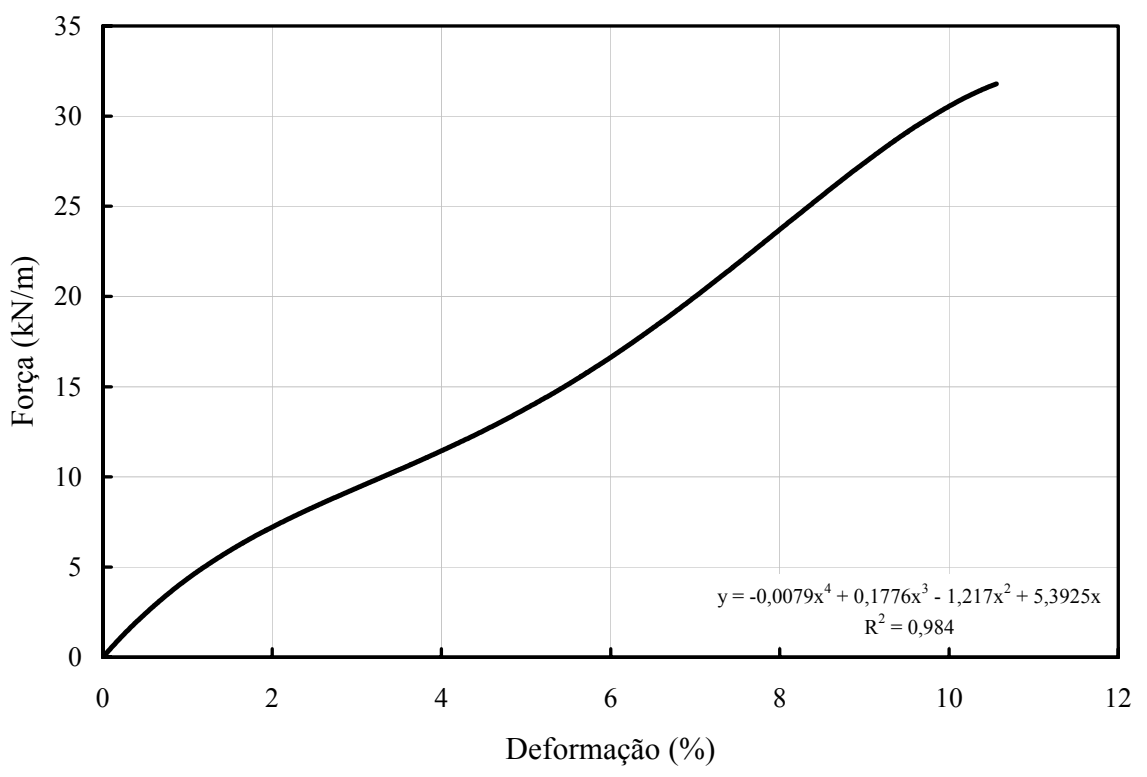

Figura 48 - Curva força vs. deformação (Fortrac 35/20-20)

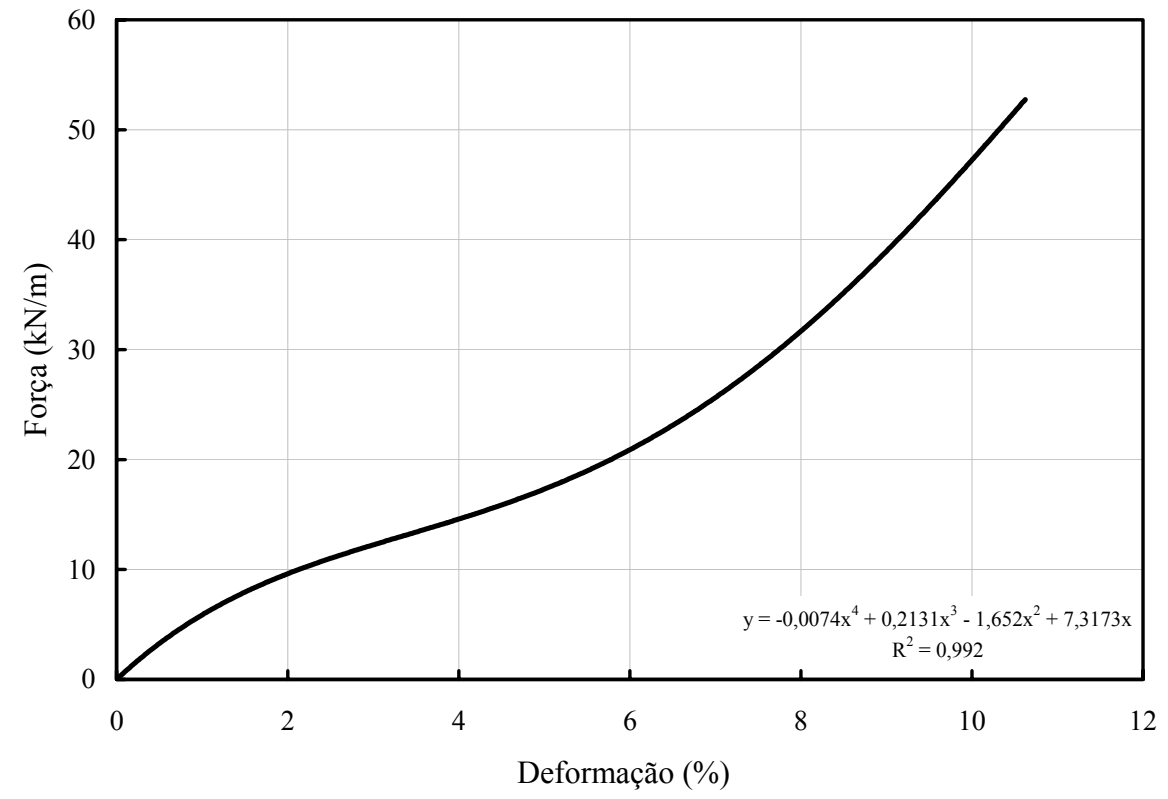

Figura 49 - Curva força vs. deformação (Fortrac 55/20-20)

Para cada modelo de geogrelha foram realizados ensaios com seis repetições e a partir destes resultados pode-se obter uma curva de tendência que melhor se ajustasse os dados. Para o modelo Fortrac35/20-20 o melhor ajuste pode ser explicitado pela expressão (31) e para o modelo Fortrac55/30-20, a expressão (32).

$$
y=-0,0079 \cdot x^{4}+0,1776 \cdot x^{3}-1,217 \cdot x^{2}+5,3925 \cdot x
$$




$$
y=-0,0074 \cdot x^{4}+0,2131 \cdot x^{3}-1,652 \cdot x^{2}+7,3173 \cdot x
$$

A curva força $v s$. deformação do modelo Fortrac 110/30-20, apresentada na Figura 50, foi obtido da literatura por indisponibilidade do material para ensaio, uma vez que o modelo produzido atualmente não apresenta as mesmas características geométricas do utilizado por Teixeira (2003).

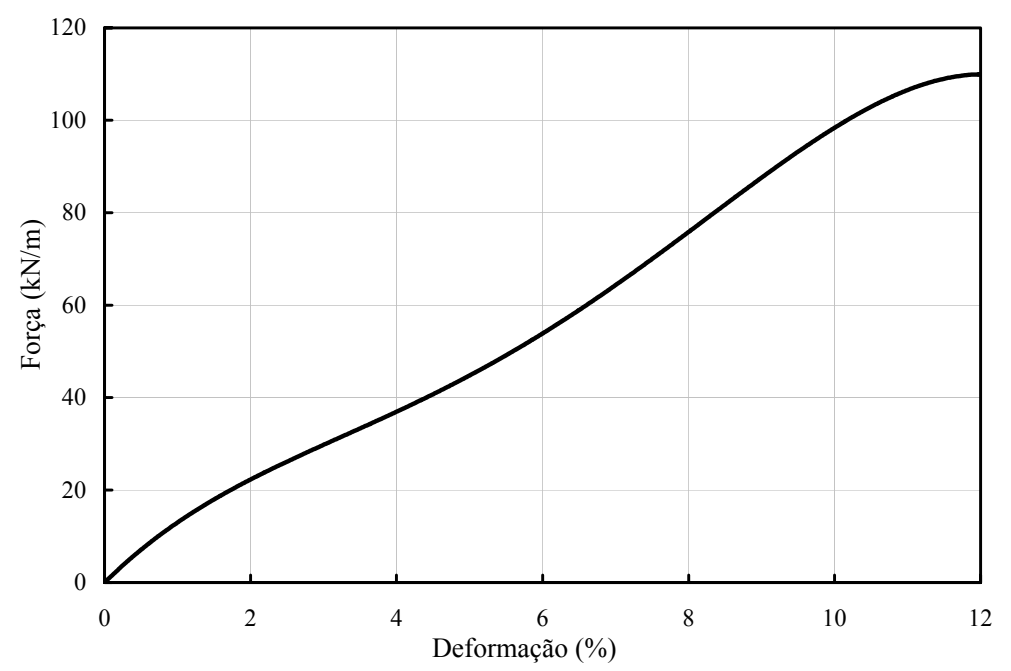

Figura 50 - Curva força vs. deformação do modelo Fortrac 110/30-20 (Teixeira, 2003).

As expressões (31) e (32) possibilitaram efetuar a correção dos deslocamentos dos corpos de prova nos ensaios de arrancamento, uma vez que nesses ensaios os deslocamentos registrados incorporam também as deformações que ocorrem no trecho não confinado (entre a face do equipamento e a face da garra).

Para todos os ensaios realizados neste trabalho o comprimento não confinado de geogrelha foi de onze centímetros $\left(l_{0}\right)$ trecho entre a garra e a face frontal do equipamento.

O procedimento de cálculo para a correção dos deslocamento consiste basicamente em: (a) ao iniciar o ensaio o comprimento inicial $\left(l_{0}\right)$ é de onze centímetros; (b) à medida que se inicia o arrancamento para cada força aplicada registra-se um valor de deslocamento $(\Delta l)$ devido a deformação da geogrelha no trecho não confinado; (c) ao se subtrair o deslocamento $(\Delta l)$ do deslocamento total obtido $\left(\delta_{t}\right)$, obtém-se o deslocamento real. Para o próximo estágio de força o comprimento inicial é obtido da soma $l_{0}$ e $\Delta l$. 


\subsection{Procedimentos de ensaios}

O procedimento de ensaio obedeceu a seguinte seqüência:

a) Preparação do solo e correção do teor de umidade.

O solo foi seco à sombra e posteriormente peneirado na malha \#4. Após, determinou-se a sua umidade higroscópica e fez-se a correção de umidade para adequálo à umidade de compactação especificada no trabalho. A fim de garantir uma homogeneização, os solos foram mantidos, após o preparo, em sacos plásticos por 24 horas. Em função da pequena quantidade de solo necessária à execução do ensaio, o controle de umidade do solo foi feito em quantidades de solo de 2 a $3 \mathrm{~kg}$.

b) Preparação da caixa de teste.

Para diminuir o efeito de atrito de interface que se desenvolve entre o solo e as paredes internas da caixa de ensaio, fez-se um revestimento interno das paredes com duas geomembranas de PVC com $0,8 \mathrm{~mm}$ de espessura, intercaladas por material lubrificante (graxa), conforme sugerido por Palmeira \& Milligan (1989). Esses autores verificaram que o grau de rugosidade das paredes internas da caixa de arrancamento pode afetar os resultados, uma vez que o atrito entre o solo e a parede pode levar a valores sobreestimados da relação $\tau / \sigma_{y}$. $\mathrm{O}$ aumento da rugosidade da parede frontal provoca um acréscimo no ângulo de atrito de interface entre o solo e a parede frontal da caixa, trazendo por conseqüência o aumento da resistência ao arrancamento da inclusão. Após, revestidas todas as paredes internas como mostrado na Figura 51, iniciava-se a compactação da primeira camada de solo. 


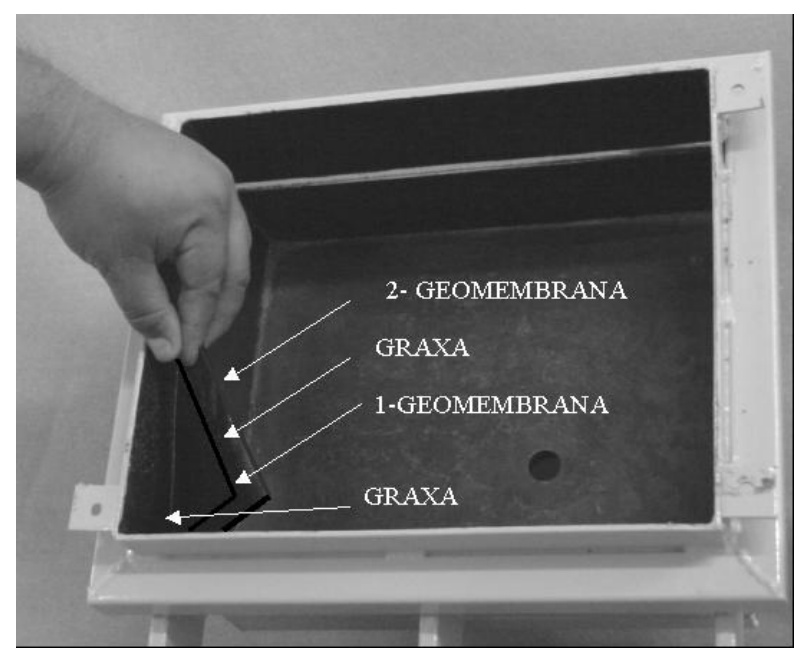

Figura 51 - Revestimento das paredes interna do equipamento.

c) Compactação do solo.

A compactação foi controlada através do conhecimento da massa de solo a ser compactada no interior da caixa de teste. A compactação foi executada em duas camadas de $0,075 \mathrm{~m}$, com volume, em cada camada, de $0,0028 \mathrm{~m}^{3}$.

O grau de compactação do solo nos ensaios em que se utilizou os solos 1, 2, 3 e 5 foi de $96 \%$ em relação à energia do ensaio do Proctor Normal. No solo 4 foram realizados ensaios com grau de compactação de 96,98 e 100\% da energia do ensaio de Proctor Normal.

Para o solo B, o grau de compactação do solo utilizado foi de 93\%, o mesmo empregado por Teixeira (2003) em seus ensaios de arrancamento de grandes dimensões. Isto foi feito para se ter as mesmas condições de ensaio (teor de umidade, grau de compactação, velocidade de arrancamento e pressões confinantes) e a mesma geogrelha, tal que permitisse uma comparação entre os resultados dos ensaios de grandes dimensões, conduzidos por Teixeira (2003) e os de pequenas dimensões realizados neste trabalho.

d) Montagem do ensaio.

A primeira camada foi compactada de maneira que a sua superfície acabada coincidisse com a metade da abertura frontal, ou seja, $0,075 \mathrm{~m}$ de espessura. Compactada a primeira camada, fazia-se uma abertura de $30 \mathrm{~mm}$ de diâmetro por $20 \mathrm{~mm}$ de profundidade e afastada de $80 \mathrm{~mm}$ da parede frontal para a acomodação da célula de 
tensão total. Em seguida, implantou-se a célula de tensão total de tal forma que ficasse aproximadamente $10 \mathrm{~mm}$ abaixo da geogrelha. O furo era depois recomposto com solo compactado de forma a se ter à superfície plana coincidente com a superfície da primeira camada compactada. A Figura 52 mostra a etapa que se antecede à colocação da inclusão.

A geogrelha era colocada sobre a primeira camada, após escarificação da superfície do solo compactado, de forma que ficasse com $110 \mathrm{~mm}$ de comprimento para fora da abertura da caixa, para a fixação na garra. A segunda camada de solo era então compactada até uma altura de $5,0 \mathrm{~mm}$ da borda da caixa de ensaio para facilitar a acomodação da bolsa inflável sobre a segunda camada de solo.

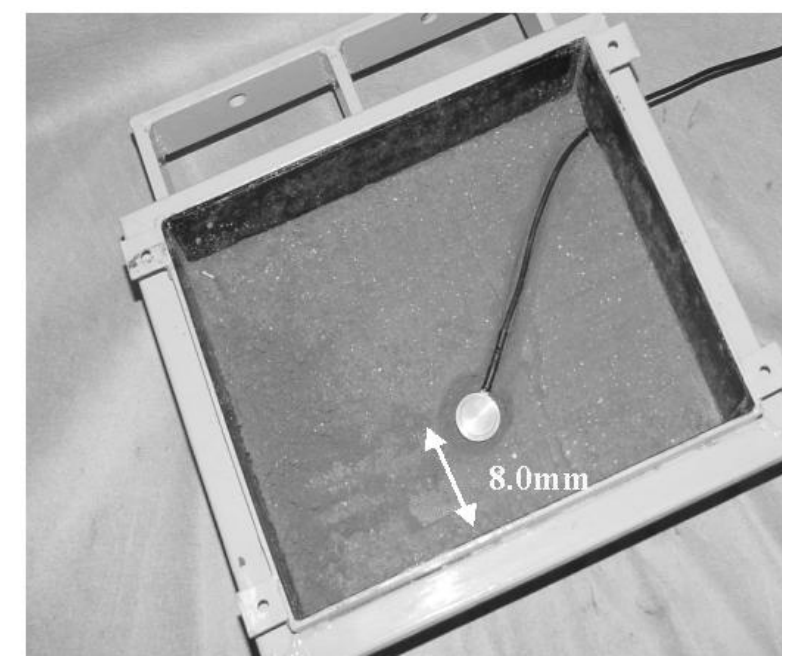

Figura 52 - Primeira camada de solo compactado e colocação da célula de carga.

A tampa era então fixada à caixa e o conjunto preso à base da máquina universal de ensaio. Aplicava-se, em seguida, a sobrecarga através de ar comprimido. Finalmente, a geogrelha era fixada à garra de tração. Cuidados eram tomados para protegê-la contra eventuais danos no aperto da garra. A Figura 53 e 54 ilustram a garra utilizada para o ensaio e uma vista frontal do equipamento montado para a execução de um ensaio. 


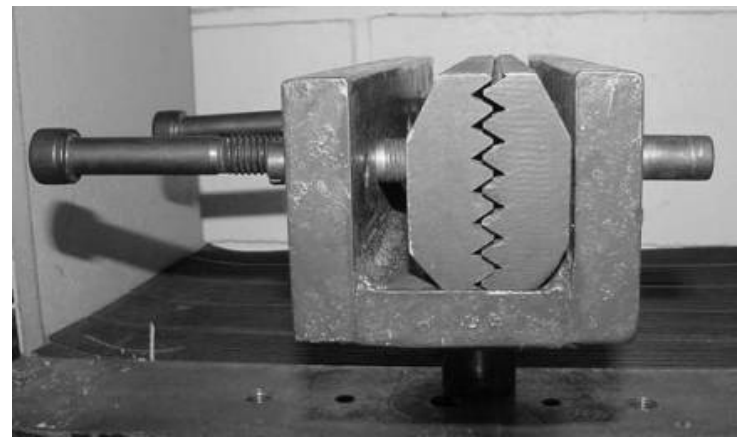

(a)

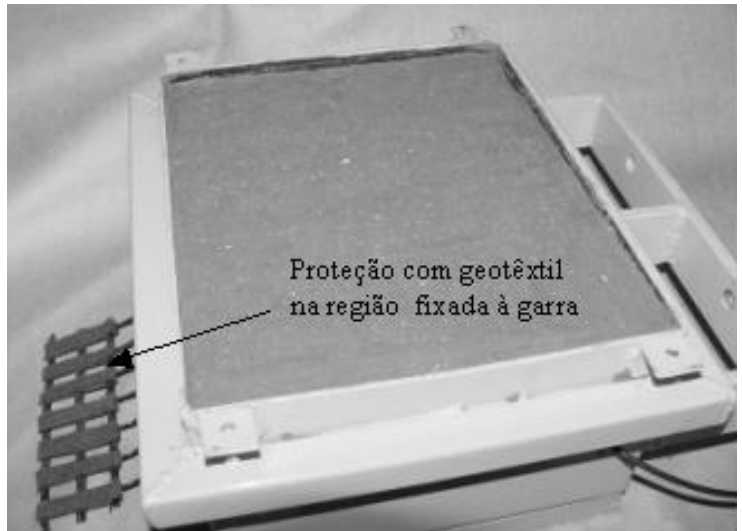

(b)

Figura 53 - (a) garra de fixação da geogrelha; (b) detalhe da proteção dos elementos de geogrelha com tiras de geotêxteis.

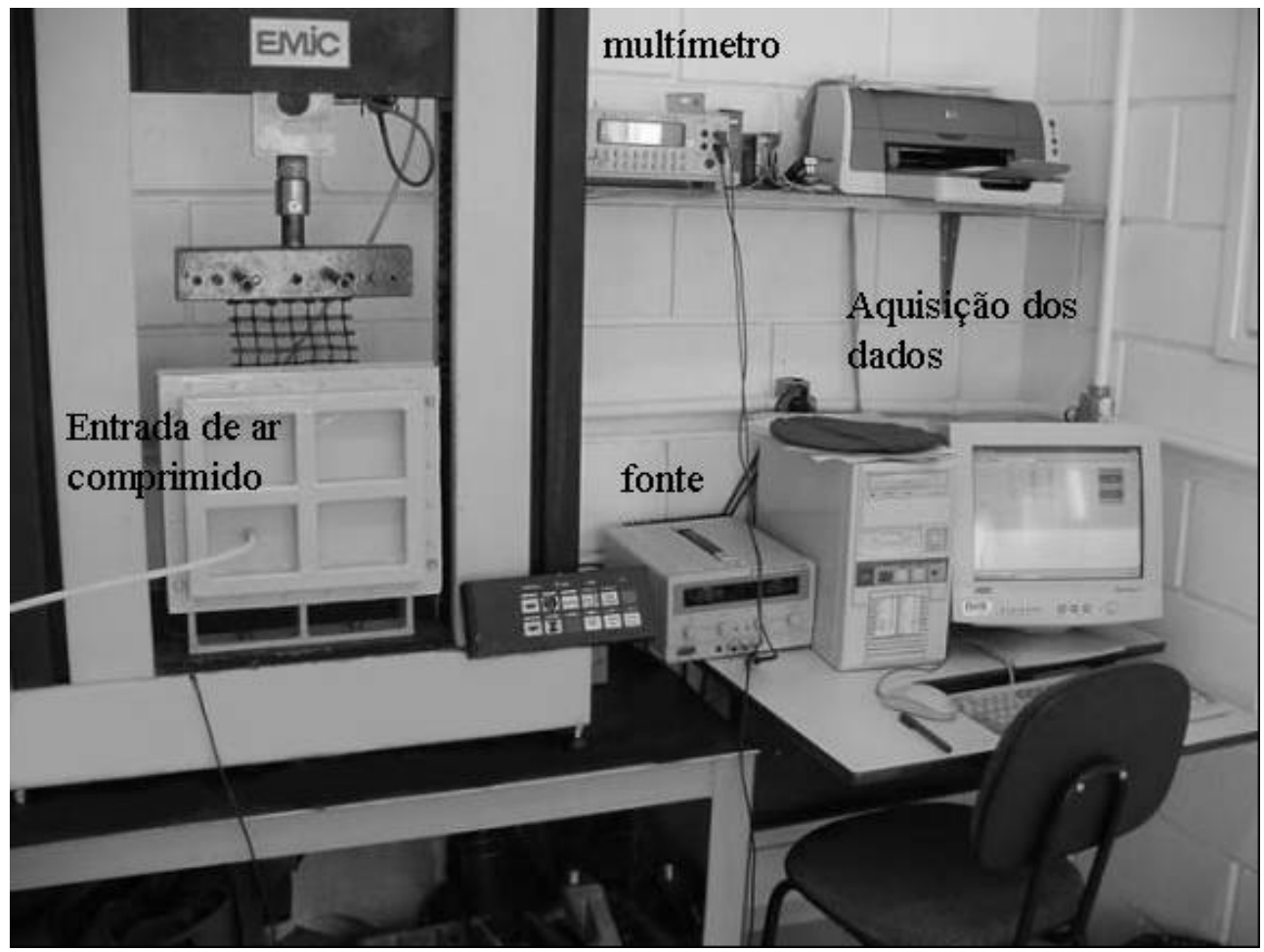

Figura 54 - Vista geral do equipamento de arrancamento durante a execução do ensaio.

e) Execução do ensaio.

Durante a execução dos ensaios, as variáveis de tempo, força resistente ao arrancamento e deslocamento foram armazenados em computador. Os dados de resposta da célula de tensão total foram anotados manualmente, através da leitura de um multímetro feita simultaneamente às de deslocamentos, a fim de correlacioná-los. A 
Figura 55 ilustra, em detalhe, a região frontal da caixa de arrancamento durante o andamento do ensaio.

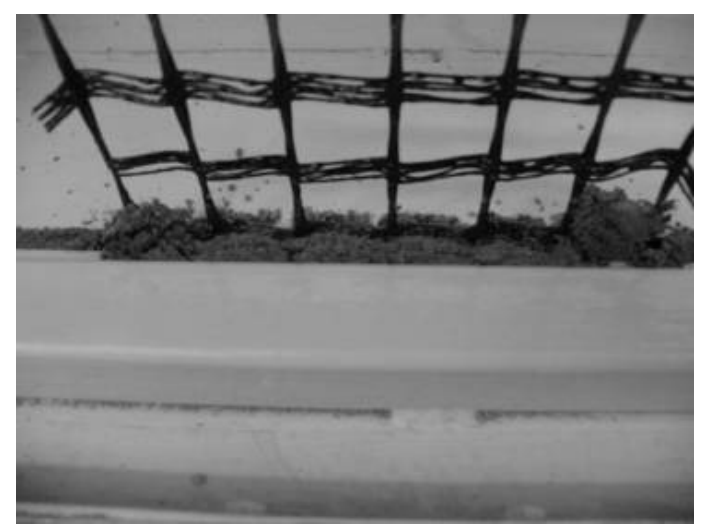

Figura 55 - Execução do ensaio de arrancamento. 


\section{CAPÍTULO 4}

\section{ENSAIOS REALIZADOS E ANÁLISES DOS RESULTADOS}

\subsection{Introdução}

Neste capítulo estão apresentados os resultados obtidos dos ensaios de arrancamento com utilização de equipamento de pequeno porte. As análises dos resultados compreendem-se em três etapas. Na primeira etapa procedeu-se a calibração do equipamento visando obter a repetitividade de resultados e o conseqüente coeficiente de interação. Na segunda etapa verificou-se a eficiência do equipamento através da comparação com resultados obtidos de ensaios em equipamentos de grandes dimensões. Nesta etapa, definiu-se ainda o tamanho aconselhável de amostra a ser utilizada nos ensaios. E na terceira etapa realizou-se uma ampla análise paramétrica de resultados de ensaios, em que variou a sobrecarga, a velocidade de ensaio, o tipo de solo, o grau de compactação e as características geométricas da inclusão.

A premissa básica deste trabalho para a execução de ensaios de arrancamento com equipamento de dimensões reduzidas foi a utilização de solos de granulometria fina, ou seja, aqueles que apresentam $\mathrm{D}_{50}$ entre 0,065 a $0,250 \mathrm{~mm}$. Tais materiais são encontrados em abundância no município de São Carlos-SP e geogrelhas com abertura de malha em torno de $20 \mathrm{~mm}$. Estas geogrelhas são denominadas geogrelhas de malha densa. 


\subsection{Viabilização do uso do equipamento de pequeno porte}

4.2.1. Variabilidade dos resultados de ensaios de arrancamento realizados com equipamento de pequeno porte.

Para efetuar a calibração do equipamento e verificar a variabilidade dos resultados fornecidos, foi elaborado um programa de ensaio, que consistiu de uma série de oito testes com as mesmas características de ensaio. A Tabela 5 apresenta os parâmetros de ensaio utilizados nesta série.

Tabela 5 - Ensaios para verificar a repetição dos resultados de ensaio de arrancamento.

\begin{tabular}{|c|c|c|c|c|c|c|c|}
\hline \multirow[t]{2}{*}{ Identificação } & \multirow{2}{*}{$\begin{array}{c}\text { Geogrelha } \\
\text { (Fortrac) }\end{array}$} & \multirow[t]{2}{*}{ Solo } & \multirow{2}{*}{$\begin{array}{c}\text { Sobrecarga } \\
(\mathrm{kPa})\end{array}$} & \multirow{2}{*}{$\begin{array}{c}\text { Velocidade } \\
\text { de ensaio } \\
(\mathrm{mm} / \mathrm{min})\end{array}$} & \multirow{2}{*}{$\begin{array}{l}\text { G.C. } \\
(\%)\end{array}$} & \multicolumn{2}{|c|}{$\begin{array}{c}\text { Quantidade de } \\
\text { elementos }\end{array}$} \\
\hline & & & & & & longit. & transv. \\
\hline Teste 1 a 8 & $55 / 30-20$ & 3 & 40 & 4,6 & 96 & 7 & 7 \\
\hline
\end{tabular}

A Figura 56 ilustra os resultados de ensaios realizados nesta série de ensaios através das curvas de deslocamento vs. força de arrancamento.

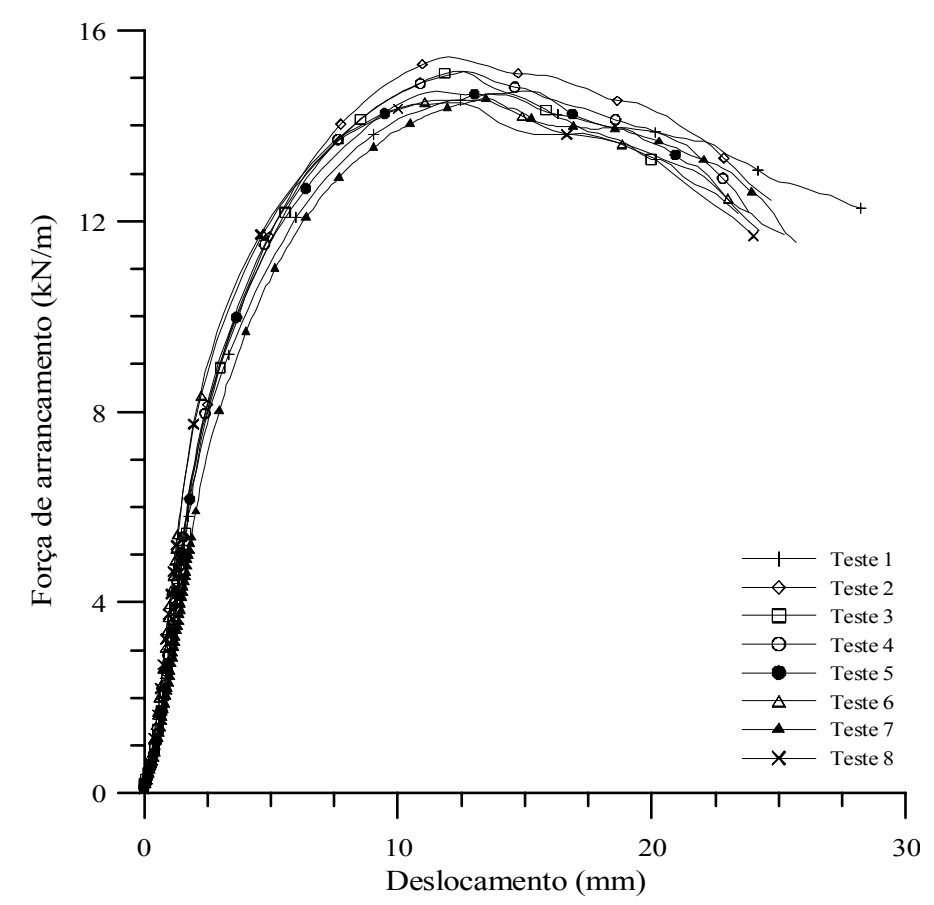

Figura 56 - Curvas de deslocamento vs. força de arrancamento obtidas de ensaios realizados para verificar a variabilidade dos resultados de ensaios. 
Nota-se que as curvas ilustradas na Figura 56 apresentam uma grande similaridade tanto no que concerne ao deslocamento quanto à força de arrancamento de pico.

A Tabela 6 apresenta os resultados das forças máximas de arrancamento e respectivos deslocamentos. A partir destes resultados obtiveram-se a média e o desvio padrão e o coeficiente de variação de ambos os parâmetros.

Tabela 6 - Valor de força de arrancamento e deslocamento no ponto de pico de carregamento.

\begin{tabular}{ccc}
\hline Identificação & Força de arrancamento $(\mathbf{k N} / \mathbf{m})$ & Deslocamento $(\mathbf{m m})$ \\
\hline Teste 1 & 14,66 & 13,49 \\
Teste 2 & 15,44 & 11,82 \\
Teste 3 & 15,15 & 12,27 \\
Teste 4 & 15,13 & 12,63 \\
Teste 5 & 14,72 & 11,55 \\
Teste 6 & 14,54 & 11,79 \\
Teste 7 & 14,56 & 13,47 \\
Teste 8 & 14,47 & 12,27 \\
Média & 14,83 & 12,41 \\
Desvio Padrão & 0,36 & 0,74 \\
Coeficiente de variação & $2,4(\%)$ & $6,0(\%)$ \\
\hline
\end{tabular}

As médias das leituras de tensões normais, registradas pela célula de tensão total durante o andamento dos ensaios, estão apresentadas na Figura 57 por intermédio das curvas de deslocamento vs. média da tensão normal. A célula foi posicionada a uma distancia de aproximadamente um centímetro da inclusão.

Observa-se que os valores, de tensão normal, obtidos na célula durante a execução do ensaio não são constantes. Como a sobre-pressão aplicada na superfície da caixa de teste mantém-se constante e igual a $40 \mathrm{kPa}$, essas oscilações apresentadas nas leituras são devidas à ação dos elementos transversais, que à medida que se deslocam promovem um fluxo de solo no processo de cisalhamento cujas oscilações são registradas pelo transdutor. Teixeira (2003) ao medir tensões similares conclui que as tensões totais no solo próximo da inclusão podem diferir bastante da sobrecarga 
aplicada durante o ensaio devido a dilatância impedida do solo e que esse fenômeno é fortemente influenciado pela presença dos elementos transversais da geogrelha.

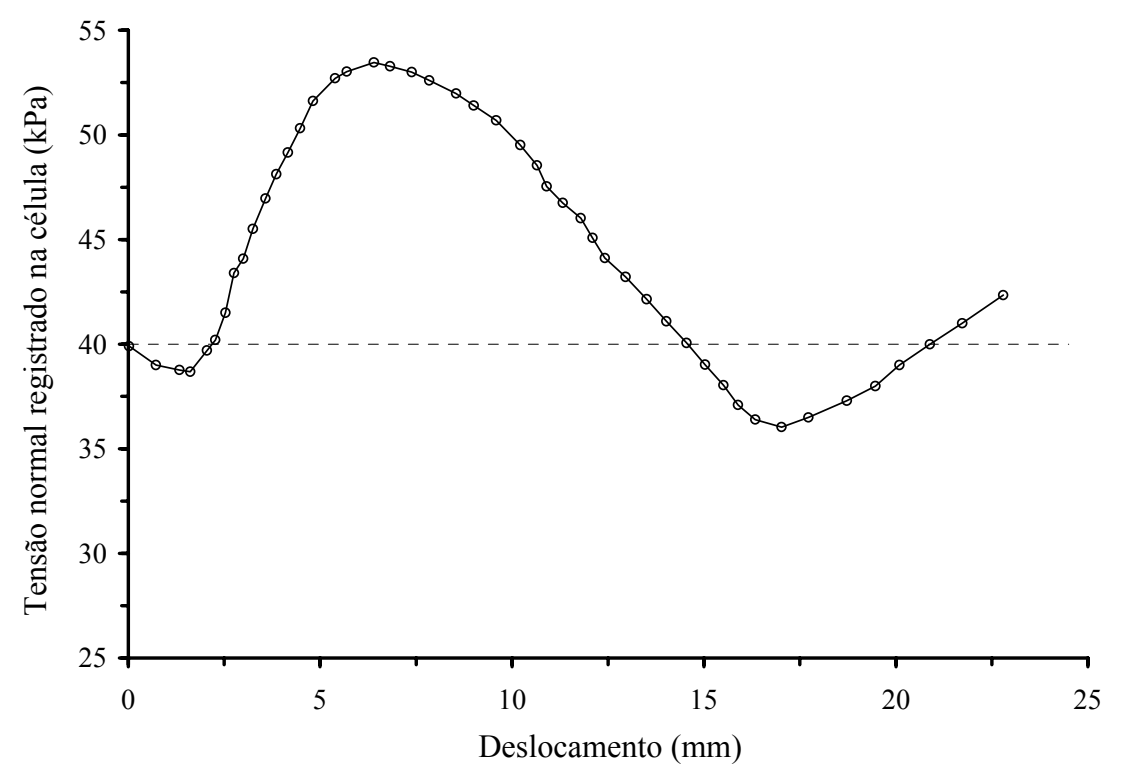

Figura 57 - Média das leituras de tensão normal, registradas pela célula, dos testes 1 a 8.

Através desta série de ensaios verificou-se que o equipamento fornece resultados de força de arrancamento e de deslocamento, com coeficiente de variação de apenas 2,4 e $6,0 \%$, respectivamente.

Uma série complementar de testes foi realizada para certificar a pequena variação da força de arrancamento obtida nos ensaios executados com o equipamento reduzido. A configuração dos quatro teste que constitui essa série de ensaio, são apresentadas na Tabela 7. As principais modificações em relação à série anterior foram o modelo de geogrelha, o tipo de solo e a direção da aplicação da força de arrancamento que, somente nesta série, foi feita no sentido dos elementos transversais.

Tabela 7 - Serie complementar de ensaios de arrancamento para averiguar a variabilidade dos resultados de força de arrancamento e deslocamento no ponto de pico.

\begin{tabular}{llcccccc}
\hline Identificação & Geogrelha & Solo & $\begin{array}{c}\text { Tensão } \\
\text { confinante } \\
(\mathrm{kPa})\end{array}$ & $\begin{array}{c}\text { Velocidade } \\
\text { de ensaio } \\
(\mathrm{mm} / \mathrm{min})\end{array}$ & $\begin{array}{c}\text { G.C. } \\
(\%)\end{array}$ & \multicolumn{2}{c}{$\begin{array}{c}\text { Quantidade de } \\
\text { elementos }\end{array}$} \\
& transv. & longit.. \\
\hline Teste 9 a 12 & $35 / 30-20$ & 1 & 40 & 4,6 & 96 & 7 & 9 \\
\hline
\end{tabular}


A Figura 58 apresenta o gráfico de deslocamento $v s$. força de arrancamento dos testes apresentados na Tabela 7. Os resultados obtidos dos ensaios estão apresentados na Tabela 8 , em que se pode perceber que os valores médios da força máxima de arrancamento e deslocamento atingiram $2974,7 \mathrm{~N}$ e $28,16 \mathrm{~mm}$, respectivamente.

Tabela 8 - Valor de força de arrancamento e deslocamento no ponto de pico de carregamento.

\begin{tabular}{ccc}
\hline Identificação & Força de arrancamento $(\mathbf{k N} / \mathbf{m})$ & Deslocamento $(\mathbf{m m})$ \\
\hline Teste 9 & 18,56 & 28,32 \\
Teste 10 & 18,08 & 27,22 \\
Teste 11 & 17,81 & 28,99 \\
Teste 12 & 18,65 & 28,11 \\
Média & 18,27 & 28,16 \\
Desvio Padrão & 0,35 & 0,73 \\
Coeficiente de variação & $1,89(\%)$ & $2,61(\%)$ \\
\hline
\end{tabular}

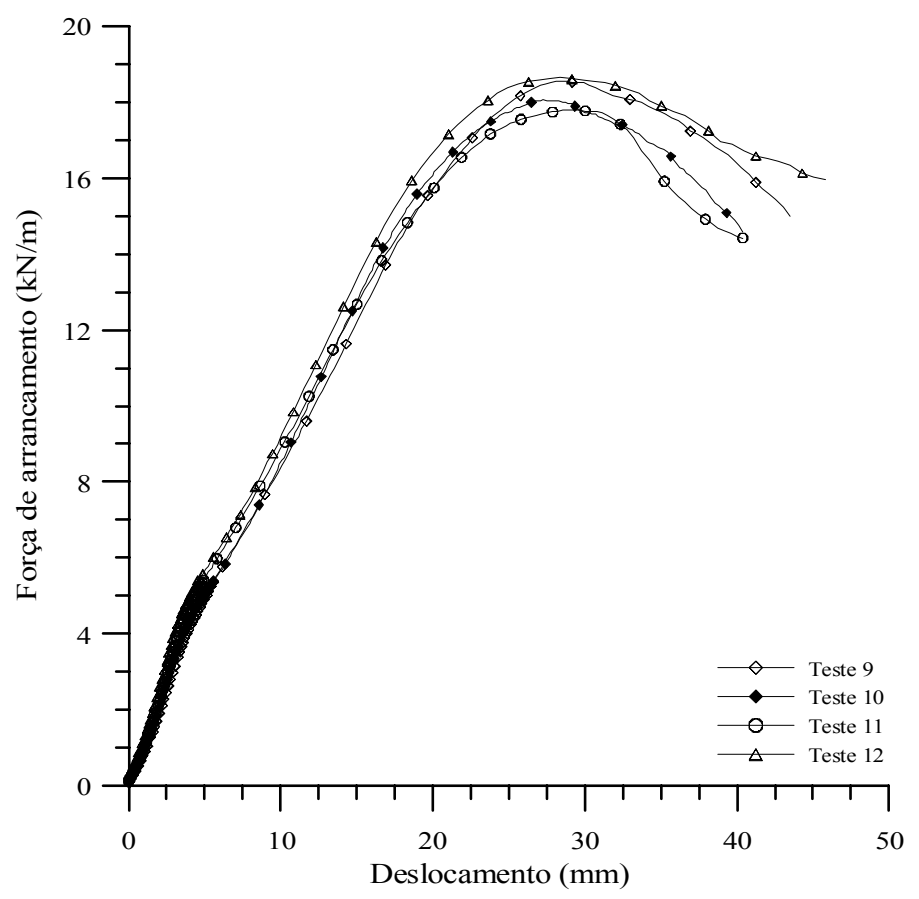

Figura 58 - Repetição do ensaio de arrancamento com a utilização do solo 1 e geogrelha1.

O valor de coeficiente de variação atingiu apenas $1,9 \%$ para a força de arrancamento e 2,6\% para o deslocamento. Estes resultados mostram assim, mais uma vez, que o equipamento fornece resultados com desvio padrão dentro de um intervalo que pode ser considerado muito bom para ensaios geotécnicos. 
Constatou-se durante a execução dos ensaios realizados nestas duas séries de testes que o teor de umidade do solo não variou mais que $0,1 \%$ do especificado e que o grau de compactação não mais que $0,5 \%$. Para a obtenção do teor de umidade do solo durante a execução dos ensaios foram retiradas três cápsulas de solo em alturas distintas no interior da caixa de arrancamento, sendo esse procedimento repetido em todos os ensaios desta série. O controle do grau de compactação foi realizado através da verificação do peso do conjunto pouco antes do início do ensaio.

\subsection{Efeito da relação entre o tamanho da amostra de geogrelha e a área} interna do equipamento.

O objetivo desta etapa do estudo foi definir qual a relação entre o tamanho mínimo do corpo-de-prova e a área interna do equipamento utilizado. Isto permitiu definir qual o número mínimo de células unitárias (entendendo-se como célula unitária o conjunto de elementos longitudinais e transversais) a partir do qual o ensaio não é mais afetado pelas dimensões do corpo de prova.

Os parâmetros dos ensaios e a força máxima de arrancamento estão apresentados na Tabela 9. Observa-se dos valores de força de arrancamento que o aumento do número de elementos longitudinais, que traduz a largura do corpo de prova, provocou uma redução da força de arrancamento para quantidades entre 2 a 10 elementos longitudinais. A partir desta quantidade, os valores de força de arrancamento tenderam a uma constante.

Tabela 9 - Série de ensaios para avaliar a largura ideal dos corpos-de-prova.

\begin{tabular}{ccccccccc}
\hline Ident. & Geog. & Solo & Sobrecarga & Vel. & G.C. & \multicolumn{2}{c}{$\begin{array}{l}\text { Quant. de } \\
\text { elementos }\end{array}$} & $\begin{array}{c}\text { Força de } \\
\text { arranc. }\end{array}$ \\
& (Fortrac) & & $(\mathrm{kPa})$ & $(\mathrm{mm} / \mathrm{min})$ & $(\%)$ & transv. & longit. & $(\mathrm{kN} / \mathrm{m})$ \\
\hline Teste 13 & $55 / 30-20$ & 5 & 40 & 4,6 & 96 & 7 & 3 & 18,15 \\
Teste 14 & $55 / 30-20$ & 5 & 40 & 4,6 & 96 & 7 & 4 & 17,36 \\
Teste 15 & $55 / 30-20$ & 5 & 40 & 4,6 & 96 & 7 & 5 & 17,03 \\
Teste 16 & $55 / 30-20$ & 5 & 40 & 4,6 & 96 & 7 & 6 & 16,44 \\
Teste 17 & $55 / 30-20$ & 5 & 40 & 4,6 & 96 & 7 & 7 & 15,71 \\
Teste 18 & $55 / 30-20$ & 5 & 40 & 4,6 & 96 & 7 & 8 & 15,35 \\
\hline
\end{tabular}




\begin{tabular}{ccccccccc}
\hline Ident. & Geog. & Solo & Sobrecarga & Vel. & G.C. & \multicolumn{2}{c}{ Quant. de } & Força de \\
elementos & arranc. & anc \\
& $($ Fortrac $)$ & & $(\mathrm{kPa})$ & $(\mathrm{mm} / \mathrm{min})$ & $(\%)$ & transv. & longit. & $(\mathrm{kN} / \mathrm{m})$ \\
\hline Teste 19 & $55 / 30-20$ & 5 & 40 & 4,6 & 96 & 7 & 9 & 15,29 \\
Teste 20 & $55 / 30-20$ & 5 & 40 & 4,6 & 96 & 7 & 10 & 15,05 \\
Teste 21 & $55 / 30-20$ & 5 & 40 & 4,6 & 96 & 7 & 11 & 15,01 \\
Teste 22 & $55 / 30-20$ & 5 & 40 & 4,6 & 96 & 7 & 12 & 15,01 \\
\hline
\end{tabular}

A Figura 59 apresenta os valores de força de arrancamento em função da largura do corpo de prova.

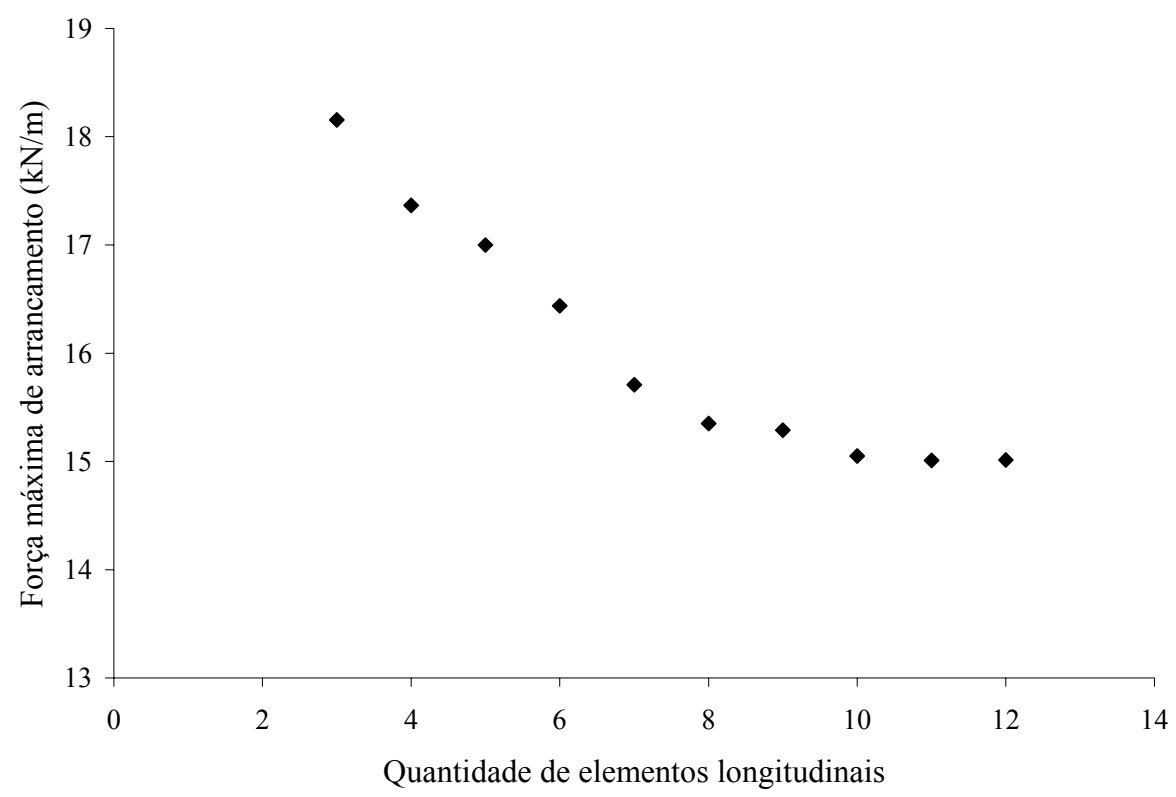

Figura 59 - Quantidade de elementos longitudinais vs. tensão máxima de arrancamento.

Com base nos resultados de ensaios apresentados na Figura 59, observa-se que para o equipamento em estudo, à medida que a largura da amostra aproxima-se da dimensão interna da caixa, a força de arrancamento tende a um valor constante. Para as geogrelhas analisadas, aconselha-se a utilização de amostra constituída de doze elementos longitudinais. Desta forma, busca-se uma configuração que mais aproxime de um estado plano de tensão, ou seja, com largura de $0,3 \mathrm{~m}$. Esta largura foi também empregada por Sugimoto (2001) que realizou uma série de ensaios de arrancamento com equipamento de dimensões reduzidas para verificar o efeito da rigidez da face frontal no comportamento da força de arrancamento de uma geogrelha inserida em 
areia. Em seus ensaios o autor utilizou, também, amostra com largura equivalente à dimensão interna do equipamento, cujas dimensões internas eram $0,68 \mathrm{~m}$ de comprimento, $0,3 \mathrm{~m}$ de largura e 0,625 de altura.

Alguns detalhes da montagem do ensaio devem ser cuidadosamente tomados, dentre eles a perfeita lubrificação das paredes internas da caixa, e a correta fixação da amostra na garra, de forma que as força sejam distribuídas uniformemente entre os elementos longitudinais.

$\mathrm{Na}$ análise do efeito do comprimento da amostra de geogrelha nos resultados dos ensaios de arrancamento, foram realizados mais cinco testes (teste 23, 24, 25, 26 e 27). Os parâmetros de ensaio estão apresentados na Tabela 10.

Nesta série de testes, buscou-se analisar o efeito do comprimento da amostra na força resistente ao arrancamento, para isso, foram realizados ensaios com amostra de largura respectiva a 8 e 12 elementos longitudinais. O coeficiente de variação da tensão de arrancamento obtido foi de 3,6\% e 0,57\% , respectivamente. Mostrando que o comprimento do corpo de prova, praticamente não afetou os valores de tensão de arrancamento.

A Figura 60 (a) e (b) apresenta as curvas força de arrancamento vs. deslocamento para os testes apresentados na Tabela 10, sendo (a) testes realizados com oito elementos longitudinais (testes 23, 24, 25 e 18) e (b) com doze elementos (testes $22,26$ e 27$)$.

Tabela 10 - Série de ensaios para avaliação do comprimento ideal dos corpos-de-prova.

\begin{tabular}{|c|c|c|c|c|c|c|c|}
\hline \multirow[t]{2}{*}{ Identificação } & \multirow{2}{*}{$\begin{array}{c}\text { Geogrelha } \\
\text { (Fortrac) }\end{array}$} & \multirow[t]{2}{*}{ Solo } & \multirow{2}{*}{$\begin{array}{c}\text { Tensão } \\
\text { confinante } \\
(\mathrm{kPa})\end{array}$} & \multirow{2}{*}{$\begin{array}{c}\text { Velocidade } \\
\text { de ensaio } \\
(\mathrm{mm} / \mathrm{min})\end{array}$} & \multirow{2}{*}{$\begin{array}{l}\text { G.C. } \\
(\%)\end{array}$} & \multicolumn{2}{|c|}{$\begin{array}{c}\text { Quantidade de } \\
\text { elementos }\end{array}$} \\
\hline & & & & & & transv. & longit.. \\
\hline Teste 23 & $55 / 30-20$ & 5 & 40 & 4,6 & 96 & 4 & 8 \\
\hline Teste 24 & $55 / 30-20$ & 5 & 40 & 4,6 & 96 & 5 & 8 \\
\hline Teste 25 & $55 / 30-20$ & 5 & 40 & 4,6 & 96 & 6 & 8 \\
\hline Teste 18 & $55 / 30-20$ & 5 & 40 & 4,6 & 96 & 7 & 8 \\
\hline Teste 22 & $55 / 30-20$ & 5 & 40 & 4,6 & 96 & 7 & 12 \\
\hline Teste 26 & $55 / 30-20$ & 5 & 40 & 4,6 & 96 & 8 & 12 \\
\hline Teste 27 & $55 / 30-20$ & 5 & 40 & 4,6 & 96 & 9 & 12 \\
\hline
\end{tabular}


A Tabela 11 apresenta os resultados de força e tensão de arrancamento utilizados para a elaboração da Figura 61 (a) e (b), adicionalmente apresenta a média aritmética, o coeficiente de variação e a dispersão de tensão de arrancamento em relação à média do conjunto.

Tabela 11 - Força e tensão de arrancamento para amostra com variação no comprimento da amostra ( $n^{0}$ de elementos transversais).

\begin{tabular}{|c|c|c|c|c|c|}
\hline \multirow[t]{2}{*}{ Identificação } & \multicolumn{2}{|c|}{$\begin{array}{c}\text { Quantidade de } \\
\text { elementos }\end{array}$} & \multirow{2}{*}{$\begin{array}{c}\text { Força de } \\
\text { arrancamento } \\
(\mathrm{kN} / \mathrm{m})\end{array}$} & \multicolumn{2}{|c|}{$\begin{array}{c}\text { Tensão de } \\
\text { arrancamento }\end{array}$} \\
\hline & longit. & transv. & & $(\mathrm{kPa})$ & Dispersão (\%) \\
\hline Teste 23 & 8 & 4 & 8,46 & 43,19 & $-1,76$ \\
\hline Teste 24 & 8 & 5 & 11,19 & 45,71 & 3,97 \\
\hline Teste 25 & 8 & 6 & 12,39 & 42,18 & $-4,06$ \\
\hline Teste 18 & 8 & 7 & 15,35 & 44,78 & 1,85 \\
\hline Média & & & & 43,97 & \\
\hline coef. de variação & & & & $3,60(\%)$ & \\
\hline Teste 22 & 12 & 7 & 15,01 & 44,41 & 0,84 \\
\hline Teste 26 & 12 & 8 & 16,58 & 43,93 & $-0,69$ \\
\hline Teste 27 & 12 & 9 & 18,85 & 43,38 & $-0,24$ \\
\hline Média & & & & 43,57 & \\
\hline coef. de variação & & & & $0,57(\%)$ & \\
\hline
\end{tabular}

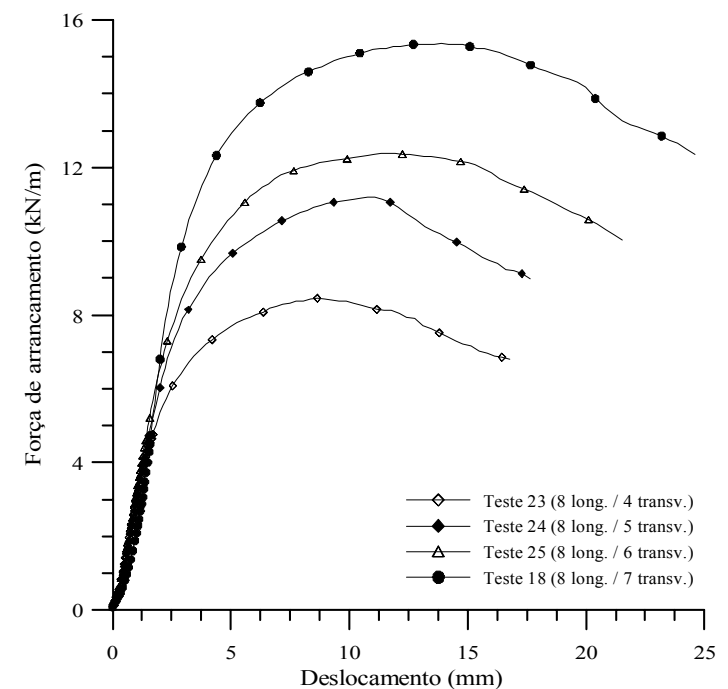

(a)

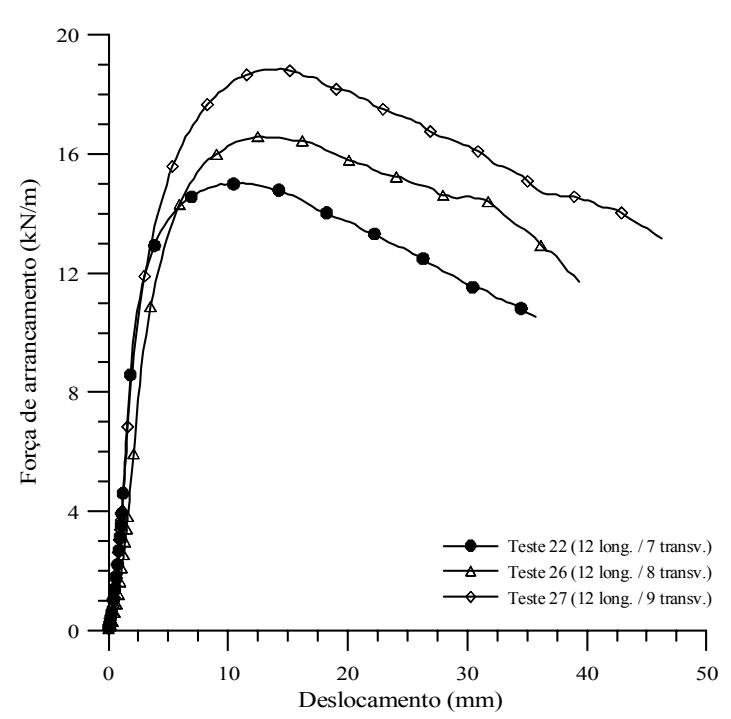

(b)

Figura 60 - Testes realizados com diferentes comprimento de amostra de geogrelha. 
Na Figura 61 (a) e (b) ilustra os resultados de tensão de arrancamento vs. a quantidade de elementos transversais de geogrelha referente as larguras fixadas em $8 \mathrm{e}$ 12 elementos longitudinais.

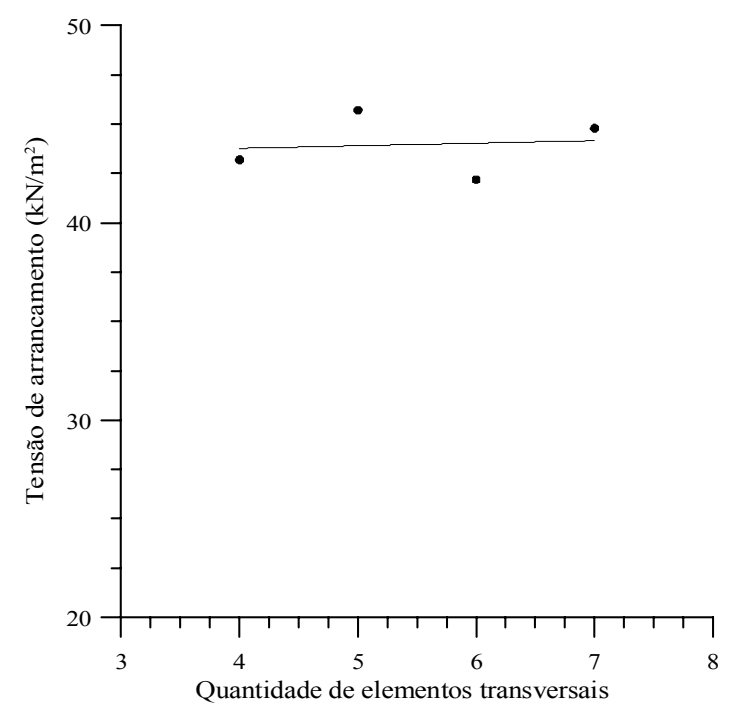

(a)

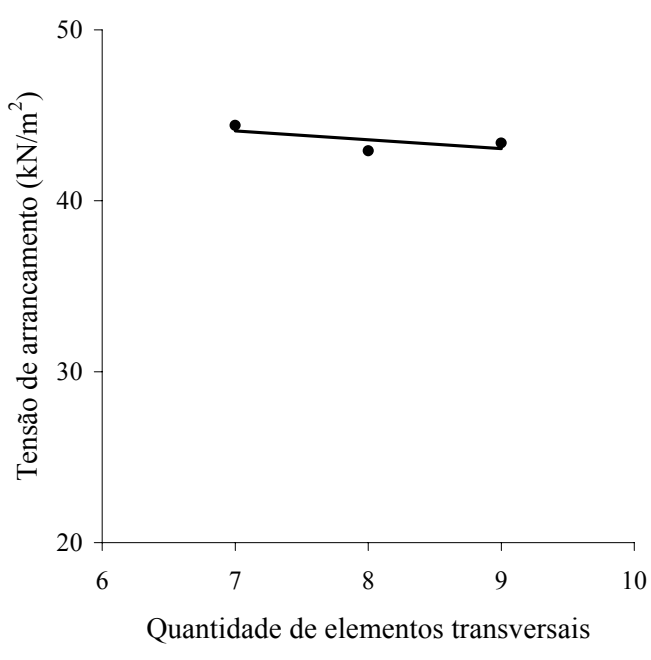

(b)

Figura 61 - Variação da quantidade de elementos transversais: (a) fixando 8 elementos longitudinais; (b) fixando 12 elementos longitudinais.

Conclui-se, dos resultados apresentados neste item, que a largura da amostra de geogrelha aconselhável para a execução do ensaio de arrancamento com a utilização deste equipamento proposto deve ser de $30 \mathrm{~cm}$. Para as geogrelhas do modelo Fortrac 35/20-20, 55/30-20 e 110/30-20, aconselha-se a utilização de doze elementos longitudinais. Quanto ao comprimento da amostra inserida no interior da caixa de arrancamento, apesar dos ensaios realizados mostrarem que a quantidade de elementos transversais pouco afeta os resultados da tensão de arrancamento, recomenda-se a utilização de um comprimento que se aproxime de vinte e cinco centímetros.

4.4. Verificação da viabilidade de uso do equipamento de pequeno porte para registro da força de arrancamento de geogrelha.

Para avaliar a viabilidade de uso do ensaio de pequeno porte na reprodução de resultados obtidos por equipamentos de grandes dimensões, foram realizados seis ensaios de forma a manter as mesmas condições dos ensaios realizados por Teixeira 
(2003), que utilizou um equipamento de $700 \mathrm{~mm}$ de largura, $1500 \mathrm{~mm}$ de comprimento e $480 \mathrm{~mm}$ de altura. Os resultados dos ensaios estão apresentados na Tabela 12.

Na Tabela 12, S1, S2 e S3 identificam os ensaios realizados por Teixeira (2003) em caixa de arrancamento de grandes dimensões e teste 28, 29, 30, 31, 32 e 33 são os ensaios executados com equipamento de pequenas dimensões. Estes ensaios seguiram rigorosamente as mesmas condições dos ensaios de grande porte. As amostras de geogrelha para os testes 28,29 e 30 são menores que as utilizadas nos testes 31,32 e 33 . O solo utilizado nesta série de ensaio foi o identificado como solo $b$, a geogrelha foi do modelo Fortrac110/30-20 e a velocidade de ensaio de arrancamento foi de 4,6 $\mathrm{mm} / \mathrm{min}$.

Tabela 12 - Características gerais do ensaios de arrancamento executados para comparar os equipamentos de grande e pequena dimensão, utilizando a geogrelha 110/30-20.

\begin{tabular}{lcccccccc}
\hline Equipamentos & Identificação & $\boldsymbol{\sigma}$ & $\mathbf{G ~ C}$ & $\boldsymbol{l}$ & \multicolumn{2}{c}{ Elementos } & $\tau_{\text {arr.max }}$ & $\boldsymbol{f}^{*}$ \\
& & $(\mathrm{kPa})$ & $(\%)$ & $(\mathrm{mm})$ & Long. & Transv. & $(\mathrm{kPa})$ & \\
\hline Pequeno porte & Teste 28 & 25 & 93 & 161 & 8 & 7 & 30,09 & 0,75 \\
Pequeno porte & Teste 29 & 50 & 93 & 161 & 8 & 7 & 38,64 & 0,68 \\
Pequeno porte & Teste 30 & 100 & 93 & 161 & 8 & 7 & 64,16 & 0,71 \\
Pequeno porte & Teste 31 & 25 & 93 & 230 & 12 & 10 & 28,33 & 0,70 \\
Pequeno porte & Teste 32 & 50 & 93 & 230 & 12 & 10 & 38,57 & 0,68 \\
Pequeno porte & Teste 33 & 100 & 93 & 230 & 12 & 10 & 61,29 & 0,68 \\
Grande porte & S1 & 25 & 93 & 600 & - & - & 29,75 & 0,74 \\
Grande porte & S2 & 50 & 93 & 600 & - & - & 36,67 & 0,64 \\
Grande porte & S3 & 100 & 93 & 600 & - & - & 61,58 & 0,68 \\
\hline
\end{tabular}

Nota: tensão normal, $\sigma$, grau de compactação, G.C.; comprimento de geogrelha inserida no solo, $l$; elementos longitudinais, Long.; elementos transversais, Transv.; $\tau_{\text {arr.max }}$ é a tensão máxima de arrancamento, e $f^{*}$ é o coeficiente de interação $\left(\tau_{\operatorname{arr} . \max } / c+\sigma . \operatorname{tg} \phi\right)$.

Comparando os resultados das tensões de arrancamento obtidos nos ensaios realizados neste trabalho com os de Teixeira (2003), observa-se que as tensões de arrancamento apresentaram valores muito próximos. E a diferença do coeficiente de interação para as diferentes sobrecargas é da mesma ordem de grandeza da encontrada no estudo de variabilidade dos resultados fornecido pelo equipamento de pequeno porte. Logo, entende-se que as diferenças observadas estão dentro do intervalo de dispersão dos resultados de ambos os equipamentos. 
Nesta série de ensaios, também se pode constatar uma variação na tensão de arrancamento para os testes realizados com amostras de tamanho diferente, conforme apresentado no item anterior.

A Figura 62 (a) apresenta duas envoltórias de resistência de interface sologeogrelha obtidas de ensaio de arrancamento de pequeno porte, sendo que a envoltória que apresentou maior adesão e angulo de atrito de interface solo-geogrelha foi a obtida dos testes realizados com amostras de 8 elementos longitudinais. A Figura 62 (b) ilustra a envoltória de interface solo-geogrelha obtidas de ensaios de arrancamento com equipamento de grande porte.

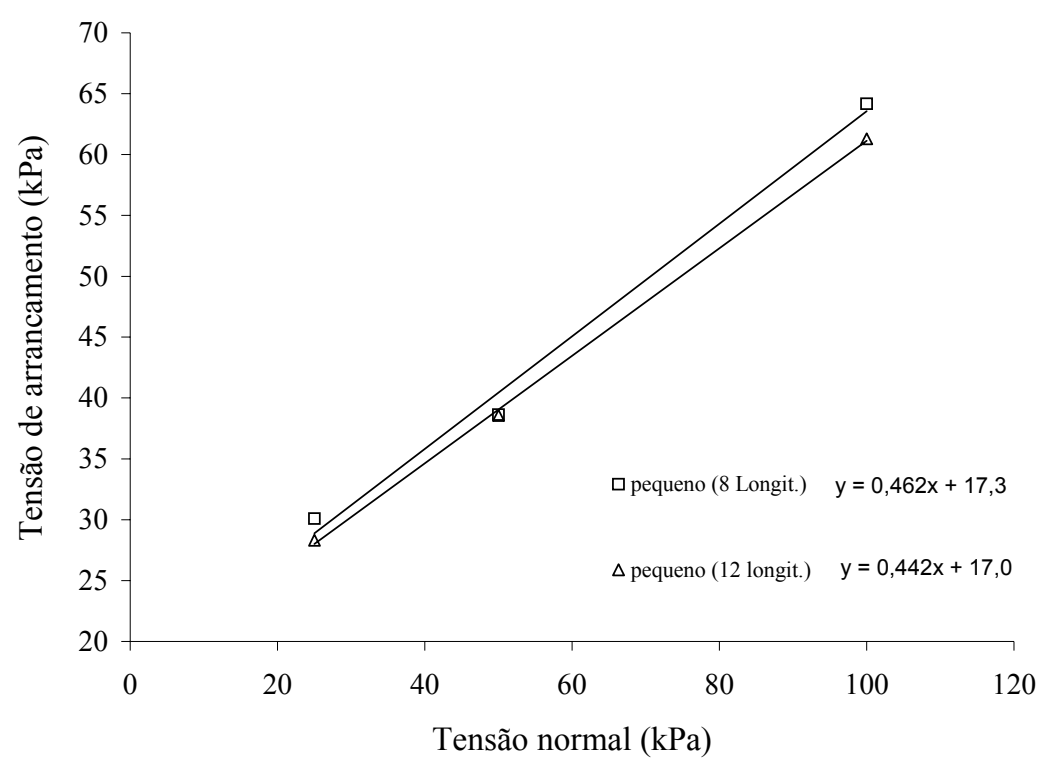

(a)

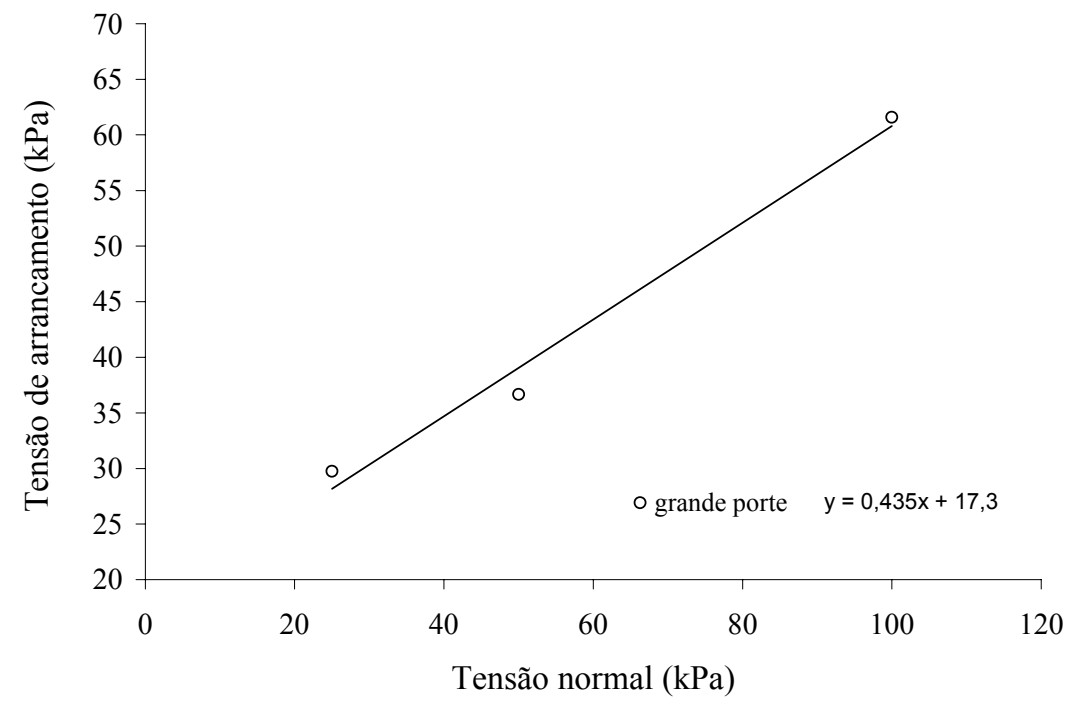

(b)

Figura 62 - Envoltórias de interface solo-geogrelha em termos de tensões totais: (a) utilizando equipamento de pequeno porte; (b) utilizando equipamento de grande porte. 
A partir destes resultados pode-se calcular os parâmetros $\lambda$ e $f$ :

$$
\begin{gathered}
\lambda=a / c \\
f=\operatorname{tg} \delta / \operatorname{tg} \phi
\end{gathered}
$$

Nestas expressões $c$ e $\phi$ são, respectivamente, a coesão e o ângulo de atrito do solo obtidos a partir do ensaio de cisalhamento direto; $a$ e $\delta$ são, respectivamente, a adesão e o ângulo de atrito de interface obtidos da envoltória de resistência ao arrancamento.

Tabela 13 - Valores obtidos das envoltórias de resistência de interface.

\begin{tabular}{ccccc}
\hline Equipamento & $\boldsymbol{a}$ & $\boldsymbol{\lambda}$ & $\delta$ & $\boldsymbol{f}$ \\
\hline Pequeno porte $\left(^{*}\right)$ & 17,3 & 0.73 & 24,8 & 0.70 \\
Pequeno porte $\left(^{* *}\right)$ & 17,0 & 0,71 & 23,9 & 0,67 \\
Grande porte & 17,3 & 0.73 & 23,5 & 0.66 \\
\hline
\end{tabular}

Nota: $(*)$ refere-se a ensaios realizados com amostra contendo 8 elementos longitudinais; $\left({ }^{* *}\right)$ contendo 12 elementos.

Pode-se afirmar que os parâmetros $\lambda$ e $\delta$ obtidos dos ensaios de grande e pequeno porte foram praticamente os mesmos, sendo que para os ensaios de pequeno porte executados com amostras de 12 elementos longitudinais a envoltória de interface solo-geogrelha praticamente coincide com a obtida de equipamento de grande porte.

A Figura 63 (a) e (b) apresenta as curvas de deslocamento vs. tensão de arrancamento para as sobrecargas de 25,50 e $100 \mathrm{kPa}$ referentes aos testes de pequeno porte com amostras de 8 e 12 elementos longitudinais, respectivamente. Percebe-se que as curvas ao atingirem a tensão de arrancamento de pico tendem a manter se constante por um determinado deslocamento. 


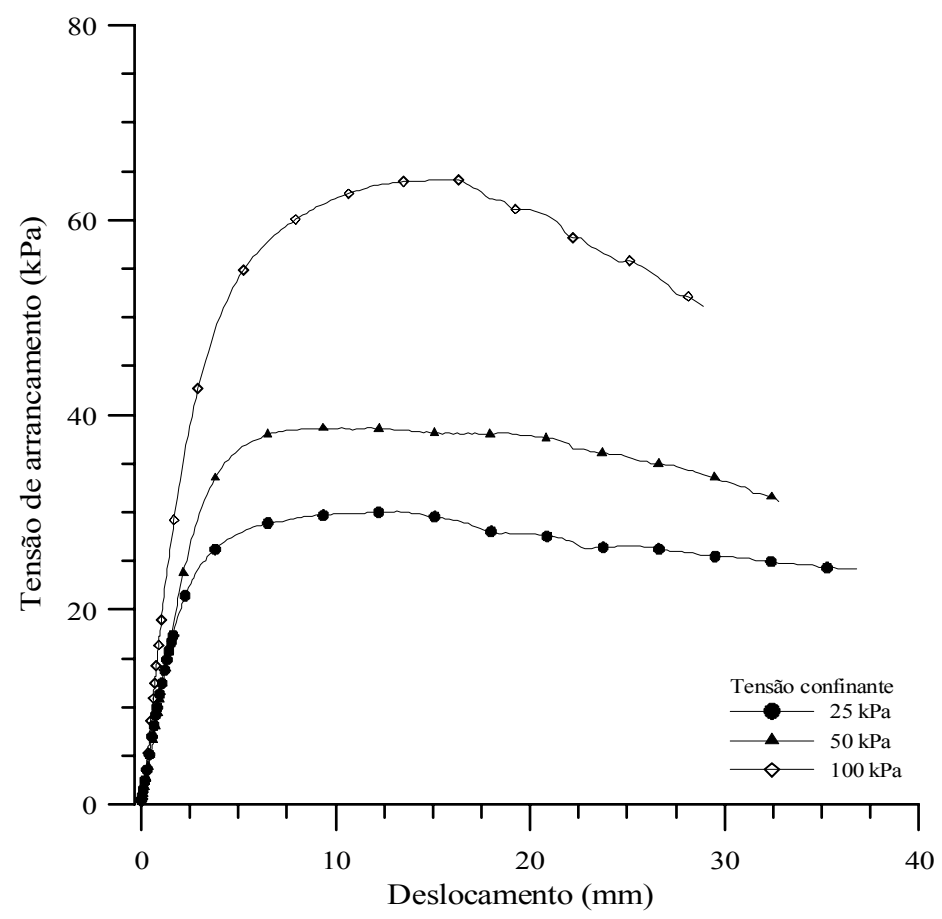

(a)

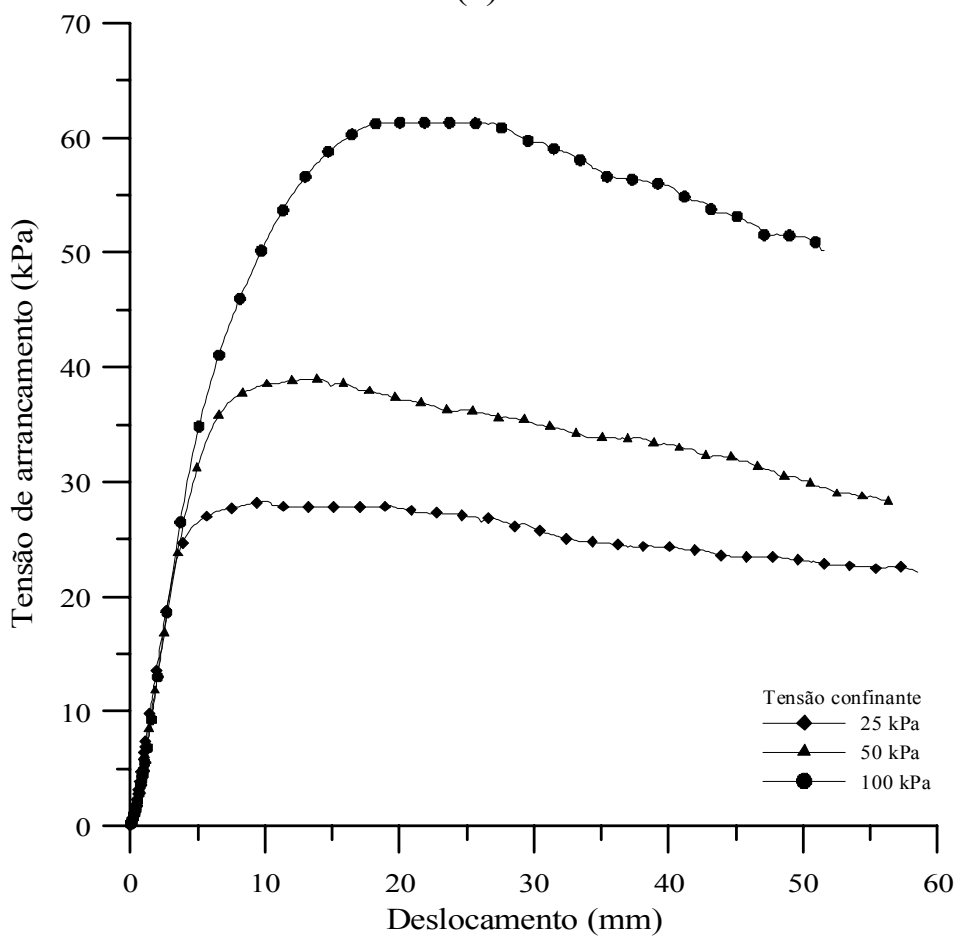

(b)

Figura 63 (a) e (b) - Tensão de arrancamento vs. deslocamento obtido de equipamento de pequeno porte: (a) amostra com 8 elementos e (b) com 12 elementos longitudinais.

A Figura 64 (a) apresenta as oscilações da tensão normal registrada na célula de tensão total durante a execução dos testes 28 a 30 e a Figura 64 (b) os testes 31 a 33. 


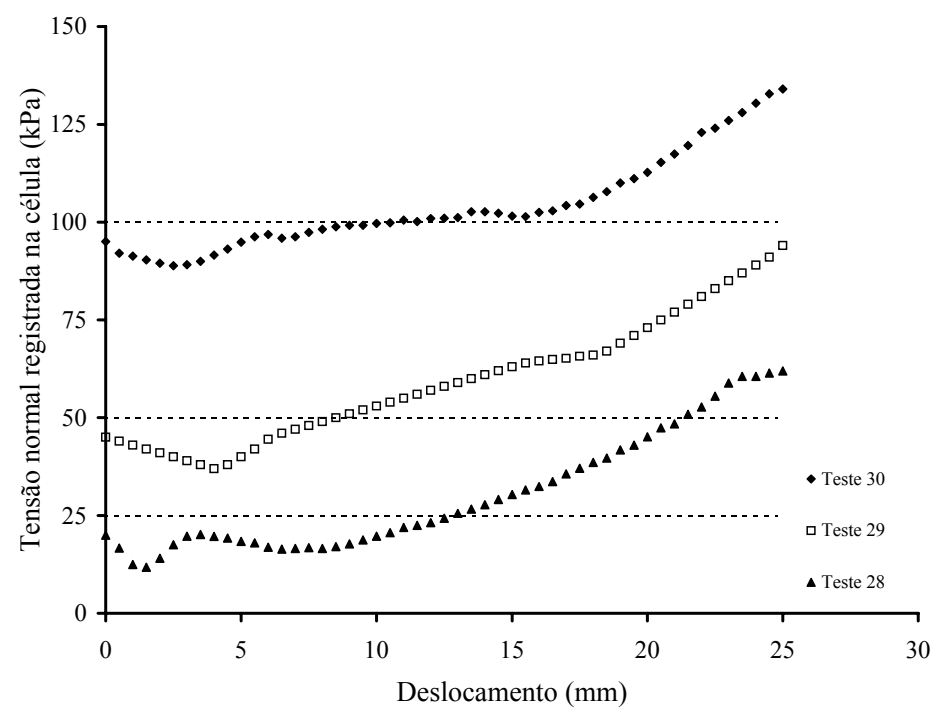

(a)

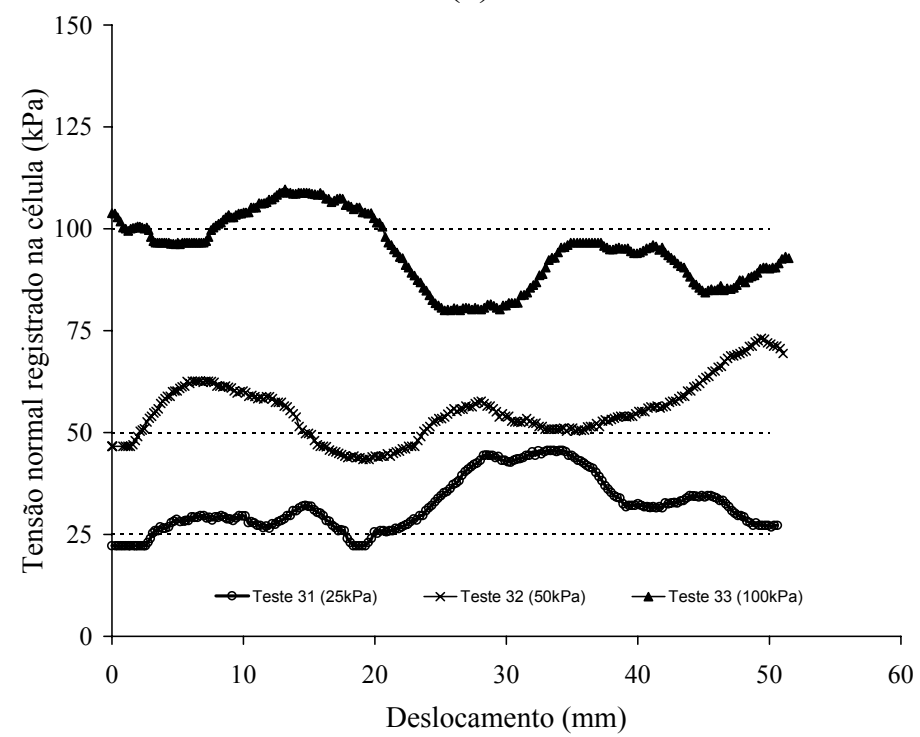

(b)

Figura 64 (a) e (b) - Deslocamento vs leituras da célula de tensão total: (a) resultados dos testes 28, 29 e 30; (b) resultados dos testes 31,32 e 33.

As curvas apresentadas na Figura 64 mostram um comportamento cíclico, em que, os picos de máximos e mínimos atingiram valores distintos das sobrecargas aplicadas. Observa-se que a amplitude dessa oscilação gira em torno de $25 \mathrm{kPa}$ para mais ou para menos nos testes realizados com amostra de 12 elementos, nestes testes manteve-se a leitura da célula por um intervalo maior, após o pico de tensão de arrancamento. No entanto, a média dos valores aproxima do valor da sobrecarga aplicada no solo.

Os resultados de tensão de arrancamento, apresentados na Tabela 12, são ilustrados graficamente na Figura 65 sendo que os resultados dos ensaios de pequeno porte contemplam os dois tamanhos de amostra utilizados. 


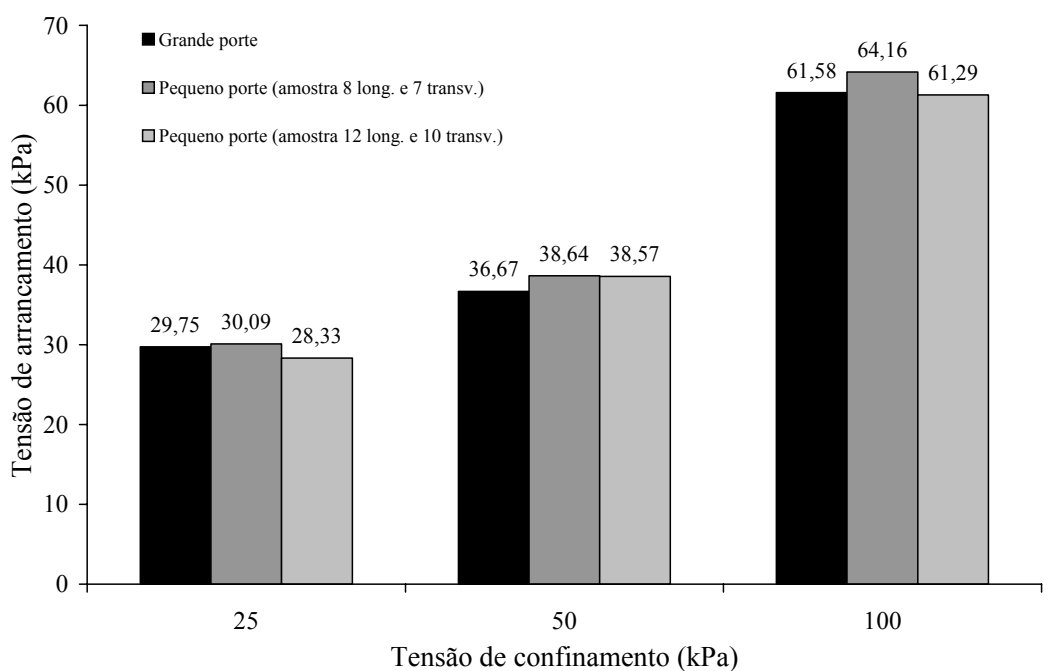

Figura 65 - Comparação das tensões de arrancamento obtidas através de equipamento de grande e pequeno porte.

Observa-se que os resultados de tensão de arrancamento, nas três tensões confinantes analisadas, mantiveram-se muito próximos. As pequenas variações observadas são da mesma ordem de grandeza do erro calculado para o equipamento, como mostra a Tabela 14 .

Tabela 14 - Resumos dos resultados obtidos dos ensaios de pequeno e grande porte e algumas comparações em termo de porcentagem.

\begin{tabular}{|c|c|c|c|c|c|c|c|c|c|}
\hline \multirow{4}{*}{$\begin{array}{c}\text { Sobrecarga } \\
\qquad(\mathrm{kPa})\end{array}$} & \multicolumn{2}{|c|}{$\begin{array}{c}\text { Equipamento } \\
\text { grande }\end{array}$} & \multirow{2}{*}{\multicolumn{3}{|c|}{$\begin{array}{l}\text { Equipamento pequeno } \\
\text { amostra (8L / 7T) } \\
\text { Dispersão em relação }\end{array}$}} & \multirow{2}{*}{\multicolumn{3}{|c|}{$\begin{array}{l}\text { Equipamento pequeno } \\
\text { amostra (12L. / 10T.) } \\
\text { Disnersão em relacão }\end{array}$}} & \multirow{4}{*}{$\begin{array}{l}\text { (*) } \\
(\%)\end{array}$} \\
\hline & \multirow{3}{*}{$\begin{array}{l}\tau_{\text {arr.max }} \\
(\mathrm{kPa})\end{array}$} & \multirow{3}{*}{$f^{*}$} & & & & & & & \\
\hline & & & ao $\tau_{\text {arrm }}$ & cande) & $f^{*}$ & ao $\tau_{a r r m}$ & ande) & \multirow[t]{2}{*}{$f^{*}$} & \\
\hline & & & $(\mathrm{kPa})$ & $(\%)$ & & $(\mathrm{kPa})$ & $(\%)$ & & \\
\hline 25 & 29,75 & 0,74 & 0,34 & 1,1 & 0,75 & $-1,42$ & $-4,8$ & 0,70 & 5,9 \\
\hline 50 & 36,67 & 0,64 & 1,97 & 5,4 & 0,68 & 1,9 & 5,2 & 0,68 & 0,2 \\
\hline 100 & 61,58 & 0,68 & 2,58 & 4,2 & 0,71 & $-0,29$ & $-0,5$ & 0,68 & 4,7 \\
\hline média & & 0,69 & & & 0,71 & & & 0,69 & \\
\hline$a(k P a)$ & 17 & & & 7,3 & & & 0 & & \\
\hline$\delta$ & 23 , & & & $8^{\circ}$ & & & $9^{\circ}$ & & \\
\hline
\end{tabular}

Nota: $\tau_{\text {arr.max }}$ é a tensão máxima de arrancamento; $f^{*}$ é coeficiente de interação $\left(\tau_{\text {arr.max }} / c+\sigma . \operatorname{tg} \phi\right)$; $a$ é a adesão; $\delta$ é o angulo de atrito de interface solo-geogrelha; (*) é a diferença entre a tensão de arrancamento obtida dos resultados de ensaio de pequeno porte com amostra de 8 e 12 elementos longitudinais. 
Comparando os resultados dos testes com amostra de 8 elementos longitudinais com os resultados dos ensaios realizados com equipamento de grande porte, pode-se verificar que o valor de tensão de arrancamento foi superior para as três sobrecargas utilizadas, no entanto o maior acréscimo foi de 5,4\% referente a sobrecarga de $50 \mathrm{kPa}$.

Quando se compara a tensão de arrancamento obtidos dos testes com mostra de 12 elementos longitudinais com o equipamento de grande porte, a maior diferença foi de $5,2 \%$ para sobrecarga de $50 \mathrm{kPa}$. Já para a sobrecarga de $25 \mathrm{kPa}$ a tensão de arrancamento foi inferior e para a de $50 \mathrm{kPa}$ os valores foram praticamente iguais.

A tensão de arrancamento, obtida de ensaio de pequeno porte, reduziu quando foi utilizados amostra com tamanho equivalente as dimensões internas do equipamento, confirmando os resultados apresentados na análise da dimensão da amostra.

A envoltória de interface solo-geogrelha dos testes com amostra de 12 elementos foi a que se aproximou mais da envoltória obtida do equipamento de grande porte, sendo praticamente coincidentes. E, esses três testes apresentaram a menor dispersão do coeficiente de interação para as três sobrecargas testadas e resultando na mesma média obtida dos ensaios de grande porte.

Os resultados obtidos desta análise sugerem que o equipamento de pequeno porte mostra-se adequado para reproduzir os resultados de força de arrancamento e, portanto, os coeficientes de interação medidos no ensaio de grande porte. Com a vantagem de ser um ensaio simples, com baixo custo de execução, de fácil montagem e com um sistema computadorizado de armazenamento de dados. Apresenta esse equipamento ainda, um ganho de tempo excepcional se comparado com o tempo gasto para executar um ensaio de arrancamento em equipamento de grande porte. Durante a realização dos ensaios pode-se notar, que o tempo gasto para cada ensaio de arrancamento foi em média de uma hora e trinta minutos, excetuando o tempo de preparação da amostra do solo (coleta, correção do teor de umidade, etc.).

\subsection{Análise paramétrica experimental com uso do equipamento de pequeno}

porte.

Para avaliar o efeito de aspectos ligados à execução do ensaio e também para aprofundar o conhecimento da influência de parâmetros geotécnicos que afetam os 
valores da força de arrancamento medida, foi realizada uma série de ensaios, cujos resultados serão descritos e analisados a seguir.

\subsubsection{Efeito da velocidade de ensaio na resistência ao arrancamento}

Para avaliar a influência da velocidade do ensaio na magnitude da força de arrancamento, foi realizada uma série de ensaios em que se variou a velocidade, adotando-se valores de $2,0 \mathrm{~mm} / \mathrm{min}, 4,6 \mathrm{~mm} / \mathrm{min}, 8,0 \mathrm{~mm} / \mathrm{min}$ e $100 \mathrm{~mm} / \mathrm{min}$. Os corpos de prova foram preparados de forma a se ter sete elementos transversais e sete longitudinais. As configurações de ensaios utilizadas para essa série estão apresentadas na Tabela 15.

Tabela 15 - Série de ensaios para analisar o efeito da velocidade de ensaio na resistência ao arrancamento.

\begin{tabular}{|c|c|c|c|c|c|c|c|}
\hline \multirow[t]{2}{*}{$\overline{\text { Identificação }}$} & \multirow{2}{*}{$\begin{array}{c}\text { Geogrelha } \\
\text { (Fortrac) }\end{array}$} & \multirow[t]{2}{*}{ Solo } & \multirow{2}{*}{$\begin{array}{c}\text { Sobrecarga } \\
(\mathrm{kPa})\end{array}$} & \multirow{2}{*}{$\begin{array}{l}\text { Velocidade } \\
\text { de ensaio } \\
(\mathrm{mm} / \mathrm{min})\end{array}$} & \multirow{2}{*}{$\begin{array}{l}\text { G.C. } \\
(\%)\end{array}$} & \multicolumn{2}{|c|}{$\begin{array}{c}\text { Quantidade de } \\
\text { elementos }\end{array}$} \\
\hline & & & & & & transv. & longit. \\
\hline Teste 34 & $55 / 30-20$ & 3 & 40 & 2 & 96 & 7 & 7 \\
\hline Teste 6 & $55 / 30-20$ & 3 & 40 & 4,6 & 96 & 7 & 7 \\
\hline Teste 35 & $55 / 30-20$ & 3 & 40 & 8 & 96 & 7 & 7 \\
\hline Teste 36 & $55 / 30-20$ & 3 & 40 & 100 & 96 & 7 & 7 \\
\hline
\end{tabular}

As curvas de deslocamento $(\mathrm{mm}) v s$. força de arrancamento $(\mathrm{kN} / \mathrm{m})$ apresentadas na Figura 66(a), permitem verificar que, para as velocidades de 2,0 $\mathrm{mm} / \mathrm{min}, 4,6 \mathrm{~mm} / \mathrm{min}$ e $8,0 \mathrm{~mm} / \mathrm{min}$, a força de arrancamento máxima praticamente manteve se dentro do intervalo de variabilidade dos resultados de ensaios analisados no item 4.2.1., e que para velocidade de $100 \mathrm{~mm} / \mathrm{min}$ ocorreu um acréscimo significativo de aproximadamente $12 \%$, na força de arrancamento $(\mathrm{kN} / \mathrm{m})$. Nota-se também, que à medida que se aumenta a velocidade do ensaio as curvas tendem a apresentar um leve deslocamento para a esquerda.

Na Figura 66(b) estão apresentadas as velocidades de ensaio em função da força máxima de arrancamento e o correspondente deslocamento observado. 


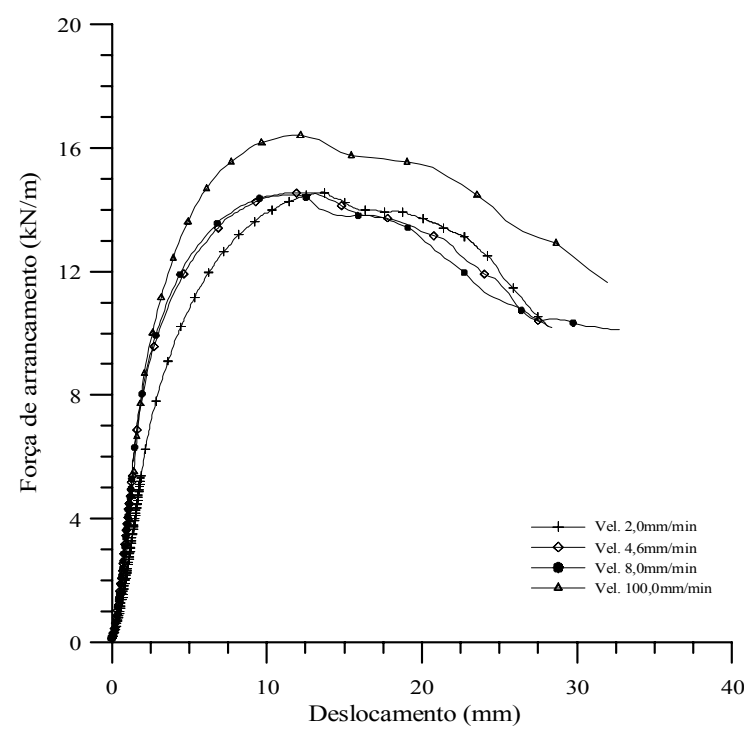

(a)

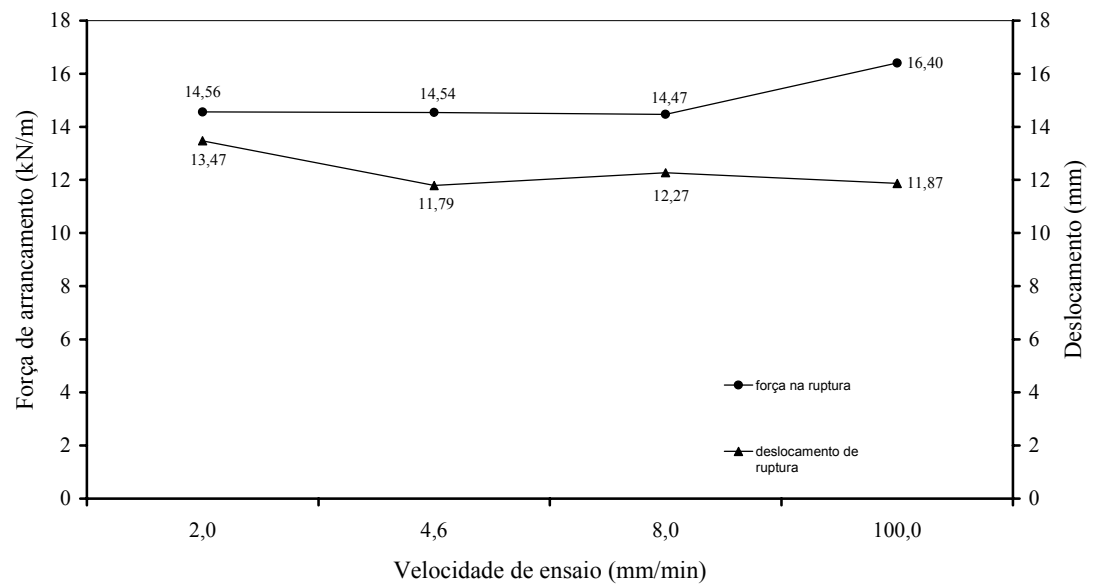

(b)

Figura 66 - (a) Efeito da velocidade de ensaio na força de arrancamento (kN/m); (b) Efeito da variação da velocidade de ensaio de arrancamento na força de arrancamento e deslocamento na ruptura.

Observa-se na Figura 66(b) que a força de arrancamento manteve-se praticamente constante nas três primeiras velocidades de ensaio utilizadas e o desvio padrão calculado foi de apenas $0,05 \mathrm{kN} / \mathrm{m}$. Entretanto, quando a velocidade passou de 8,0 para $100,0 \mathrm{~mm} / \mathrm{min}$ a força de arrancamento apresentou um acréscimo superior a 10\%. Em termos de deslocamento, constatou-se um decréscimo quando a velocidade passou de 2 para $8 \mathrm{~mm} / \mathrm{min}$ e as demais velocidades ao deslocamento apresentou pequenas oscilações.

Estudos do efeito da velocidade na força de arrancamento foram elaborados também por Lopez \& Ladeira (1996) que realizaram ensaios de arrancamento com variação da velocidade, em geogrelha de polietileno de alta densidade inseridas em 
areia. Em seus resultados foi observado um aumento de $18 \%$ na força de arrancamento quando a velocidade passou de 5,4 para $22,0 \mathrm{~mm} / \mathrm{min}$.

Os resultados da literatura ajustam-se muito bem aos obtido no presente trabalho. Portanto pode-se conclui que o aumento da velocidade de ensaio proporciona um aumento na força de arrancamento. Além disso, pode-se também perceber que o aumento resulta em um incremento de rigidez do sistema solo-reforço e de uma redução na capacidade de rearranjo dos grãos de solo por efeito do corte da amostra.

Considerando que a Norma ASTM-D6706-01 recomenda-se a utilização de velocidade de ensaio de $1,0 \mathrm{~mm} / \mathrm{min}$, tomou-se o cuidado de verificar se a utilização de velocidade de 4,6mm/min afetaria a resistência ao arrancamento. Para isso, foram realizados mais três ensaios com velocidades de 1,2 e $5 \mathrm{~mm} / \mathrm{min}$. Nesses testes utilizouse o solo 2, a geogrelha 55/30-20, uma sobrecarga de $40 \mathrm{kPa}$ e grau de compactação de $96 \%$. Pode-se, mais uma vez, verificar que nesse intervalo de velocidade analisado os resultados obtidos ficaram dentro do intervalo de dispersão do ensaio. Figura 67 apresenta as curvas de deslocamento $v s$ força de arrancamento.

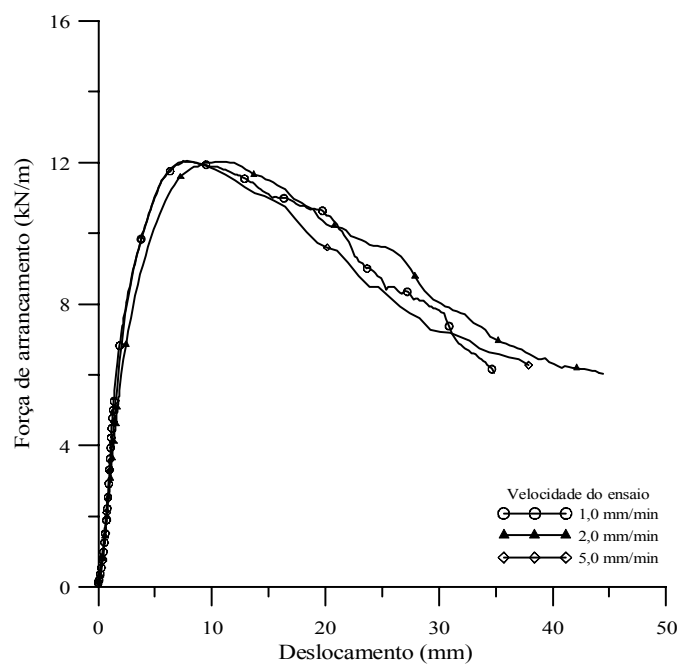

Figura 67 - Resultados de ensaios de arrancamento com velocidades de 1,2 e $5 \mathrm{~mm} / \mathrm{min}$ com a utilização do solo 2 .

Devido às pequenas variações observadas entre os valores de força de arrancamento e deslocamento medidos para velocidades de ensaio situadas no intervalo de 1 a $5 \mathrm{~mm} / \mathrm{min}$, optou-se por utilizar a velocidade de arrancamento de 4,6 $\mathrm{mm} / \mathrm{min}$ para os demais ensaios. Outro fator que levou a adoção da velocidade de ensaio de $4,6 \mathrm{~mm} / \mathrm{min}$ foi à necessidade de tempo suficiente para anotações das tensões normais registradas na célula de tensão total, e ainda por ter sido a mesma velocidade utilizada 
nos ensaios realizados em equipamento de grande porte realizados por Teixeira (2003) que foi utilizado como referência para comparação.

\subsubsection{Efeito da sobrecarga na resistência ao arrancamento}

A tensão confinante pode afetar tanto a resistência ao arrancamento quanto os deslocamentos relativos entre o solo e a geogrelha. A fim de verificar este comportamento, foram realizados ensaios em que se variou a sobrecarga aplicada sobre o solo. Nesta análise, foram utilizados os solos identificados como solo1, 2, 3, 4, e 5. Os detalhes dos ensaios estão apresentados na Tabela 16.

Tabela 16 - Série de ensaios para analisar o efeito da sobrecarga na resistência ao arrancamento.

\begin{tabular}{|c|c|c|c|c|c|c|c|}
\hline \multirow[t]{2}{*}{ Identificação } & \multirow{2}{*}{$\begin{array}{c}\text { Geogrelha } \\
\text { (Fortrac) }\end{array}$} & \multirow[t]{2}{*}{ Solo } & \multirow{2}{*}{$\begin{array}{c}\text { Sobrecarga } \\
(\mathrm{kPa})\end{array}$} & \multirow{2}{*}{$\begin{array}{l}\text { Velocidade } \\
\text { de ensaio } \\
(\mathrm{mm} / \mathrm{min})\end{array}$} & \multirow{2}{*}{$\begin{array}{l}\text { G.C. } \\
(\%)\end{array}$} & \multicolumn{2}{|c|}{$\begin{array}{c}\text { Quantidade de } \\
\text { elementos }\end{array}$} \\
\hline & & & & & & transv. & longit. \\
\hline Teste 37 & $35 / 30-20$ & 1 & 20 & 4,6 & 96 & 7 & 7 \\
\hline Teste 38 & $35 / 30-20$ & 1 & 40 & 4,6 & 96 & 7 & 7 \\
\hline Teste 39 & $35 / 30-20$ & 1 & 60 & 4,6 & 96 & 7 & 7 \\
\hline Teste 40 & $35 / 30-20$ & 2 & 20 & 4,6 & 96 & 7 & 7 \\
\hline Teste 41 & $35 / 30-20$ & 2 & 40 & 4,6 & 96 & 7 & 7 \\
\hline Teste 42 & $35 / 30-20$ & 2 & 60 & 4,6 & 96 & 7 & 7 \\
\hline Teste 43 & $35 / 30-20$ & 2 & 80 & 4,6 & 96 & 7 & 7 \\
\hline Teste 44 & $35 / 30-20$ & 3 & 20 & 4,6 & 96 & 7 & 7 \\
\hline Teste 45 & $35 / 30-20$ & 3 & 40 & 4,6 & 96 & 7 & 7 \\
\hline Teste 46 & $35 / 30-20$ & 3 & 60 & 4,6 & 96 & 7 & 7 \\
\hline Teste 47 & $35 / 30-20$ & 3 & 80 & 4,6 & 96 & 7 & 7 \\
\hline Teste 48 & $35 / 30-20$ & 4 & 20 & 4,6 & 96 & 7 & 7 \\
\hline Teste 49 & $35 / 30-20$ & 4 & 40 & 4,6 & 96 & 7 & 7 \\
\hline Teste 50 & $35 / 30-20$ & 4 & 80 & 4,6 & 96 & 7 & 7 \\
\hline Teste 51 & $35 / 30-20$ & 5 & 20 & 4,6 & 96 & 7 & 7 \\
\hline Teste 52 & $35 / 30-20$ & 5 & 40 & 4,6 & 96 & 7 & 7 \\
\hline Teste 53 & $35 / 30-20$ & 5 & 80 & 4,6 & 96 & 7 & 7 \\
\hline
\end{tabular}


As Figuras 68(a) a 72(a) ilustram o efeito da sobrecarga nas curvas de deslocamento $v s$. força de arrancamento. As envoltórias de resistência de interface sologeogrelha para cada solo analisado estão apresentadas nas Figuras 68(b) a 72(b).

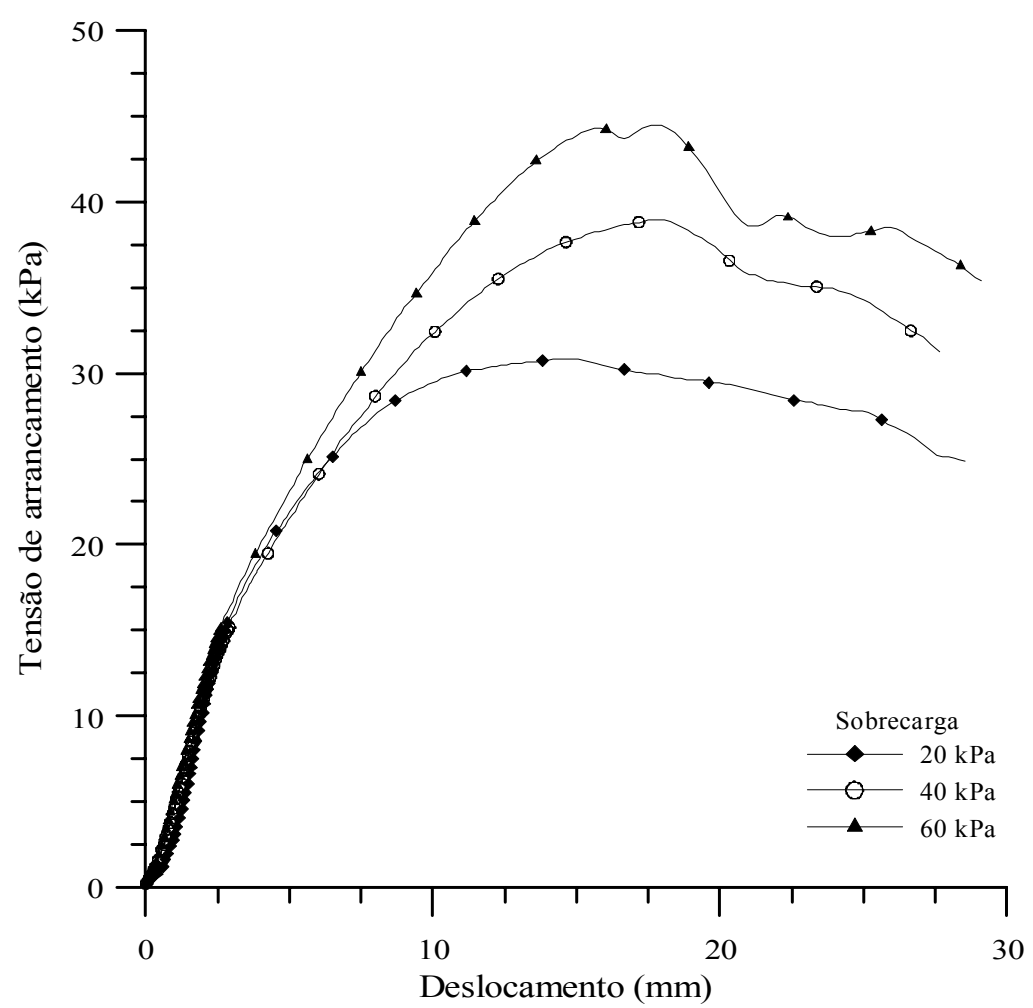

(a)

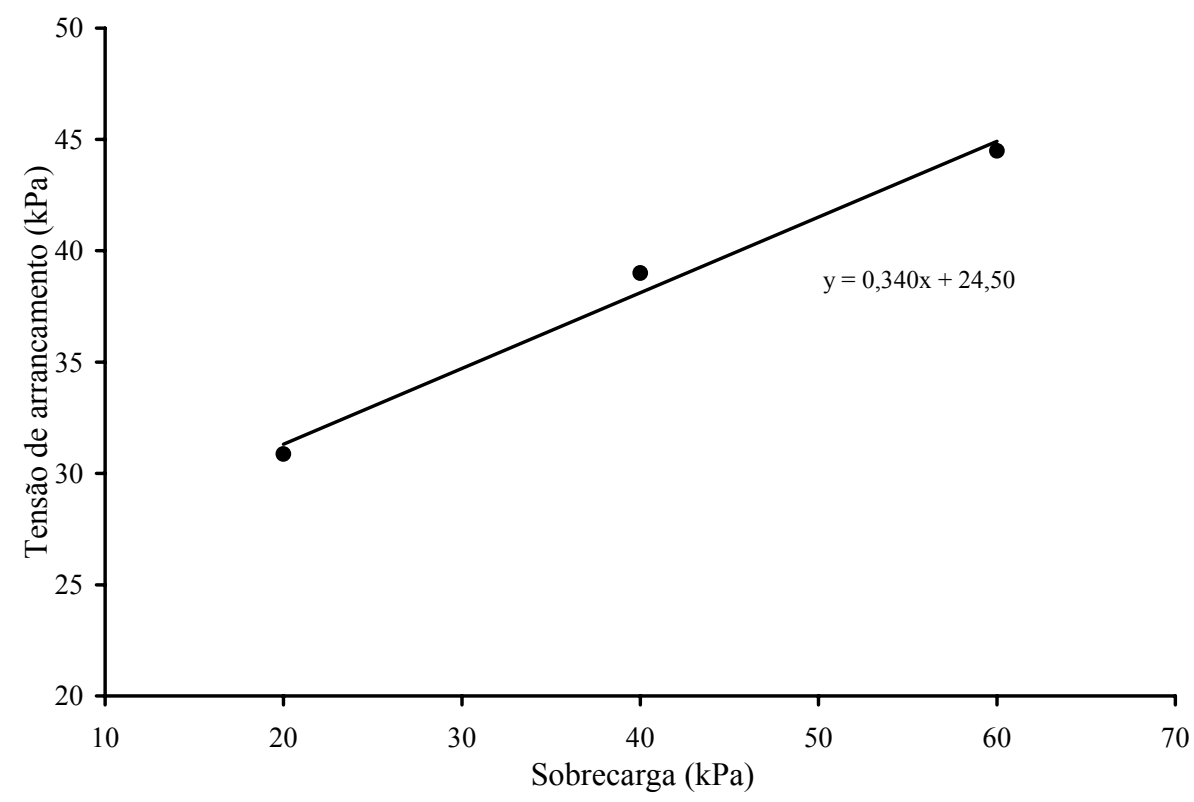

(b)

Figura 68 - Efeito da sobrecarga na resistência ao arrancamento para o solo 1: (a) curvas deslocamento $v$ s. tensão de arrancamento; (b) envoltória de resistência de interface solo-geogrelha. 


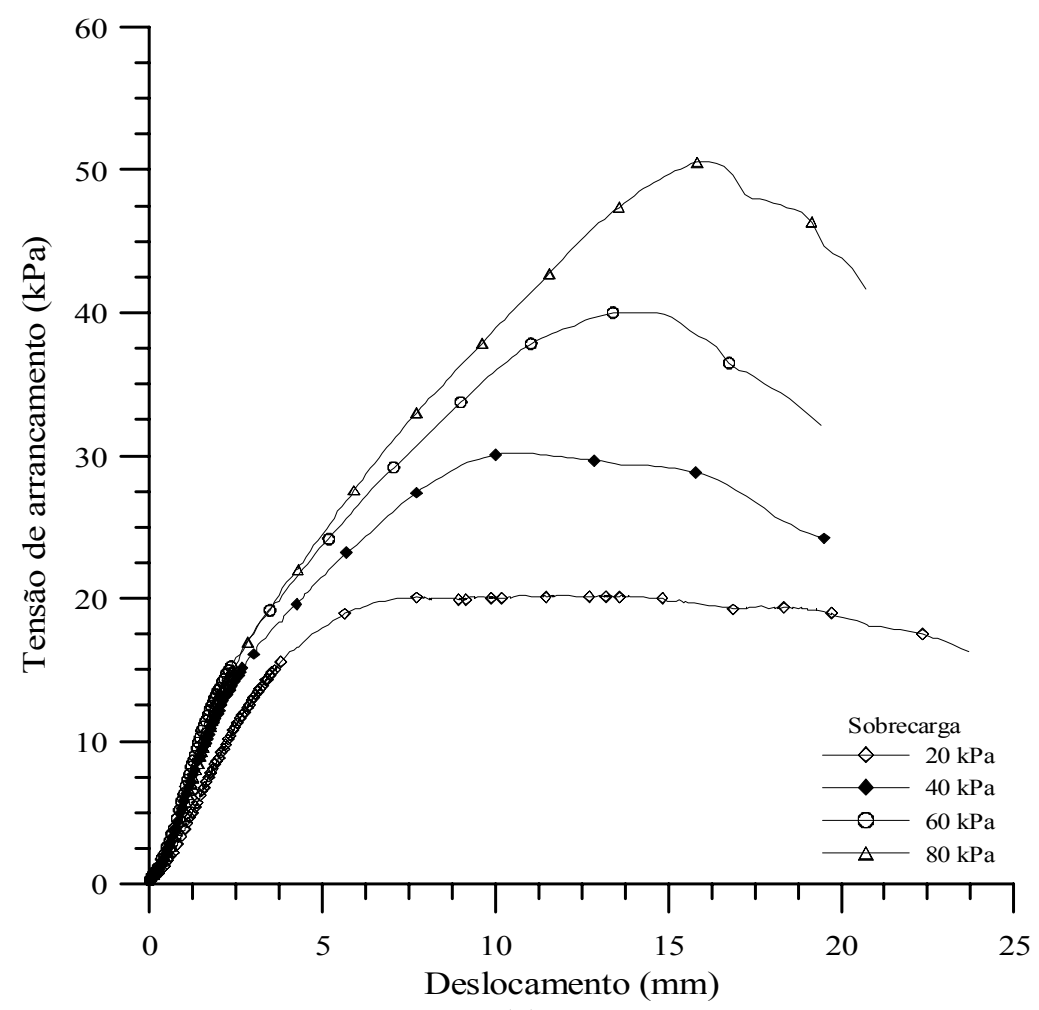

(a)

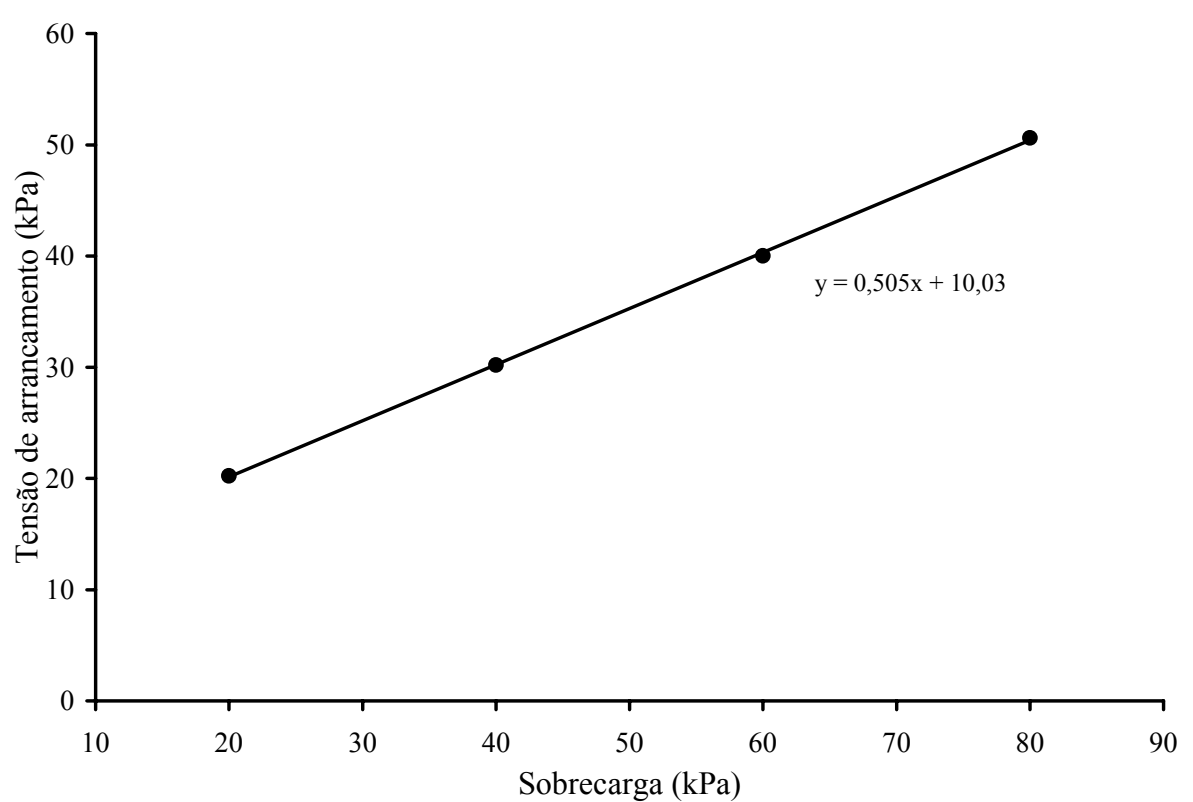

(b)

Figura 69 - Efeito da sobrecarga na resistência ao arrancamento para o solo 2: (a) curvas deslocamento vs. tensão de arrancamento; (b) envoltória de resistência de interface solo-geogrelha. 


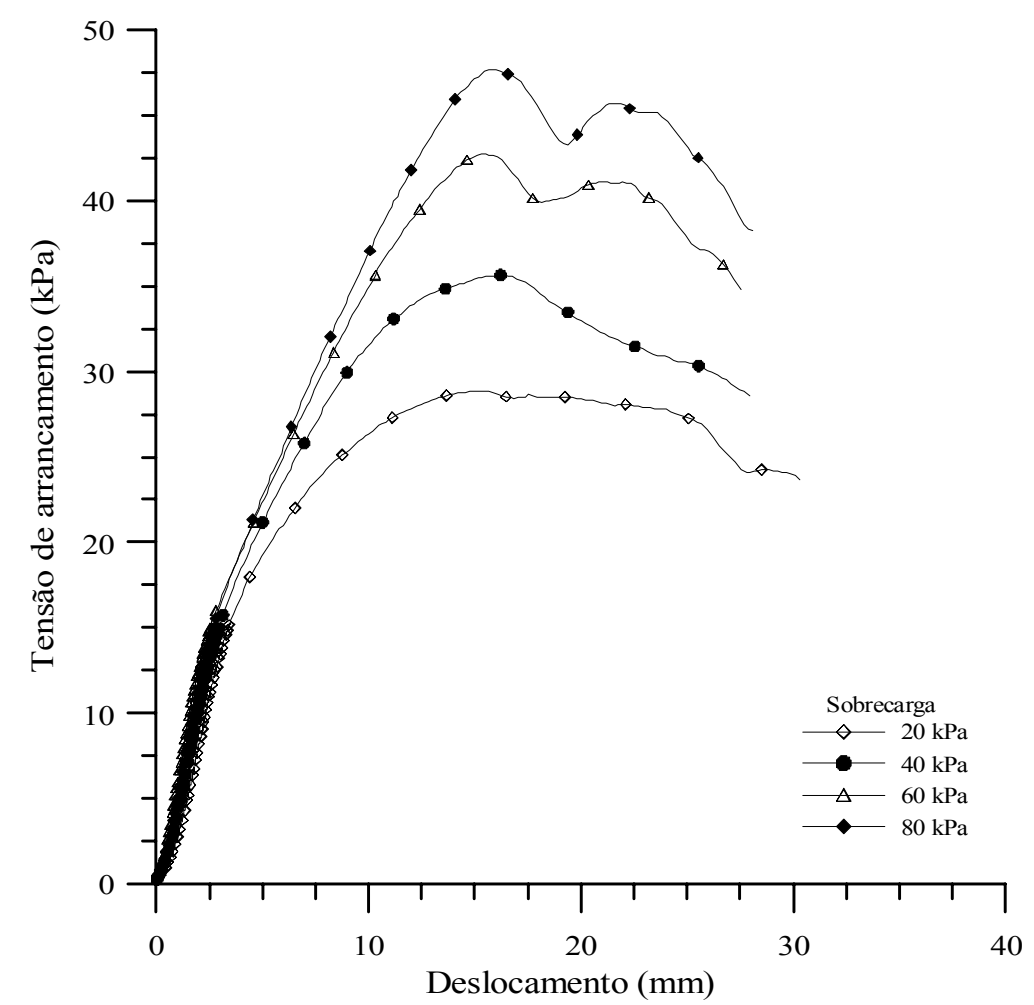

(a)

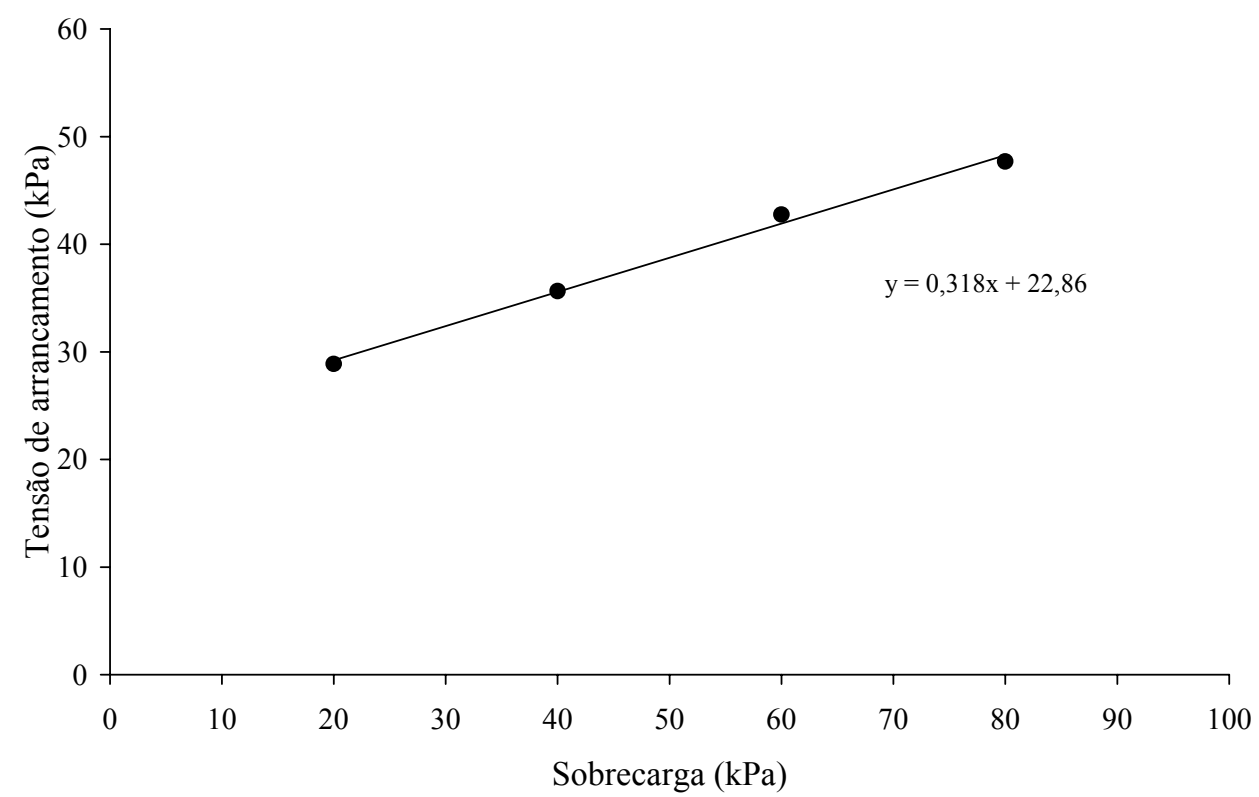

(b)

Figura 70 - Efeito da sobrecarga na resistência ao arrancamento para o solo 3: (a) curvas deslocamento vs. tensão de arrancamento; (b) envoltória de resistência de interface solo-geogrelha. 


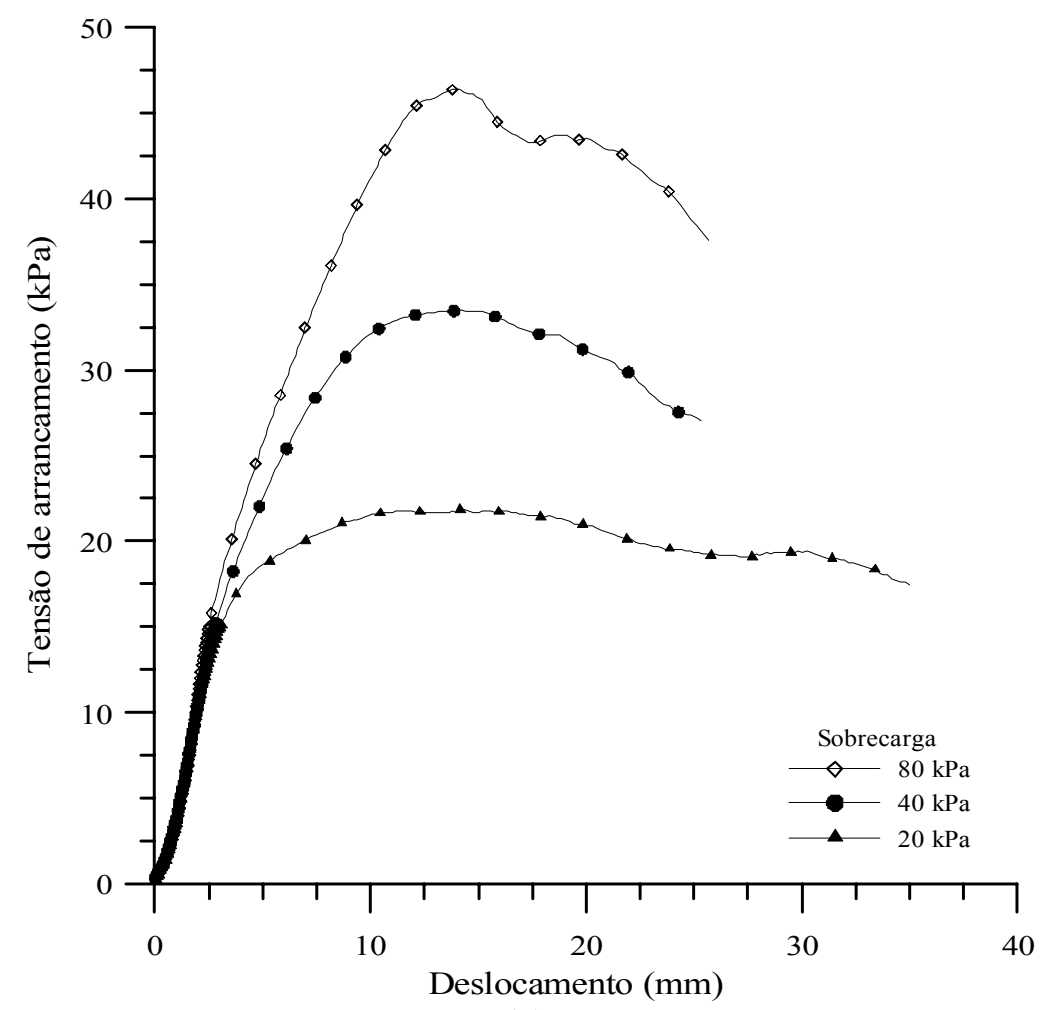

(a)

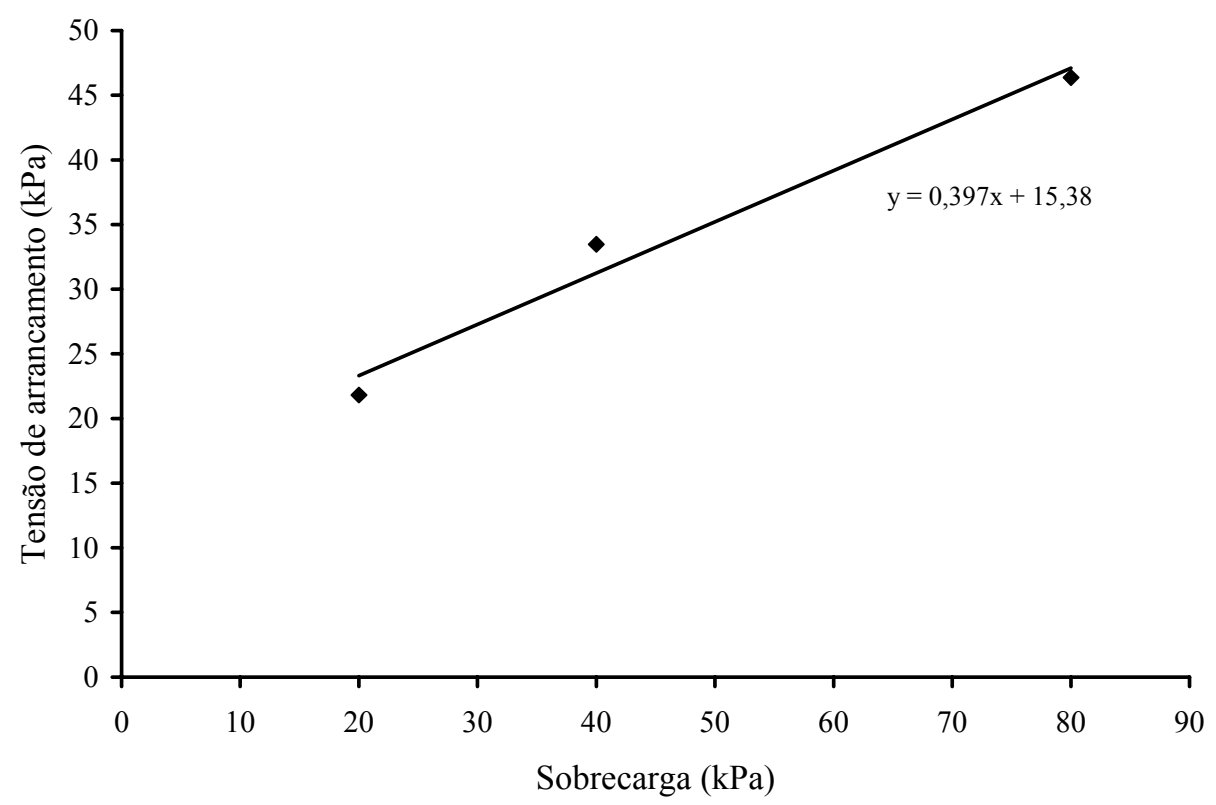

(b)

Figura 71 - Efeito da sobrecarga na resistência ao arrancamento para o solo 4: (a) curvas deslocamento vs. tensão de arrancamento; (b) envoltória de resistência de interface solo-geogrelha. 


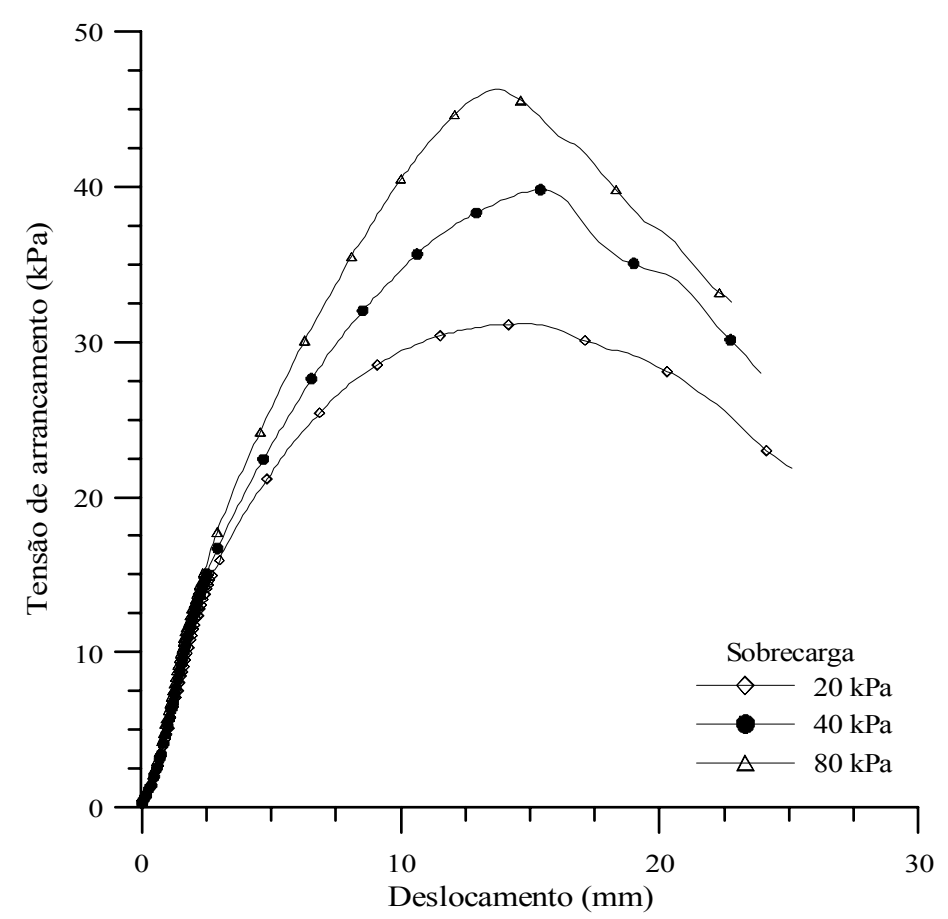

(a)

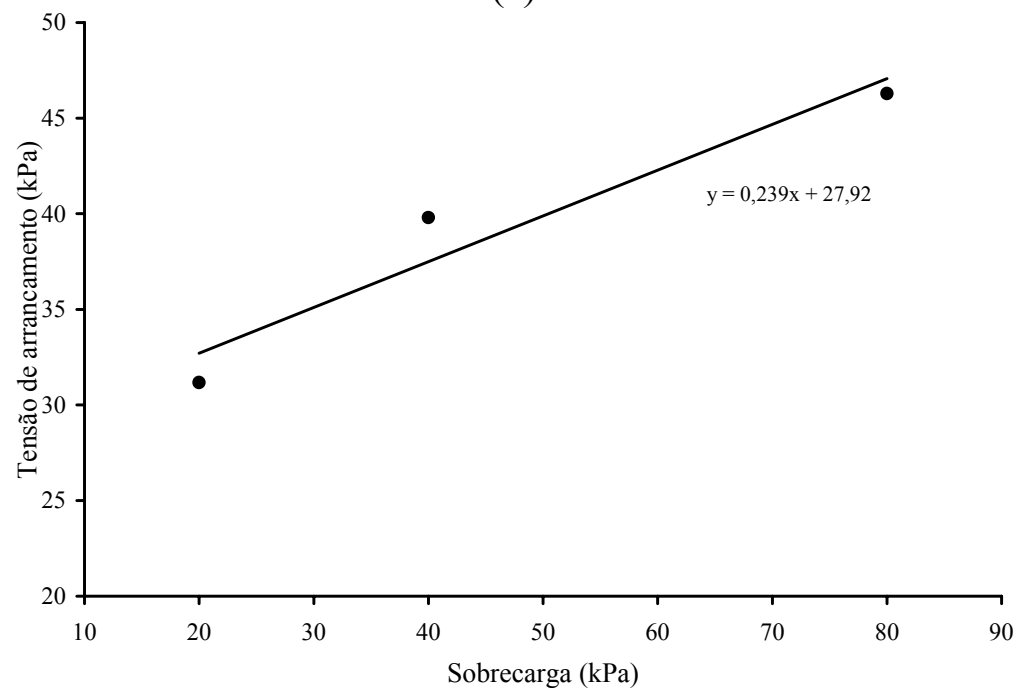

(b)

Figura 72 - Efeito da sobrecarga na resistência ao arrancamento para o solo 5: (a) curvas deslocamento vs. tensão de arrancamento; (b) envoltória de resistência de interface solo-geogrelha.

As curvas apresentadas fornecem algumas informações qualitativas com relação ao comportamento da inclusão durante o arrancamento. Pode-se perceber, por exemplo, das curvas de deslocamento vs. tensão de arrancamento, que existe um padrão de comportamento para cada solo utilizado. Verifica-se que, o aumento da sobrecarga, além de causar aumento da força de arrancamento ruptura, provoca um aumento da rigidez do sistema, ou seja, percebe-se um deslocamento da curva tensão de arrancamento vs. deslocamento para a esquerda conforme já demonstrados por Alfaro et al. (1995) e Ochiai et al. (1996) em ensaios similares. 
Além disto, os resultados mostram que para sobrecarga de $20 \mathrm{kPa}$ a queda póspico da força de arrancamento é relativamente menor do que para sobrecargas mais elevadas em alguns casos, enquanto em outros praticamente inexiste. Para os solos em que esta queda é ainda evidenciada à medida que se aumenta a sobrecarga aplicada a queda pós-pico da tensão de arrancamento intensifica-se atingindo o máximo para as sobrecargas de $80 \mathrm{kPa}$.

Observa-se nas envoltórias de resistência de interface solo-inclusão que os pontos de maior resistência ao arrancamento aumentam linearmente com o aumento da sobrecarga aplicada.

\subsubsection{Efeito do grau de compactação do solo na resistência ao} arrancamento

Para o estudo da influência do grau de compactação do solo nas magnitudes das forças de arrancamento e dos deslocamentos relativos entre solo e geogrelha, foram realizados nove ensaios, sendo três deles para cada grau de compactação, conforme mostra a Tabela 17.

Tabela 17 - Ensaios realizados para estudo do efeito da compactação do solo nos parâmetros de arrancamento.

\begin{tabular}{cccccccc}
\hline Identificação & Solo & Geogrelha & $\begin{array}{c}\text { G.C. } \\
\mathbf{( \% )}\end{array}$ & $\begin{array}{c}\sigma \\
\mathbf{( k P a )}\end{array}$ & $\begin{array}{c}\text { Velocidade } \\
(\mathbf{m m} / \mathbf{m i n})\end{array}$ & \multicolumn{2}{c}{ Elementos } \\
& & & & & & Transversais & Longitudinais \\
\hline Teste 48 & 4 & 1 & 96 & 20 & 4,6 & 7 & 7 \\
Teste 49 & 4 & 1 & 96 & 40 & 4,6 & 7 & 7 \\
Teste 50 & 4 & 1 & 96 & 80 & 4,6 & 7 & 7 \\
Teste 54 & 4 & 1 & 98 & 20 & 4,6 & 7 & 7 \\
Teste 55 & 4 & 1 & 98 & 40 & 4,6 & 7 & 7 \\
Teste 56 & 4 & 1 & 98 & 80 & 4,6 & 7 & 7 \\
Teste 57 & 4 & 1 & 100 & 20 & 4,6 & 7 & 7 \\
Teste 58 & 4 & 1 & 100 & 40 & 4,6 & 7 & 7 \\
Teste 59 & 4 & 1 & 100 & 80 & 4,6 & 7 & 7 \\
\hline
\end{tabular}


Os valores obtidos estão representados nas Figuras 73 (a) e (b). Estes resultados mostram que, com o aumento do grau de compactação do solo, há um aumento praticamente linear da força de arrancamento. Isto foi observado para as três tensões confinantes ensaiadas, sendo que o maior acréscimo da força de arrancamento $(5,3 \%)$ ocorreu quando o grau de compactação foi aumentado de $96 \%$ para $98 \%$, para a tensão de confinamento de $20 \mathrm{kPa}$.

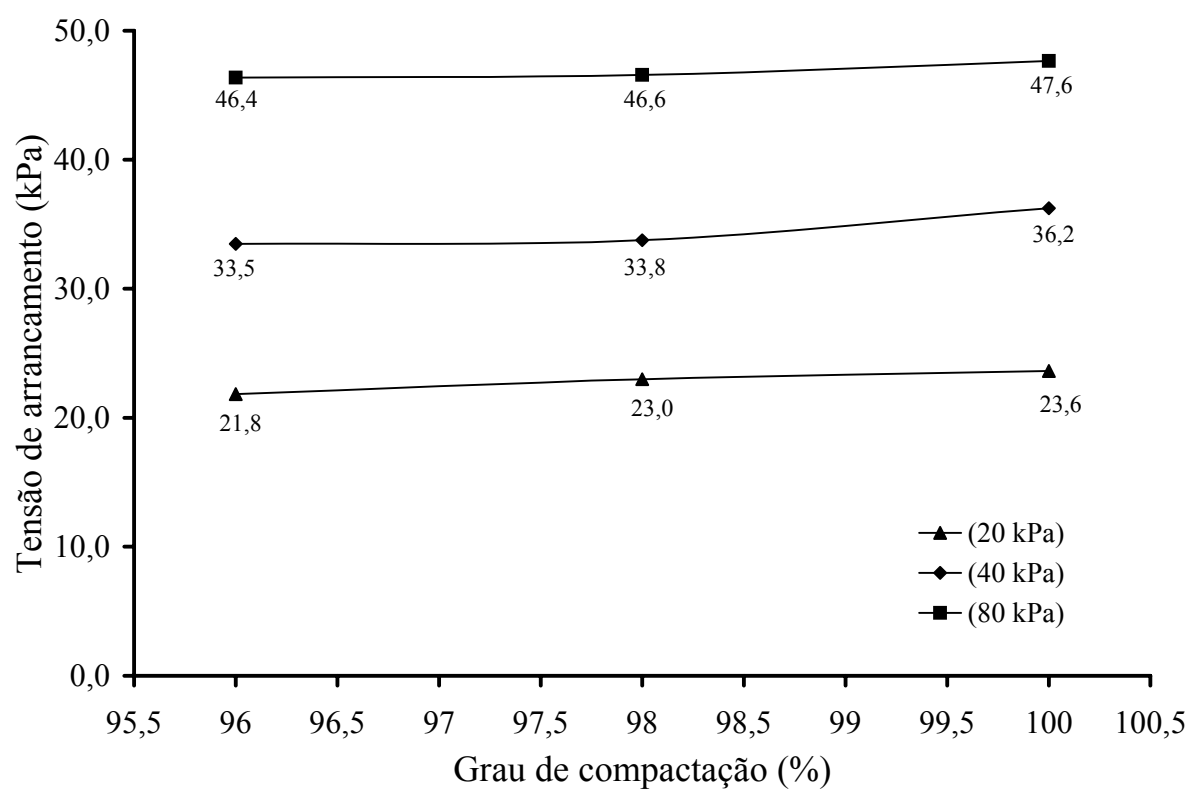

(a)

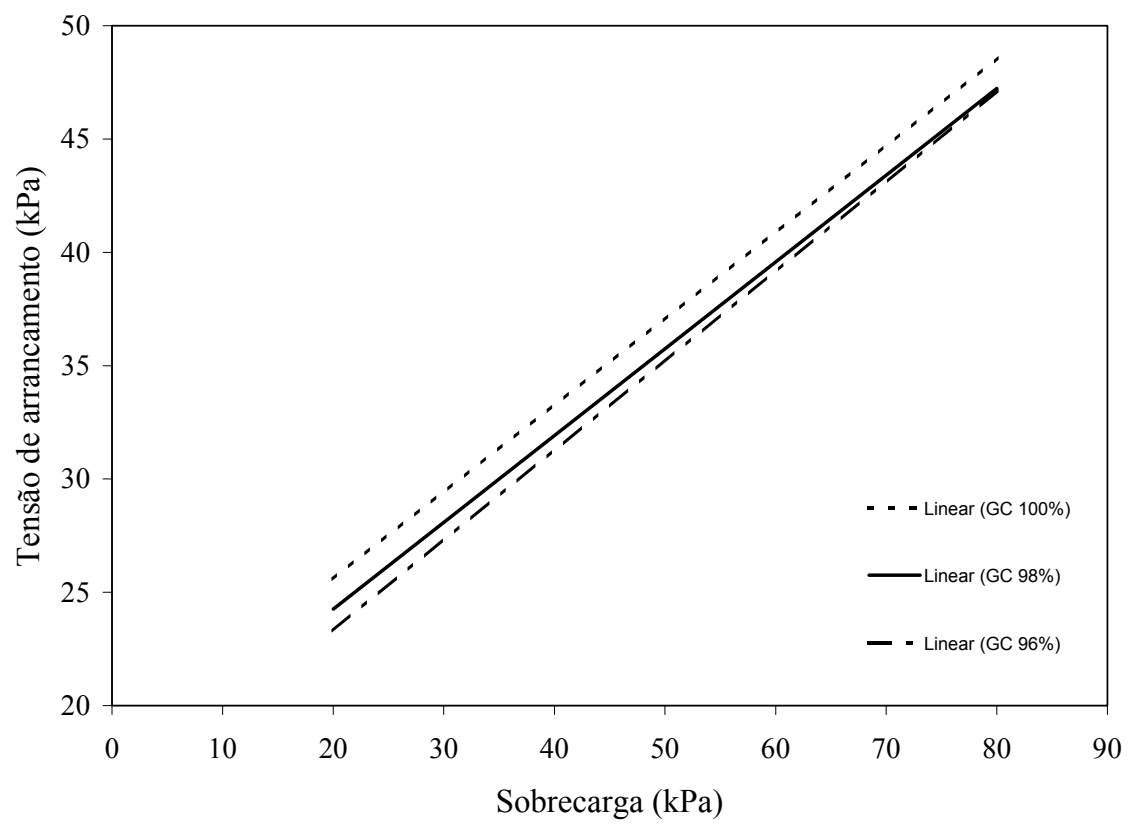

(b)

Figura 73 - Efeito do grau de compactação na tensão de arrancamento. 
Conforme verificado na Figura 73, um aumento no grau de compactação conduziu a um aumento da adesão , $a$, sem no entanto afetar significativamente o ângulo de atrito de interface solo-geogrelha, $\delta$, que praticamente se manteve constante.

Na Figura 74, ao comparar os gráficos com grau de compactação 96, 98 e 100\%, nota-se que, por essa diferença ser muito pequena, as curvas apresentam comportamento muito próximo. Nota-se, uma queda pós-pico acentua-se a medida que aumenta o grau de compactação.

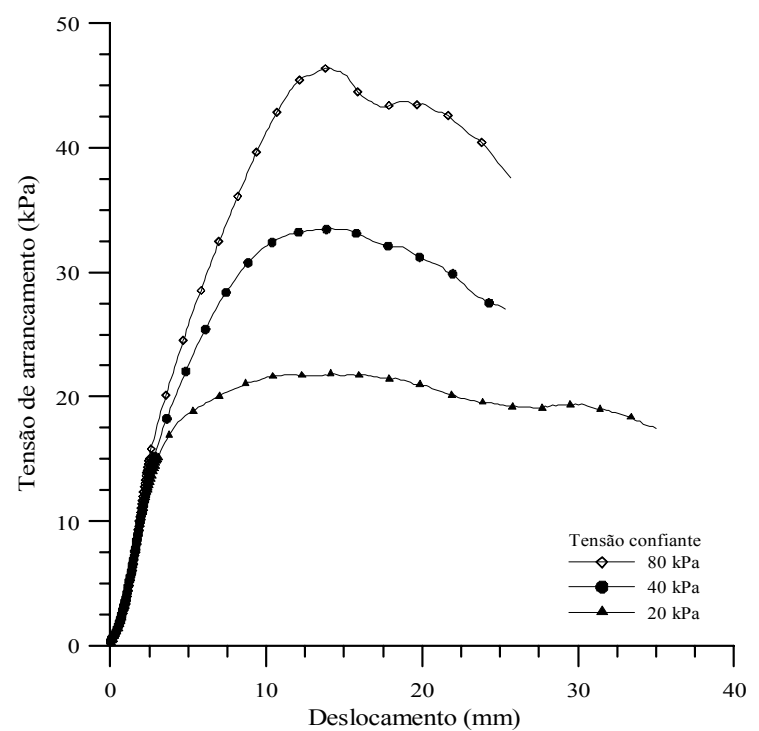

(a)

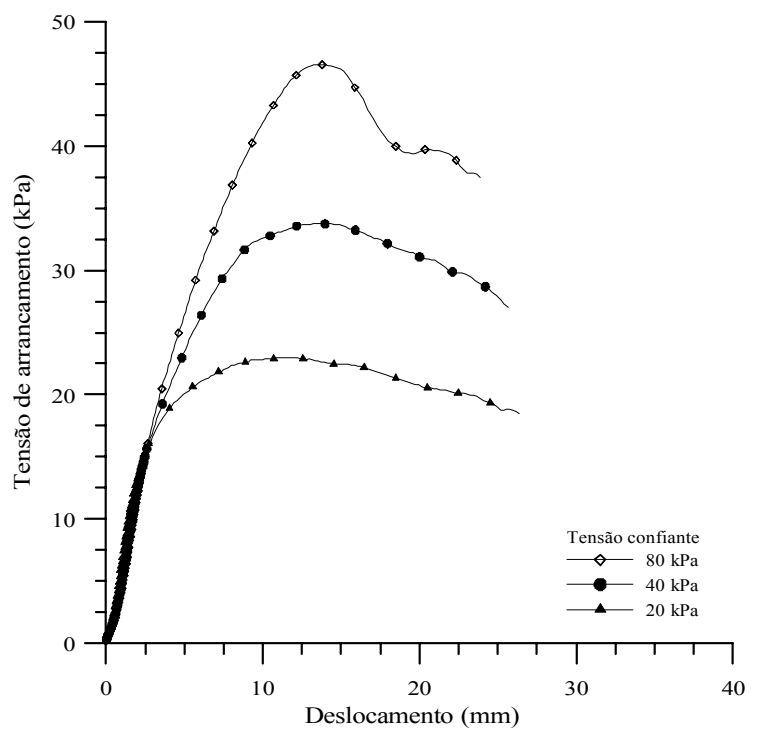

(b)

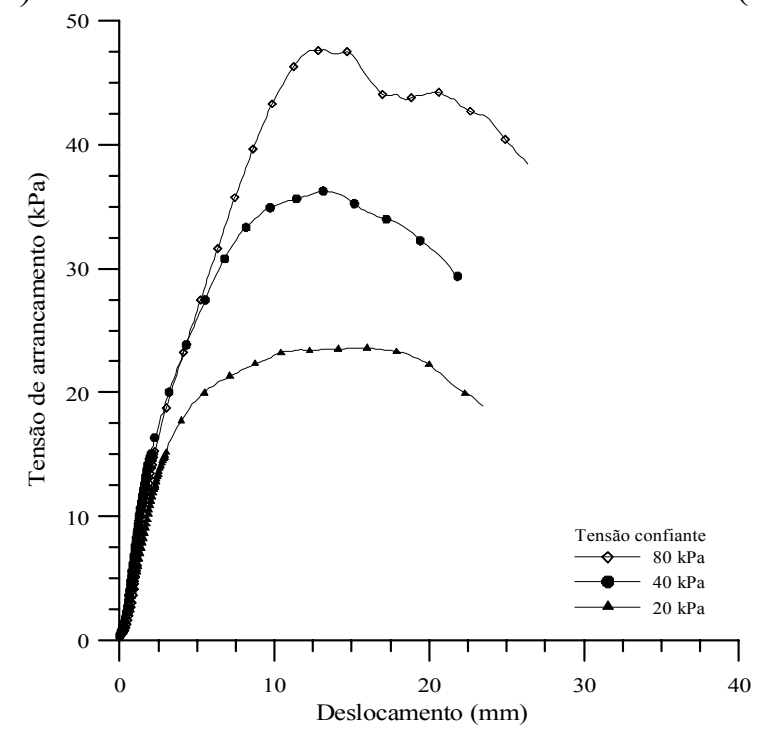

(c)

Figura 74 - Efeito do grau de compactação na tensão de arrancamento: (a) 96\% ; (b) $98 \%$ e (c) $100 \%$. 


\subsubsection{Comparação entre tipos de geogrelha na resistência ao arrancamento}

Para analisar o efeito da geometria da inclusão nos resultados de força de arrancamento foram realizados ensaios utilizando as geogrelhas 35/20-20 e 55/30-20. Nesta etapa foram utilizados os ensaios realizados com a geogrelha 35/20-20 para os solo 2 e 3, já apresentados na Tabela 16, sendo estes identificados como os testes de 40 a 47. Para efeito de comparação foram executados mais nove ensaios para o modelo 55/30-20. A tabela 18 apresenta os parâmetros utilizados nos ensaios.

Tabela 18 - Série de ensaios para analisar o efeito da geometria da geogrelha na resistência ao arrancamento.

\begin{tabular}{|c|c|c|c|c|c|c|c|}
\hline \multirow[t]{2}{*}{ Identificação } & \multirow{2}{*}{$\begin{array}{c}\text { Geogrelha } \\
\text { (Fortrac) }\end{array}$} & \multirow[t]{2}{*}{ Solo } & \multirow{2}{*}{$\begin{array}{c}\text { Tensão } \\
\text { confinante } \\
(\mathrm{kPa})\end{array}$} & \multirow{2}{*}{$\begin{array}{c}\text { Velocidade } \\
\text { de ensaio } \\
(\mathrm{mm} / \mathrm{min})\end{array}$} & \multirow{2}{*}{$\begin{array}{l}\text { G.C. } \\
(\%)\end{array}$} & \multicolumn{2}{|c|}{$\begin{array}{c}\text { Quantidade de } \\
\text { elementos }\end{array}$} \\
\hline & & & & & & transv. & longit.. \\
\hline Teste 60 & $55 / 30-20$ & 2 & 20 & 4,6 & 96 & 7 & 7 \\
\hline Teste 61 & $55 / 30-20$ & 2 & 40 & 4,6 & 96 & 7 & 7 \\
\hline Teste 62 & $55 / 30-20$ & 2 & 60 & 4,6 & 96 & 7 & 7 \\
\hline Teste 63 & $55 / 30-20$ & 2 & 80 & 4,6 & 96 & 7 & 7 \\
\hline Teste 64 & $55 / 30-20$ & 3 & 0 & 4,6 & 96 & 7 & 7 \\
\hline Teste 65 & $55 / 30-20$ & 3 & 20 & 4,6 & 96 & 7 & 7 \\
\hline Teste 6 & $55 / 30-20$ & 3 & 40 & 4,6 & 96 & 7 & 7 \\
\hline Teste 66 & $55 / 30-20$ & 3 & 80 & 4,6 & 96 & 7 & 7 \\
\hline Teste 67 & $55 / 30-20$ & 3 & 100 & 4,6 & 96 & 7 & 7 \\
\hline
\end{tabular}

Os resultados dos ensaios realizados com o solo 2 são apresentados na Figura 75 (a) e (b) através das curvas de deslocamento vs. força de arrancamento e das envoltórias de resistência de interface solo-inclusão, respectivamente.

Dos resultados obtidos da Figura 75 pode-se observar que os deslocamentos necessários para se mobilizar a força máxima de arrancamento para a geogrelha 1 foram superiores aos da geogrelha 2. Isto ocorre devido ao espaçamento entre os elementos transversais da geogrelha 1 serem um pouco maior do que os da geogrelha 2 e reflete a importância dos membros transversais na magnitude de força de arrancamento. 


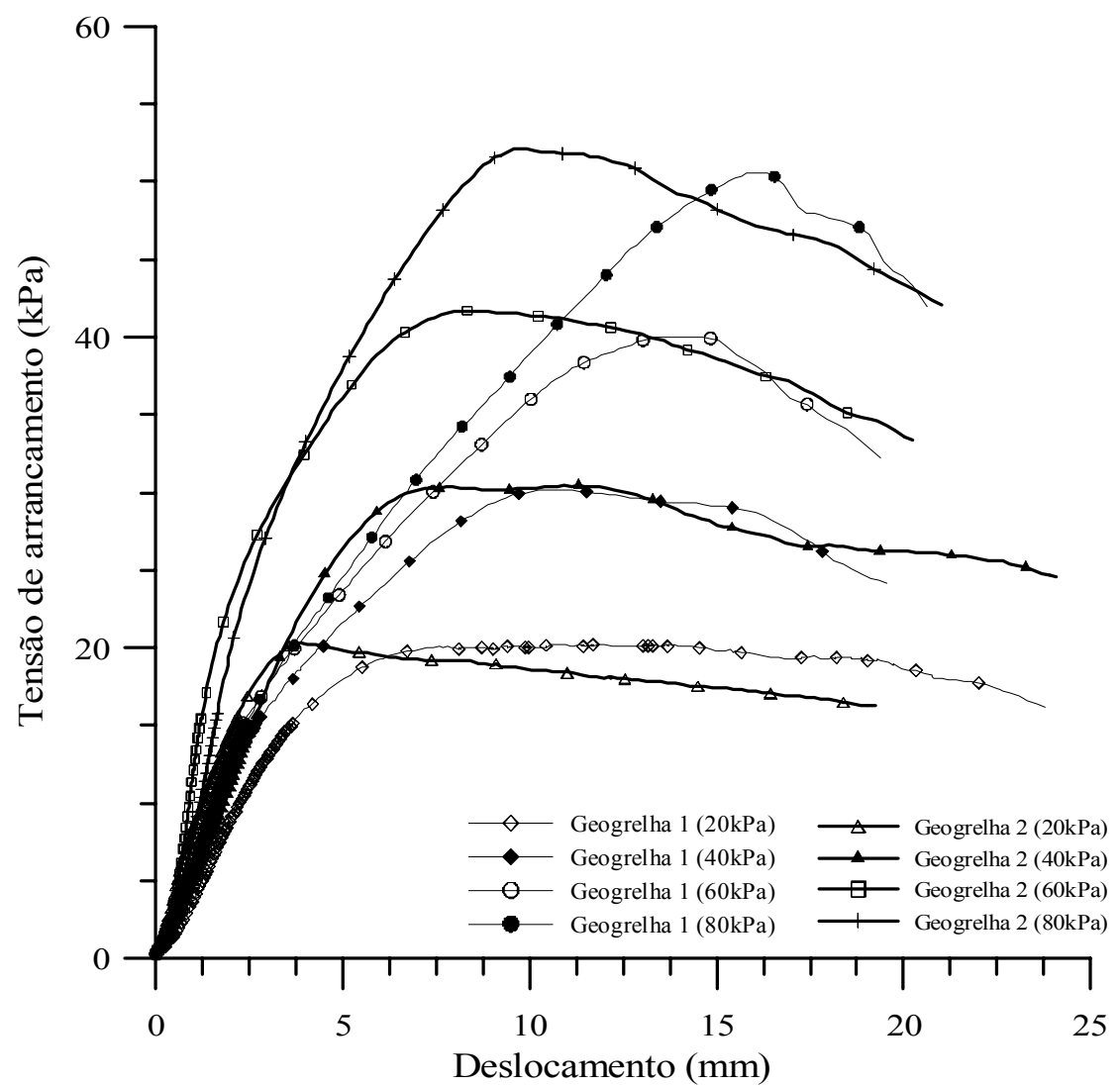

(a)

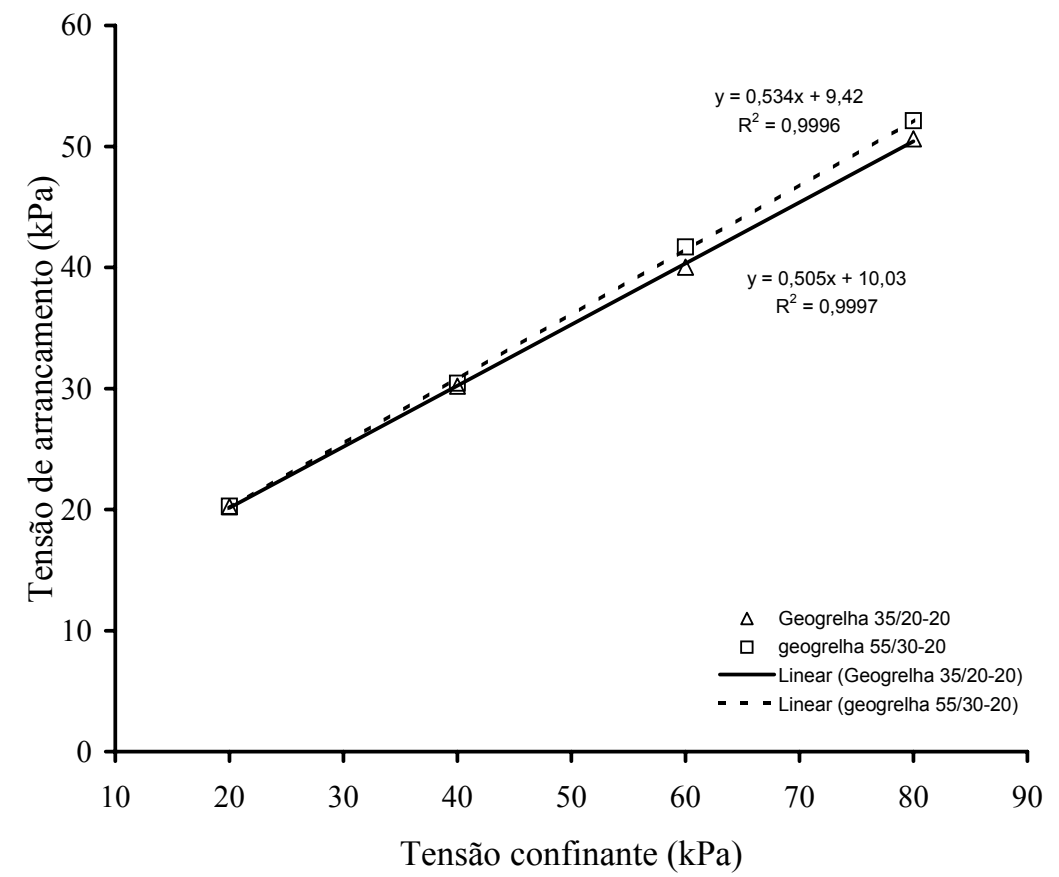

(b)

Figura 75 - Comparação entre resultados obtidos com as geogrelhas Fortrac 35/20-20 e 55/30-20 (solo 2): (a) curvas deslocamento vs. tensão de arrancamento; (b) envoltória de resistência de interface. 
Quanto à tensão de arrancamento os resultados dos testes mostraram que para tensões confinantes de 20 e $40 \mathrm{kPa}$ os valores obtidos foram praticamente iguais. Porém para tensões confinantes de 60 e $80 \mathrm{kPa}$ os resultados da geogrelha 55/30-20 apresentaram um acréscimo da máxima tensão de arrancamento de aproximadamente 4 e 3\%, respectivamente. Esse aumento está vinculado ao pequeno aumento na espessura dos elementos transversais da geogrelha55/30-20.

A Figura 76 repete-se a comparação das duas geogrelhas, entretanto, faz-se uma substituição do solo utilizado a fim de confirmar o ocorrido com o solo anteriormente analisado.

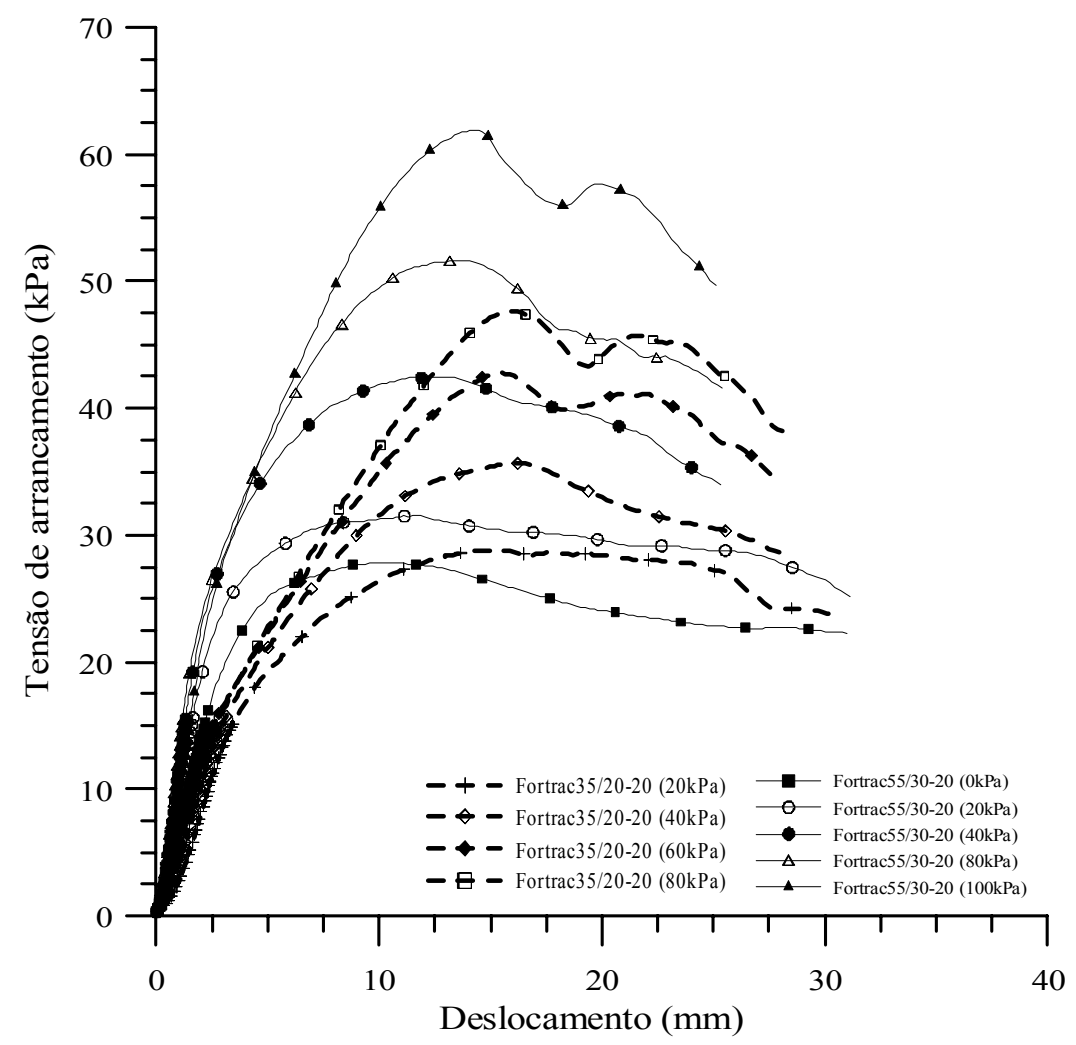

Figura 76 - Comparação das curvas deslocamento vs. tensão de arrancamento obtidas com geogrelhas Fortrac 1 e 2, inserido no solo 3.

As curvas apresentadas na Figura 76 mostram mais uma vez que a geogrelha 1 necessita de maior deslocamento para atingir o pico de resistência ao arrancamento. Todavia, percebe-se também, que os resultados obtidos com a geogrelha 2 são superiores aos obtidos com a geogrelha 1. Esse aumento relativo de tensão de arrancamento observado com o uso do solo 3 foi superior ao obtidos com o solo 2, em que praticamente não houve uma diferença significativa entre os resultados obtidos para ambas geogrelhas. 
A Figura 77 apresenta as envoltórias de resistência de interface solo-geogrelha referente as geogrelhas 1 e 2 inseridas no solo 3.

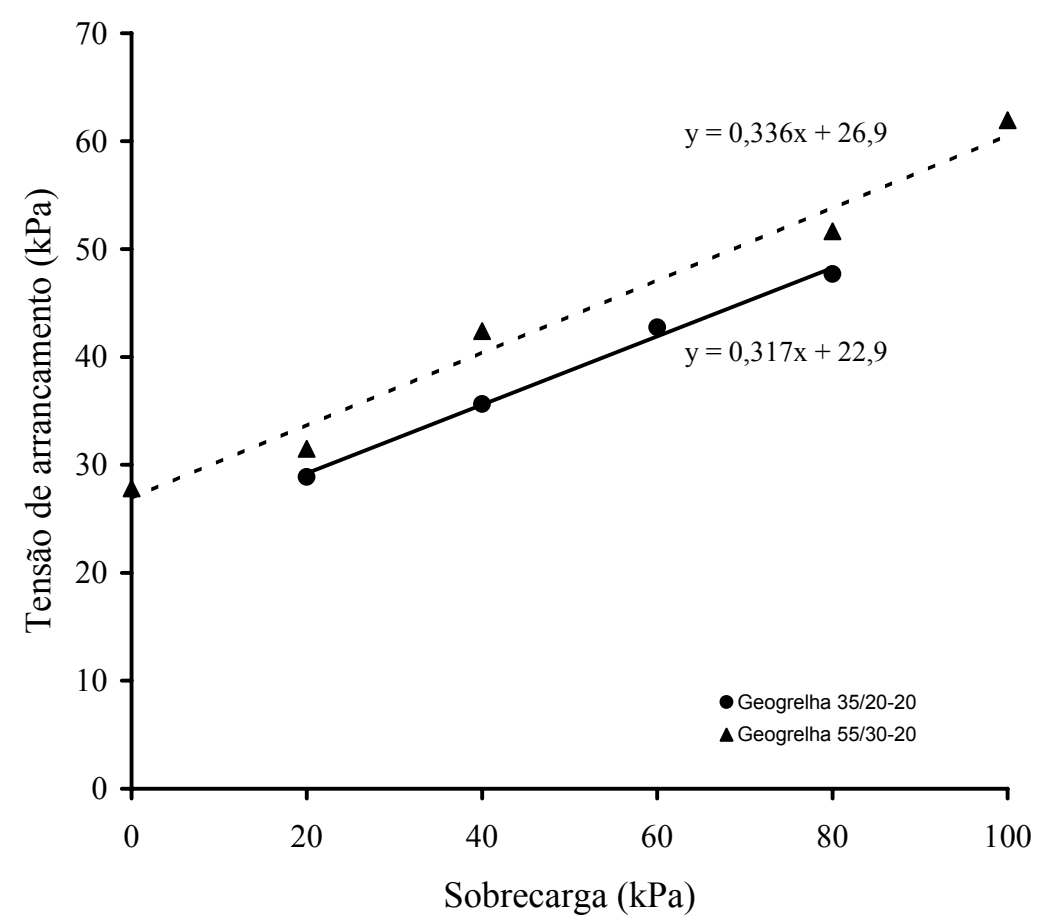

Figura 77 - Comparação dos resultados obtidos das geogrelhas Fortrac 1 e 2 através das envoltórias de resistência de interface solo-geogrelha.

As envoltórias de resistência de interface mostram que tanto o atrito quanto a adesão apresentaram valores superiores para geogrelha 2. Esse acréscimo foi da ordem de $17,7 \%$ para adesão e 5,6\% para o angulo de atrito de interface.

Os resultados apresentados neste item mostram que a comparação da resistência ao arrancamento entre os dois modelos de geogrelha, por estas apresentarem uma geometria muito parecida, não possibilitou uma adequada analise dos efeitos da geometria da inclusão no comportamento da resistência de interface solo-inclusão. Pode-se observar que a geogrelha 1 necessitou de maiores deslocamento com relação a geogrelha 2 para atingir a resistência de pico e que a diferença na força de arrancamento entre as duas geogrelhas foi mais pronunciada no solo 3 do que no solo 2 , sendo que o solo 2 apresenta um $D_{50}$ duas vezes maior que o solo 3 , mostrando, em termos qualitativos que o efeito da geometria da geogrelha está relacionada ao tipo de solo utilizado. Estudos similares, apresentados por Lopez \& Lopez, 1999, mostram que a abertura da malha e a espessura dos elementos transversais da geogrelha, bem como, a 
dimensão relativa, das partículas de solo, determina o comportamento da tensão cisalhante na interface solo-geossintético.

\subsubsection{Efeito do tipo de solo utilizado na resistência ao arrancamento}

Nesta análise foram comparados os resultados de ensaios arrancamento realizados com os cinco tipos de solo. Os resultados estão apresentados na Tabela 19 e se referem a adesão $(a)$ e ângulos de atrito de interface solo-geogrelha $(\delta)$ obtidos através das envoltórias de resistência ao arrancamento, em termos de tensões totais, apresentadas no item 4.5.2. Os solos foram compactados com teor de umidade ótima e com grau de compactação de 96\% (Energia Proctor Normal). Os ângulos de atrito interno dos solos e as coesões foram obtidos dos ensaios de cisalhamento direto, cujos corpos de provas foram moldados nas mesmas condições dos ensaios de arrancamento.

Tabela 19 - Parâmetros de resistência de interface solo-geogrelha e de resistência ao cisalhamento do solo.

\begin{tabular}{ccccc}
\hline Identificação & $(\boldsymbol{\phi})$ & $(\boldsymbol{c})$ & $(\boldsymbol{d})$ & $(\boldsymbol{a})$ \\
\hline Solo 1 & 34,6 & 30 & 18,8 & 24,5 \\
Solo 2 & 33,3 & 9,8 & 26,5 & 10,0 \\
Solo 3 & 34,8 & 27,5 & 17,6 & 22,9 \\
Solo 4 & 33,7 & 21 & 21,7 & 15,4 \\
Solo 5 & 29 & 32,6 & 13,4 & 27,9 \\
\hline
\end{tabular}

Nota: $\phi$ e $c$ são o angulo de atrito interno do solo e a coesão obtidos de ensaio de cisalhamento; $\delta$ e $a$ são o angulo de atrito e coesão de interface solo-geogrelha obtidos dos ensaios de arrancamento.

Para análise do efeito do tipo de solo na resistência ao arrancamento de geogrelha foram utilizados os resultados dos testes $38,41,45,49$ e 52 já apresentados na Tabela 16, referente aos ensaios realizados com a geogrelha 1, utilizando sobrecarga de $40 \mathrm{kPa}$, velocidade de 4,6 mm/min. A Figura 78 apresenta as curvas de deslocamento vs. tensão de arrancamento dos cinco solos analisados. 


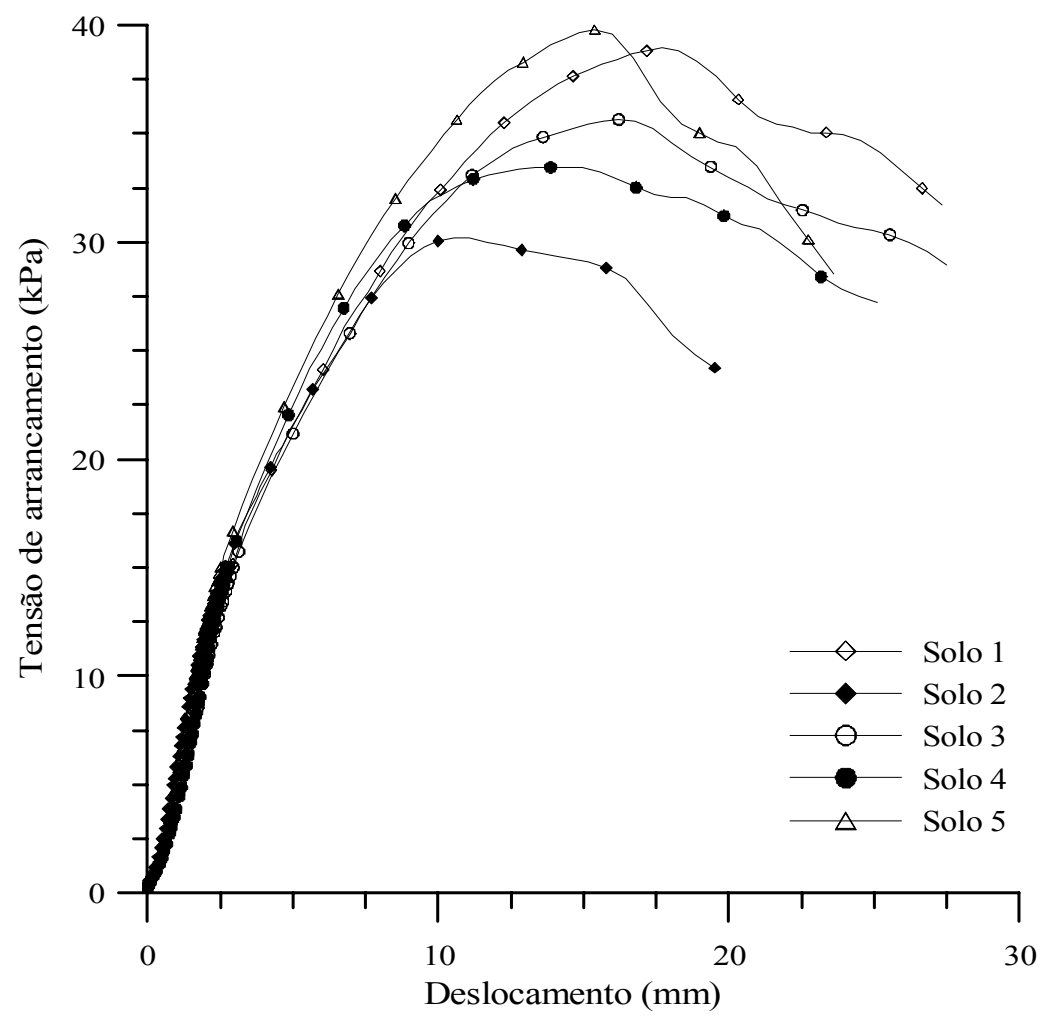

Figura 78 - Curvas de deslocamento vs. tensão de arrancamento para os cinco solos analisados com sobrecarga de $40 \mathrm{kPa}$.

Os resultados apresentados na Tabela 20, referem-se à tensão de pico de arrancamento $\left(\tau_{\text {arr.max }}\right)$ e ao respectivo deslocamento. Apresenta-se também o coeficiente de interação $(f)$, diâmetro médio das partículas de solo $\left(D_{50}\right)$ e porcentagem de argila obtida das curvas granulométricas.

Tabela 20 - Valores máximos de tensão de arrancamento e deslocamento.

\begin{tabular}{lccccc}
\hline & $\begin{array}{c}\tau_{\text {arrmax }} \\
(\mathbf{k P a})\end{array}$ & $\begin{array}{c}\text { Deslocamento } \\
(\mathbf{m m})\end{array}$ & $\begin{array}{c}(\boldsymbol{f}) \\
\mathbf{D}_{\mathbf{5 0}} \\
\mathbf{( m m )}\end{array}$ & \% de argila \\
\hline Solo 1 & 38,99 & 17,91 & 0,49 & 0,11 & 28 \\
Solo 2 & 30,21 & 10,49 & 0,76 & 0,24 & 11 \\
Solo 3 & 35,65 & 16,17 & 0,46 & 0,055 & 23 \\
Solo 4 & 33,47 & 14,12 & 0,60 & 0,16 & 16 \\
Solo 5 & 39,80 & 15,32 & 0,43 & 0,10 & 31 \\
\hline
\end{tabular}


A partir dos resultados apresentados na Tabela 20, pode-se perceber um aumento praticamente linear da tensão de arrancamento com a porcentagem de argila, conforme mostra a Figura 79.

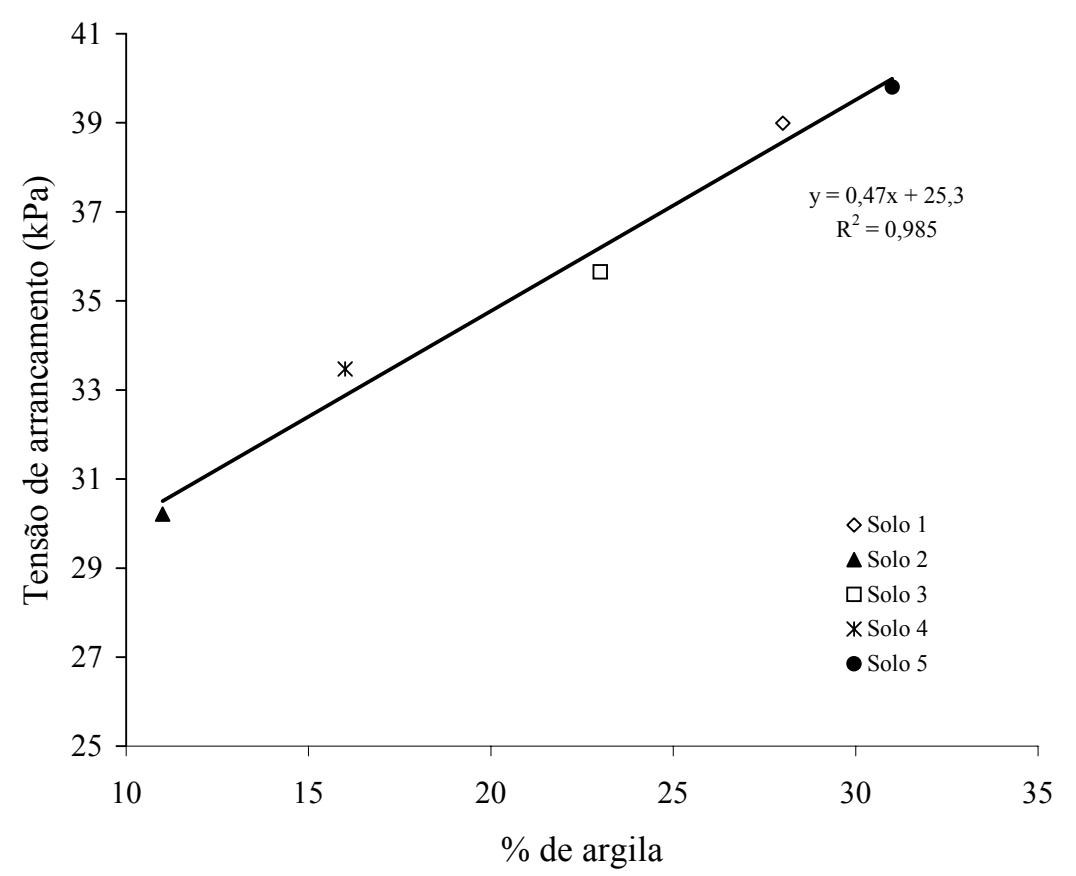

Figura 79 - Efeito do tipo de solo na resistência ao arrancamento representado pela relação entre \% de argila vs. tensão de arrancamento.

Quando a análise comparativa é feita com o coeficiente de interação (razão entre a tangente do angulo atrito de interface solo-geogrelha e do solo) e o diâmetro médio das partículas de solo $\left(D_{50}\right)$, observa-se que o solo 3 não segue o comportamento linear demonstrado pelos demais solos analisados, conforme apresenta a Figura 80. Desprezando-se o solo 3, nota-se que solos com partículas de maiores diâmetro apresentaram melhor interação com a geogrelha analisada. 


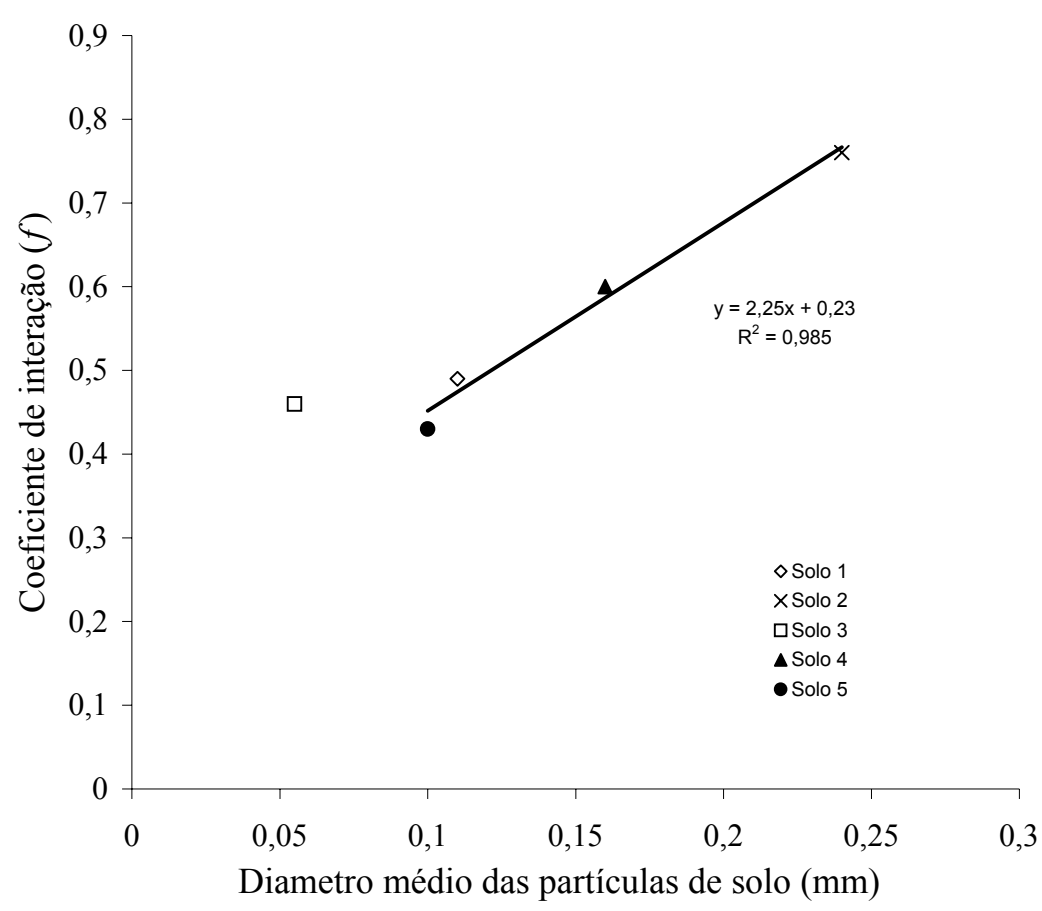

Figura 80 - Diâmetro médio das partículas de solo vs. coeficiente de interação.

$\mathrm{Na}$ análise dos deslocamentos necessários para atingir a resistência máxima ao arrancamento referente aos cinco solos estudados, não se pode verificar alguma relação do deslocamento com os parâmetros apresentados na Tabela 20. Entretanto, percebe-se que no caso dos solos 2 e 3 , com maiores $D_{50}$, necessitaram de menores deslocamentos para atingir a resistência máxima ao arrancamento.

Conclui-se, portanto, que o tipo de solo afeta significativamente na resistência ao arrancamento, mostrando uma relação linear com a percentagem de argila presente no solo, quanto ao deslocamento não se pode verificar, com os dados obtidos, uma tendência com nenhum dos parâmetros apresentados.

\subsubsection{Valores das tensões normais obtidas através da célula de tensão total.}

As Figuras 81 a 88 apresentam as leituras de variação da tensão normal em função do deslocamento da amostra, registradas na célula de tensão total referente aos testes apresentados no capítulo 4. Observa-se destes resultados que em todos os ensaios apresentaram uma oscilação dos valores das tensões normais, conforme já mencionado. Contudo, algumas observações adicionais puderam ser extraídas do conjunto de figuras. 
A Figura 81 apresenta a variação da tensão normal registrada na célula em função do deslocamento durante a execução dos testes $34,6,35,36$, em que se variou a velocidade de ensaio.

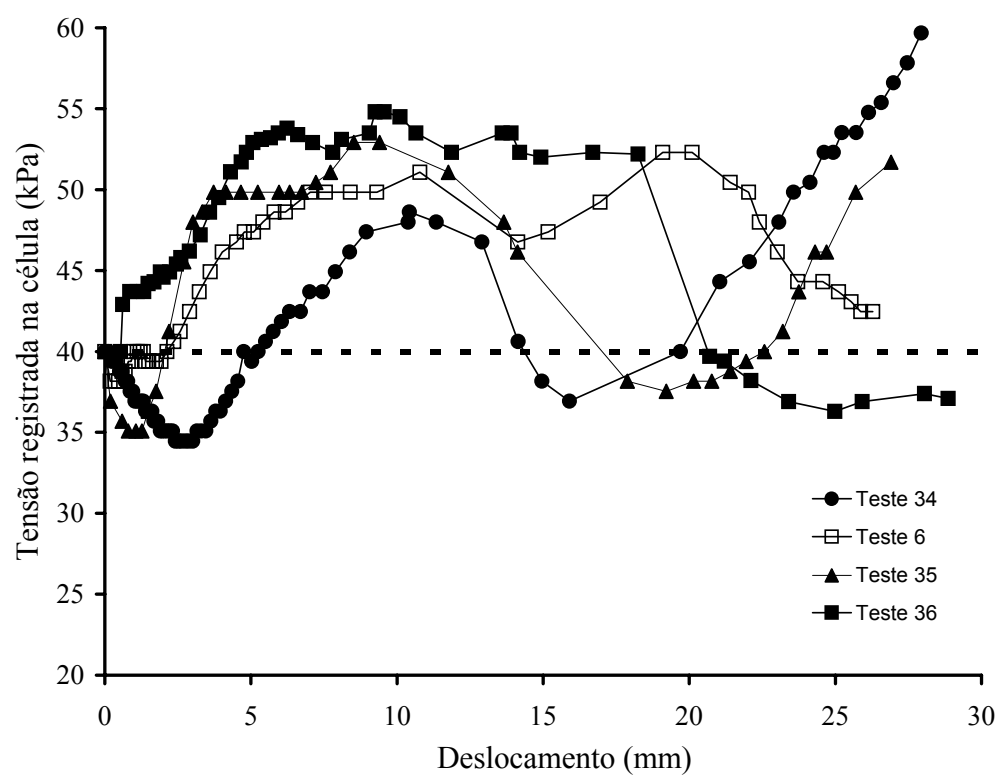

Figura 81- Leituras de tensão normal obtidas com a utilização da célula (testes referente ao estudo da velocidade de ensaio).

As figuras 82 a 86 apresentam as leituras de tensão normal registrada na célula em função do deslocamento durante a execução do ensaio, em que se variou a sobrecarga aplicada a superfície do solo compactado.

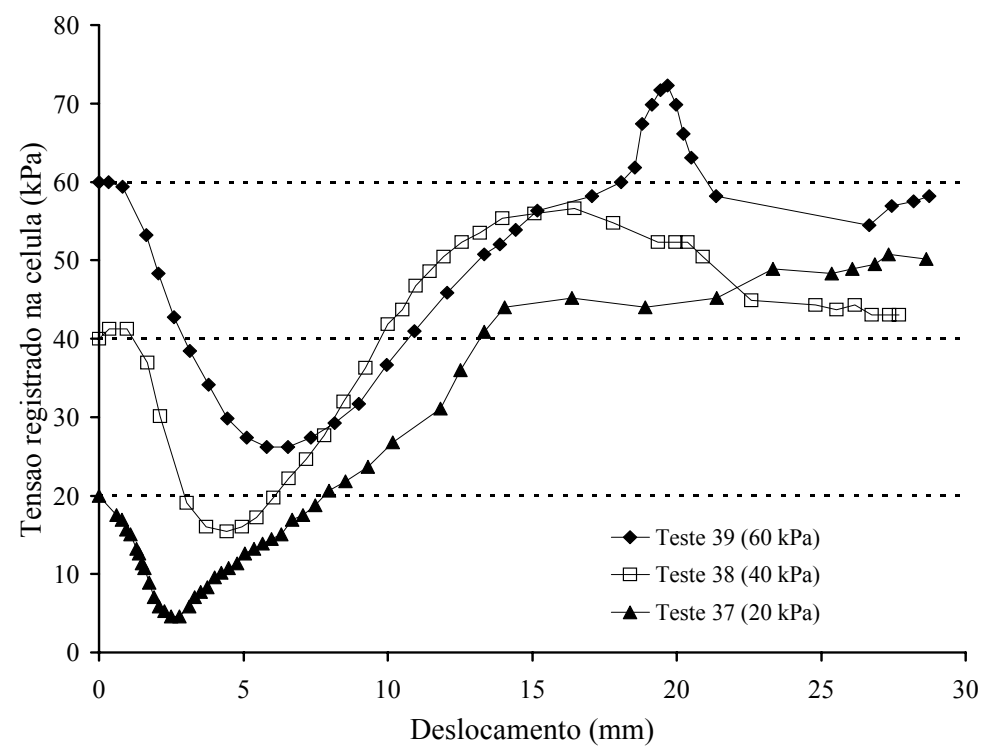

Figura 82 - Leituras de tensão normal obtidas com a utilização da célula (testes referente efeito da sobrecarga no ensaio de arrancamento utilizando o solo 1). 


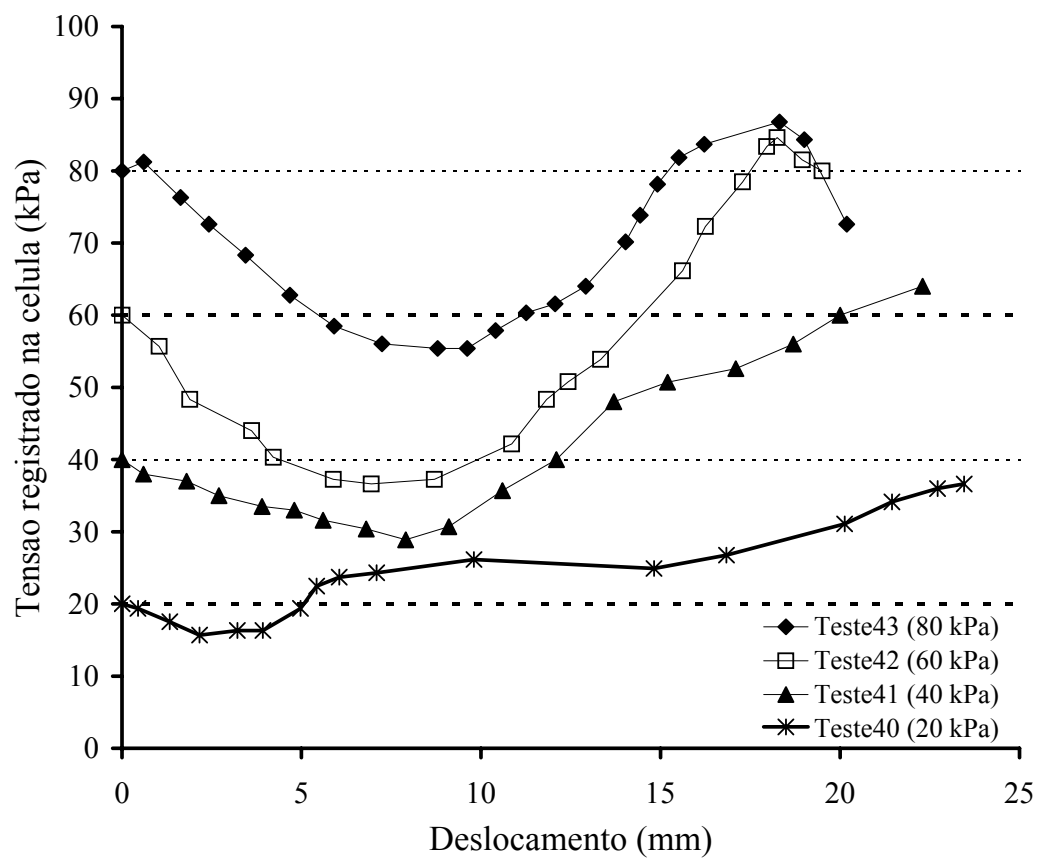

Figura 83 - Leituras de tensão normal obtidas com a utilização da célula (testes referente efeito da sobrecarga no ensaio de arrancamento utilizando o solo 2).

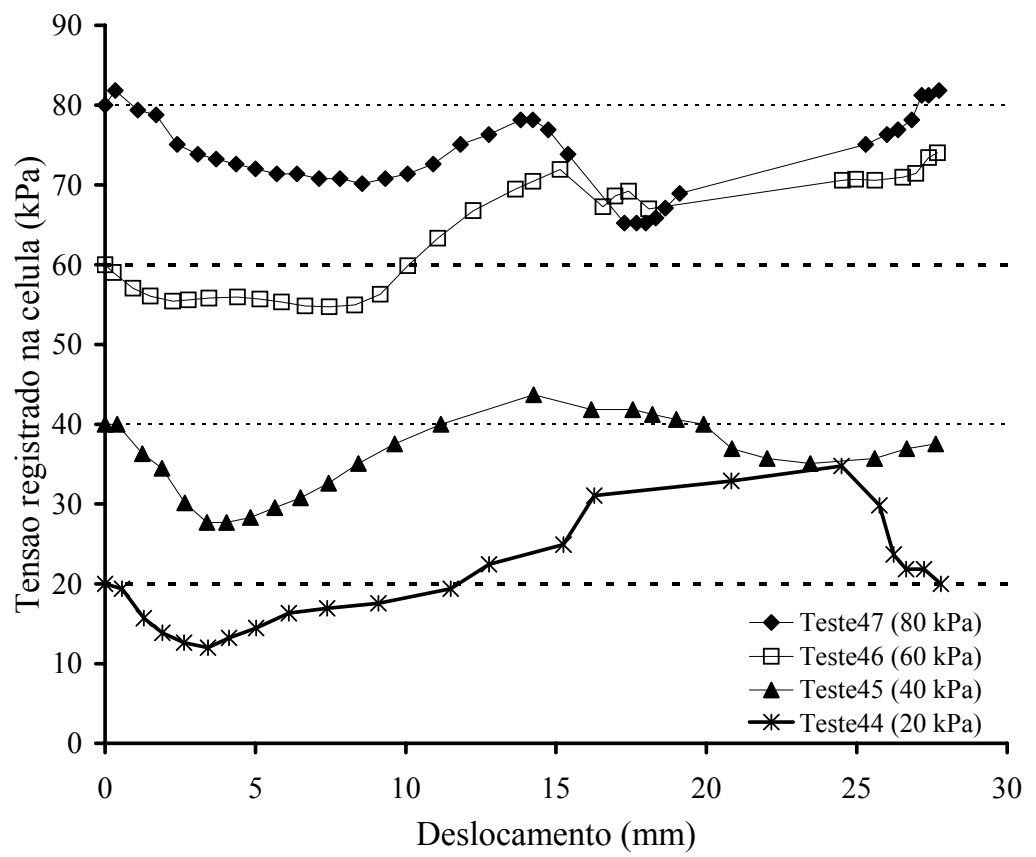

Figura 84 - Leituras de tensão normal obtidas com a utilização da célula (testes referente efeito da sobrecarga no ensaio de arrancamento utilizando o solo 3 ). 


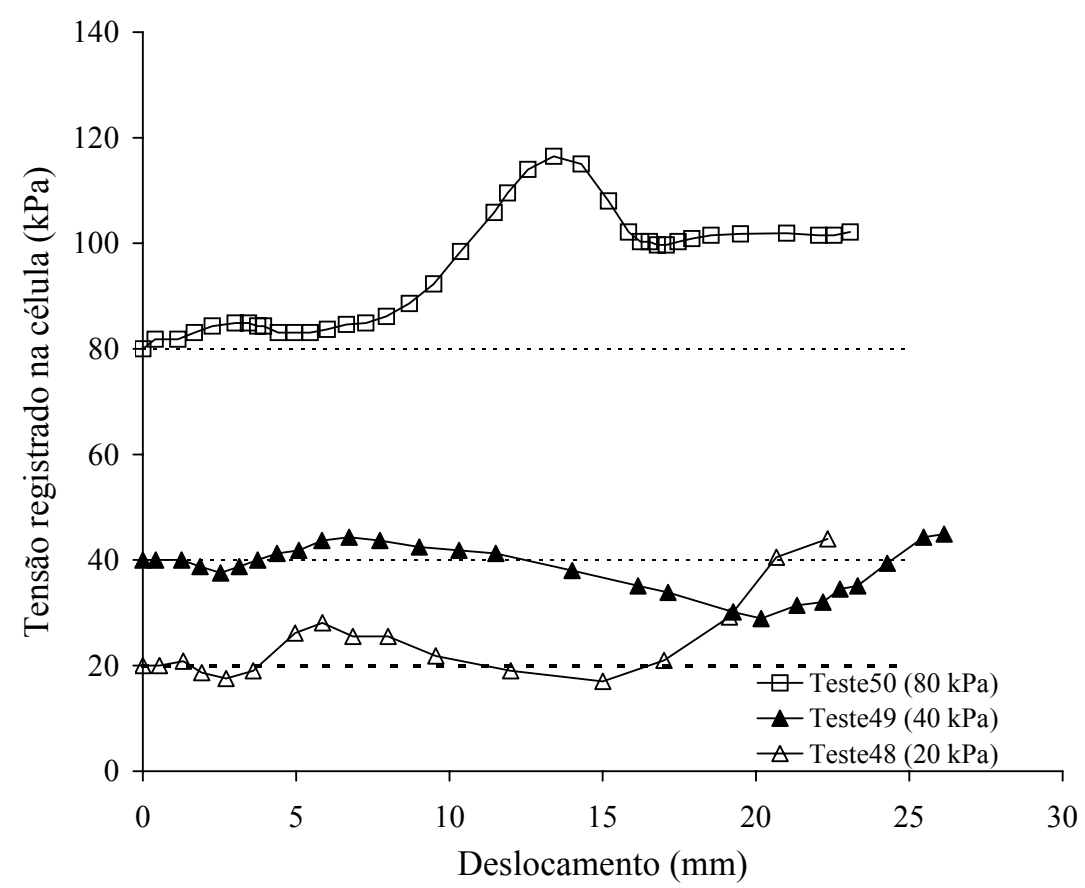

Figura 85 -Leituras de tensão normal obtidas com a utilização da célula (testes referente efeito da sobrecarga no ensaio de arrancamento utilizando o solo 4).

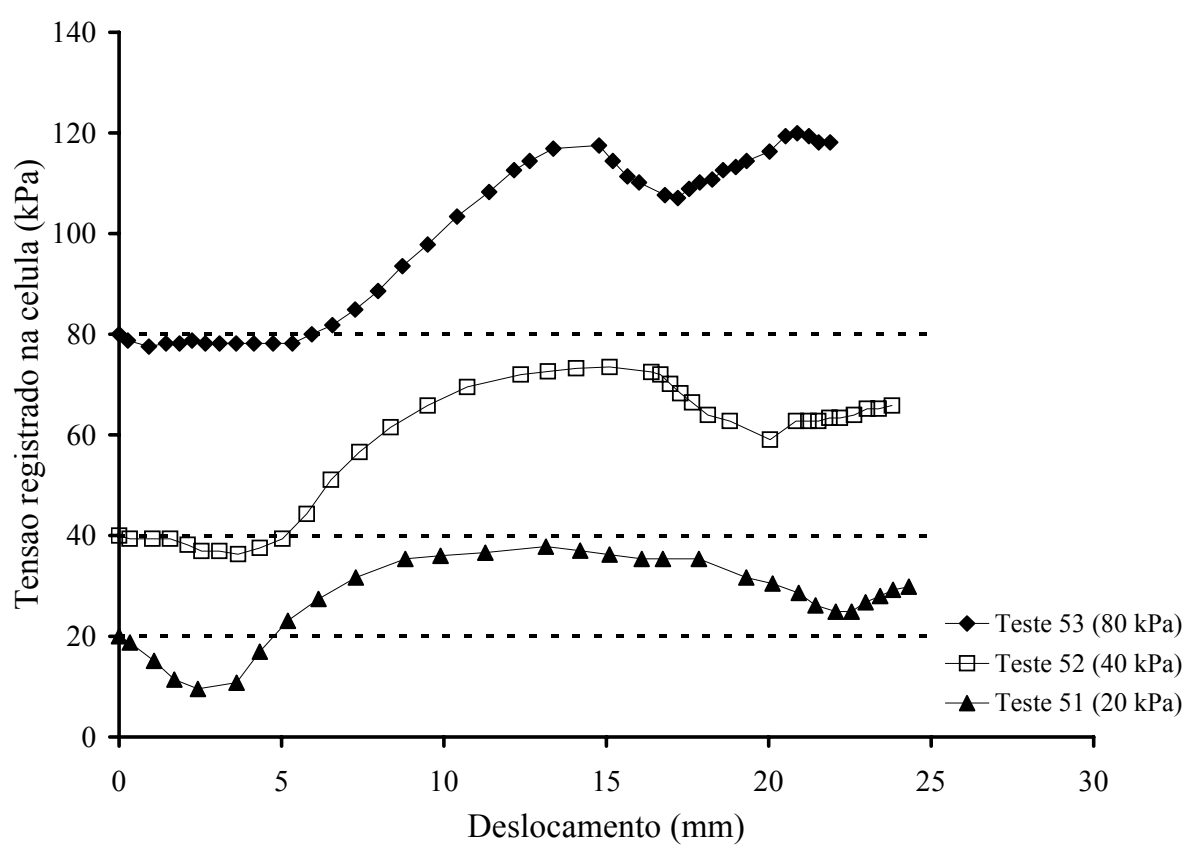

Figura 86 - Leituras de tensão normal obtidas com a utilização da célula (testes referente efeito da sobrecarga no ensaio de arrancamento utilizando o solo 5).

As Figuras 87 e 88 são leituras de tensões normais obtidas dos resultados de ensaios realizados com o solo 4, em que se buscou averiguar um possível efeito do grau de compactação na distribuição das tensões normais ao nível da inclusão. Os graus de compactação utilizados forem de 98 e 100\%, respectivamente. Alem desses, a Figura 85 
apresenta os resultados referentes ao grau de compactação de $96 \%$ da energia de Proctor Normal.

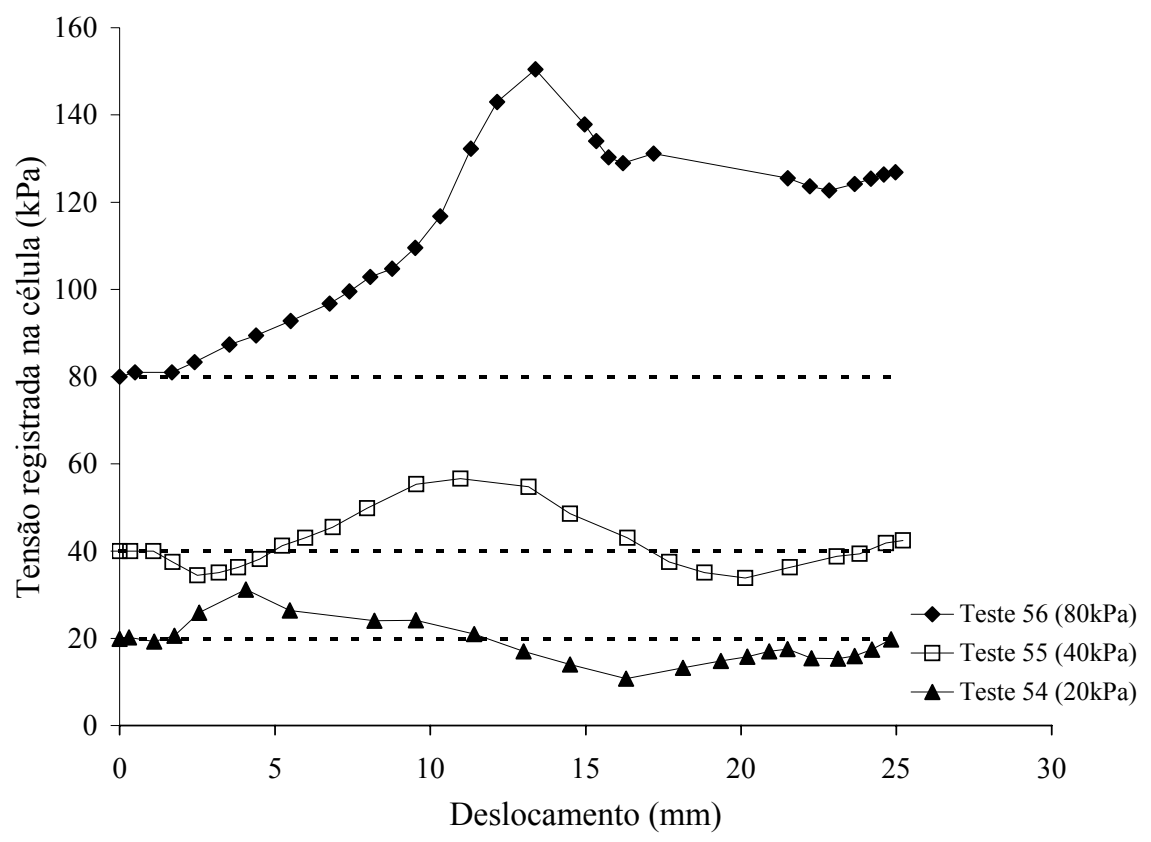

Figura 87 - Leituras de tensão normal obtidas com a utilização da célula (testes referente efeito do GC no ensaio de arrancamento utilizando o solo 4 com GC 98\%).

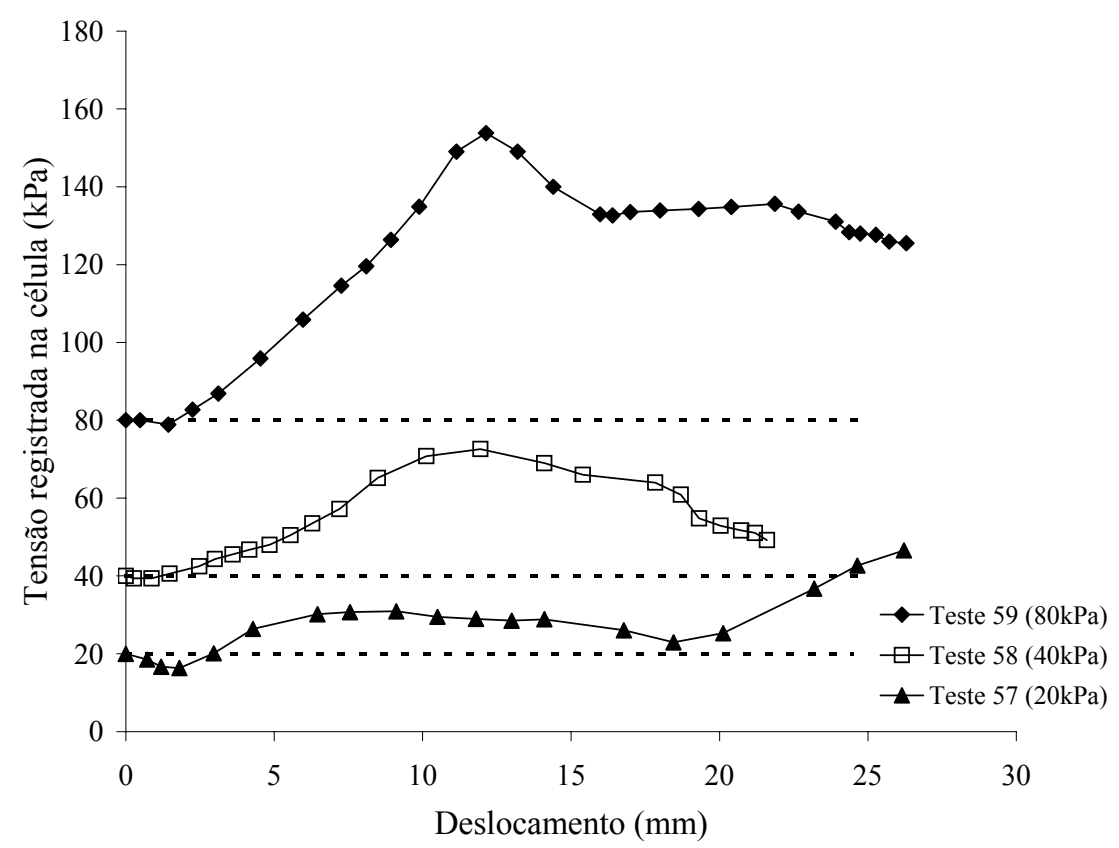

Figura 88 - Leituras de tensão normal obtidas com a utilização da célula (testes referente efeito do GC no ensaio de arrancamento utilizando o solo 4 com GC 100\%).

Analisando as figuras apresentadas neste item, verifica-se que o efeito do aumento da velocidade de arrancamento não permitiu notar um comportamento padrão 
nas oscilações de tensão normal registra na célula durante a execução do ensaio que evidenciasse o efeito da velocidade. Ao variar o grau de compactação de 96, 98 e 100\% do Proctor Normal (solo 4; sobrecarga de $40 \mathrm{kPa}$ ) no entanto, constatou um aumento da maior tensão registrada na célula de aproximadamente 20,40 e $60 \mathrm{kPa}$, respectivamente. Quanto ao tipo de solo pode-se verificar que os Solos 1, 2 e 4, com maiores diâmetro médio das partículas de solo, apresentaram maiores níveis de oscilações nas leituras. Nota-se, ainda, que o aumento da sobrecarga leva a uma maior restrição da dilatância do solo, conseqüentemente há uma maior tensão normal no momento em que o elemento transversal de geogrelha está sobre a célula e um alívio desta tensão no momento imediatamente subseqüente à passagem do elemento transversal. Isto foi constatado também por Dyer (1985), que através de ensaios utilizando foto-elasticidade, observou que durante os ensaios de arrancamento de grelhas as regiões logo após os elementos transversais apresentavam baixo nível de tensão.

Conclui-se, assim, que esta oscilação registrada na célula é resultado, possivelmente, da combinação do efeito da dilatância do solo quando este sofre um processo de corte e da forte influência dos elementos transversais de geogrelha, que provocam sobre o solo da região imediatamente posterior a estes elementos. 


\section{CAPÍTULO 5}

\section{CONCLUSÕES}

O principal objetivo deste trabalho foi avaliar a viabilidade de uso do ensaio de arrancamento de dimensões reduzidas para se obter os parâmetros de arrancamento de geogrelhas de malha com abertura de $20 \mathrm{~mm}$, quando implantadas em solos com diâmetro das partículas inferior a $2 \mathrm{~mm}$. Para demonstrar esta eficiência do equipamento, primeiramente, verificou-se a repetitividade dos resultados de ensaio. Os resultados mostram que o equipamento é perfeitamente confiável quanto à obtenção da força resistente ao arrancamento, pois se nota nitidamente que as curvas de deslocamento vs força de arrancamento apresentam uma grande similaridade e que tanto o deslocamento quanto à força de arrancamento de pico encontram-se num intervalo consideravelmente pequeno.

E em seguida, os resultados de ensaio obtidos com equipamento de pequenas dimensões foram comparados com resultados fornecidos por testes similares executados com um equipamento de grandes dimensões. Os resultados de ambos os equipamentos foram praticamente idênticos. A pequena variação observada entre os resultados obtidos pode ser creditada a dispersão dos resultados de ambos os equipamentos.

Nesta etapa, ainda se determinou o tamanho ideal de amostra de geogrelhas a ser utilizada nos ensaios realizados. Baseados nos resultados dos testes, o tamanho de amostra com dimensões que preencheu praticamente toda a área disponível da caixa foi o que demonstrou ser o mais apropriado para a realização dos ensaios de arrancamento. Para as geogrelhas analisadas neste trabalho recomenda-se a utilização de amostra constituídas de 12 elementos longitudinais e 10 elementos transversais. 
Paralelamente, foi efetuada uma análise paramétrica ampla, avaliando aspectos que afetam a força de arrancamento, sejam eles ligados à execução do ensaio em si, sejam eles de cunho geotécnico. Foram avaliados: o nível de sobrecarga, a velocidade de ensaio, a granulometria do solo, as características geométricas e de resistência da geogrelha. Este estudo permitiu concluir que:

a) A velocidade de ensaio situada no intervalo de 1 a $5 \mathrm{~mm} / \mathrm{min}$ pouco influencia os resultados da força de arrancamento. Para velocidade elevada, como $100 \mathrm{~mm} / \mathrm{min}$, no entanto, os resultados de força de arrancamento apresentaram valores superiores, mostrando que a velocidade de ensaio tem um forte efeito na resistência ao arrancamento, conforme apresentados Lopes \& Ladeira (1996) em estudos similares. Nos ensaios realizados neste trabalho optou-se pela utilização da velocidade de $4,6 \mathrm{~mm} / \mathrm{min}$, pois possibilitou a comparação com os resultados de ensaios de arrancamento com equipamento de grandes dimensões obtidos da literatura e tempo suficiente para anotações das leituras fornecidas pela célula de tensão total;

b) O aumento do grau de compactação promoveu um aumento progressivo na resistência ao arrancamento;

c) A resistência ao arrancamento apresentou uma variação crescente, praticamente linear, com o aumento das tensões confinantes. Além disto, nota-se que, com o aumento da sobrecarga, a inclinação da curva após a máxima tensão de arrancamento acentua-se, ou seja, a curva resultante apresenta-se parecida com de um material de comportamento plástico. Portanto, um ajuste linear mostrou-se perfeitamente aceitável para representar a envoltória de resistência de interface sologeogrelha, conforme apresentado por Teixeira (2003).

d) As geogrelhas utilizadas apresentaram resistências ao arrancamento de mesma magnitude tendo em vista que suas geometrias são semelhantes. Quanto aos valores de deslocamentos, a geogrelha 1 apresentou maior deslocamento para atingir o pico de resistência ao arrancamento, se comparada com a geogrelha 2.

e) Os solos com maiores teores de argila apresentaram menores coeficientes de interações. Nota-se que, à medida que se aumenta o diâmetro médio das partículas de solo melhora-se essa interação solo-geogrelha e, por conseguinte, diminui-se o deslocamento necessário para atingir a resistência máxima ao arrancamento.

f) A alternância das tensões verticais registradas pela célula de tensão total é devida à forte influência dos elementos transversais da geogrelha na propagação das tensões normais ao longo do processo de arrancamento, como demonstrado por Teixeira 
e Bueno (1999). Entretanto, a amplitude dessas oscilações pode ser afetada por fatores tais como: grau de compactação, sobrecarga aplicada e o tipo de solo. 


\title{
REFERÊNCIAS BIBLIOGRÁFICAS
}

\author{
ALAGIYAWANNA, A.M. N., SUGIMOTO, M., SATO, S., TOYOTA, H. (2001), \\ "Influence of longitudinal and transverse members on geogrid pullout deformation",
} Geotextiles and Geomembranes 19, 483-507.

ALAGIYAWANNA, A.M. N., SUGIMOTO, M., ASCE, A. M. (2003), “Pullout behavior of geogrid by test and numerical analysis”, Journal of Geotechnical and Geoenvironmental Engineering, april, pp. 361-371.

ALFARO, M.C., MIURA, N. \& BERGADO, D.T. (1995), "Soil-Geogrid Reinforcement Interaction by Pullout and Direct Shear Tests", Geotechnical Testing Journal, (18): 2, 157-167.

ALFARO, S. et al. (1995), "Pullout interaction mechanism of geogrid strip reinforcement”. Geosynthetics International, vol. 2, no. 4.

ASTM - D6706-01 (2001), “ Standard test method for measuring geosynthetic pullout resistance in soil”.

BAKEER, R.M, AHMED, H.A.R \& NAPOLITANO. (1998a), "Pullout and Shear Tests on Geogrid Reinforced Lightweight Aggregate", Geotextiles and Geomembranes $16,119-133$. 
BAKEER, R.M, AHMED, H.A.R \& NAPOLITANO. (1998b), “Geotextile Friction Mobilization During Field Pullout Test", Geotextiles and Geomembranes 16, 73-85.

BAUER, G. E. \& SHANG, Q. (1993), “Pullout Resistance of Large Geogrid Specimens in Site Specifc Soils". Geotechnical Engineering, V. 24 n. 1.

BERGADO, D. T., SHIVASHANKAR, R., ALFARO, M. C., CHAI, J. C. \& BALASUBRAMANIAM, A. S. (1993) "Interaction Behavior of Steel Grid Reinforcements in Clayey Sand”. Géotechnique (43):4, 589-603.

BERGADO, D. T. \& CHAI, J. C. (1994), “Pullout Force/Displacement Relationship of Extensible Grid Reinforcements”, Geotextiles and Geomembranes, (13): 5, 295-316.

BERGADO, D. T., CHAI, J. C. and MIURA, M. (1996) "Prediction of pullout resistance and pullout force-displacement relationship for inextensible grid reinforcements". Soil and Foundations (36):4, 11-22.

BRAND, S. R. \& DUFFY, D. M. (1987), "Strength and Pullout Testing of Geogrids". Geosynthetics Conference, New Orleans, Vol. 1, pp. 226-236.

BOLTON, M. D. (1986), “The streght and dilatancy of sands”. Geotechnique, vol 36, n.01, pp. 65-78.

BOLTON, M. D. (1986), “The streght and dilatancy of sands”. Geotechnique, vol 36, n.02, pp. 219-236.f

BUENO, B.S. (2004), "Matéria prima", capitulo 2 do livro Manual brasileiro de geossintéticos - Coordenador José Carlos Vertematti - São Paulo, ed. Edgard Blücher. 
CHANG, D.T., SUN, T.S \& HUNG, F. (1995), "Pullout Mechanism of Geogrids Under Confinement by Sandy and Clayey Soils”. Transportation Research Record No. 1474, pp. 64-72.

ClAYBOURN, A. F. \& WU, J. T. H. (1993). “Geosynthetic-Reinforced Soil Wall Design" Geotextiles ans Geomembranes 12 No. 8 pp. 707-724.

CHRISTOPHER, B. R., et al. (1990), “Reinforced soil structures, volume I. Design and construction guidelines”. Federal Hwy. Administration rep. No. FHWA/RD/89-043.

CHRISTOPHER, B. R. \& BERG, R. R. (1990), "Pull evaluation of geosynthetics in cohesive soils”. Geotextiles, Geomembranes and ralated products, Den Hoedt (ed.), rotterdam, pp. 731-737.

FARRAG, K., ACAR Y.B. \& JURAN I. (1993), "Pull-Out Resistance of Geogrid Reinforcements". Geotextiles and Geomembranes. (12): 3, 133-159.

HAYASHI, S., SHAHU, J. T. \& WATANABE, K. (1999), "Changes in Interface Stresses During Pullout Tests on Geogrid Strip Reinforcement", Geotechnical Testing Journal, Vol. 22, pp. 32-38.

HOUlSBY, G. T. (1991), "How the Dilatancy of Soils Affects their Behaviour". Proceedings of the Tenth European Conference on Soil Mechanics and Foundations Engineering. Vol. 4, Florence, pp. 1189-1202.

INGOLD, T.S. (1983a), “Laboratory Pull-Out Testing of Grid Reinforcements in Sand”. Geotecnical Testing Journal, (6): 3, 101-111.

INGOLD, T.S.(1983b), “A Laboratory Investigation of Grid Reinforcements in Clay". Geotecnical Testing Journal, (6): 3, 112-119. 
JEWEll, R. A., MilligAN, G. W. E., SARSBY, R. W. \& DUBOIS, D. (1984), "Interaction Between Soil and Geogrids". Proceeding, Symposium on Polymer Grid Reinforcement in Civil Engineering, Science and Engneering Research Council and Netlon Limited pp. 18-30.

JEWELL, R. A. (1990), “Reinforcement Bond Capacity”. Geotechnique 40, No. 3, 513 518.

JEWELL, R. A. (1991), “Application of Revised Design Charts for Steeps Reinforced Slopes”. Geotextiles and Geomembranes 10, No. 3, pp. 203-233.

JEWELL, R. A. (1996), "Soil reinforcement woth geotextiles". Ciria special Publication, 123, ed. Thomas Telford - Londres - Grã-Bretanha.

JURAN I., HALIS, M. \& FARRAG, K. (1990), "Strain Compatibility Analysis for Geosynthetics Reinforced Soil Walls” J. Geotech Engn., ASCE, 116(2), 312-29

JURAN I., HALIS, M. \& FARRAG, K. (1990), "Strain Compatibility Analysis for Geosynthetics Reinforced Soil Walls” J. Geotech Engn., ASCE, 116(2), 312-29

KLEIN, R. J. et al. (2003), "Estudo dos Efeitos na Propriedades do Material Compactado em Obras de Reforço de Base de Pavimentos com geossintéticos”. IV Simpósio Brasileiro de Geossintéticos, ABMS, Porto Alegre-RS.

LADEIRA, M.A.S.A. \& LOPES, M.L. (1995), “Estudo dos Fenômenos da Interação Solo- Geossintéticos Através de Ensaios de Arranque”. Revista Geotecnia, 74:39-49.

LESHCHINSKY, D. \& PERRY, E. B. (1989), "On the Design of GeosyntheticReinforced Walls" Geotextiles and Geomembranes 8 No.4 pp. 311-323. de Janeiro, pp. 1257-62. 
LOPES, M. L. \& LADEIRA, M. (1996), “Influence of the Confinement, Soil Density and Displacement Ratio on Soil - Geogrid Interaction”. Geotextiles and Geomembranes 14, No. 10 pp. 543-554.

LOPES, M. L. \& LADEIRA, M. (1996b), "Role of specimen geometry soil height and sleeve length on the pullout behaviour of geogrids". Geosynthetics International, Vol. 3, no. 6 .

LOPES, M. L. (1998), "Comportamento ao arranque de reforços danificados". Geotecnia, No.83 pp. 27-36.

LOPES, M. L. \& LADEIRA, M. (1998), “Avaliação do papel das condições de ensaio na definição da resistência ao arranque dos reforços”.' Geotecnia, No.82 pp. 5-16.

LOPES, M. \& LOPES, M. L. (1999), “Mecanismo de interacção solo-geogrelhas-papel da granulometria do solo e das barras transversais do reforço”. Geotecnia, No.87 pp. $5-32$.

LOPES, M. \& LOPES, M. L. (1999b), “Soil-geosynthetic interaction-Influence of soil particle size and geosynthetic structure”. Geosynthetics International, Vol. 6, no.4.

MIURA, N. et al. (1990), "Polymer Grid Reinforced Pavement on Soft Clay Grounds ". Geotextiles and geomembranes, Vol. 9.

MIYATA, K. (1996), “Walls reinforced with fiber reinforced plastic geogrid in Japan”. Geosynthetics International, (3): 1, 1-11.

NAKAMURA, T., MITACHI, T., IKEURA, I. (2003), “Estimating method for the insoil deformation behavior of geogrid based on the results of direct box shear test". Soil and Foundations, vol 43, n⿳⺈, pp. 47-57. 
OCHIAI, H., OTANI, J. HAYASHIC, S. \& HIRAI, T. (1996), "The Pull-Out Resistance of Geogrids in Reinforced Soil”. Geotextiles and Geomembranes (14): 1942.

PALMEIRA, E.M. \& MILLIGAN, G.W.E. (1989), “Large Scale Direct Shear Tests on Reinforced Soil'. Soil and Foundations, 29(1), 18-30.

PALMEIRA, E.M. \& MILLIGAN, G.W.E. (1989), "Scale and Other Factors Affecting the Results of the Pullout Tests of Grids Buried in Sand". Geotechnique 39. No. 3, 551584.

PALMEIRA, E. M. (1992), “Aterros Sobre Solos Moles Reforçados com Geossintéticos". In Anais, 10. Simpósio Brasileiro Sobre GeossintéticosGeossintéticos'92, Brasília, 1992, 1:276-300 São Paulo: Associação Brasileira de Mecânica dos Solos e Engenharia Geotécnica.

PALMEIRA, E. M. (2002), "Embankments", capítulo 10 do Book Geosynthetic Applications, ed. Thomas, pp.45.

PALMEIRA, E. M. (2004), “Bearing force mobilisation in pull-out tests on geogrids”. Geotextiles and Geomembranes (22): 481-509.

PETERSON, L. M. \& ANDERSON, L. R. (1980), "Pullout resistance of geogrid reinforced soil”. M.Sc Thesis, Utah State University, Logan, Utah.

RAJU, D.M., LO, S.C.R., GOPALAN M. \& GAO, J. (1998), “On Large-scale Laboratory Pull-out Testing”, Geotechnical Engineering Journal (29) No. 2, 123-155.

RAYMOND, G., ISMAIL, I. (2003), “The effect of geogrid reinforcement on unbound aggregates". Geotextiles and Geomembranes (21): 355-380. 
ROWE, P. W. (1962). “The stress-dilatancy relation for static equilibrium of na assembly of particle in contact”. Proc. R. Soc. 269 A, pp. 500-527.

Sugimoto, M., AlAgiYAWANNA, A. M. N., KADOGUCHI, K. (2001), "Influence of rigid and flexible face on geogrid pullout tests". Geotextiles and Geomembranes (19): 257-277.

TAN, S. A. et al. (2001), "Large-scale drainage behaviour ofcomposite geotextile and geogrid in residual soil". Geotextiles and geomembranes (19): 163-176.

TEERAWATTANASUK, C. \& BERGADO D.T. (2003), "Prediction of pullout capacity using hexagonal wire mesh reinforcement and sand backfill". Journal of the Southeast Asian Geotechnical Society, pp 59-70.

TEIXEIRA, S. H. C. (1999), “Construção e Calibração de um Equipamento de Ensaios de Arrancamento de Geossintéticos", Dissertação de Mestrado - Escola de Engenharia de São Carlos - Universidade de São Paulo, 157p.

TEIXEIRA, S.H.C. e BUENO, B. S. (2002), “Comportamento de geogrelhas implantadas em um solo arenoso fino e solicitadas ao arrancamento”. Solos e Rochas, vol. 25 , No. 2.

TEIXEIRA, S. H. C. (2003), "Estudo da interação solo-geogrelha em testes de arrancamento e a sua aplicação na análise e dimensionamento de maciços reforçados", Tese de Doutorado - Escola de Engenharia de São Carlos - Universidade de São Paulo, $218 \mathrm{p}$.

TOMLINSON, M. J. (1994). "Pile design and construction practica”. Fourth edition, E \& FN SPON - London. Glasgow. New York. Melbourne. Madras. 
VERTEMATTI, J. C. (2004), “Aplicações em Reforço de Solos”, capitulo 4 do livro Manual brasileiro de geossintéticos - Coordenador José Carlos Vertematti - São Paulo, ed. Edgard Blücher.

VILAR, O. M., (S/D), “Resistência ao Cisalhamento”. Minuta - Mecânica dos Solos.

VOOTTIPRUEX, P., BERGADO, D.T., OUNJAICHON, P. (2000), “pullout and direct shear resistance of hexagonal wire mesh reinforcement in weathered Bangkok clay". Geotechnical Engineering Journal, vol 31, pp. 43-62.

YOGORAJAH, I. \& YEO, K. C. (1994). “Finite Element of Pull-out Tests with Load and Strain Measurements”. Geotextiles and Geomembranes 13. No.1, pp. 43-54. 